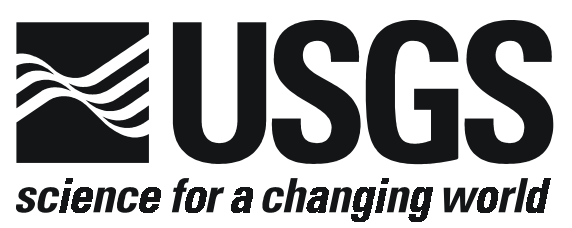

\title{
DEEP REGIONAL RESISTIVITY STRUCTURE ACROSS THE BATTLE MOUNTAIN-EUREKA AND CARLIN TRENDS, NORTH-CENTRAL NEVADA
}

\author{
by \\ Brian D. Rodriguez \\ and \\ Jackie M. Williams 1 \\ Open-File Report 01-346 \\ on-line edition \\ 2001
}

This report is preliminary and has not been reviewed for conformity with U.S. Geological Survey editorial standards and stratigraphic nomenclature. Any use of trade, product, or firm names is for descriptive purposes only and does not imply endorsement by the U.S. Government.

U.S. DEPARTMENT OF THE INTERIOR

U.S. GEOLOGICAL SURVEY

1 Denver, Colorado 


\title{
TABLE OF CONTENTS
}

\author{
ABSTRACT \\ INTRODUCTION \\ MAGNETOTELLURIC METHOD \\ MAGNETOTELLURIC SURVEYS \\ $\begin{array}{ll}\text { MAGNETOTELLURIC DATA } & 7\end{array}$ \\ RESISTIVITY MODELS 9 \\ $\begin{array}{lr}\text { DISCUSSION } & 10\end{array}$ \\ $\begin{array}{ll}\text { SUMMARY } & 12\end{array}$ \\ REFERENCES CITED 13 \\ APPENDIX A OBSERVED AND CALCULATED DATA - PROFILE MT4 18 \\ APPENDIX B OBSERVED AND CALCULATED DATA - PROFILE MT3 65 \\ APPENDIX C OBSERVED AND CALCULATED DATA - PROFILE MT2 122 \\ APPENDIX D OBSERVED AND CALCULATED DATA - PROFILE MT1 139 \\ ILLUSTRATIONS \\ Figure 1. Index map 16 \\ $\begin{array}{ll}\text { Figure 2. Resistivity models } & 17\end{array}$
}




\section{ABSTRACT}

Magnetotelluric data collected along four, regional scale, southwest-to-northeast profiles show deep resistivity structures beneath the Battle Mountain-Eureka and Carlin gold trends in north-central Nevada, which appear consistent with tectonic breaks in the crust that possibly served as channels for hydrothermal fluids. It seems likely that gold deposits along these linear trends were, therefore, controlled by deep regional crustal fault systems.

Two-dimensional resistivity modeling of the magnetotelluric data generally show resistive (30 to 1,000 ohm-m) crustal blocks broken by narrow, sub-vertical, two-dimensional, conductive (1 to $10 \mathrm{ohm}-\mathrm{m})$ zones that are indicative of large-scale crustal fault zones. These inferred fault zones are regional in scale, trend southeast-to-northwest, and extend to mid-crustal $(20 \mathrm{~km})$ depths. The conductors are about 3 to $15 \mathrm{~km}$ wide, extend from 1 to $8 \mathrm{~km}$ below the surface to about $20 \mathrm{~km}$ depth, and show two-dimensional electrical structure with general north to northwesterly strikes. From connecting the locations of the conductors together, a single regional crustal fault zone can be inferred that is about $10 \mathrm{~km}$ wide within the upper crust and about 150-km long. It coincides with the Battle Mountain-Eureka mineral trend. The images also show regional changes in the resistive crust from north to south. Most of Reese River Valley and Boulder Valley are underlain by a thick $(20 \mathrm{~km})$ southwest-to-northeast section of conductive ( 1 to $10 \mathrm{ohm}-\mathrm{m}$ ) rock, suggesting that hightemperature fluids are more pervasive in this area (Battle Mountain Heat-Flow High), which implies that the crust beneath these valleys is more fractured than in the areas surveyed to the south.

\section{INTRODUCTION}

Many sediment-hosted gold deposits occur along linear trends in northern Nevada. The distribution and genesis of these deposits along the Battle Mountain-Eureka (BME) and Carlin gold trends is not fully understood. In general, most models agree that regional structures played an important role in the spatial distribution of these deposits (e.g. Arehart and others, 1993; Ilchik and Barton, 1997; Radtke, 1985; Shawe, 1991; Sillitoe and Bonham, 1990; Tosdal, 1998). To investigate crustal structures that may be related to the genesis of gold deposits along these trends, four regional southeast-to-northwest profiles of magnetotelluric (MT) soundings were acquired in 1996, 1997, 1999, and 2000 (lines MT1 to MT4, Figure 1). Resistivity modeling of the MT data can be used to infer the deep resistivity structure of the crust. Such structures may reflect possible tectonic 
controls on the emplacement of mineral deposits along these linear trends, and so may be used to help improve critical gold endowment estimates in the Humboldt River Basin.

\section{MAGNETOTELLURIC METHOD}

The magnetotelluric (MT) method is a passive surface geophysical technique, which uses the earth's natural electromagnetic fields to investigate the electrical resistivity structure of the subsurface. The resistivity of geologic units is largely dependent upon their fluid content, porosity, degree of fracturing, temperature, and conductive mineral content (Keller, 1989). Saline fluids within the pore spaces and fracture openings can reduce resistivities in a resistive rock matrix. Also, resistivity can be lowered by the presence of conductive clay minerals, carbon, and metallic mineralization. It is common for altered volcanic rocks to contain authigenic minerals that have resistivities ten times lower than those of the surrounding rocks (Nelson and Anderson, 1992). Increased temperatures cause higher ionic mobility and mineral activation energy, reducing rock resistivities significantly. Unaltered, unfractured igneous rocks are normally very resistive (typically 1,000 ohm-m or greater), whereas fault zones will show low resistivity (less than $100 \mathrm{ohm}-\mathrm{m}$ ) when they are comprised of rocks fractured enough to have hosted fluid transport and consequent mineralogical alteration (Eberhart-Phillips and others, 1995). Carbonate rocks are moderately to highly resistive (hundreds to thousands of ohm-m) dependent upon their fluid content, porosity, fracturing, and impurities. Marine shales, mudstones, and clay-rich alluvium are normally very conductive (a few ohm-m to tens of ohm-m). Unaltered, metamorphic rocks (non-graphitic) are moderately to highly resistive (hundreds to thousands of ohm-m). Tables of electrical resistivity for a variety of rocks, minerals and geological environments may be found in Keller (1987) and Palacky (1987).

The MT method can be used to probe the crust from depths of tens of meters to depths of tens of kilometers (Vozoff, 1991). Natural variations of the Earth's magnetic and electric field are measured and recorded at each MT station. The main frequency bands used by the MT method are 10,000 $\mathrm{Hz}$ to $1 \mathrm{~Hz}$ from worldwide lightning activity and $1 \mathrm{~Hz}$ to $0.0001 \mathrm{~Hz}$ from geomagnetic micropulsations. The natural electric and magnetic fields propagate vertically in the earth because the very large resistivity contrast between the air and the earth causes a vertical refraction of both fields transmitted into the earth (Vozoff, 1972). 
The natural electric and magnetic fields are recorded in two orthogonal, horizontal directions. The vertical magnetic field ("tipper") is also recorded. The resulting time-series signals are used to derive earth tensor apparent resistivities and phases by first converting them to complex cross-spectra using FFT (fast-Fourier-transform) techniques. Least-squares, crossspectral analysis (Bendat and Piersol, 1971) is used to solve for a tensor-transfer function that relates the observed electric fields to the magnetic fields under the assumption that the Earth consists of a two-input, two-output, linear system with the magnetic fields as input and the electric fields as output (Rodriguez and others, 1996). Prior to conversion to apparent resistivity and phase, the tensor is normally rotated into principal directions that correspond to the direction of maximum and minimum apparent resistivity. For a two-dimensional (2-D) Earth, the MT fields can be de-coupled into transverse electric (TE) and transverse magnetic (TM) modes; 2-D modeling is generally done to fit both modes. When the geology satisfies the 2-D assumption, the MT data for the TE mode is assumed to represent the situation when the electric field is along the geologic strike, and the data for the TM mode is assumed to represent the situation when the electric field is across strike. The MT method is well suited for studying complicated geological environments because the electric and magnetic relations are sensitive to vertical and horizontal variations in resistivity. The method is capable of establishing whether the electromagnetic fields are responding to subsurface terranes of effectively 1-, 2-, or 3-dimensions. An introduction to the MT method and references for a more advanced understanding are contained in Dobrin and Savit (1988) and Vozoff (1991).

\section{MAGNETOTELLURIC SURVEYS}

Sixty-nine MT soundings were located along four regional southwest-to-northeast profiles (MT1 to MT4, Figure 1) of varying lengths $(40$ to $110 \mathrm{~km}$ ) with spacing that varied from 1.3 to 19.5 $\mathrm{km}$. The profile orientations are roughly perpendicular to the $\mathrm{BME}$ and Carlin gold trends. The MT soundings span as far northwest as Reese River Valley and Boulder Valley near Battle Mountain and as far southeast as Long Valley, east of the Alligator Ridge mine.

The following table lists the MT station locations in the four regional southwest-to-northeast profiles (Figure 1). These locations were found using either on-site GPS measurements or digitized from 100,000 scale field maps (Williams and Rodriguez, 2000; Williams and Rodriguez, 2001; Williams and others, 2001a; Williams and others, 2001b; Williams and others, 2001c). Coordinates are referenced to the 1866 Clarke spheroid and North 
American 1927 Western United States datum. Longitude and latitude format below is decimal degrees. Elevation is in meters.

\begin{tabular}{|c|c|c|c|}
\hline Station & Longitude & Latitude & Elev (m) \\
\hline \multicolumn{4}{|c|}{ MT4 } \\
\hline 98 & -117.23117 & 40.44410 & 1440 \\
\hline $12 \mathrm{~A}$ & -117.12441 & 40.44999 & 1430 \\
\hline $13 \mathrm{~A}$ & -117.05447 & 40.46508 & 1420 \\
\hline $14 \mathrm{~A}$ & -116.98314 & 40.49695 & 1390 \\
\hline $16 \mathrm{~A}$ & -116.94524 & 40.51559 & 1360 \\
\hline $19 A$ & -116.89245 & 40.51839 & 1390 \\
\hline $20 A$ & -116.86685 & 40.52878 & 1350 \\
\hline $22 \mathrm{~A}$ & -116.84852 & 40.55662 & 1340 \\
\hline $23 \mathrm{~A}$ & -116.82223 & 40.56811 & 1350 \\
\hline $24 \mathrm{~A}$ & -116.79907 & 40.58977 & 1340 \\
\hline $25 \mathrm{~A}$ & -116.78090 & 40.61226 & 1400 \\
\hline 71 & -116.76773 & 40.69609 & 1350 \\
\hline $26 \mathrm{~A}$ & -116.70164 & 40.66617 & 1450 \\
\hline $27 \mathrm{~A}$ & -116.54826 & 40.73778 & 1410 \\
\hline $28 \mathrm{~A}$ & -116.44901 & 40.78003 & 1420 \\
\hline 9 & -116.36060 & 40.76114 & 1490 \\
\hline 1 & -116.33037 & 40.79034 & 1550 \\
\hline 2 & -116.31374 & 40.80459 & 1650 \\
\hline 24 & -116.29118 & 40.79805 & 1650 \\
\hline 25 & -116.25092 & 40.79475 & 1770 \\
\hline 26 & -116.22477 & 40.82100 & 1600 \\
\hline 27 & -116.18810 & 40.80681 & 1600 \\
\hline 28 & -116.15437 & 40.80115 & 1600 \\
\hline \multicolumn{4}{|c|}{ MT3 } \\
\hline 16 & -117.03204 & 40.03355 & 1740 \\
\hline 15 & -116.92586 & 40.06778 & 1595 \\
\hline $1 \mathrm{~A}$ & -116.84890 & 40.15161 & 1590 \\
\hline $2 \mathrm{~A}$ & -116.75097 & 40.20433 & 1500 \\
\hline $5 A$ & -116.66432 & 40.23551 & 1475 \\
\hline $3 \mathrm{~A}$ & -116.58452 & 40.27633 & 1445 \\
\hline $4 \mathrm{~A}$ & -116.57803 & 40.29375 & 1445 \\
\hline 14 & -116.55498 & 40.35025 & 1445 \\
\hline 13 & -116.56650 & 40.43708 & 1460 \\
\hline 12 & -116.46765 & 40.55145 & 1495 \\
\hline 19 & -116.41989 & 40.59568 & 1445 \\
\hline 11 & -116.40231 & 40.67147 & 1525 \\
\hline 10 & -116.36736 & 40.73788 & 1490 \\
\hline 9 & -116.36060 & 40.76114 & 1490 \\
\hline 1 & -116.33037 & 40.79034 & 1550 \\
\hline 2 & -116.31374 & 40.80459 & 1650 \\
\hline 3 & -116.30656 & 40.82193 & 1700 \\
\hline 4 & -116.30516 & 40.84248 & 1800 \\
\hline 5 & -116.29302 & 40.85368 & 1730 \\
\hline
\end{tabular}




\begin{tabular}{|c|c|c|c|}
\hline & & & \\
\hline 6 & -116.27523 & 40.86021 & 1660 \\
\hline 7 & -116.26662 & 40.87744 & 1640 \\
\hline 8 & -116.25457 & 40.89239 & 1645 \\
\hline 20 & -116.22196 & 40.93338 & 1675 \\
\hline 21 & -116.18823 & 40.95701 & 167 \\
\hline 22 & -116.16402 & 41.00800 & 1710 \\
\hline 29 & -116.09901 & 41.03600 & 184 \\
\hline 23 & -116.03185 & 41.10000 & 190 \\
\hline 54 & -116.38179 & 41.44002 & 21 \\
\hline & & & \\
\hline 17 & -116.83356 & 39.96701 & 1950 \\
\hline $11 \mathrm{~A}$ & -116.73088 & 39.94657 & 177 \\
\hline $10 \mathrm{~A}$ & -116.65782 & 40.03011 & 179 \\
\hline $6 \mathrm{~A}$ & -116.58502 & 40.03230 & 172 \\
\hline $9 A$ & -116.48118 & 40.06390 & 179 \\
\hline $8 \mathrm{~A}$ & -116.42011 & 40.08985 & 172 \\
\hline $7 \mathrm{~A}$ & -116.32249 & 40.09119 & 17 \\
\hline 18 & -116.16121 & 40.09325 & 18 \\
\hline & & & \\
\hline 88 & -116.47773 & 39.52744 & 18 \\
\hline 87 & -116.27814 & 39.55249 & 18 \\
\hline 86 & -116.15948 & 39.60576 & $18^{\circ}$ \\
\hline 85 & -116.04913 & 39.62802 & 18 \\
\hline 89 & -115.97073 & 39.75141 & 17 \\
\hline 109 & -115.87795 & 39.70953 & 18 \\
\hline 83 & -115.80588 & 39.73506 & 20 \\
\hline 82 & -115.71711 & 39.79929 & 17 \\
\hline 81 & -115.63851 & 39.79379 & 18 \\
\hline 108 & -115.53142 & 39.76552 & \\
\hline 79 & -115.47101 & 39.80462 & 20 \\
\hline 77 & -115.39775 & 39.81638 & 18 \\
\hline 78 & -115.32175 & 39.83858 & \\
\hline
\end{tabular}

\section{MAGNETOTELLURIC DATA}

Frequencies sampled ranged from 0.002 to $300 \mathrm{~Hz}$ using single station recordings of both orthogonal horizontal components of the electric and magnetic fields, along with the vertical magnetic field at stations $12 \mathrm{~A}$ to $28 \mathrm{~A}, 1,11,14,71,77,79$ to 89, 98, 108, and 109 (Williams and Rodriguez, 2000; Williams and Rodriguez, 2001; Williams and others, 2001a; Williams and others, 2001b; Williams and others, 2001c). Sampling this frequency range in previous areas of widely varying geology has allowed us to probe the crust from depths of hundreds of meters to depths of tens of kilometers (Rodriguez and others, 1996). The recorded time-series data were transformed to the frequency domain and Fourier analyzed to determine a two-dimensional apparent 
resistivity and phase tensor at each site. The data were rotated to maximum and minimum apparent resistivity directions so that propagation modes for the signals were decoupled into TE and TM modes.

A measure of the dimensionality for MT data is provided by the impedance skew of the impedance tensor (Vozoff, 1972) and the impedance polar plots (Reddy and others, 1977). By examining the tensor impedances, the dimensionality (2- or 3-D) of electrical structures and the general strikes of 2-D structures were determined for different frequencies. MT stations whose impedances were 3-D in the lower frequencies (Williams and Rodriguez, 2000; Williams and Rodriguez, 2001; Williams and others, 2001a; Williams and others, 2001b; Williams and others, 2001c) are indicated with triangle symbols in Figure 1. Predicted values of the electric field can be computed from the measured values of the magnetic field (Vozoff, 1991). The coherence of the predicted electric field with the measured electric field is a measure of the signal-to-noise ratio provided in the multiple coherency plot. Values are normalized between 0 and 1, where values at 0.5 signify signal levels equal to noise levels. For this data set, coherencies were generally at an acceptable level, except at times in the "dead band" (0.1 to 1 $\mathrm{Hz})$ and at times in the lower frequencies $(0.002$ to 0.1$)$. Overall data quality was fair to good for profiles MT1, MT2, and MT4, and fair to poor for MT3 (Williams and Rodriguez, 2000; Williams and Rodriguez, 2001; Williams and others, 2001a; Williams and others, 2001b; Williams and others, 2001c). The worst data points were ignored and the data used in the modeling generally had predicted coherencies above $90 \%$ and $60 \%$ for the higher and lower quality data, respectively.

In the Appendix, observed data of each MT sounding for each profile (MT1 to MT4) are represented by descrete values (circle and $x$ symbols) of the TE and TM modes from the raw data curves (Williams and Rodriguez, 2000; Williams and Rodriguez, 2001; Williams and others, 2001a; Williams and others, 2001b; Williams and others, 2001c). Calculated data for each profile are represented by solid (TE mode) and dashed (TM mode) lines interpolated from the descrete values output from the 2-D finite element model (Figure 2). 


\section{RESISTIVITY MODELS}

Wannamaker (1983) found that MT responses in the northern Basin and Range are fundamentally 3-D in nature. However, because 3-D modeling is very time-consuming, 2-D modeling was used to construct the preliminary resistivity cross-sections shown in Figure 2. Wannamaker and others (1984) have demonstrated in 3-D resistivity (MT) modeling that approximating 3-D structure beneath a centrally located profile with 2-D modeling is best achieved when fitting the TM curve even at the expense of fitting the TE curve. However, because TM data are quite insensitive to the depth extent of a subsurface body (Eberhart-Phillips and others, 1995), the depths to the base of the bodies in the model are not well constrained. Clarifying the limits of the model structures with $3-D$ resistivity modeling is needed.

Resistivity models (Figure 2) assuming a 2-D earth were constructed for each profile using the forward modeling finite element algorithm of Wannamaker and others [1987]. The resistivity models generally fit the TM data better than the TE data (see Appendix A, B, C, and D), although fits to the TE data were generally satisfactory for stations where 2-D structure was indicated (Figure 2). However, because of the widespread 3-D character of the results, we focus only on the gross structure determined by the models.

The variable-dimension finite-element grid cells used for

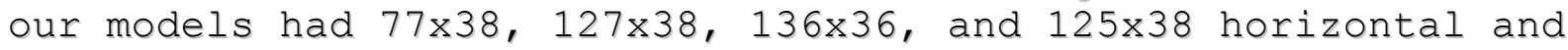
vertical nodes for profiles MT1, MT2, MT3, and MT4, respectively. The edges of the model were extended to 900-, 980-, 550-, and $890-\mathrm{km}$ horizontally and 450-, 450-, 200-, and 450-km vertically for profiles MT1, MT2, MT3, and MT4, respectively, so as to minimize edge effects. The resolution of the resistivity boundaries used for each model is somewhat subjective. If different resistivities are used, then boundary positions and layer depths would have to be adjusted to achieve similar fits to the observed data. The extreme case would be to use a model with a "continuous" resistivity gradient from low to high resistivities. The resolution of the resistivity boundaries is also, in part, a function of our model grid mesh design. We have attempted to keep each model simple. The MT profile models (Figure 2) are stacked as though viewed from the southeast end of the BME trend (Figure 1). The model depths are relative to the surface. 


\section{DISCUSSION}

The resistivity model for profile MT4 (Figure 2) shows high crustal resistivity (300 to $1,000 \mathrm{ohm}-\mathrm{m}$ ) beneath the Carlin trend, characteristic of carbonates or intruded rock, although significant portions of the model below 5 to $10 \mathrm{~km}$ depth beneath the Carlin trend is poorly defined because of poor data quality. The narrow, sub-vertical, 2-D, low resistivity (1 to $10 \mathrm{ohm}-\mathrm{m}$ ) zone beneath stations $20 \mathrm{~A}$ to $24 \mathrm{~A}$ that penetrates to mid-crustal depths (from 5 to $20 \mathrm{~km}$ depth) is hard to explain other than by a major crustal-dimension fault or fracture zone (Eberhart-Phillips et al., 1995). The low resistivities are likely caused by material associated with faulting or fracture filling, such as mylonitic breccia, brine-filled fractures, argillaceous

alteration from hydrothermal fluids, substantial graphitic carbon associated with shearing, or a combination of these (EberhartPhillips et al., 1995). Additional support for a fault zone interpretation is the 2-D electrical structure. In the upper 8 $\mathrm{km}$, the resistive (30 to $1,000 \mathrm{ohm}-\mathrm{m})$ crustal blocks near Battle Mountain (beneath station 16A, Figure 1) appear to be broken by a southwest-to-northeast fault zone. Other conductive zones in this model are 3-D in character and so are not interpreted as crustal fault zones, however, the large 3-D conductive (1 ohm-m) zone from 1 to $12 \mathrm{~km}$ depth between stations $27 \mathrm{~A}$ and $28 \mathrm{~A}$ is characteristic of a geothermal resource area (GRA).

The resistivity model for profile MT3 (Figure 2) also shows a high crustal resistivity (300 to $1,000 \mathrm{ohm}-\mathrm{m})$ beneath the carlin trend, characteristic of carbonates or intruded rock. Exposures of Cretaceous quartz monzonite near MT station 4, Tertiary granodiorite about one mile southeast of station 2, widespread re-crystallized carbonates in these areas (Evans, 1980), and a broad magnetic high (Grauch, 1996) support the presence of a large, concealed, pluton. Most of the MT sites inside the Carlin trend indicate 3-D resistivity structure at depth (Williams and Rodriguez, 2000). The narrow, sub-vertical, 2-D, low resistivity (1 to $10 \mathrm{ohm}-\mathrm{m}$ ) zone, extending to about 20 $\mathrm{km}$ depth beneath station 8 is interpreted as a crustal fault zone. The moderately resistive (30 to $300 \mathrm{ohm}-\mathrm{m})$ rocks in the upper $5 \mathrm{~km}$ northeast and southwest of the Carlin trend probably correspond to carbonates in the near surface where local outcrops exist (stations 11, 10, 9, 1, 5, 29, and 23) or other unknown volcanic and/or clastic sedimentary rocks at depth (Grauch and others, 1998). The low resistivity (3 ohm-m) zone beneath stations 12 and 19 correlates with a known geothermal resource area (Beowawe KGRA, Figure 1). The narrow, sub-vertical, 2-D, low resistivity ( 3 to $10 \mathrm{ohm}-\mathrm{m}$ ) zone, extending to about $20 \mathrm{~km}$ depth beneath station $5 \mathrm{~A}$ is interpreted as a crustal fault zone. Significant portions of the model below 5 to $10 \mathrm{~km}$ depth at the southwest and northeast sections are poorly defined because of 
poor data quality. Other conductive zones in this model are 3-D in character and so are not interpreted as crustal fault zones.

Crustal resistivity for profile MT2 (Figure 2) across the eastern part of the BME trend $(1,000 \mathrm{ohm}-\mathrm{m}$, between stations 7A and 9A) is also characteristic of carbonates or intruded rocks. Southwest of this high resistivity body, a narrow, sub-vertical, 2-D, low resistivity (1 to $10 \mathrm{ohm}-\mathrm{m}$ ) zone, extending to about 20 $\mathrm{km}$ depth is interpreted as a crustal fault zone. The inferred crustal fault zone is more resistive (from $1 \mathrm{ohm}-\mathrm{m}$ to $10 \mathrm{ohm}-\mathrm{m}$ ) near 15-km depth, where it intersects the top of the brittleductile transition (Holbrook and others, 1991). Grauch and others (1998) show that sub-horizontal seismic reflectors from COCORP seismic-reflection data (Potter and others, 1987) in this depth range occur near a horizontal resistivity boundary near 15$\mathrm{km}$ depth (brittle-ductile transition) that shows a change to lower resistivity (from 1,000 ohm-m to $100 \mathrm{ohm}-\mathrm{m}$ ). Potter and others (1987) suggested the west-dipping reflection might be an inclined magma feeder for the Northern Nevada rift, whose magnetic-high expression is between stations $9 \mathrm{~A}$ and $8 \mathrm{~A}$ (Grauch and others, 1998). Another horizontal resistivity boundary that shows a general change to lower resistivity (from 100 ohm-m to 30 ohm-m) occurs below $20 \mathrm{~km}$ depth, where Holbrook and others (1991) suggested that rising basaltic magmas intrude the ductile lower crust with mafic sills.

The resistivity model for profile MT1 (Figure 2) shows high crustal resistivity $(300 \mathrm{ohm}-\mathrm{m})$, characteristic of carbonates or intruded rock, beneath Alligator Ridge (station 108, Figure 1) that is in-line with a southeast extension of the Carlin trend. The narrow, sub-vertical, 2-D, low resistivity (3 to 10 ohm-m) zone, extending to about $20 \mathrm{~km}$ depth beneath station 79 is interpreted as a crustal fault zone. The resistive crustal blocks near Alligator Ridge (station 79) appear to be broken by a south-to-north fault zone in the upper 5 to $10 \mathrm{~km}$. The narrow, sub-vertical, 2-D, low resistivity (3 ohm-m) zone, extending to about $20 \mathrm{~km}$ depth beneath station 87 is interpreted as a crustal fault zone. Other conductive zones in this model are 3-D in character and so are not interpreted as crustal fault zones.

The crustal conductors, in general, are not well constrained laterally due to wide station spacing, giving 3 to $15 \mathrm{~km}$ as the overall range of widths. The images also show regional changes in the resistive crust from north to south. Most of Reese River Valley and Boulder Valley are underlain by a thick (20 km) southwest-to-northeast section of conductive ( 1 to $10 \mathrm{ohm}-\mathrm{m}$ ) rock, suggesting that high-temperature fluids are more pervasive in this area (Battle Mountain Heat-Flow High, MT4, Figure 2). In turn, this implies that the crust is more highly fractured in the vicinity of profile MT4 than in the areas surveyed to the south. 


\section{SUMMARY}

Strengthening the suggestion of Shawe (1991), MT data collected along four, regional scale, southwest-to-northeast profiles show deep resistivity structures beneath the Battle Mountain-Eureka (BME) and Carlin gold trends in north-central Nevada, which appear consistent with tectonic breaks in the crust that possibly served as channels for hydrothermal fluids. It seems likely that gold deposits along these linear trends were, therefore, controlled by deep regional crustal fault systems.

Two-dimensional resistivity modeling of the MT data was used to image the deep resistivity structure in the study area. The models generally show resistive (30 to 1,000 ohm-m) crustal blocks broken by narrow, sub-vertical, two-dimensional, conductive ( 1 to $10 \mathrm{ohm}-\mathrm{m}$ ) zones that are indicative of largescale crustal fault zones. These inferred fault zones are regional in scale, trend southeast-to-northwest, and extend to mid-crustal $(20 \mathrm{~km})$ depths. The conductors are about 3 to $15 \mathrm{~km}$ wide, extend from 1 to $8 \mathrm{~km}$ below the surface to about $20 \mathrm{~km}$ depth, and show two-dimensional electrical structure with general north to northwesterly strikes. From connecting the locations of the conductors together, a single regional crustal fault zone can be inferred that is about $10 \mathrm{~km}$ wide within the upper crust and about $150-\mathrm{km}$ long. It coincides with the BME mineral trend.

The interpreted structure from these profiles should provide constraints for future geologic interpretations of the genesis of gold deposits along the Carlin and BME trends. The deep regional resistivity structure across the Carlin and BME trends has huge implications for large gold resources in northeastern Nevada, because it reveals major crustal structures that were probably responsible for the deformation and shattering of upper crustal rocks providing local permeable zones favorable for fluid flow and precipitation of gold ores. This implies that the potential for many additional undiscovered deeper-level deposits in the Carlin trend is large.

Acknowledgments. We thank Douglas P. Klein for his contributions to this study before his retirement from the U.S. Geological Survey. We also thank V.J.S. Grauch with the U.S. Geological Survey and Louise Pellerin with the University of Utah, Energy and Geoscience Institute for their helpful comments and suggestions to this report. 


\section{REFERENCES CITED}

Arehart, G.B., Foland, K.A., Naeser, C.W., and Kesler, S.E., 1993, 40Ar/39Ar, K/Ar, and fission track geochronology of sediment-hosted disseminated gold deposits at Post-Betze, Carlin Trend, northeastern Nevada: Economic Geology, vol. 88 , no. 3, p. 622-646.

Bendat, J.S., and Piersol, A.G., 1971, Random Data: Analysis and Measurement Procedures: New York, Wiley Interscience, $407 \mathrm{p}$.

Dobrin, M.D., and Savit, C.H., 1988, Introduction to Geophysical Prospecting (4th ed.): New York, McGraw-Hill, $867 \mathrm{p}$.

Eberhart-Phillips, D., Stanley, W. D., Rodriguez, B. D. and Lutter, W. J., 1995, Surface seismic and electrical methods to detect fluids related to faulting: Journal of Geophysical Research, vol. 100, no. B7, pp. 12,919-12,936.

Evans, J.G., 1980, Geology of the Rodeo Creek NE and Welches Canyon quadrangles, Eureka county, Nevada: U.S. Geological Survey Bulletin 1473, 81 p.

Grauch, V.J.S., 1996, Magnetically interpreted, granitoid plutonic bodies, in Singer, D.A., Ed., An analysis of Nevada's metal-bearing mineral resources: Nevada Bureau of Mines and Geology Open-File Report 96-2, p. 7-1 to 7-16.

Grauch, V.J.S., Klein, D.P., and Rodriguez, B.D., 1998, Progress on understanding the crustal structure near the Battle Mountain-Eureka mineral trend from geophysical constraints, in Tosdal, R.M., ed., 1998, Contributions to the gold metallogeny of northern Nevada: U.S. Geological Survey Open-File Report 98-338, p. 8-14.

Holbrook, W. S., Catchings, R. D., and Jarchow, C. M., 1991, Origin of deep crustal reflections: Implications of coincident seismic refraction and reflection data in Nevada: Geology, v. 19, p. 175-179.

Ilchik, R.P. and Barton, M.D., 1997, An amagmatic origin of Carlin-type gold deposits: Economic Geology, vol. 92, no. 3, p. 269-288.

Keller, G.V., 1987, Rock and mineral properties, in Electromagnetic Methods in Applied Geophysics Theory: M.N. Nabighian, Ed., Society of Exploration Geophysicists, Tulsa, Oklahoma, v. 1, p. 1351. 
Keller, G.V., 1989, Electrical properties, in Carmichael, R.S., Ed., Practical handbook of physical properties of rocks and minerals: CRC Press, Boca Raton, Florida, p. 359-427.

Nelson, P.H. and Anderson, L.A., 1992, Physical properties of ash flow tuff from Yucca Mountain, Nevada: Journal of Geophysical Research, vol. 97, no. B5, p. 6823-6841.

Palacky, G.J., 1987, Resistivity characteristics of geologic targets, in Electromagnetic Methods in Applied Geophysics Theory: M.N. Nabighian, Ed., Society of Exploration Geophysicists, Tulsa, Oklahoma, vol. 1, p. 53129.

Potter, C. J., Liu, C-S., Huang, J., Zheng, L., Hauge, T. A., Hauser, E. C., Allmendinger, R. W., Oliver, J. E., Kaufman, S., and Brown, L., 1987, Crustal structure of north-central Nevada: results from COCORP deep seismic profiling: Geological Society of America Bulletin, v. 98, p. 330-337.

Radtke, A.S., 1985, Geology of the Carlin gold deposit, Nevada: U.S. Geological Survey Professional Paper 1267, 124 p.

Reddy, I.K., Rankin, D., and Phillips, R.J., 1977, Threedimensional modelling in magnetotelluric and magnetic variational sounding: Geophysics Journal of the Royal Astronomical Society, vol. 51, p. 313-325.

Rodriguez, B.D., Stanley, W.D., and Williams, J.M., 1996, Axial structures within the Reelfoot rift delineated with magnetotelluric surveys: U.S. Geological Survey Professional Paper $1538-\mathrm{K}, 30 \mathrm{p}$.

Shawe, D.R., 1991, Structurally controlled gold trends imply large gold resources in Nevada, in Geology and ore deposits of the Great Basin, Symposium Proceedings: Raines, G.L., Lisle, R.E., Schafe, R.W., Wilkinson, W.H., Eds., Geological Society of Nevada, Reno, vol. 1, p. 199-212.

Sillitoe, R.H. and Bonham, H.F., 1990, Sediment-hosted gold deposits; distal products of magmatic-hydrothermal systems: Geology, vol. 18, no. 2, p. 157-161.

Struhsacker, E.M., Jones, E., and Green, S.M., 1996, Roadside geology and precious-metal mineralization along the I-80 corridor, Reno to Elko, Nevada, in Struhsacker, E.M. and Green, S.M., eds., Geology and ore deposits of the American Cordillera - Field Trip Guidebook Compendium: Geological Society of Nevada, Reno, Nevada, p. 3. 
Tosdal, R.M., 1998, Contributions to the gold metallogeny of northern Nevada: U.S. Geological Survey Open-File Report 98$338,290 \mathrm{p}$.

Vozoff, K., 1972, The magnetotelluric method in the exploration of sedimentary basins: Geophysics, vol. 37, p. 98-141.

Vozoff, K., 1991, The magnetotelluric method, in Electromagnetic methods in applied geophysics: M.N. Nabighian, Ed., Society of Exploration Geophysicists, Tulsa, Oklahoma, vol. 2, part B, p. 641-711.

Wannamaker, P.E., 1983, Resistivity structure of the northern Basin and Range: Geothermal Resources Council, Special Report No. 13, p. 345-361.

Wannamaker, P.E., Hohmann, G.W. and Ward, S.H., 1984, Magnetotelluric responses of three-dimensional bodies in layered earths: Geophysics, vol. 49, no. 9, p. 1517-1533.

Wannamaker, P.E., Stodt, J. A. and Rijo, L., 1987, PW2D: finite element program for solution of magnetotelluric responses of two-dimensional earth resistivity structure, (User documentation): Earth Science Laboratory, University of Utah Research Institute, Salt Lake City, Utah, 40 p.

Williams, J.M. and Rodriguez, B.D., 2000, Deep electrical geophysical measurements across the Carlin trend, Nevada: U.S. Geological Survey Open-File Report 00-419, 141 p.

Williams, J.M. and Rodriguez, B.D., 2001, Magnetotelluric data across the Battle Mountain-Eureka and Carlin trends, north of Eureka, Nevada: U.S. Geological Survey Open-File Report $01-168,135 \mathrm{p}$.

Williams, J.M. Rodriguez, B.D., and Klein, D.P., 2001a, Magnetotelluric data across the Battle Mountain-Eureka and Carlin trends, north of Cortez, Nevada: U.S. Geological Survey Open-File Report 01-117, 154 p.

Williams, J.M. Rodriguez, B.D., and Klein, D.P., 2001b, Magnetotelluric data across the Battle Mountain-Eureka and Carlin trends, south of Cortez, Nevada: U.S. Geological Survey Open-File Report 01-118, 109 p.

Williams, J.M. Rodriguez, B.D., and Klein, D.P., 2001c, Magnetotelluric data across the Battle Mountain-Eureka and Carlin trends, near Battle Mountain, Nevada: U.S. Geological Survey Open-File Report 01-228, 205 p. 


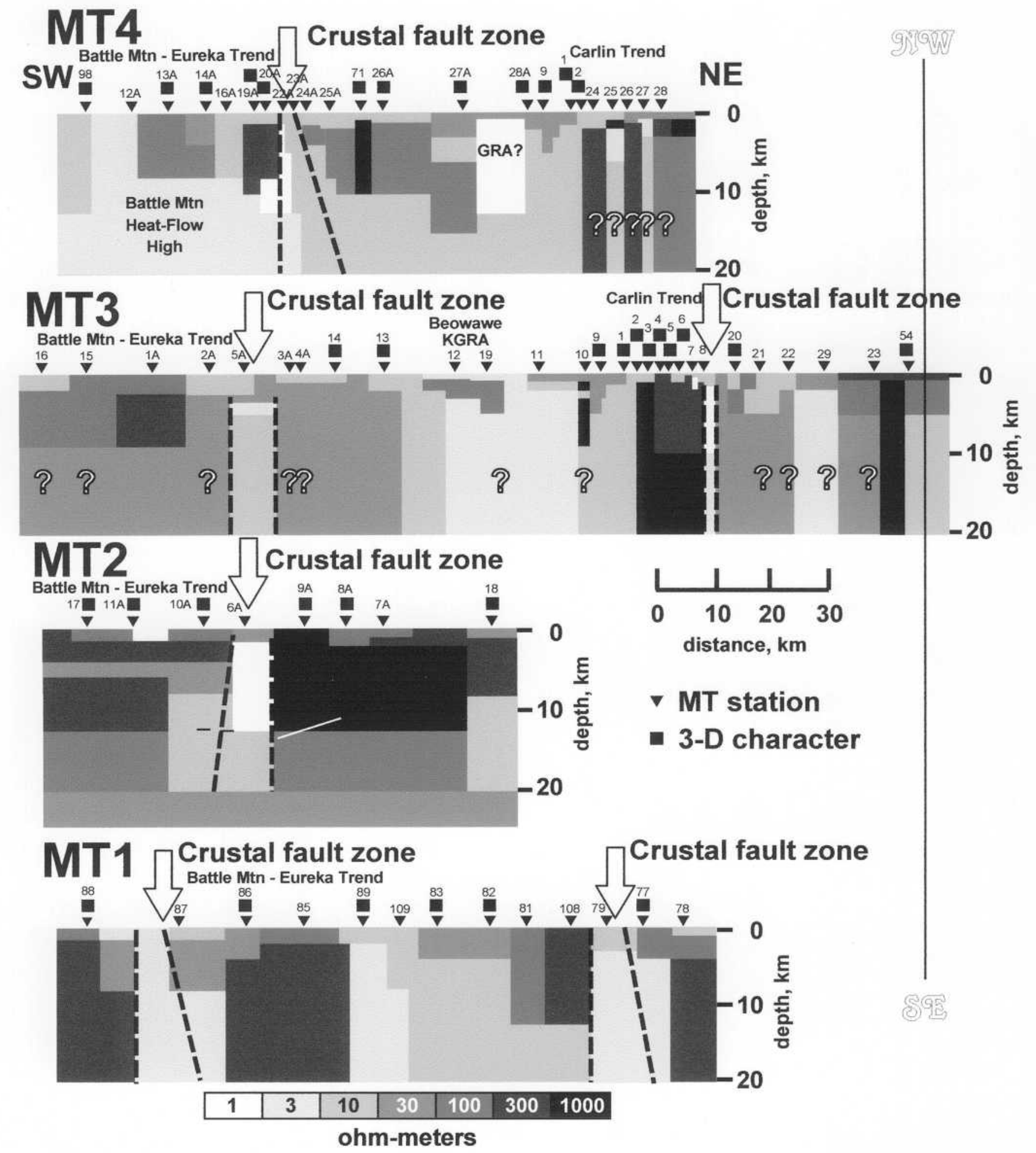

Figure 2. Magnetotelluric (MT) profile, two-dimensional, resistivity models (MT1 to MT4) stacked in relative positions along a northwest-to-southeast line (Figure 1). Depths are from ground surface. White arrows mark interpreted crustal fault zones. Black squares show stations whose MT data indicated three-dimensional character in the lower frequencies. Black and white solid lines on MT2 are COCORP seismic reflectors (Potter and others, 1987). Question marks indicate poor model definition from poor data quality. Vertical exaggeration is 1.4 . 


\section{OBSERVED AND CALCULATED DATA - PROFILE MT4}

Magnetotelluric (MT) observed (circle and $\mathrm{x}$ symbols) and calculated (solid and dashed lines are TE and TM modes, respectively) resistivity and phase data for profile MT4. See the "Magnetotelluric Data" section of this report for a description of the observed data and the "Resistivity Models" section for a description of the calculated data. 
Station 98

APPARENT RESISTIVITY

Fish Creek Mtns, NV 100k

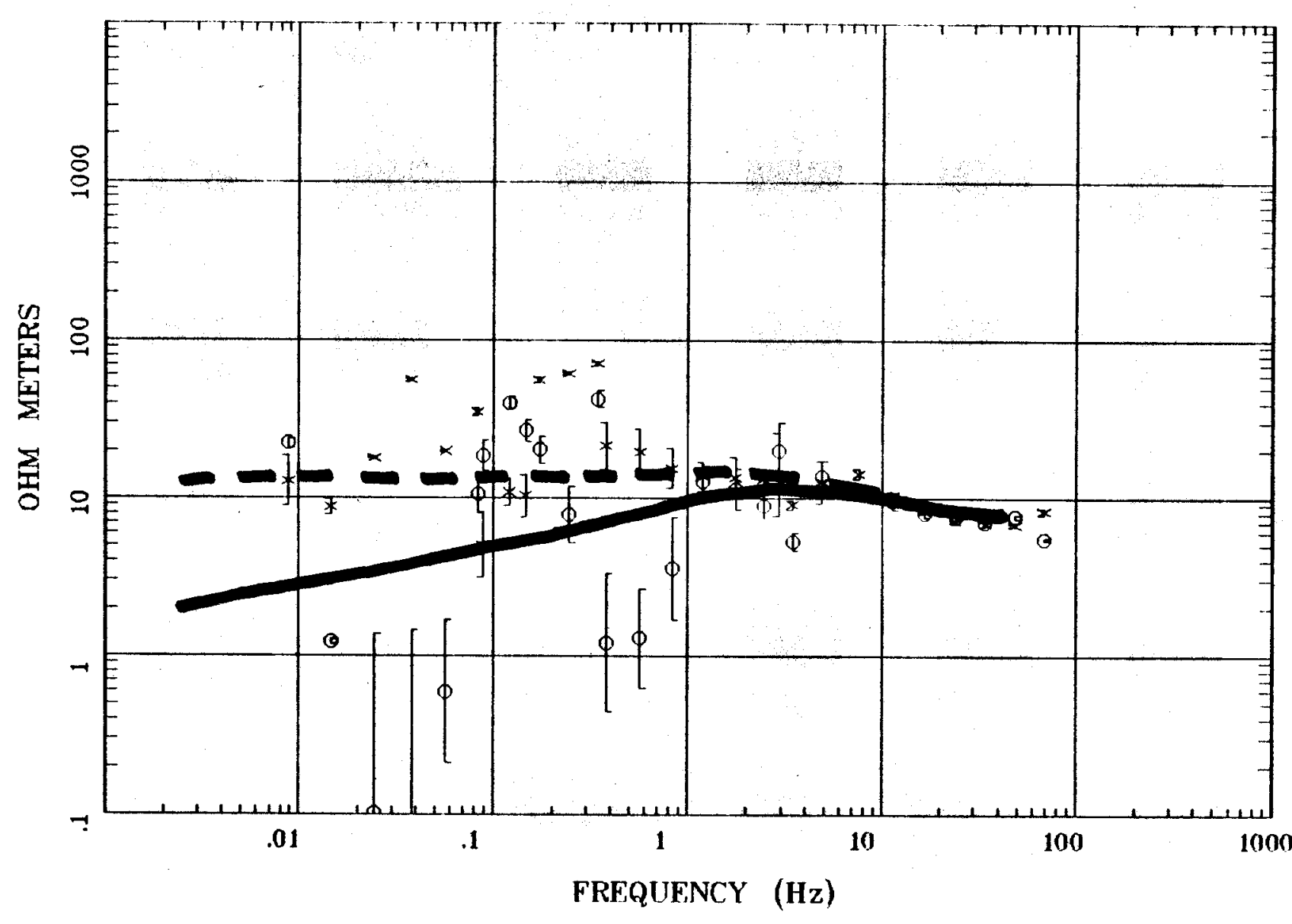

Client:

Remote: none

Acquired: 13:1 Jul 30. 2000

Survey Co:USGS
Rotation:

Filename: hrgec.avg

Channels: Ch1 Ch2 Ch3 Ch4 Ch5 Ch3 Ch4

Plotted: 08:24 Dec 08, 2000

- EMI - ElectroMagnetic Instruments 
Station 98

IMPEDANCE PIIASF;

Fish Creek Mlns, NV 100k

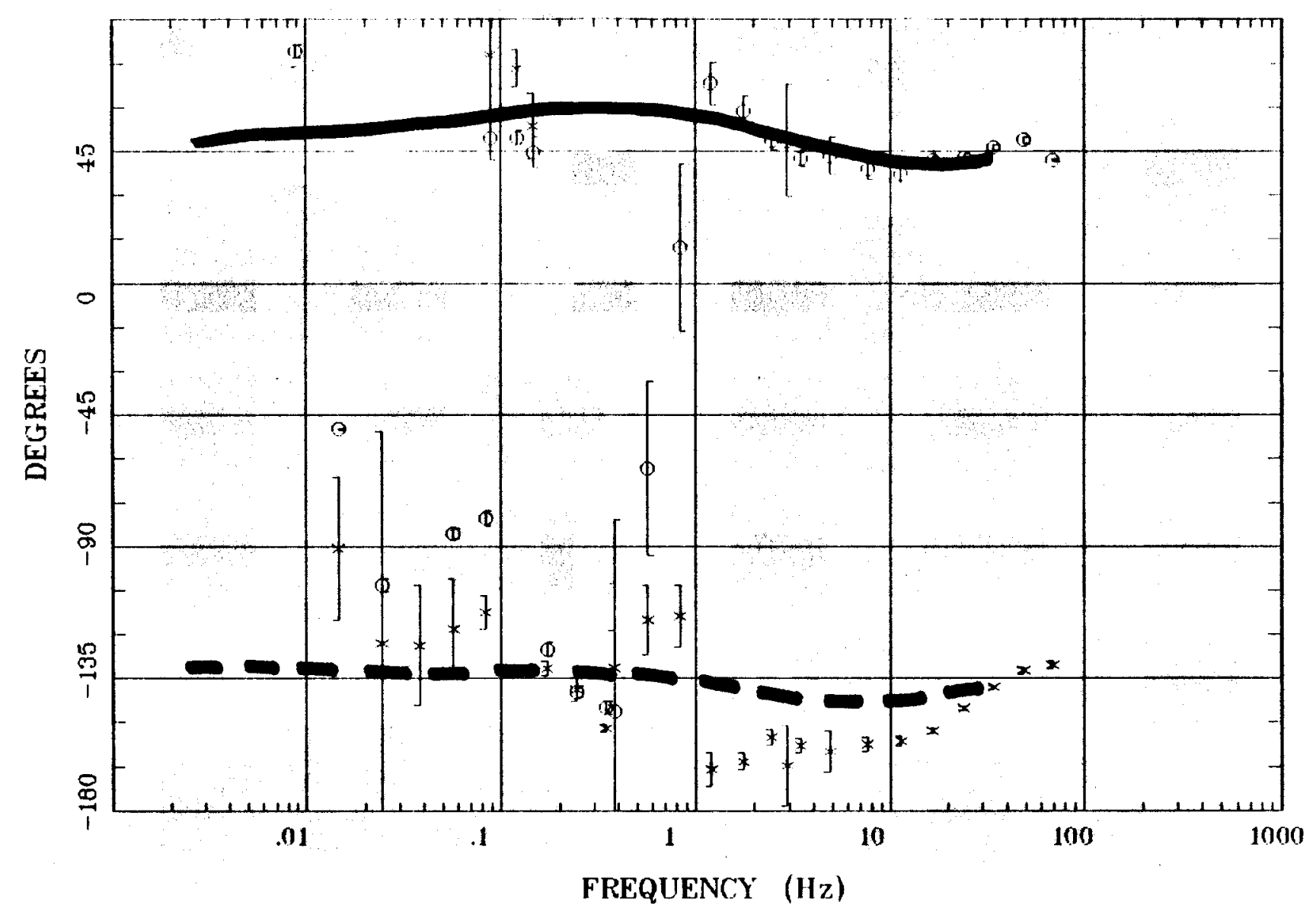

Client:

Remote: none

Acquired: 13:1 Jul 30, 2000

Survey co:USGS
Rotation:

Filename: hr98c.avg

Channels: Ch1 Ch2 Ch3 Ch4 Ch5 Ch3 Ch4

Plotted: 08:24 [Dec 08, 2000

< EMI - ElectroMagnetic Instruments > 
Station 12A

APPARENT RESISTIVITY

battle mtn No. NV

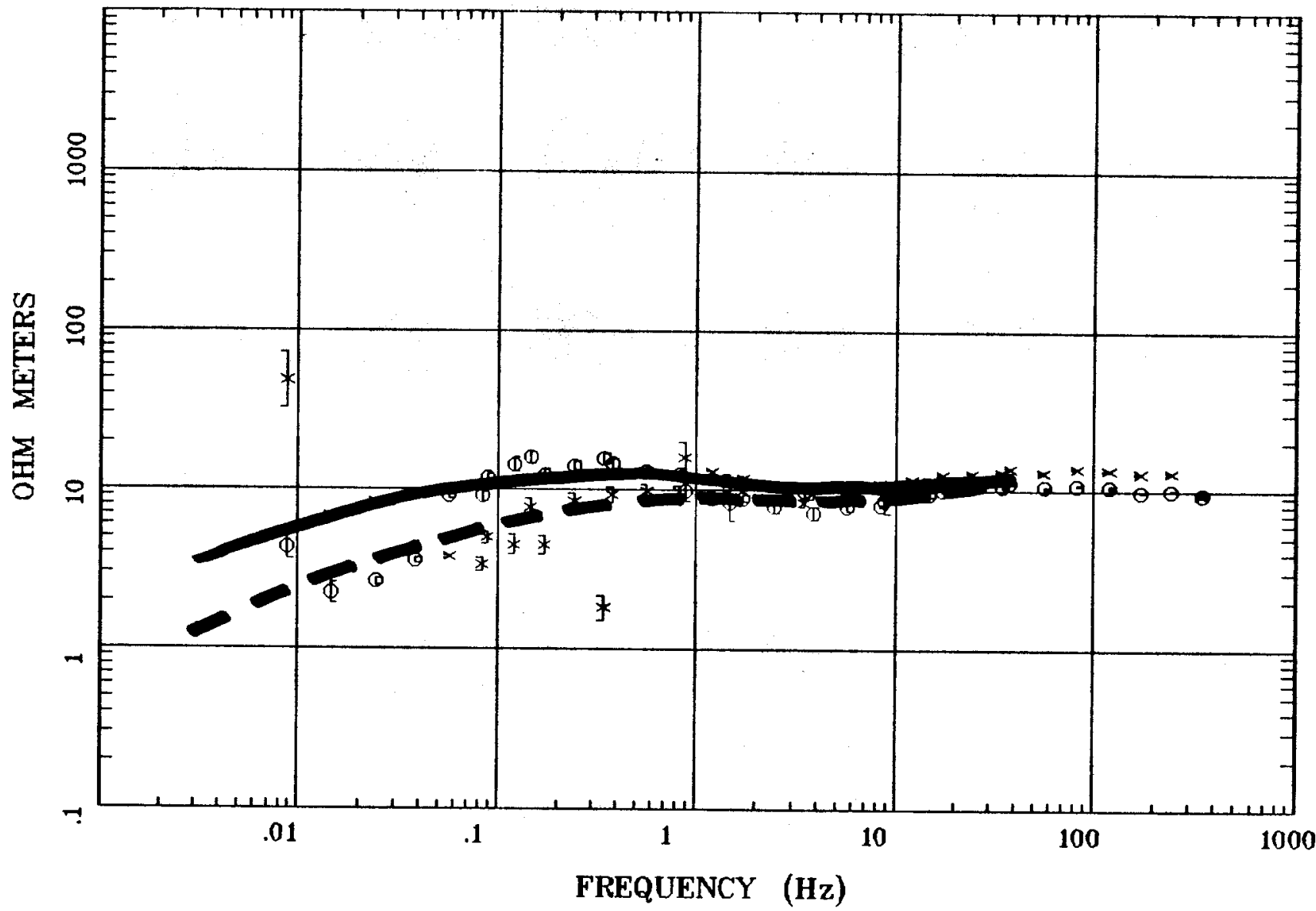

Client:

Remote: e-field local ref Acquired: 17:0 Jul 09, 1997 Survey Co:
Rotation:

Filename: nna12.all

Channels: Ch1 Ch2 Ch3 Ch4 Ch5 Ch6 Ch7

Plotted: 08:51 Dec 08, 2000

< EMI - ElectroMagnetic Instruments > 
Station 12A

IMPEDANCE PHASE

battle mtn No. NV

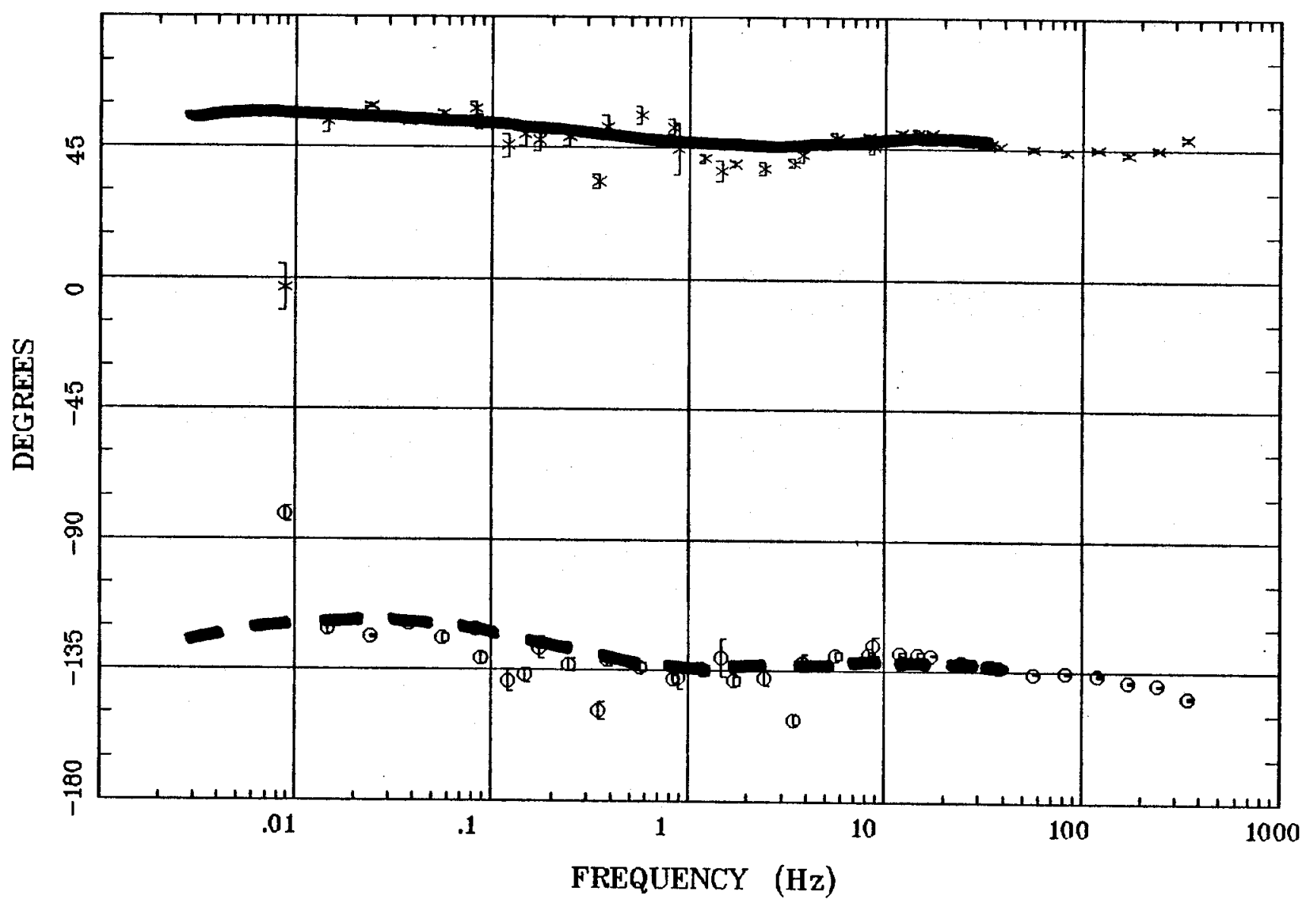

Client:

Remote: e-field local ref

Acquired: 17:0 Jul 09, 1997 Survey Co:

Rotation:

Filename: nna12.all

Channels: Ch1 Ch2 Ch3 Ch4 Ch5 Ch6 Ch7

Plotted: 08:51 Dec 08, 2000

< EMI - ElectroMagnetic Instruments > 
Battle Mtn.

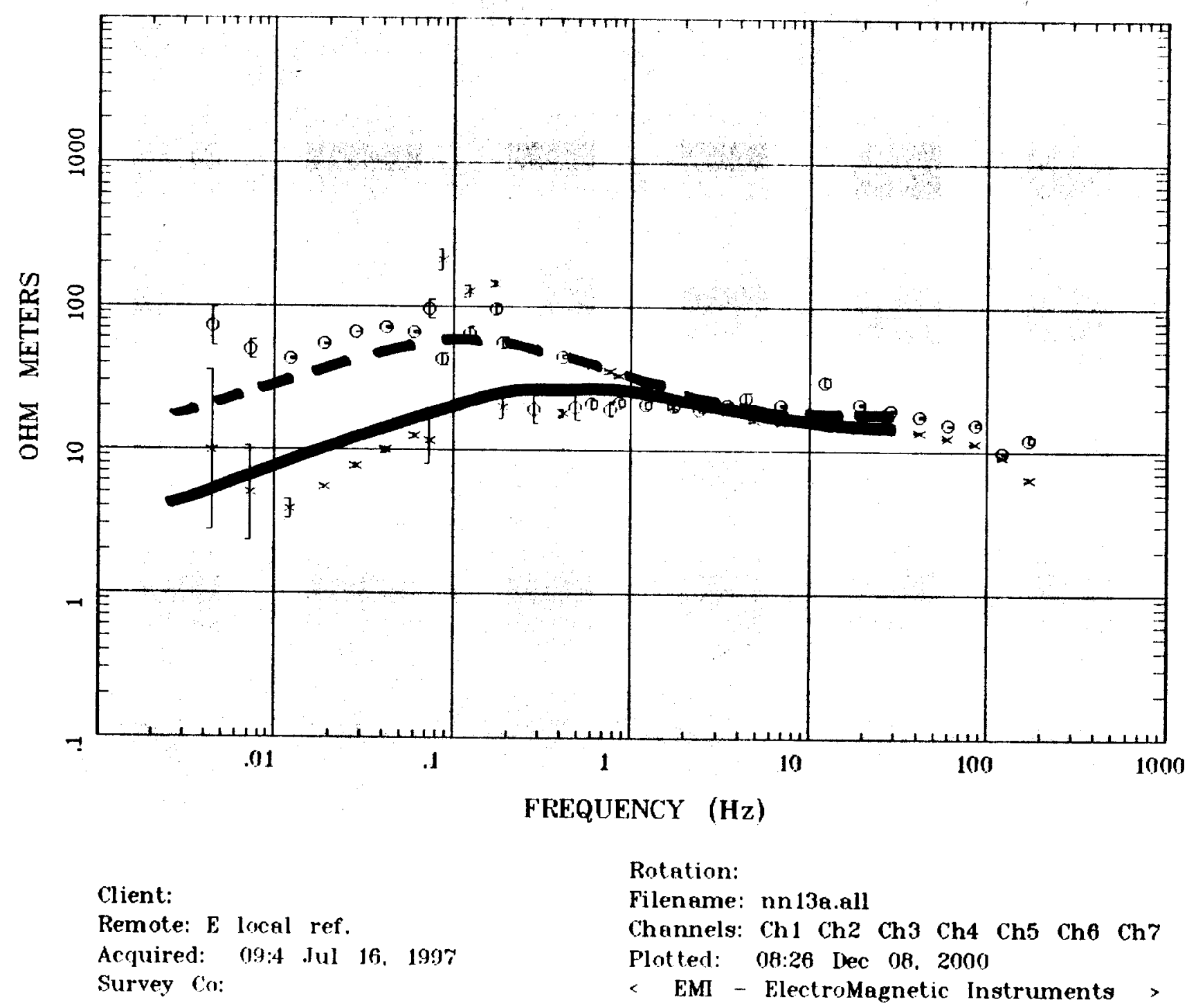


IMPEDANCE PIIASE;

Fattle Mtn.

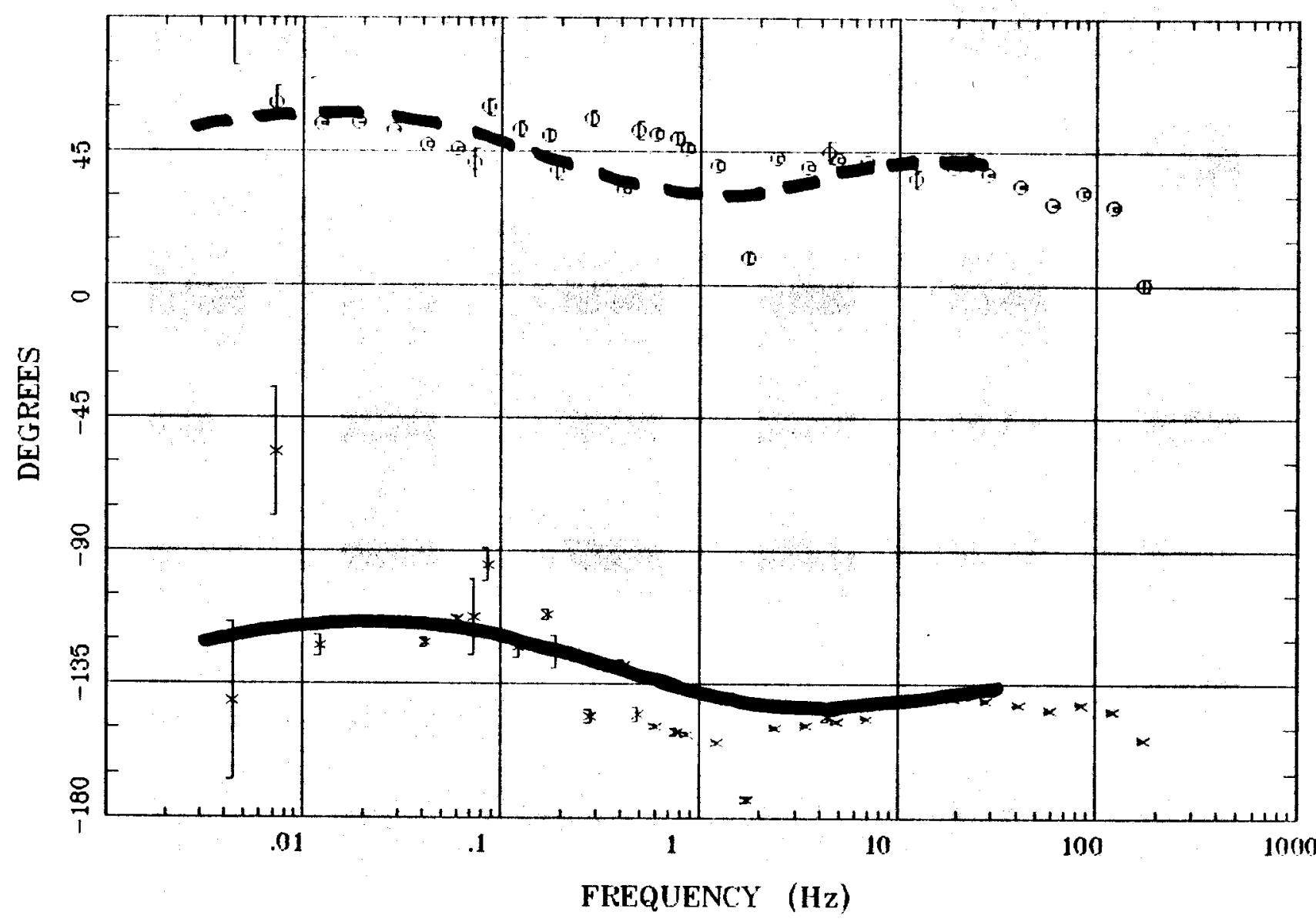

Client:

Remote: E local ref.

Acquired: 09:4 Jul 16. 1997

Survey Co:
Rotation:

Filename: nn 13a.all

Channels: Ch1 Ch2 Ch3 Ch4 Ch5 Che Ch7

Plotted: 08:26 [nec 08. 2000

- EMI - ElectroMagnetic Instruments 
Station 14A

APPARENT RESISTIVITY

liattle Mtn.

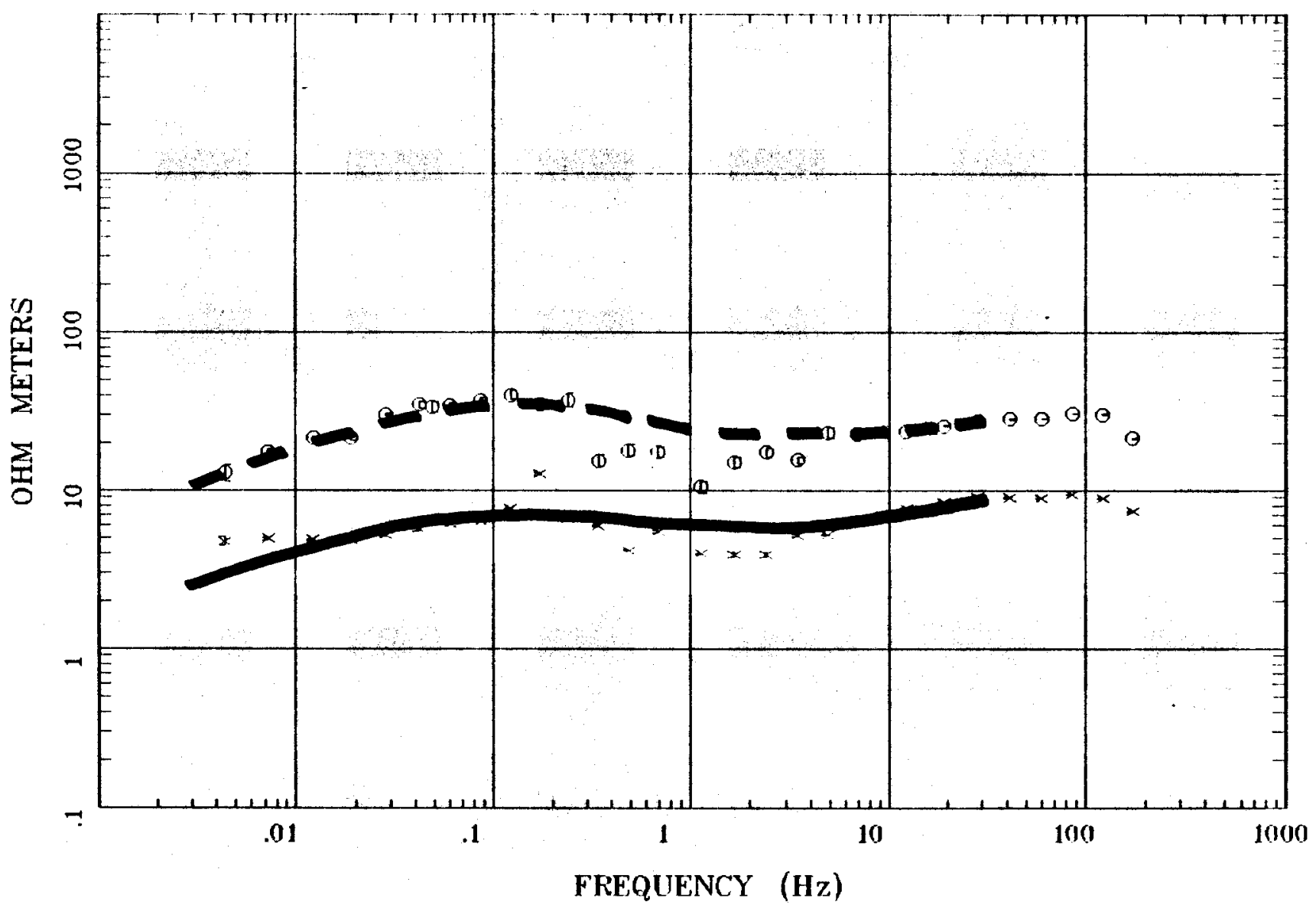

Client:

Remote: $E$ local ref.

Acquired: 10:0 Jul 17, 1997

Rotation

Filen ame: nn 14.all

Channels: Ch1 ch2 Ch3 Ch4 Ch5 Ch6 Ch7

Plotted: 08:27 Dec 08, 2000

Survey Co:

EMI - ElectroMagnetic Instruments 


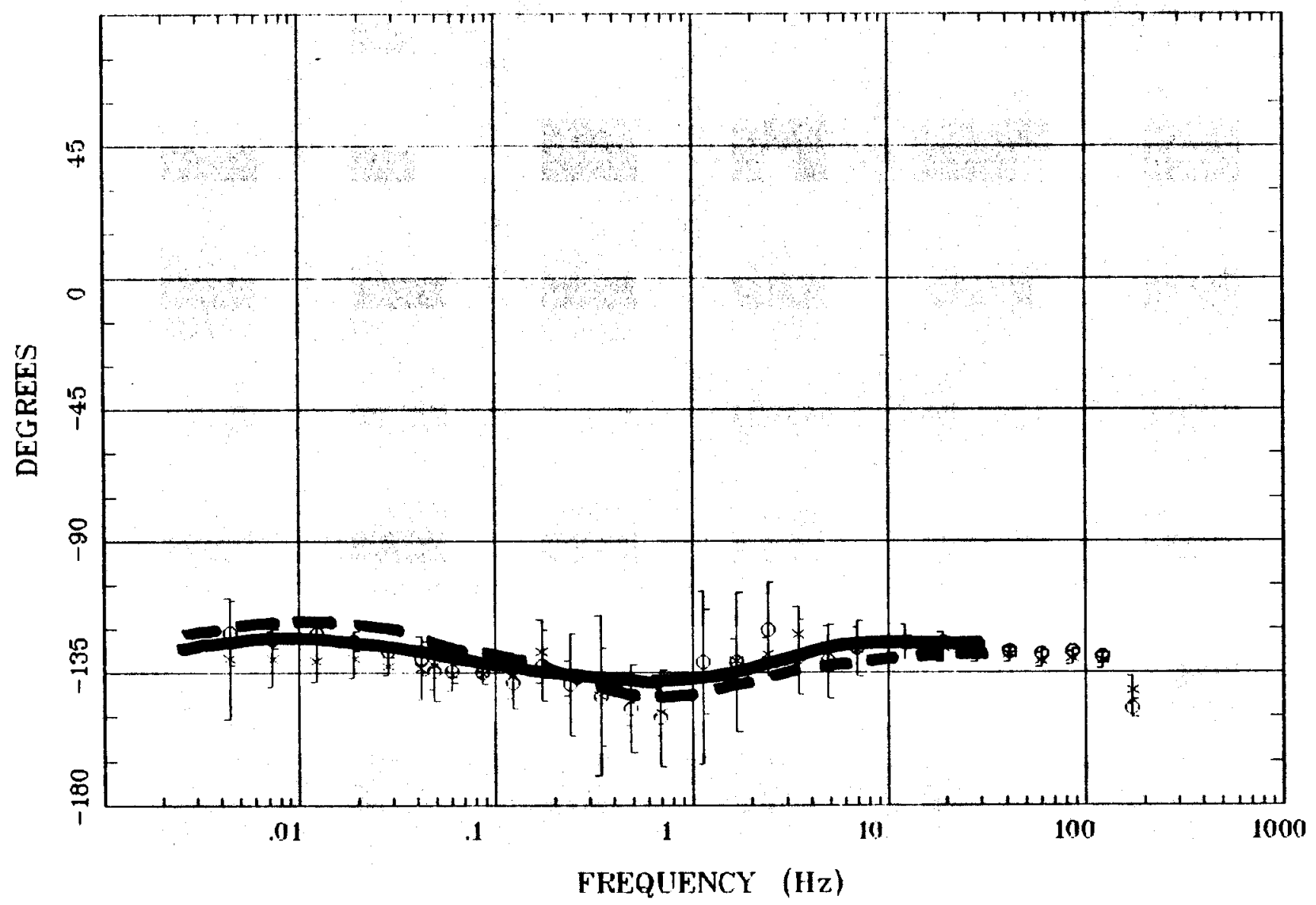

Client:

Remote: E local ref.

Acculuired: 10:0 .Jul 17. 1997

Survey co:
Rotation:

Filename: nn14.all

Channels: Ch1 Ch2 Ch3 Ch4 Ch5 Ch6 Ch7

Plotted: $08: 27$ [nec 08. 2000

- EMI - ElectroMagnetic Instruments > 


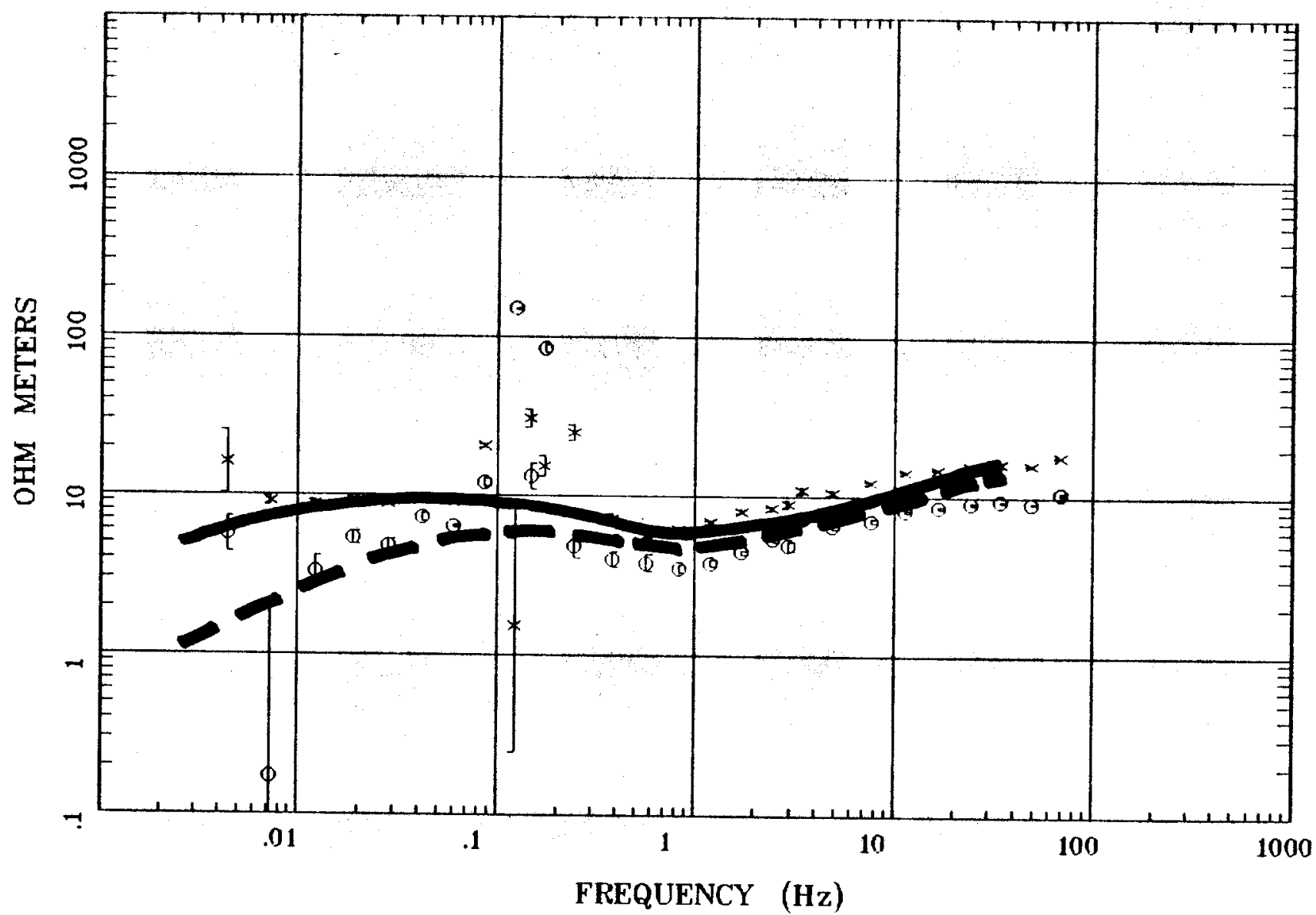

Client:

Remote: e-field local ref

Acquired: 15:2 Jul 11. 1997

Survey Co
Rotation:

Filename: nn 16.all

Channels: Ch1 Ch2 Ch3 Ch4 Ch5 Ch6 Ch7

Plotted: 08:30 Dec 08, 2000

- EMI - ElectroMagnetic Instruments 


\section{Station 16A}

IMPEDANCE PHASE

Battle Mtn.

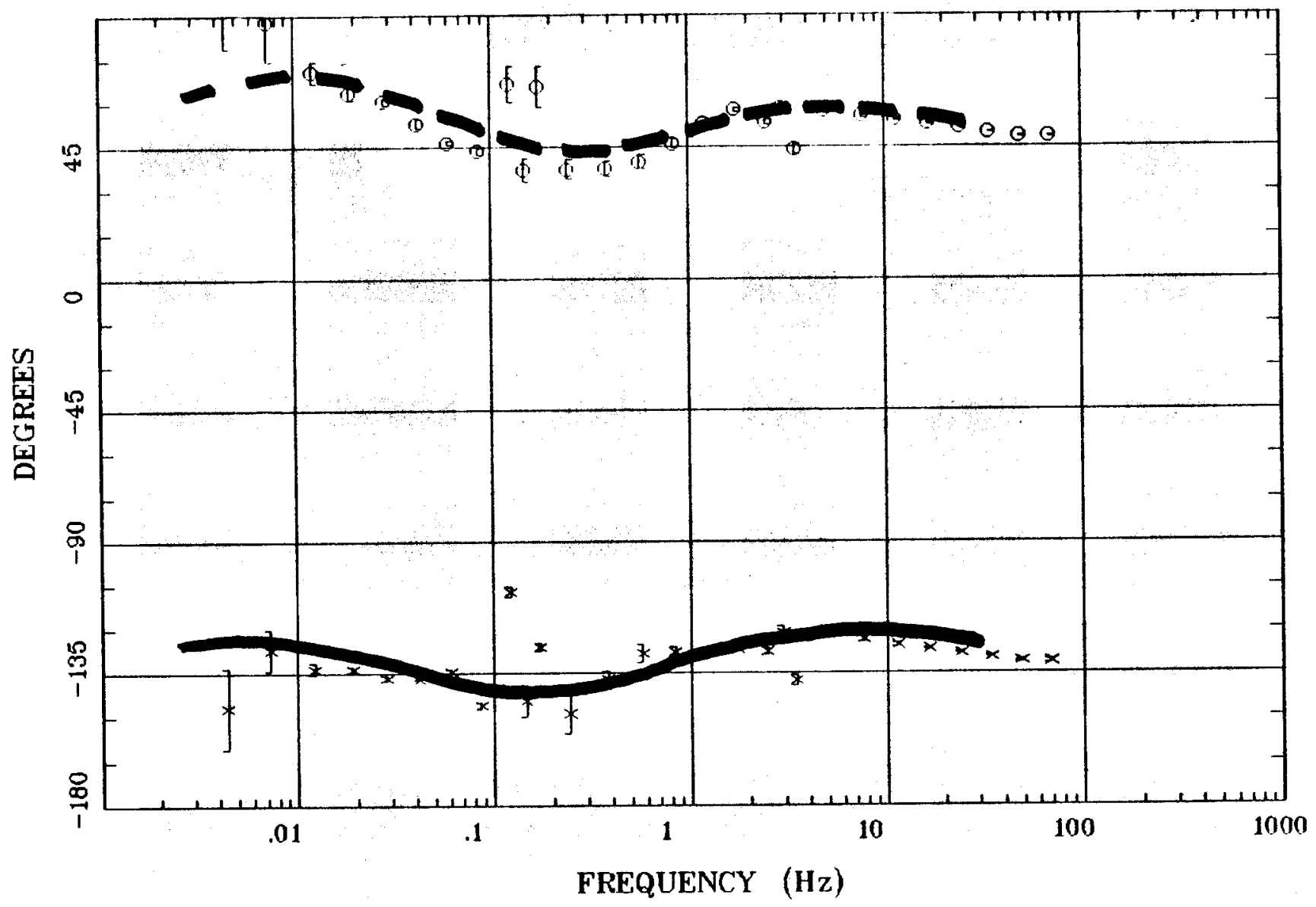

Client:

Remote: e-field local ref

Acquired: 15:2 Jul 11. 1997

Rotation:

Filen ame: nn 16.all

Channels: Ch1 Ch2 Ch3 Ch4 Ch5 Ch6 Ch7

Plotted: 08:30 Dec 08, 2000

Survey Co:

- EMI - ElectroMagnetic Instruments 


\section{Station 19A}

APPARENT RESISTIVITY

Battle Mtn.

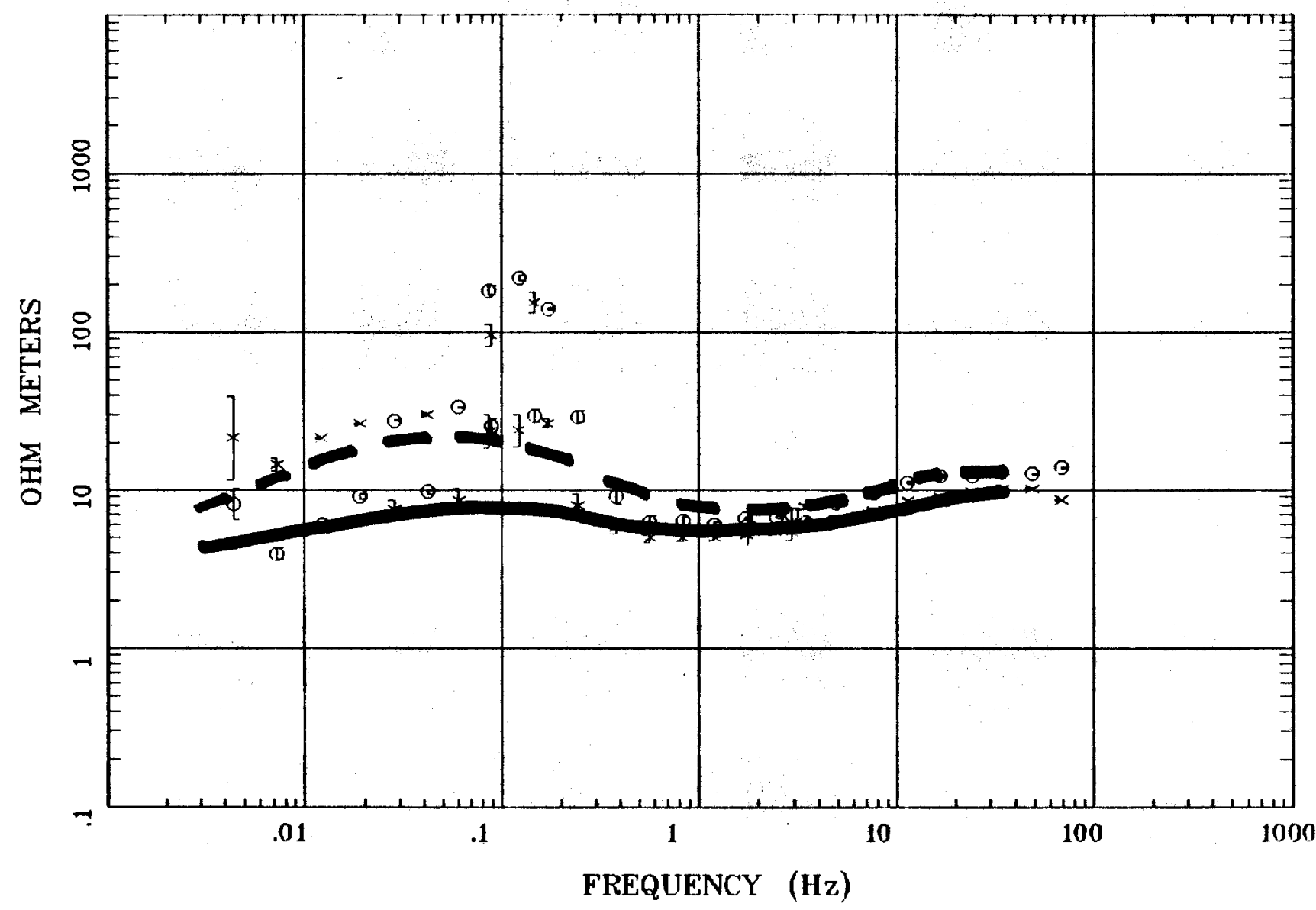

Client:

Remote: e-field local ref Acquired: 12:1 Jul 11. 1997 Survey Co:

Rotation:

Filename: nn 19.all

Channels: Ch1 Ch2 Ch3 Ch4 Ch5 Ch6 Ch7 Plotted: 08:31 Dec 08, 2000

- EMI - ElectroMegnetic Instruments , 
Station 19A

IMPEDANCE, FIIASE

Battle MIn.

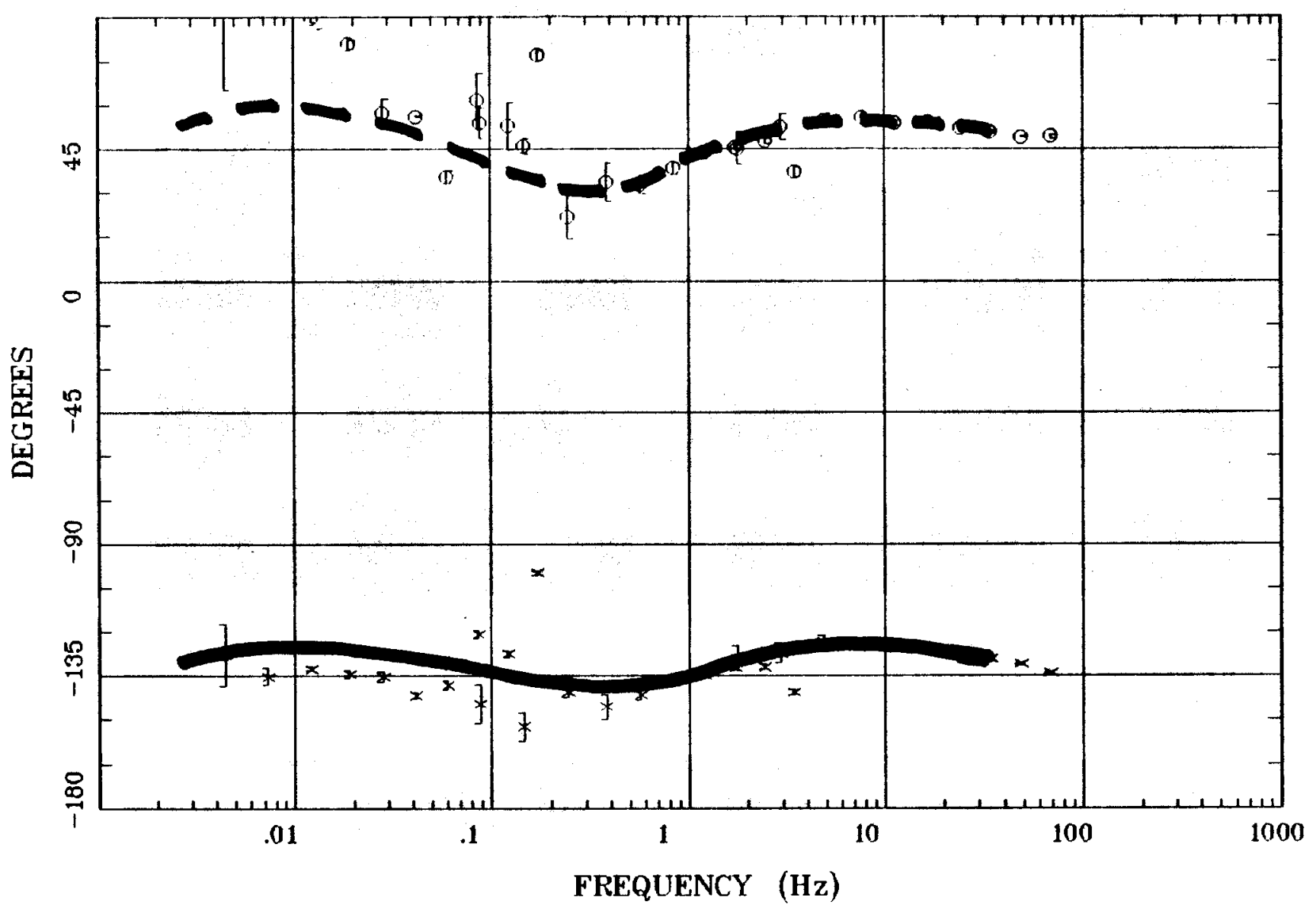

Client:

Remote: e-field local ref Acquired: 12:1 Jul 11, 1997 Survey Co:
Rotation:

Filename: nn19.all

Channels: Ch1 Ch2 Ch3 Ch4 Ch5 Ch6 Ch7

Plotted: 08:31 Dec 08, 2000

\& EMI - ElectroMagnetic Instruments 


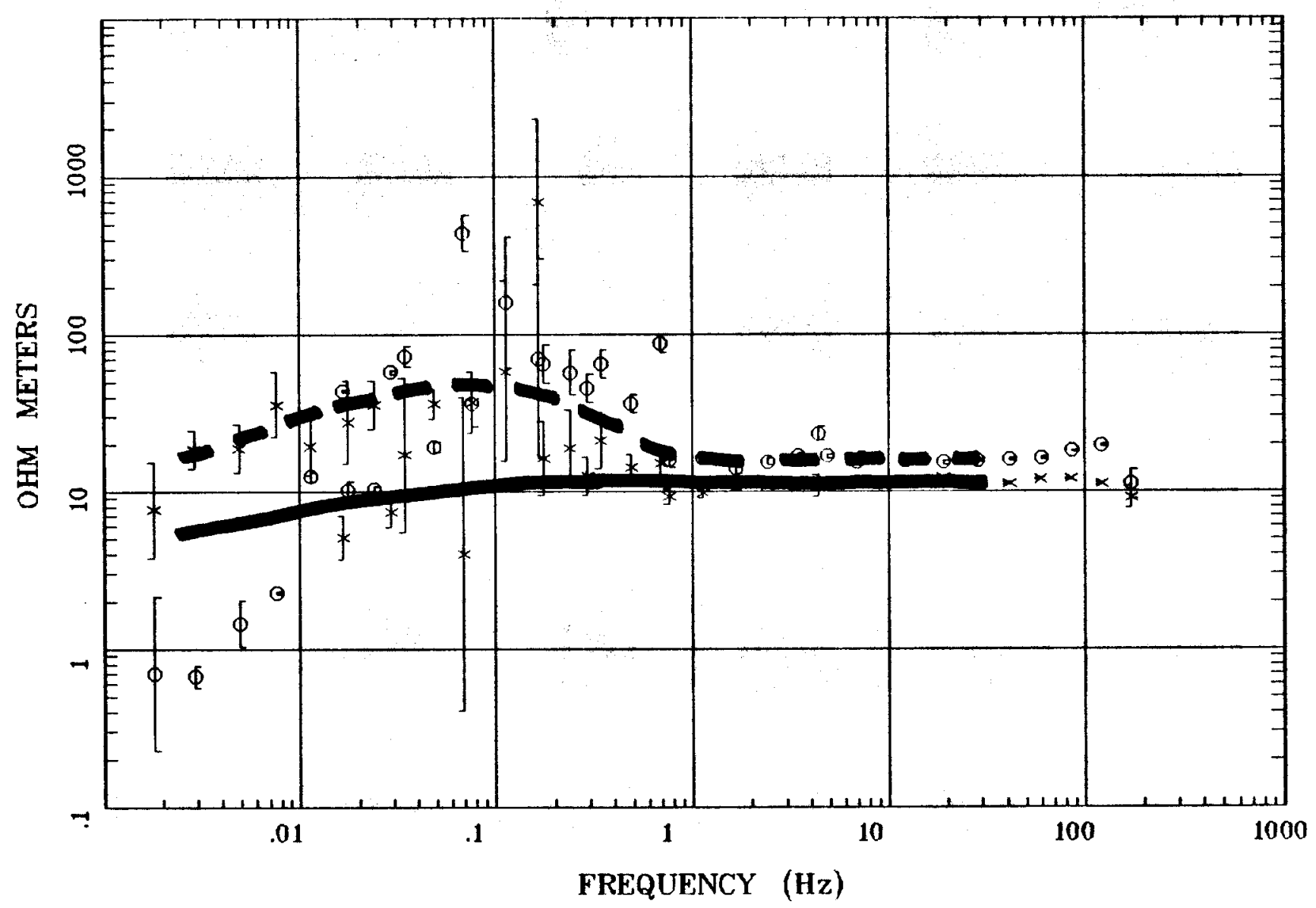

Client:

Remote: E local ref.

Acquired: 15:1 Jul 18, 1997

Survey Co:
Rotation:

Filename: nnz0.all

Channels: Ch1 Ch2 Ch3 Ch4 Ch5 Ch6 Ch7

Plotted: 08:32 Dec 08. 2000

< EMI - ElectroMagnetic Instruments 


\section{Station 20A}

IMPEDANCE FIIASE

Battle Mtn.

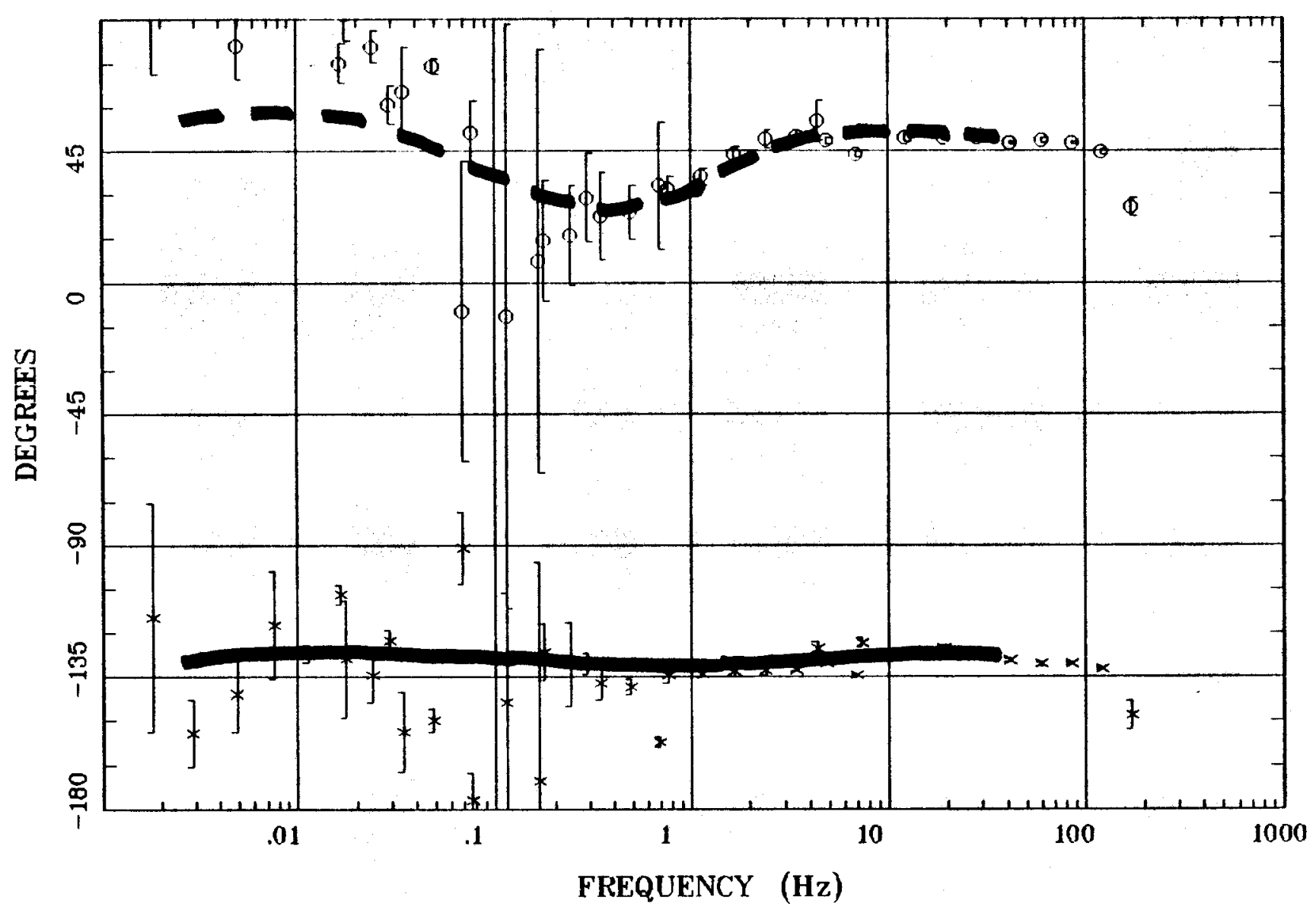

Client:

Remote: E local ref.

Acquired: 15:1 .Jul 18. 1997

Surver Co:

\section{Rotation:}

Filename: nn20.all

Channels: Ch1 Ch2 Ch3 Ch4 Ch5 Ch6 Ch7

Plotted: 08:32 Ilec 08. 2000

• EMI - ElectroMagnetic Instruments > 
Station 22A

Battle Mtn.

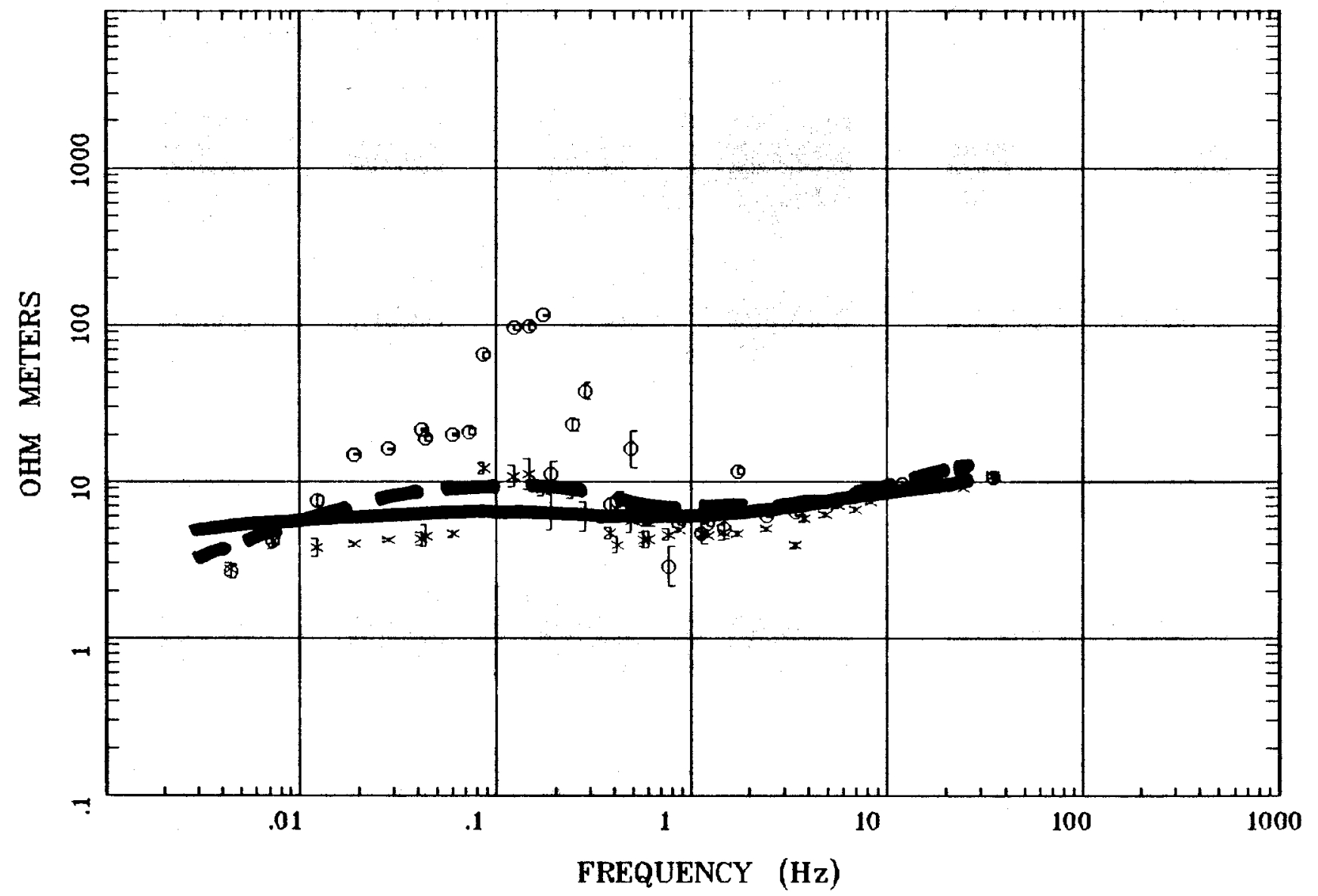

Client:

Remote: e-field local ref

Acquired: 19:5 Jul 10, 1997 Survey Co:
Rotation:

Filename: nn22e.all

Channels: Ch1 Ch2 Ch3 Ch4 Ch5 Ch6 Ch7 Plotted: 08:34 Dec 08, 2000

< EMI - ElectroMagnetic Instruments > 


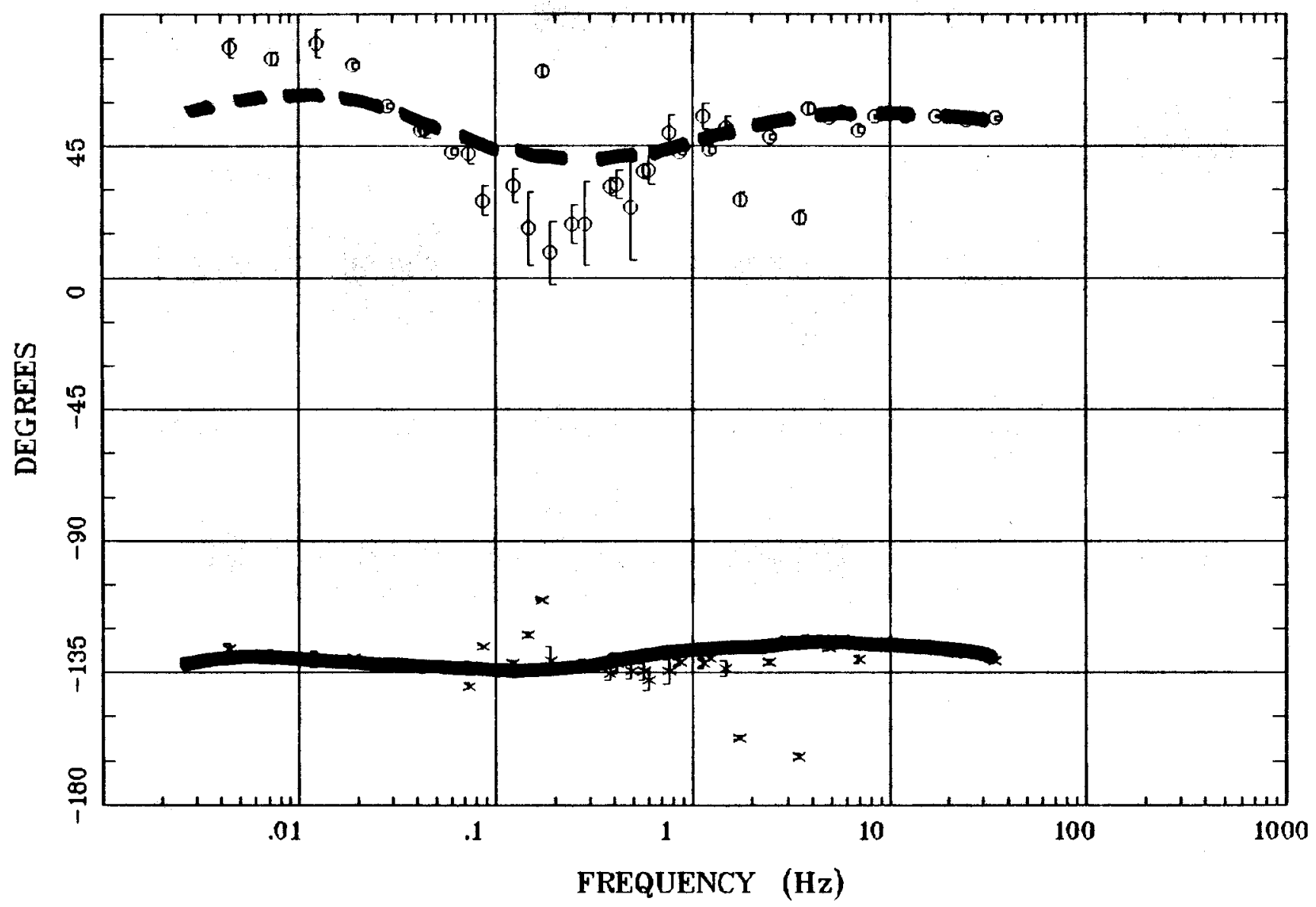

Client:

Remote: e-field lacal ref Acquired: $19: 5$ Jul 10, 1997 Survey co:
Rotation:

Filename: nnz2e.all

Channels: Ch1 Ch2 Ch3 Ch4 Ch5 Ch6 Ch7 Plotted: 08:34 Dec 08, 2000

<EMI - ElectroMagnetic Instruments > 


\section{APPARENT RESISTIVITY}

Station 23A

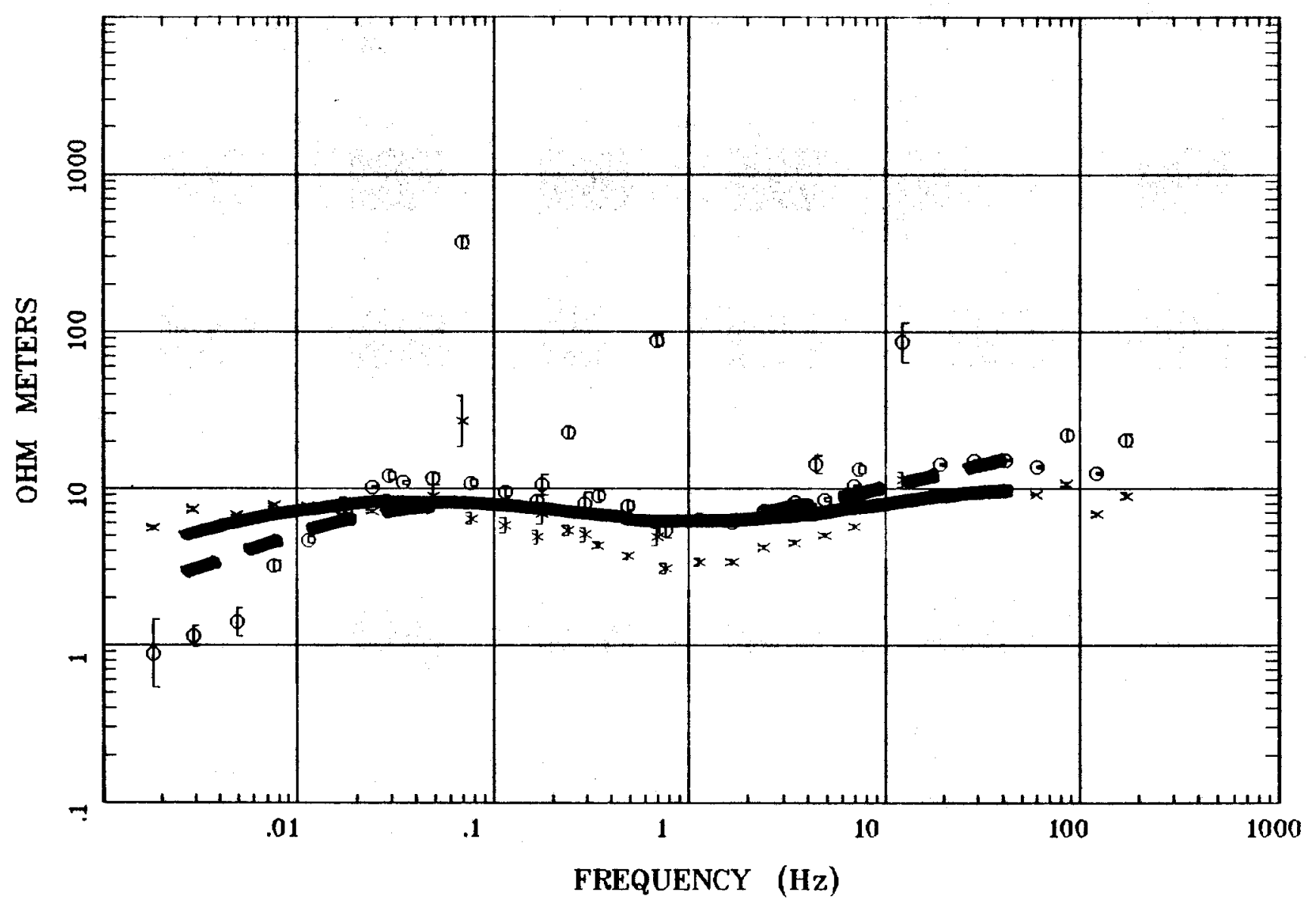

Client:

Remote: E local ref.

Acquired: 09:2 Jul 15, 1997

Survey Co:
Battle Mtn.

$$
1000
$$

FREQUENCY (Hz)

\section{Rotation:}

Filename: nnz3a.all

Channels: Ch1 Ch2 Ch3 Ch4 Ch5 Ch6 Ch7

Plotted: 08:36 Dec 08, 2000

< EMI - ElectroMagnetic Instruments > 


\section{Station 23A}

IMPEDANCE PHASE

Battle Mtn.

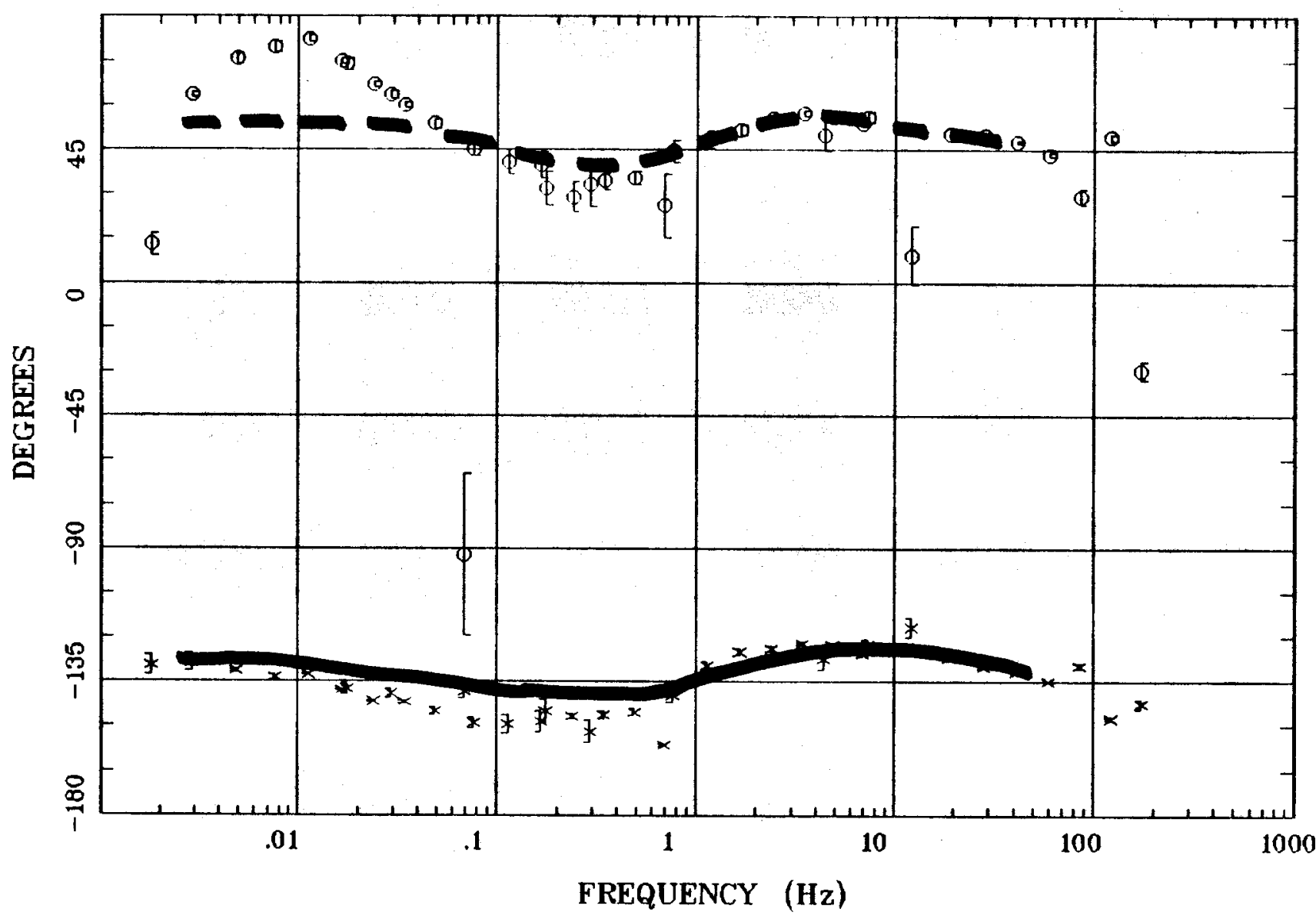

Client:

Remote: E local ref.

Acquired: 09:2 Jul 15, 1997 Survey Co:
Rotation:

Filename: nn23a.all

Channels: Ch1 Ch2 Ch3 Ch4 Ch5 Ch6 Ch7

Plotted: 08:36 Dec 08, 2000

- EMI - ElectroMagnetic Instruments 


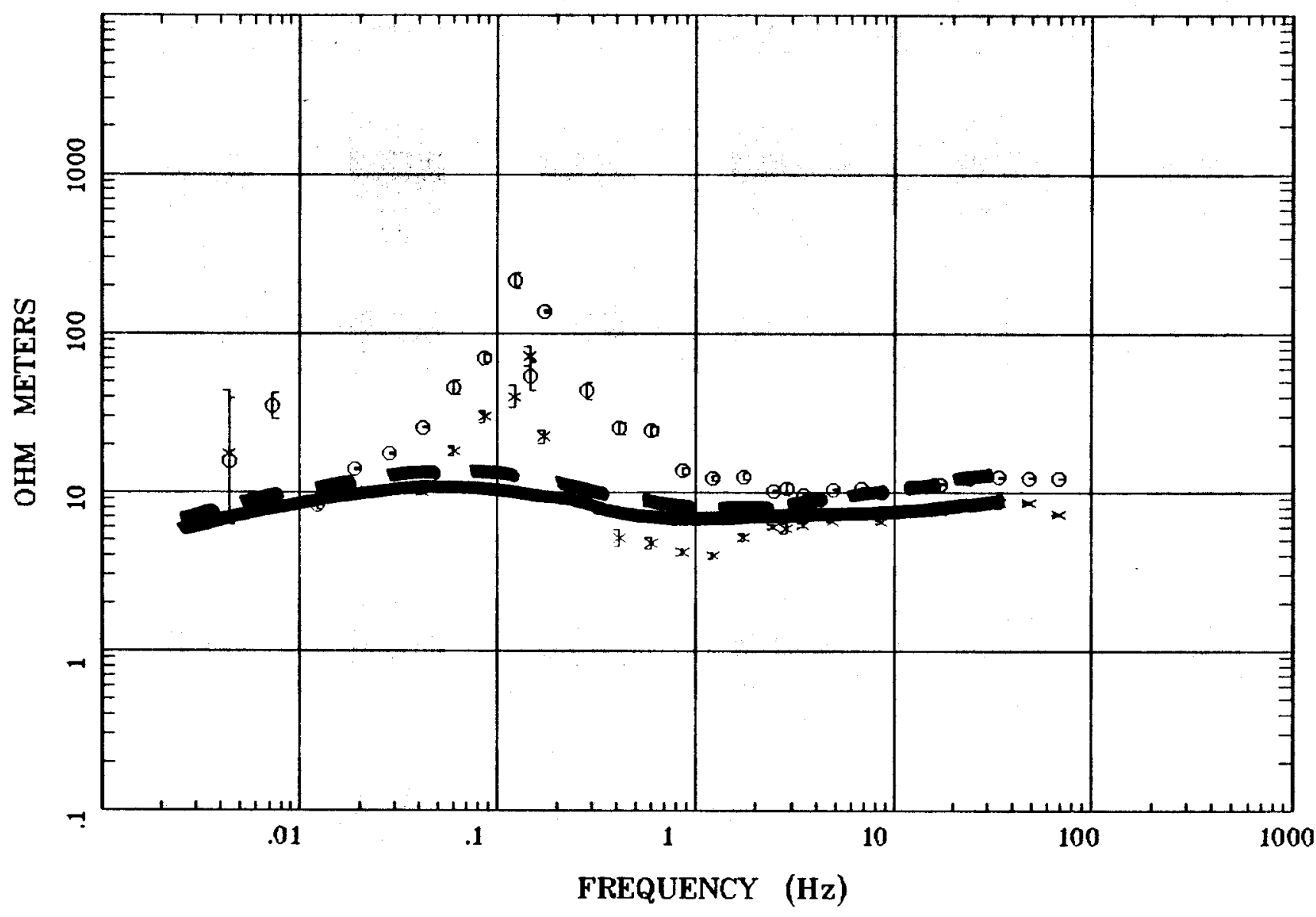

Client:

Remote: e-field local ref

Acquired: 10:2 Jul 12, 1997 Survey Co:
Rotation:

Filename: nn24c.all

Channels: Ch1 Ch2 Ch3 Ch4 Ch5 Ch6 Ch7 Plotted: 08:37 Dec 08, 2000

< EMI - ElectroMagnetic Instruments > 
Station 24A

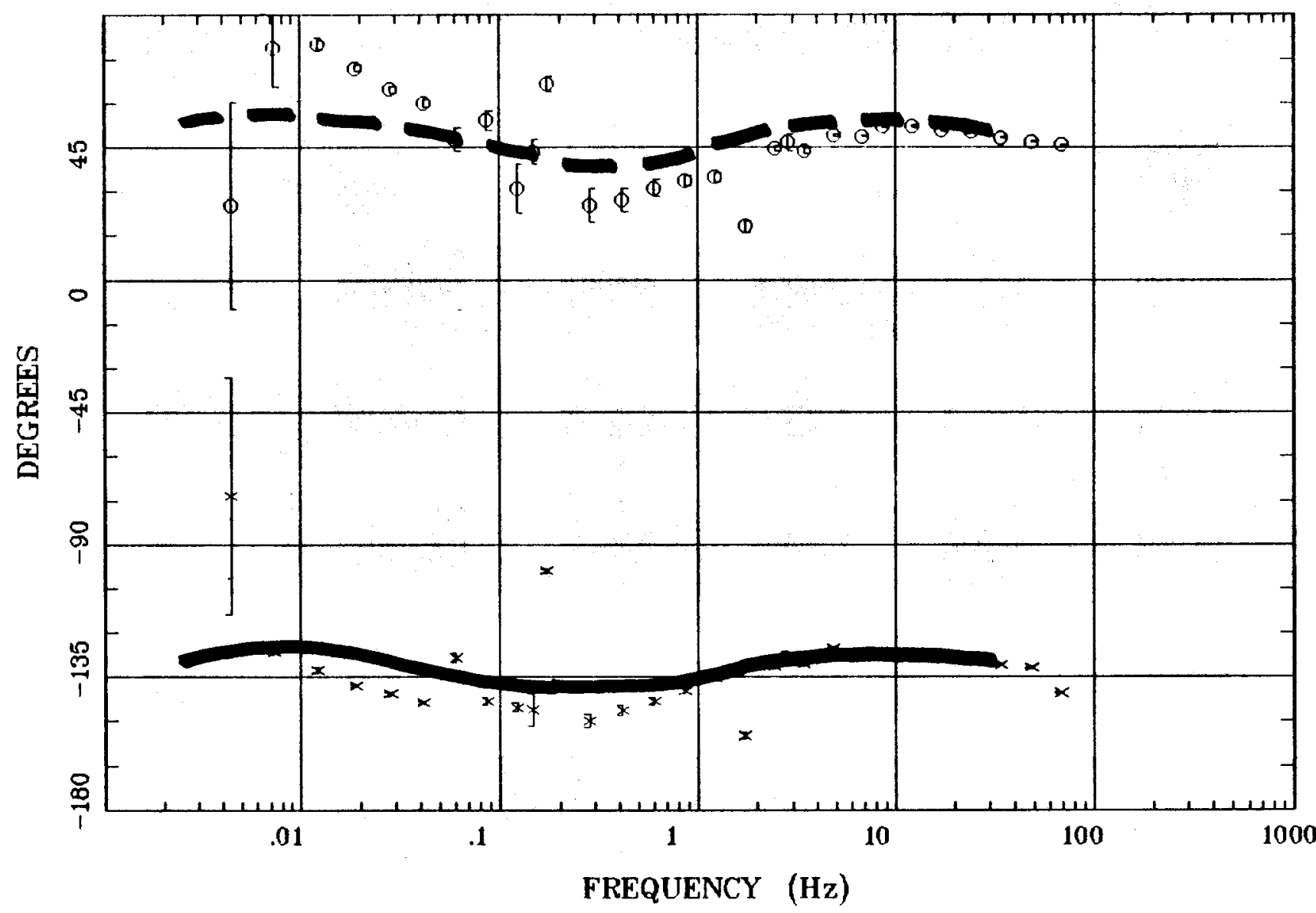

Client:

Remote: e-field local ref Acquired: 10:2 Jul 12, 1997

Survey co:
Rotation:

Filename: nn24c.all

Channels: Ch1 Ch2 Ch3 Ch4 Ch5 Ch6 Ch7

Plotted: 08:37 Dec 08, 2000

$<$ EMI - ElectroMagnetic Instruments 


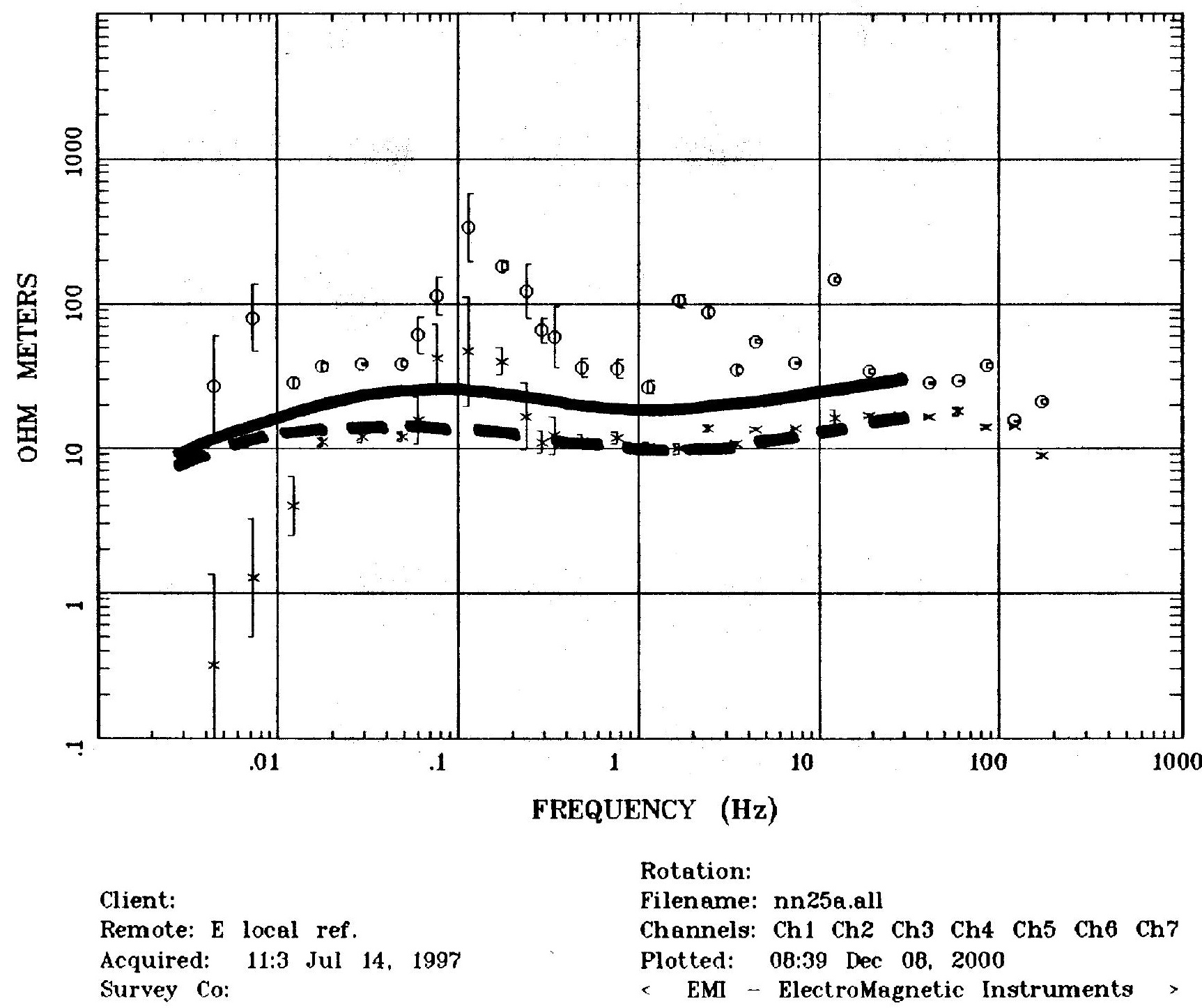


Station 25A

IMPEDANCE PHASE

Battle Mtn.

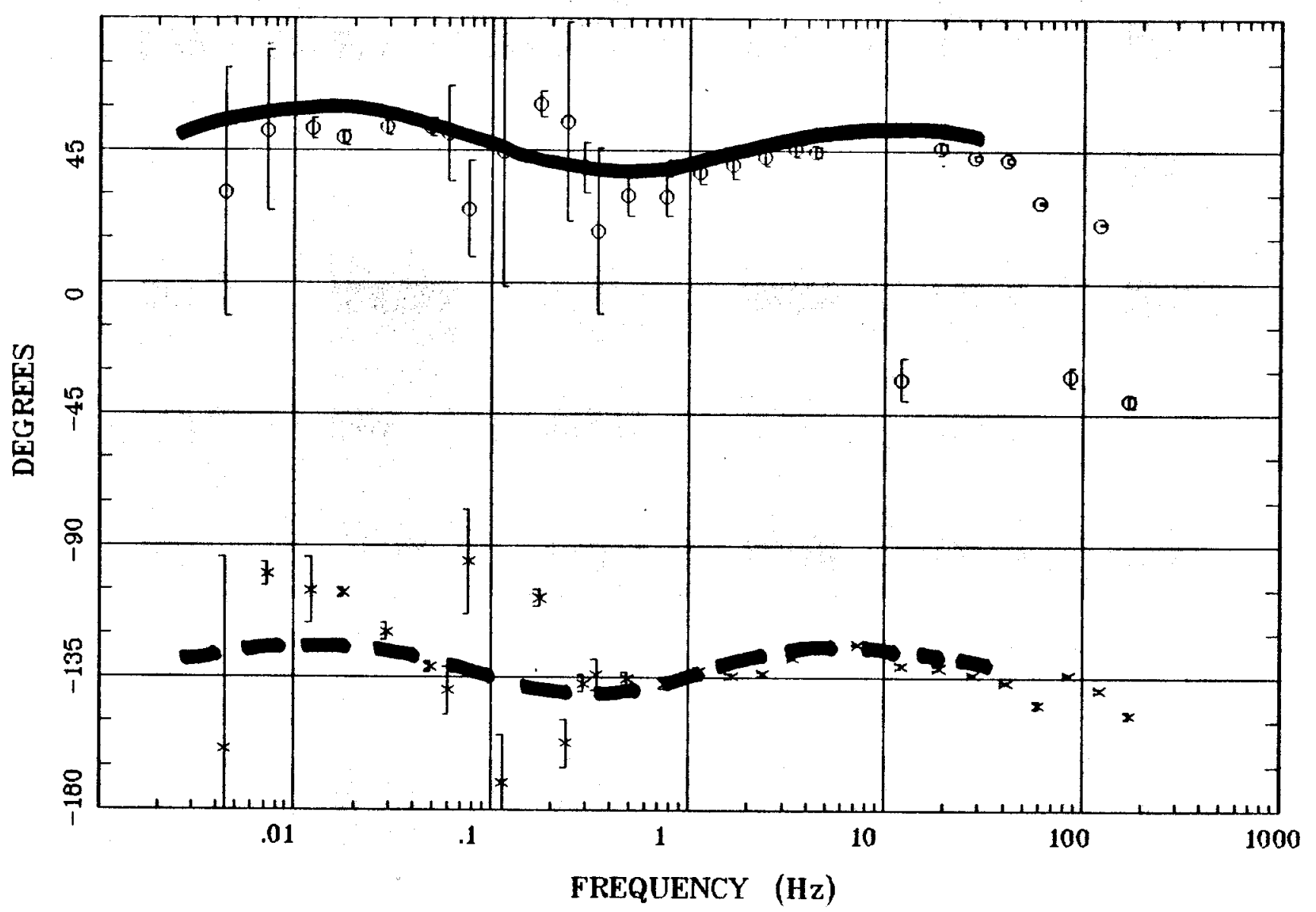

Client:

Rotation:

Filename: nn25a.all

Channels: Ch1 Ch2 Ch3 Ch4 Ch5 Ch6 Ch7

Plotted: 08:39 Dec 08, 2000

Acquired: 11:3 Jul 14. 1997

Survey Co:

< EMI - ElectroMagnetic Instruments 
Battle Mountain, NV

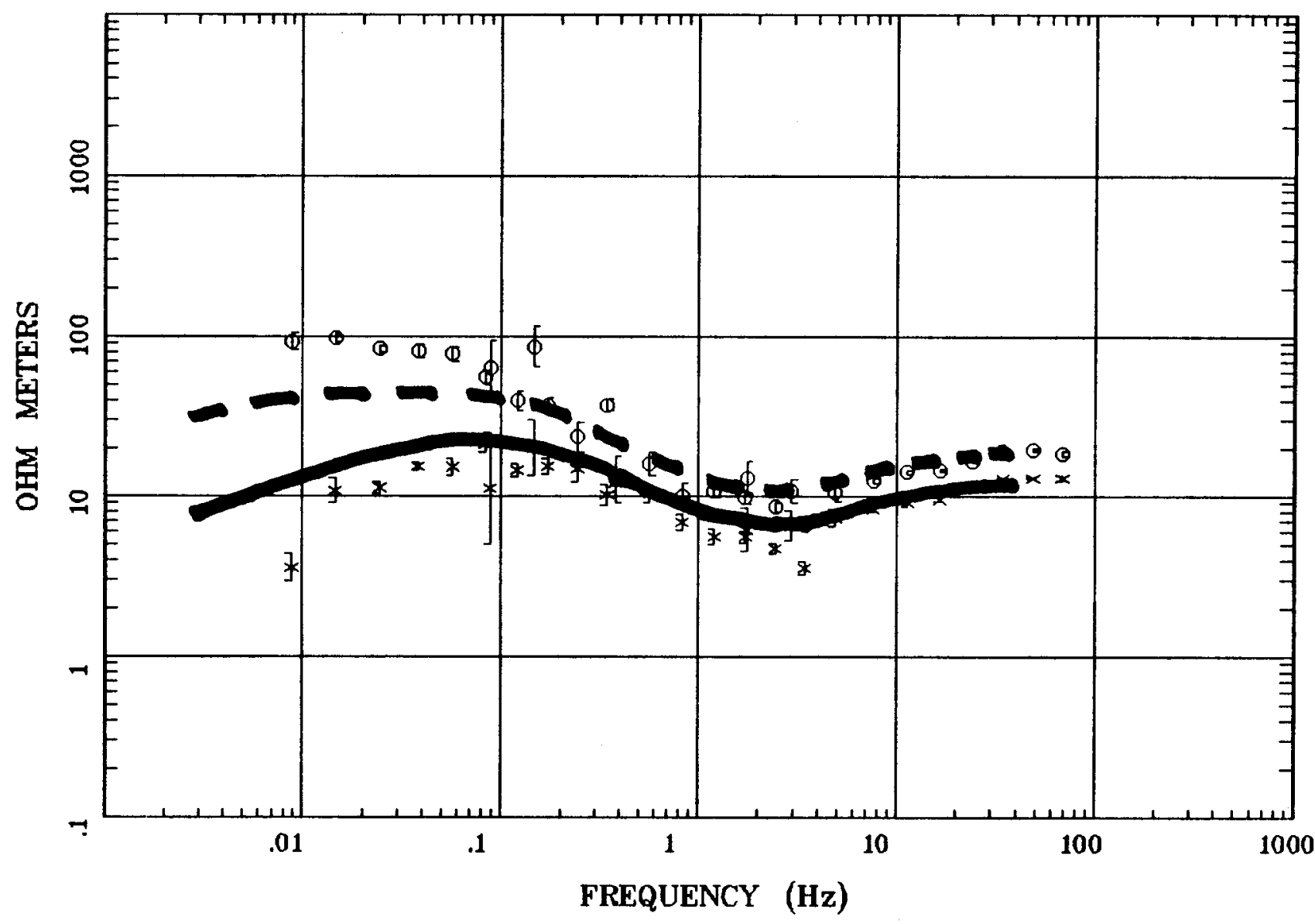

Client:

Remote: local

Acquired: 10:3 Jul 31, 1999

Survey Co:USGS
Rotation:

Filename: hr71.avg

Channels: Ch1 Ch2 Ch3 Ch4 Ch5 Ch3 Ch4

Plotted: 15:24 Jan 23, 2001

$\langle$ EMI - ElectroMagnetic Instruments > 


\section{Station 71}

IMPEDANCE PHASE

Battle Mountain, NV

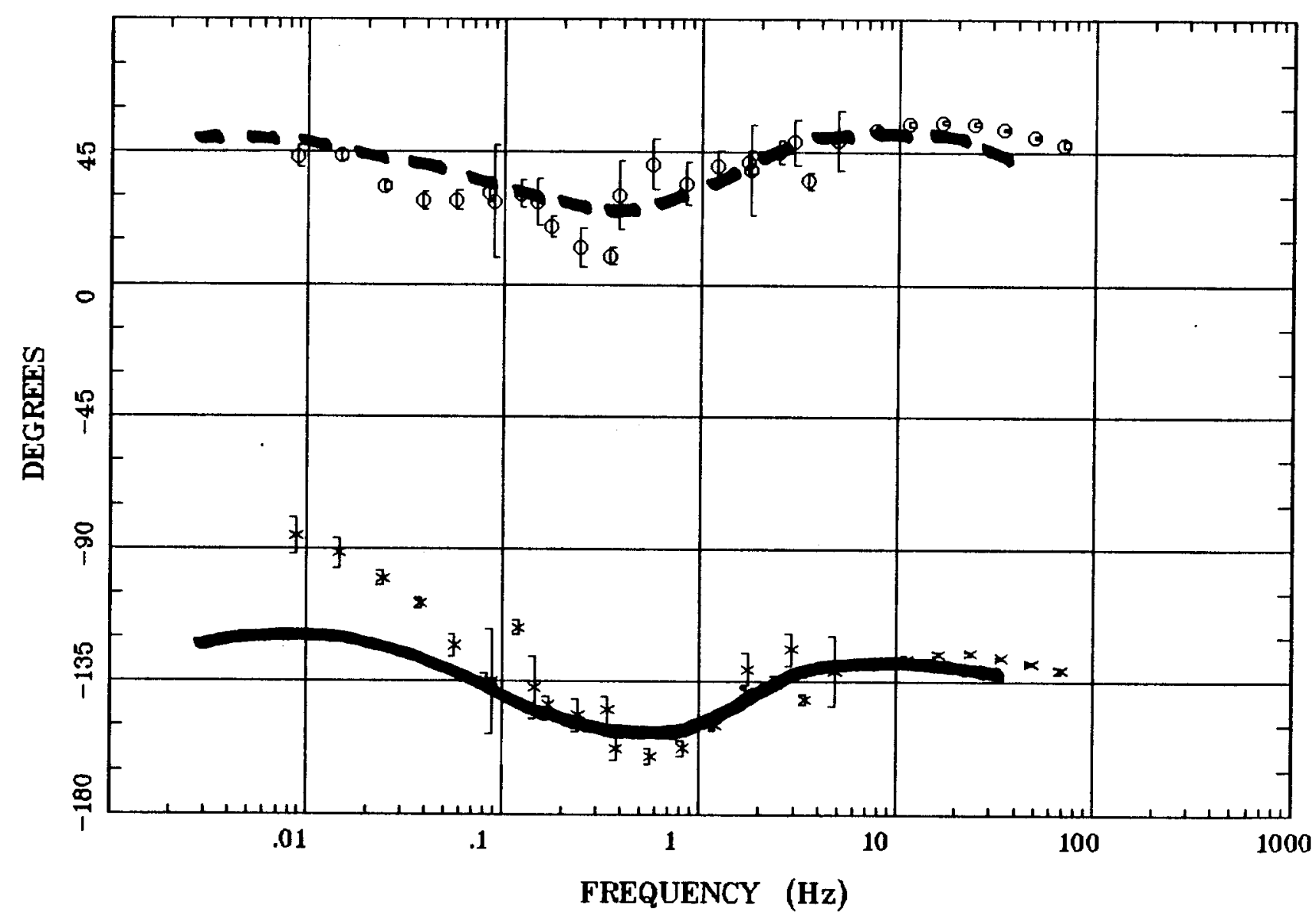

Client:

Remote: local

Acquired: 10:3 Jul 31, 1999

Survey Co:USGS
Rotation:

Filename: hr'71.avg

Channels: Ch1 Ch2 Ch3 Ch4 Ch5 Ch3 Ch4 Plotted: 15:24 Jan 23, 2001

< EMI - ElectroMagnetic Instruments > 
Station 26A

APPARENT FESISTIVITY

Battle Mtn.

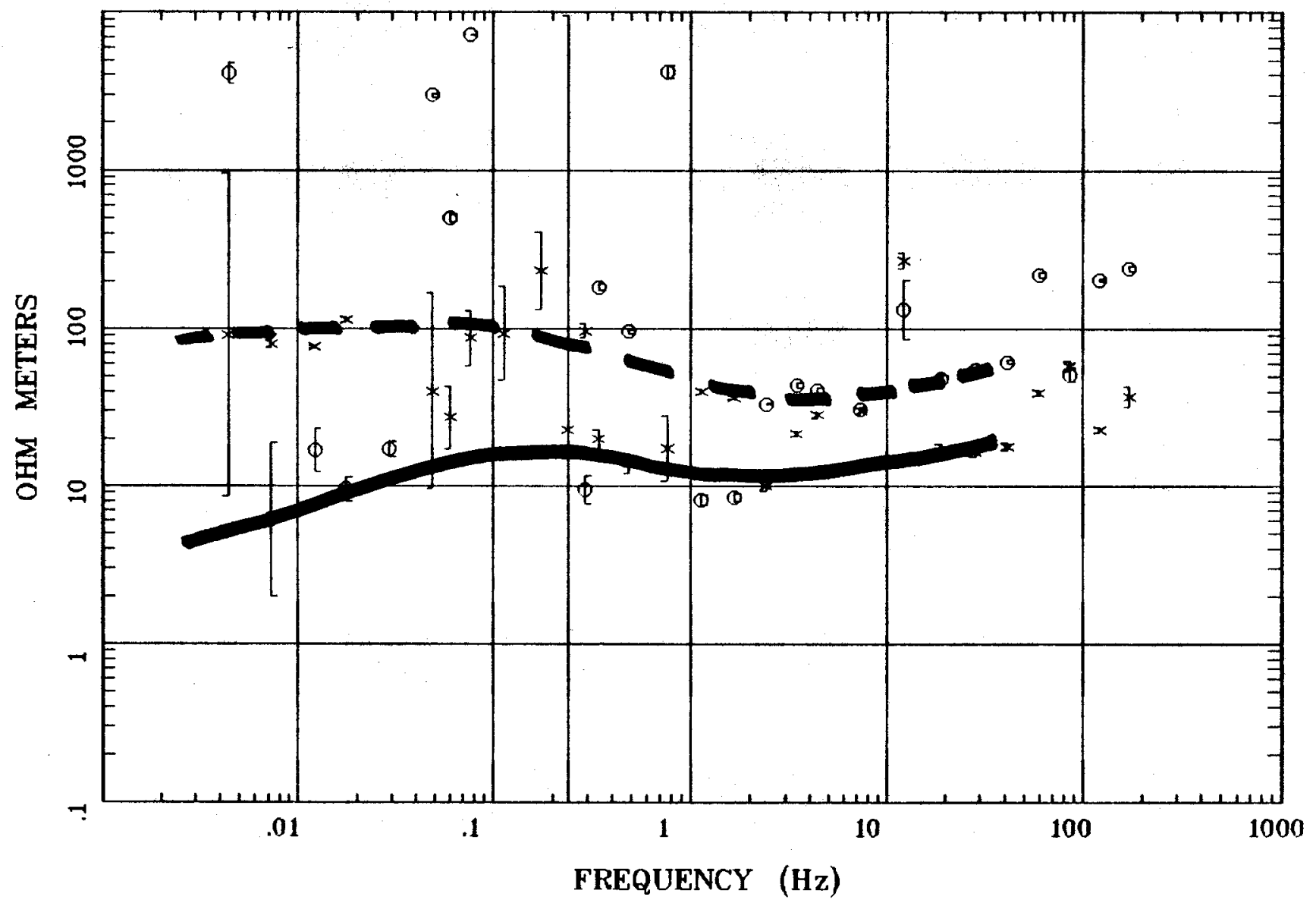

Client:

Remote: $\mathrm{E}$ local ref.

Acquired: 17:5 Jul 14, 1997

Survey Co:

Rotation:

Filename: nn26a.all

Channels: Ch1 Ch2 Ch3 Ch4 Ch5 Ch6 Ch7

Plotted: 08:40 Dec 08, 2000

< EMI - ElectroMagnetic Instruments > 


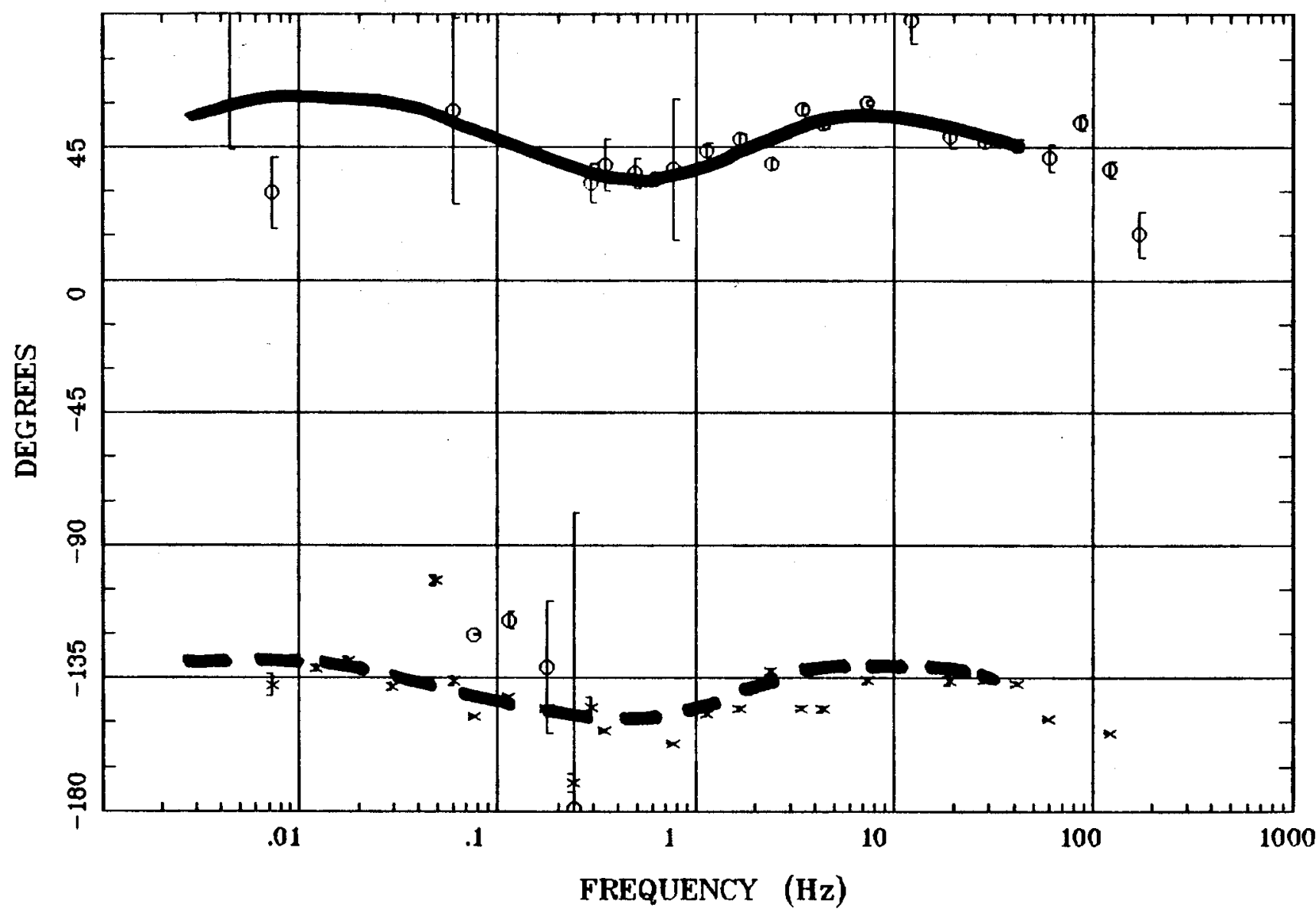

Client:

Remote: E local ref.

Acquired: 17:5 Jul 14, 1997

Survey Co:
Rotation:

Filename: nn26a.all

Channels: Ch1 Ch2 Ch3 Ch4 Ch5 Ch6 Ch7

Plotted: 08:40 Dec 08, 2000

< EMI - ElectroMagnetic Instruments 
Station 27A

APPARENT RESISTIVITY ...Battle Mtn...

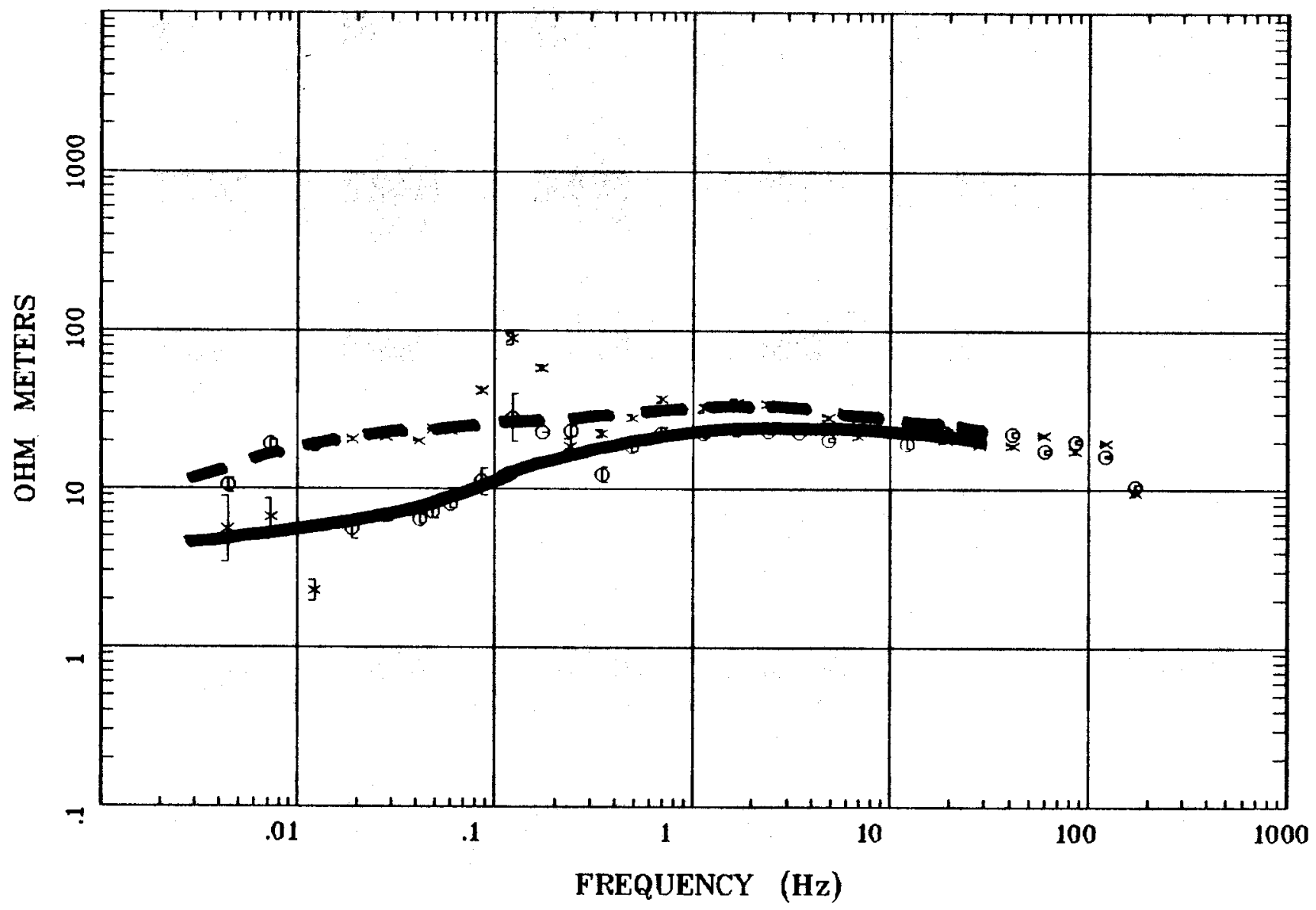

Client:

Remote: E local ref.

Acquired: $\quad$ 12:0 Jul $\cdot 21,1997$

Survey Co:

Rotation:

Filename: nn27a.all

Channels: Ch6 Ch7 Ch8 Ch9 Ch10Ch1 Ch2

Plotted: 08:43 Dec 08, 2000

< EMI - ElectroMagnetic Instruments 


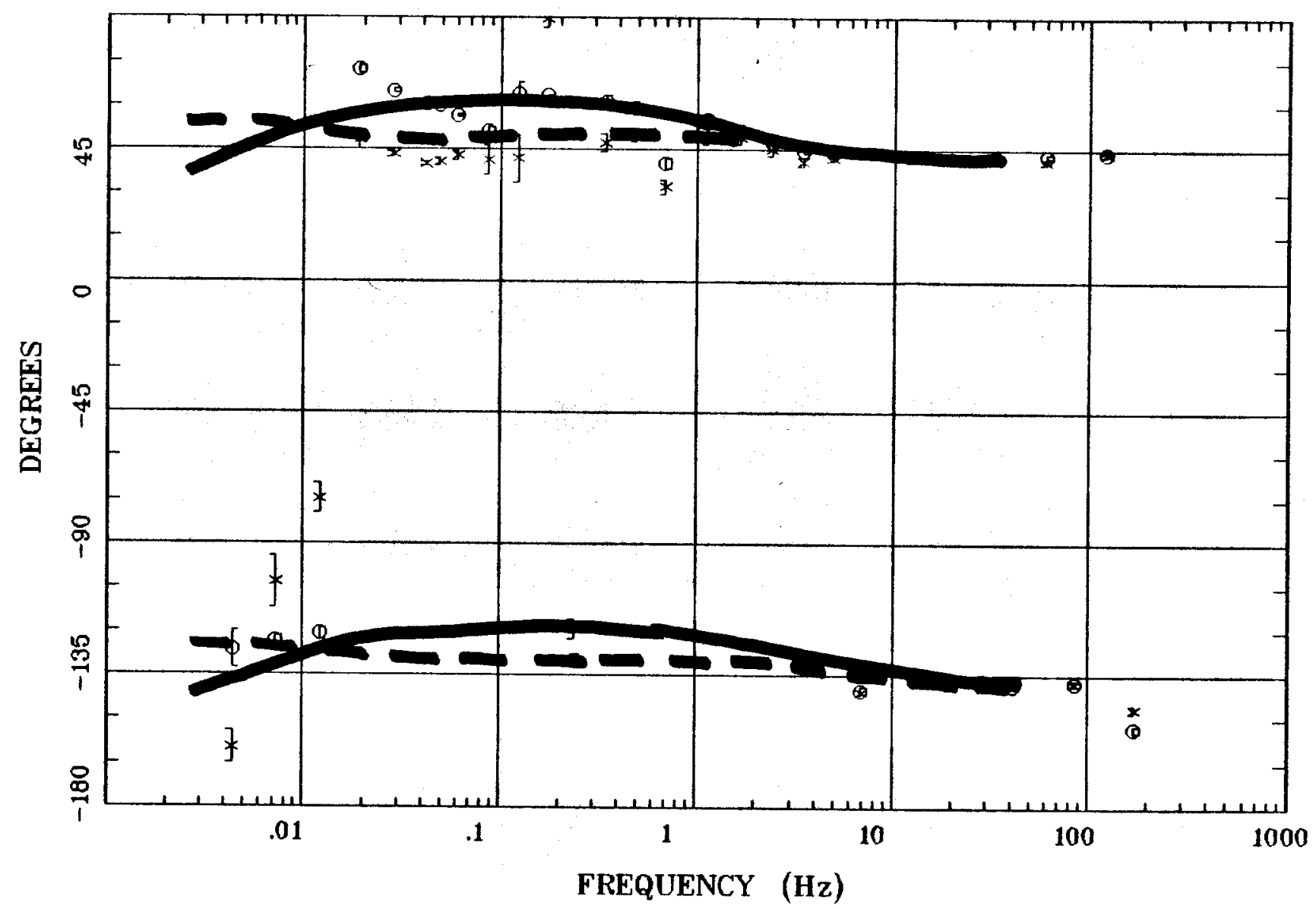

Client:

Remote: E local ref.

Acquired: 12:0 Jul 21, 1997

Survey Co:

Rotation:

Filename: nnz7a.all

Channels: Ch6 Ch7 Ch8 Ch9 Ch10Ch1 Ch2

Plotted: 08:43 Dec 08, 2000

< EMI - ElectroMagnetic Instruments > 


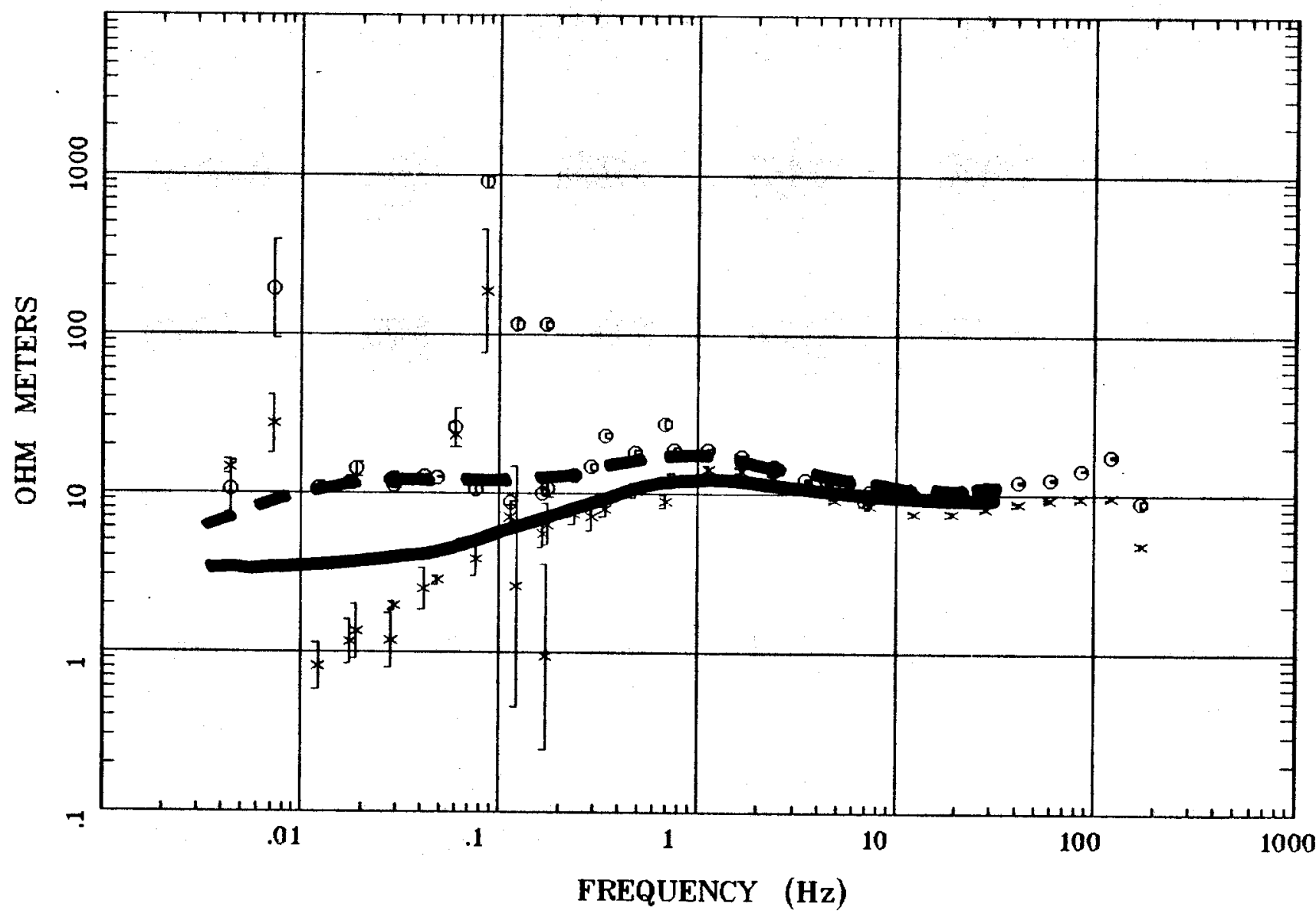

Client:

Remote: E local ref.

Acquired: 18:4 Jul 21, 1997 Survey Co:
Rotation:

Filename: nn28.ell

Channels: Ch6 Ch' Ch8 Ch9 Ch10Ch1 Ch2

Plotted: 08:44 Dec 08, 2000

< EMI - ElectroMagnetic Instruments 
...Battle Mtn...

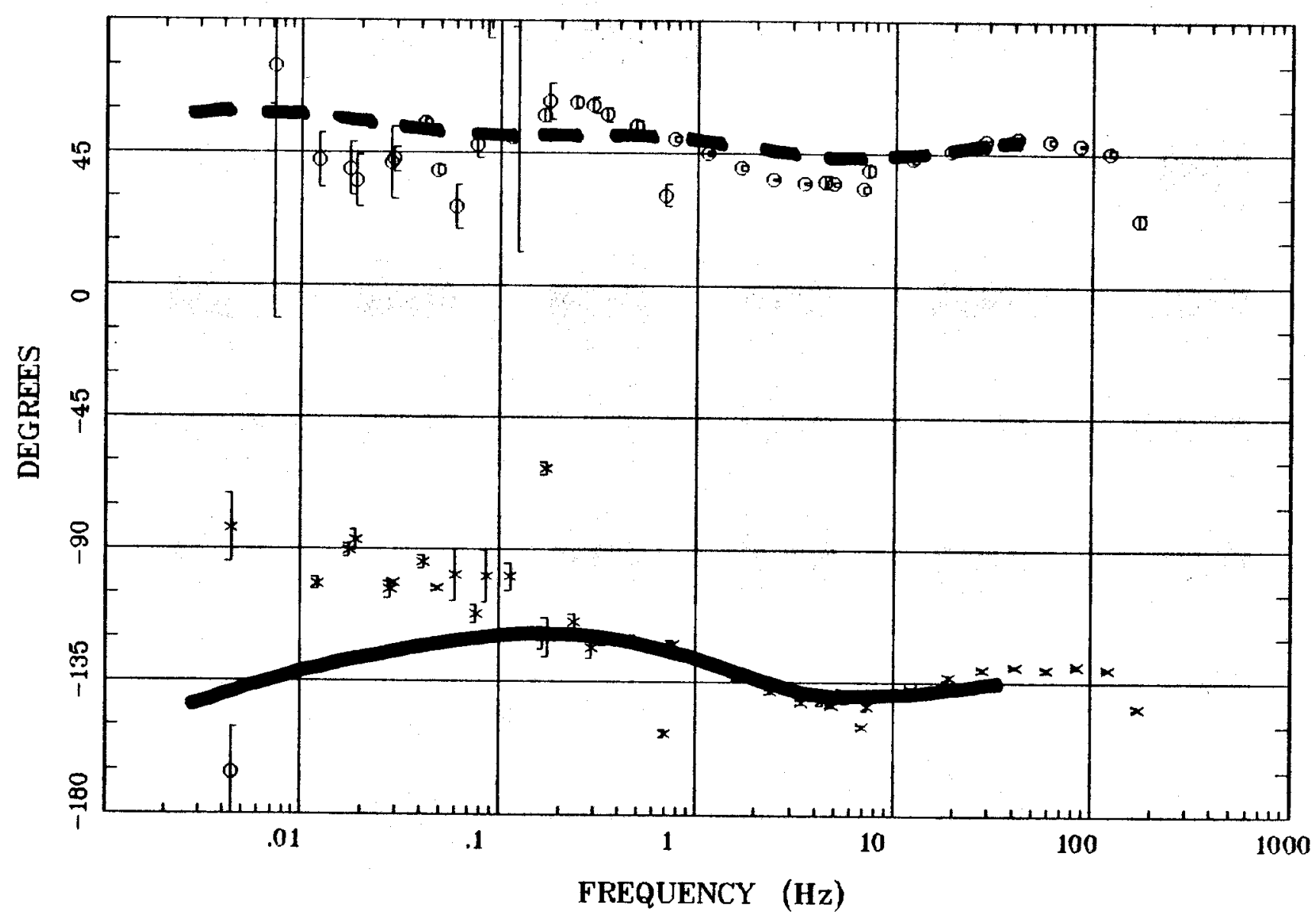

Client:

Remote: E local ref.

Acquired: 18:4 Jul 21, 1997

Survey Co:
Rotation:

Filename: nn28.all

Channels: Ch6 Ch7 Ch8 Ch9 Ch 10Ch1 Ch2 Plotted: 08:44 Dec 08, 2000

- EMI - ElectroMagnetic Instruments 


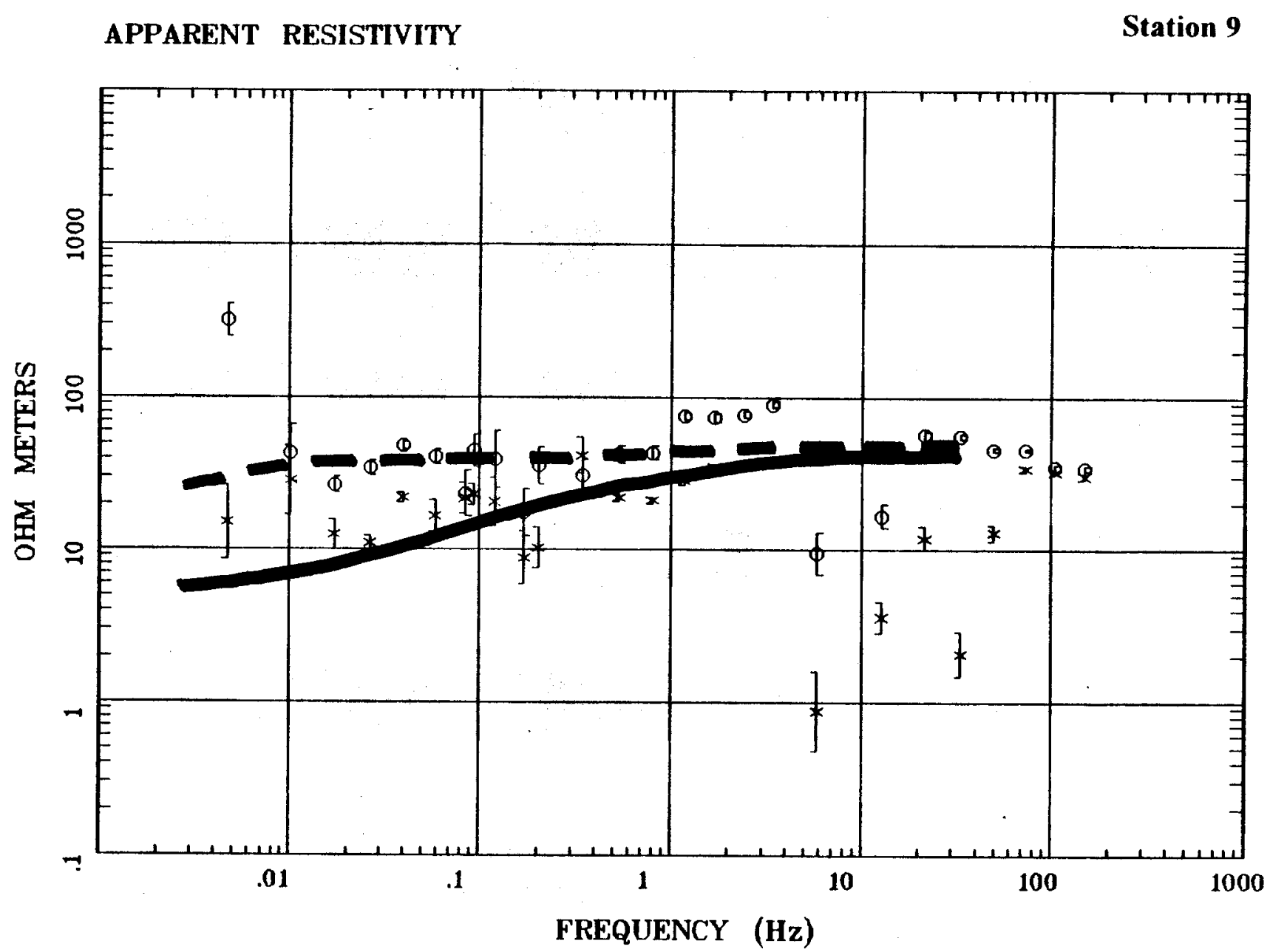

Client:

Remote:

Acquired:

Survey Co:
Rotation:

Filename: CT09A

Channels: Ch1 Ch2 Ch3 Ch4 Ch5 Ch6 Ch7

Plotted: 08:25 Sep 17, 1998

< EMI - ElectroMagnetic Instruments 


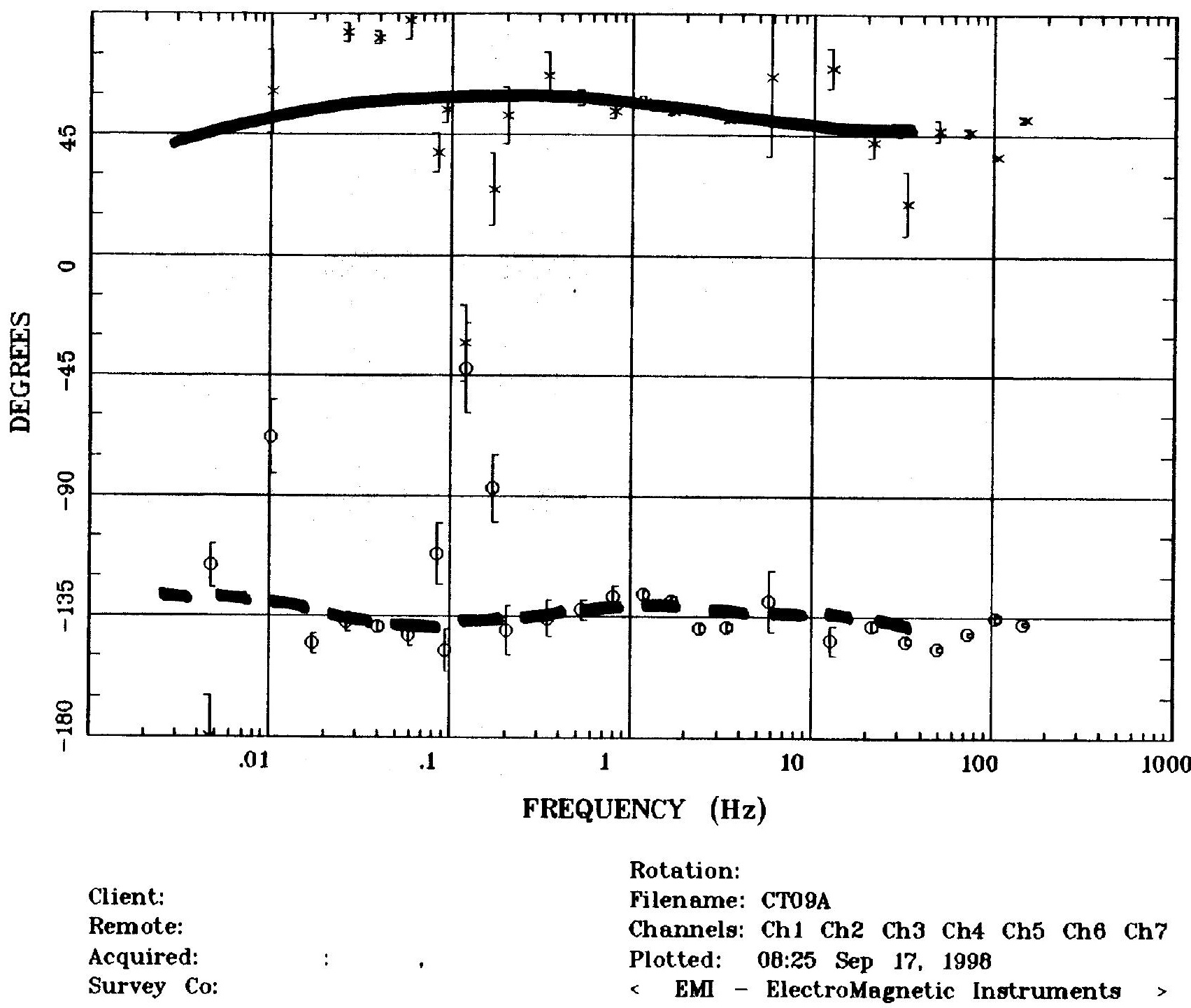




\section{Station 1}

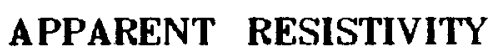

Carlin, Nevada

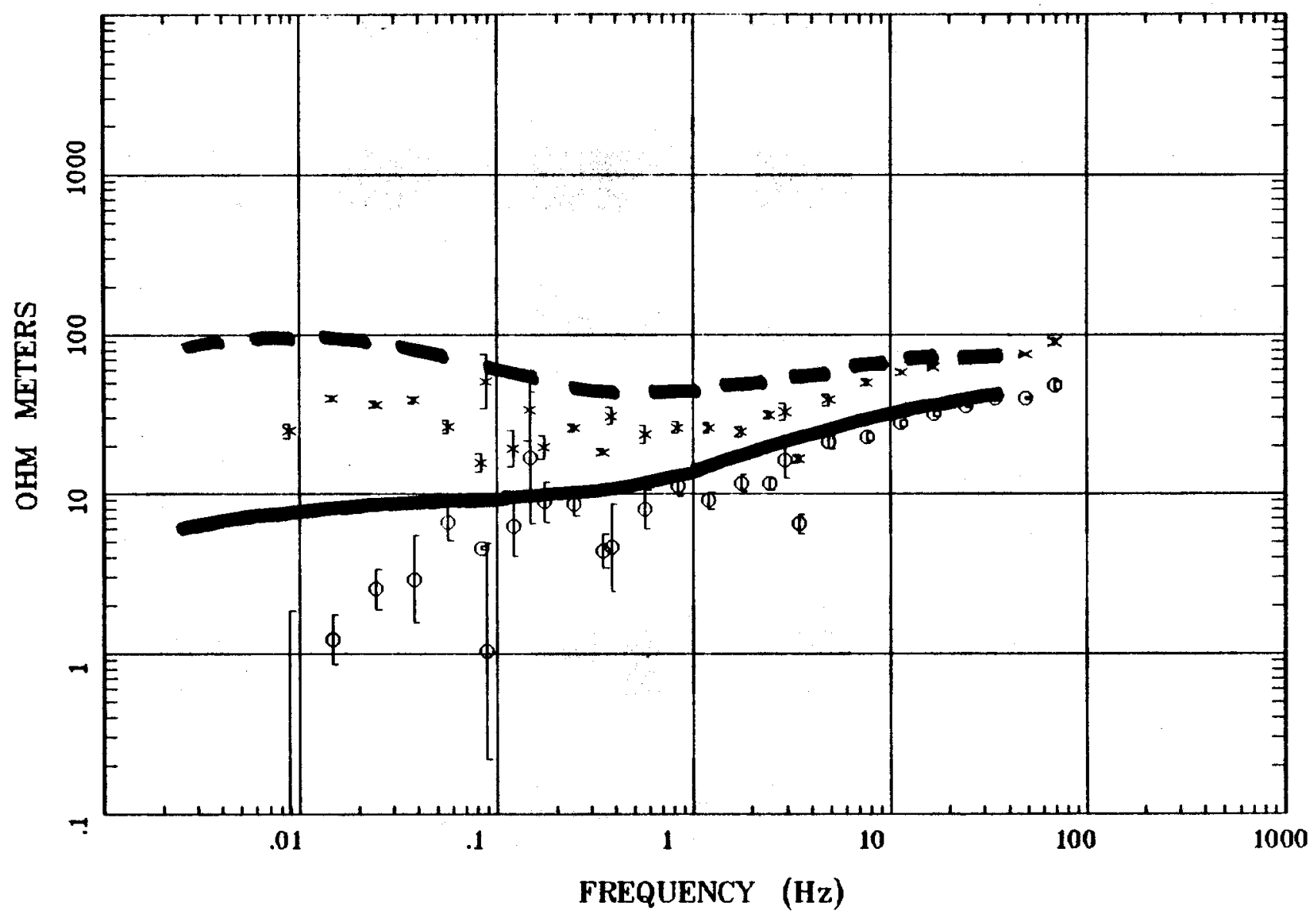

Client:

Remote: local

Acquired: 13:4 Jul 26. 1999

Survey Co:USGS
Rotation:

Filename: ct01.avg

Channels: Ch1 Ch2 Ch3 Ch4 Ch5 Ch8 Ch9

Plotted: 15:42 Jan 24, 2001

, EMI - ElectroMagnetic Instruments > 


\section{IMPEDANCE PHIASE}

Carlin, Nevada

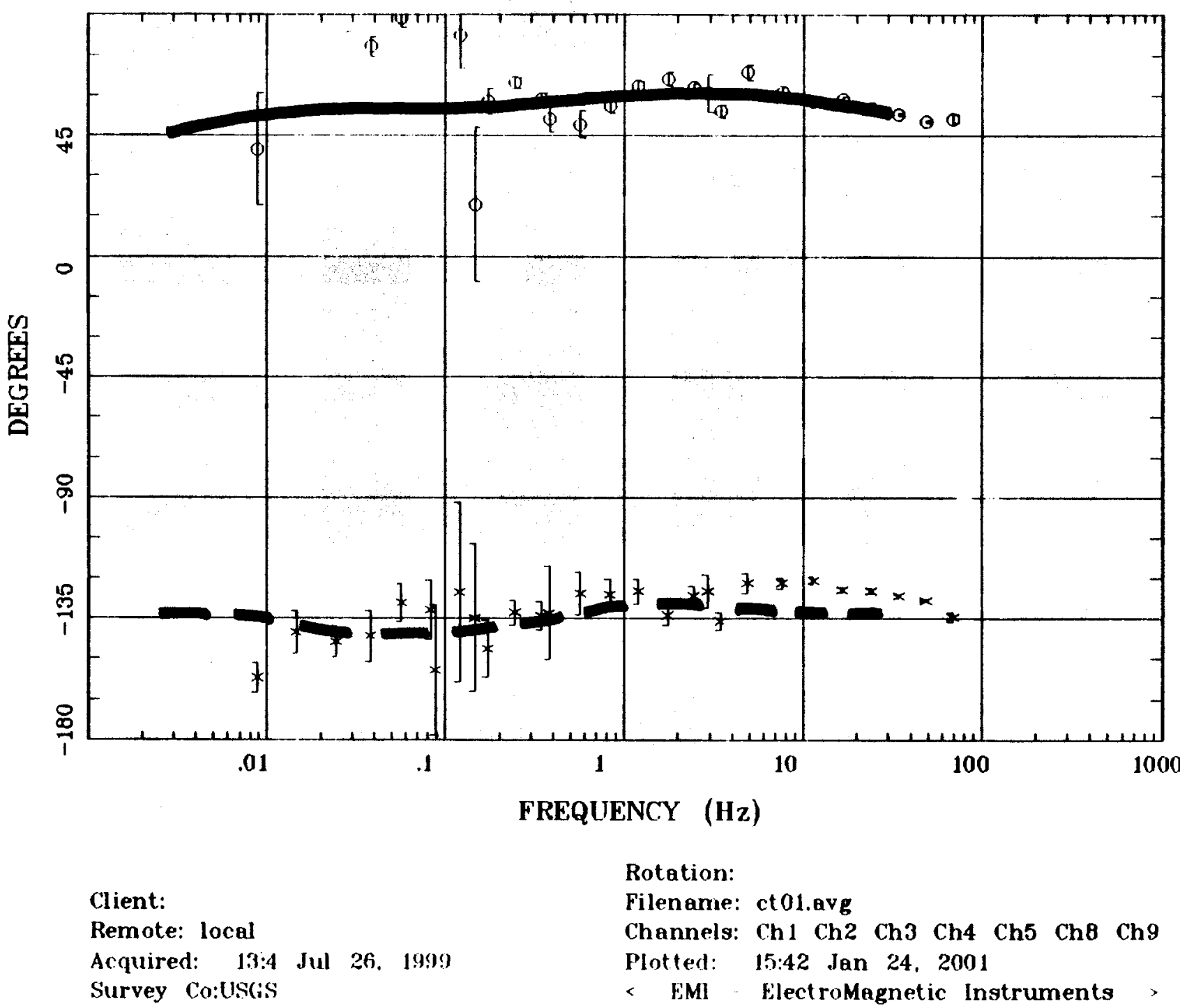




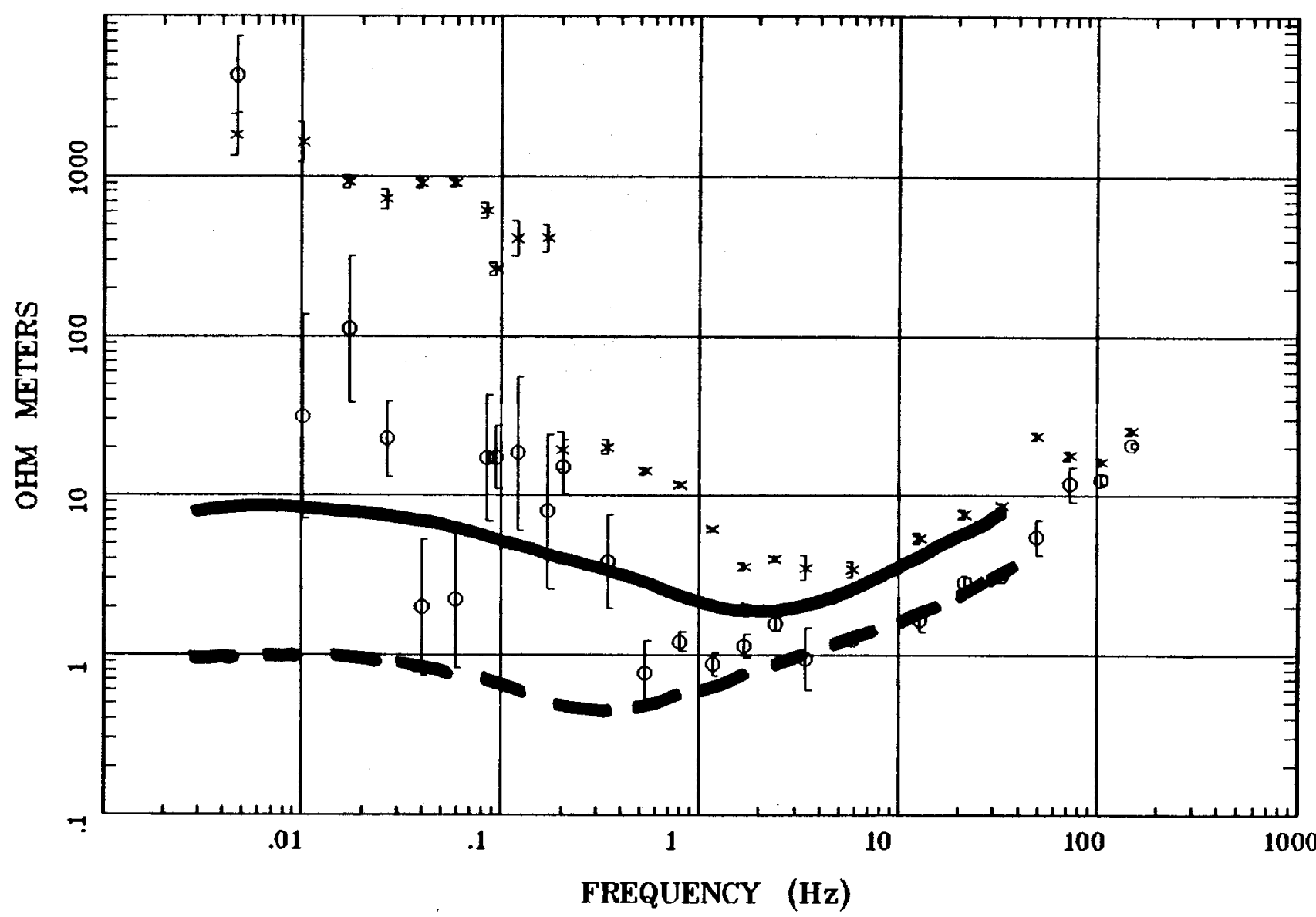

Client:

Remote:

Acquired:

Survey Co:
Rotation:

Filename: CT02A

Channels: Ch1 Ch2 Ch3 Ch4 Ch5 Che Ch7

Plotted: 08:43 Sep 17, 1998

< EMI - ElectroMagnetic Instruments 


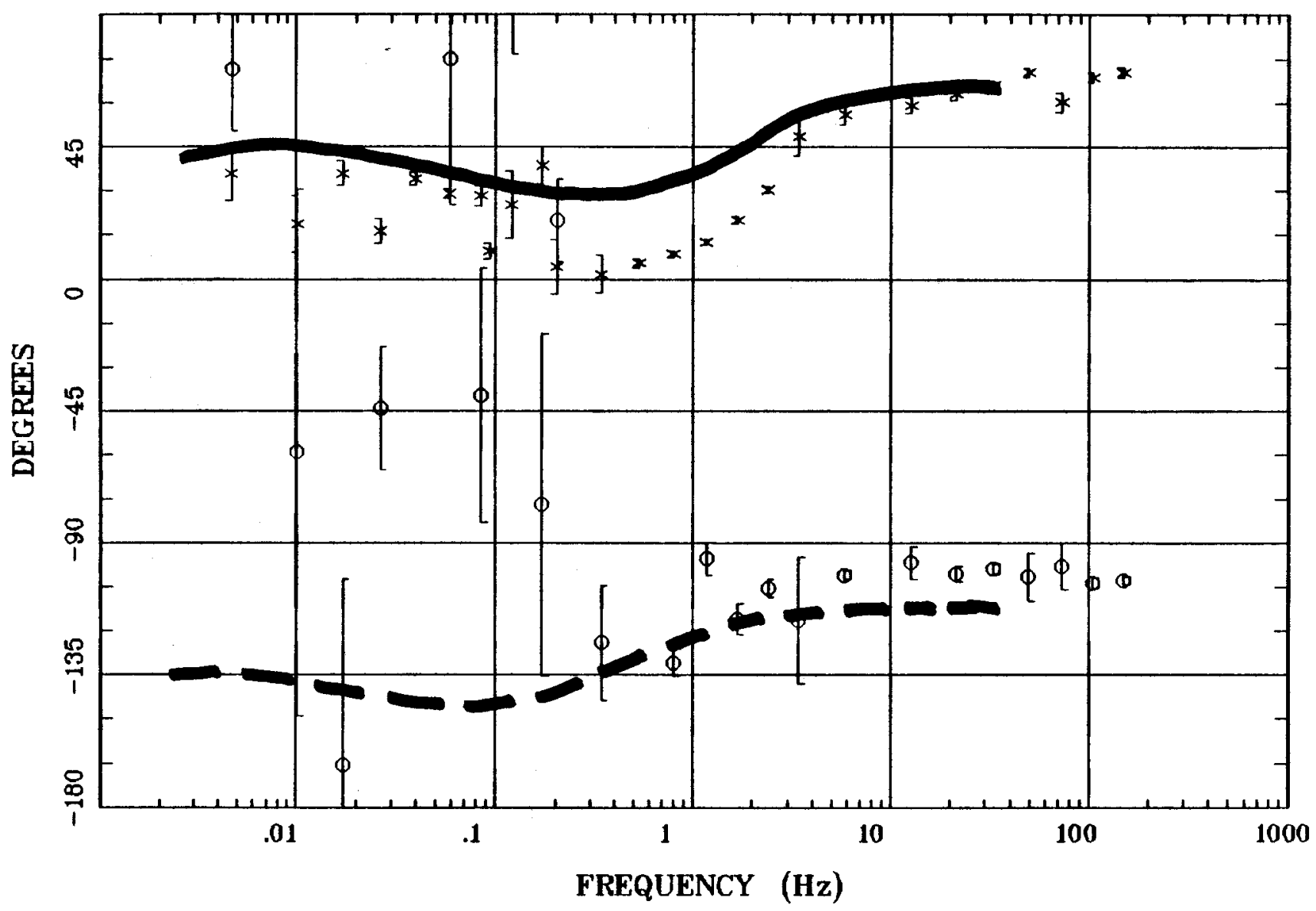

Client:

Remote:

Acquired:

Survey Co:
Rotation:

Filename: CT02A

Channels: Ch1 Ch2 Ch3 Ch4 Ch5 Ch6 Ch7

Plotted: 08:43 Sep 17, 1998

< EMI - ElectroMagnetic Instruments > 


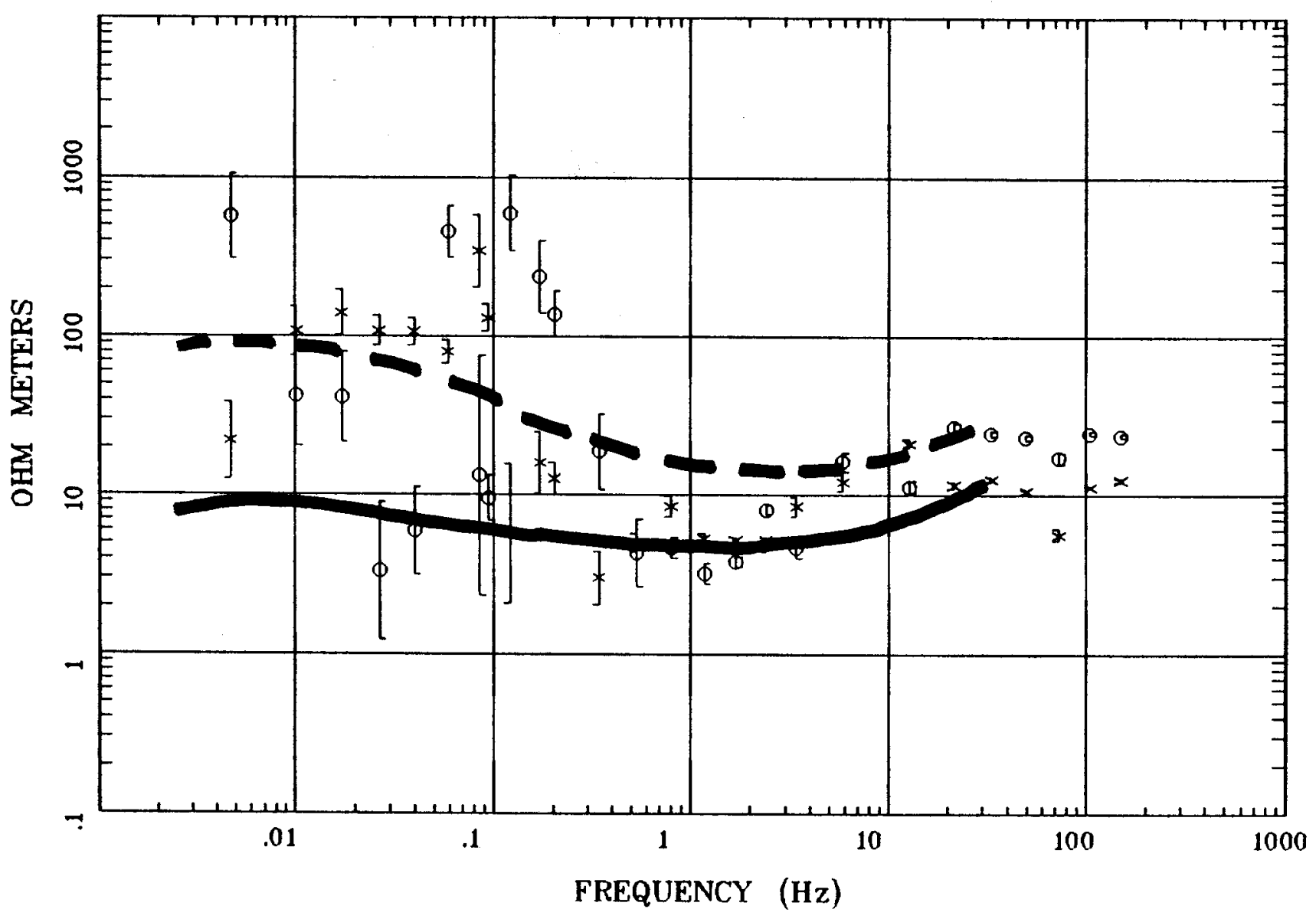

Client:

Remote:

Acquired:

Survey Co:
Rotation:

Filename: CT24C

Channels: Ch1 Ch2 Ch3 Ch4 Ch5 Ch6 Ch7

Plotted: 15:57 Dec 11, 2000

$<$ EMI - ElectroMagnetic Instruments , 
IMPEDANCE PHASE

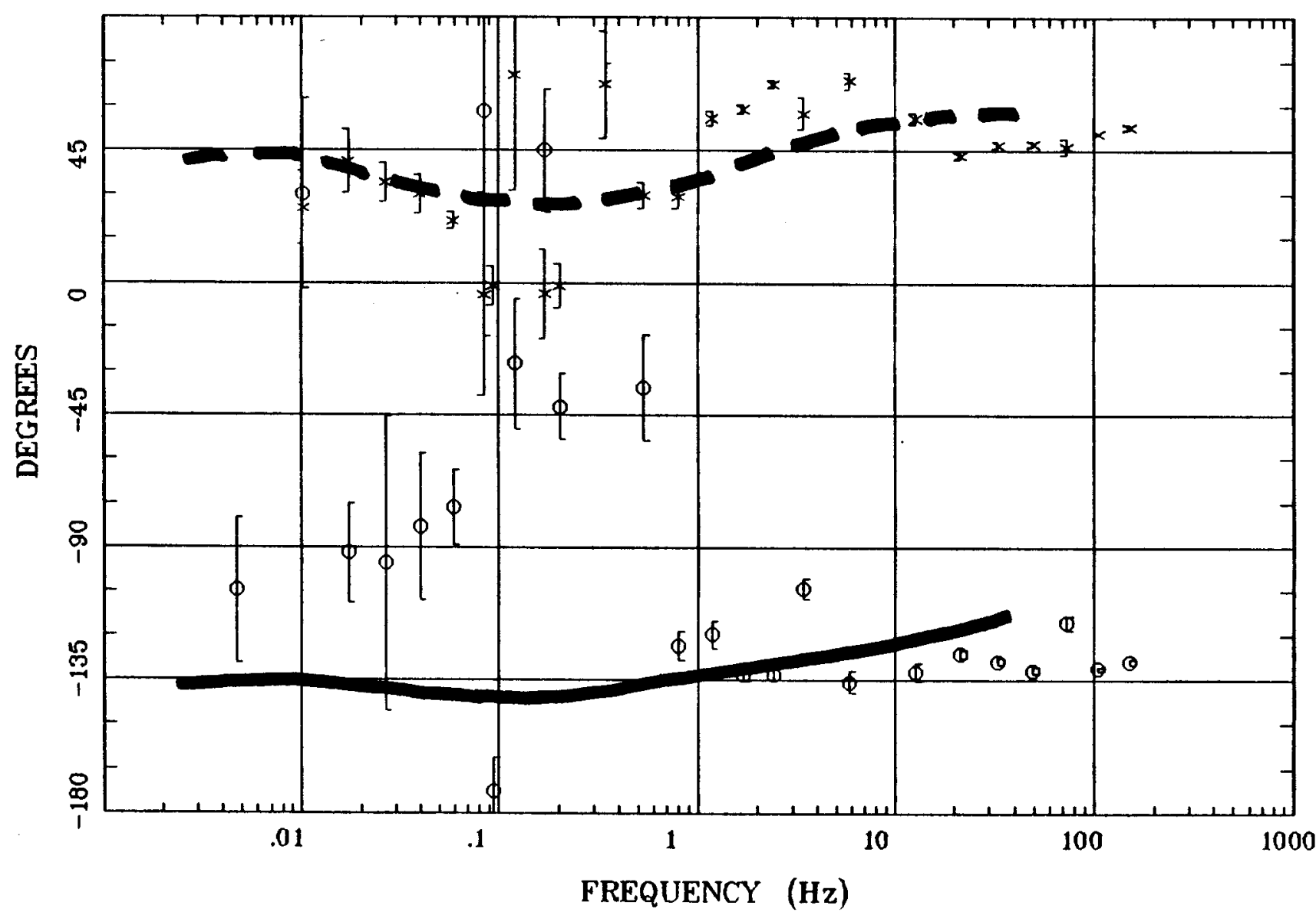

Client:

Remote:

Acquired:

Survey Co:
Rotation:

Filename: CT24C

Channels: Ch1 Ch2 Ch3 Ch4 Ch5 Ch6 Ch7

Plotted: 15:57 Dec 11, 2000

< EMI - ElectroMagnetic Instruments 


\section{APPARENT RESISTIVITY}

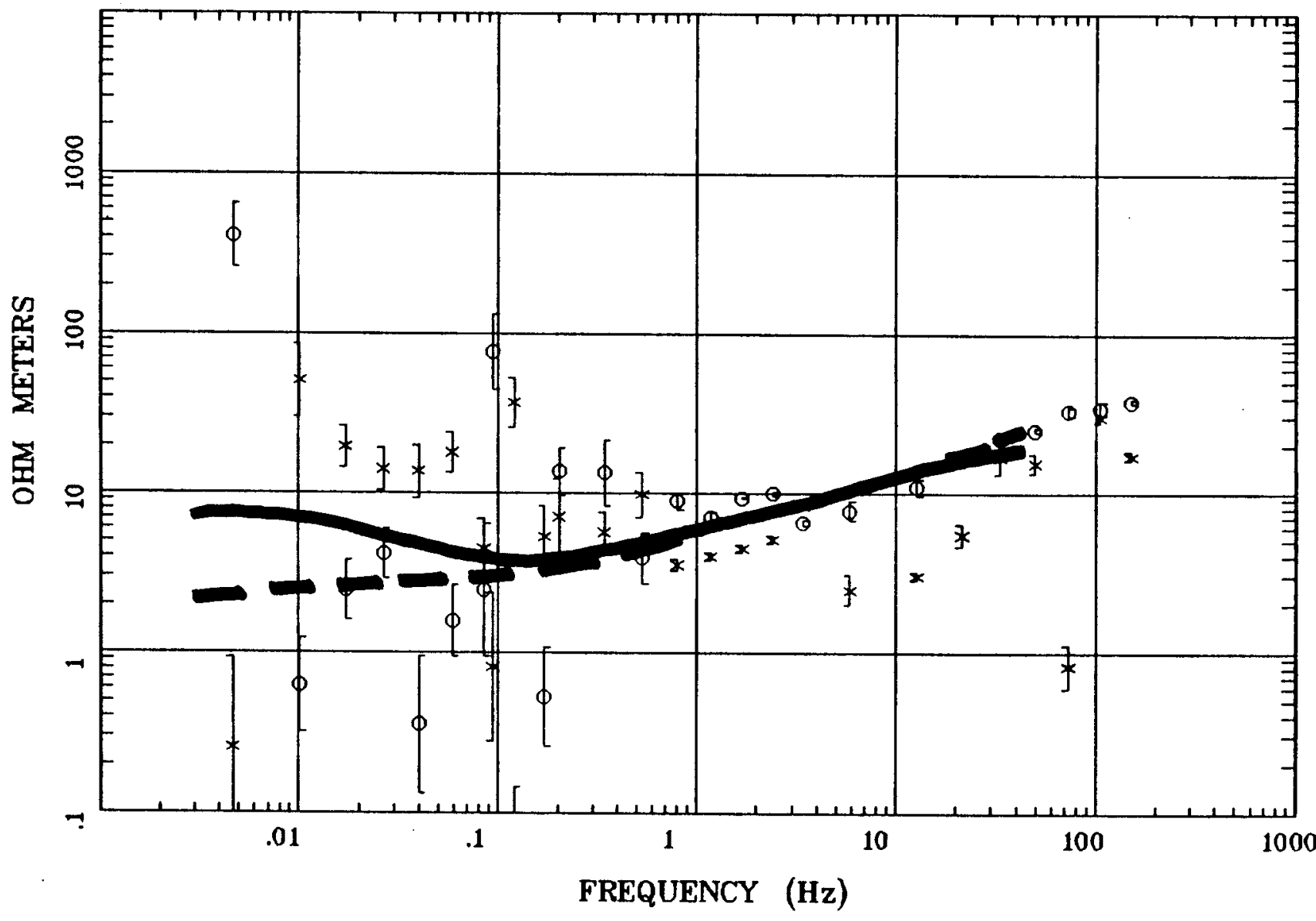

Client:

Remote:

Acquired:

Survey Co:
Rotation:

Filename: CT25D

Channels: Ch1 Ch2 Ch3 Ch4 Ch5 Ch6 Ch7

Plotted: 15:58 Dec 11, 2000

< EMI - ElectroMagnetic Instruments 
Station 25

\section{IMPEDANCE PHASE}

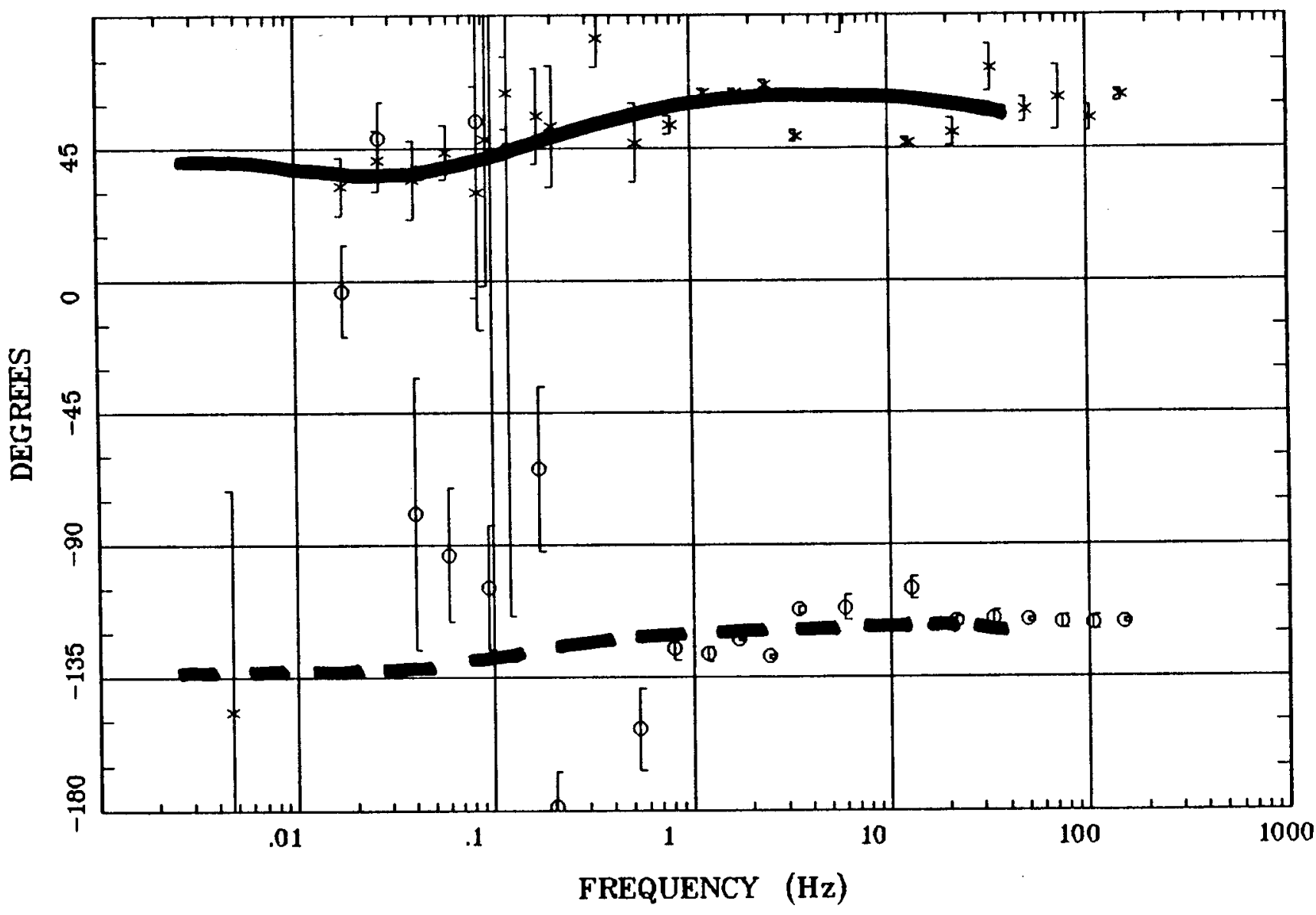

Client:

Remote:

Acquired:

Survey Co:
Rotation:

Filename: CT25D

Channels: Ch1 Ch2 Ch3 Ch4 Ch5 Ch6 Ch7

Plotted: 15:58 Dec 11, 2000

c EMI - ElectroMagnetic Instruments 


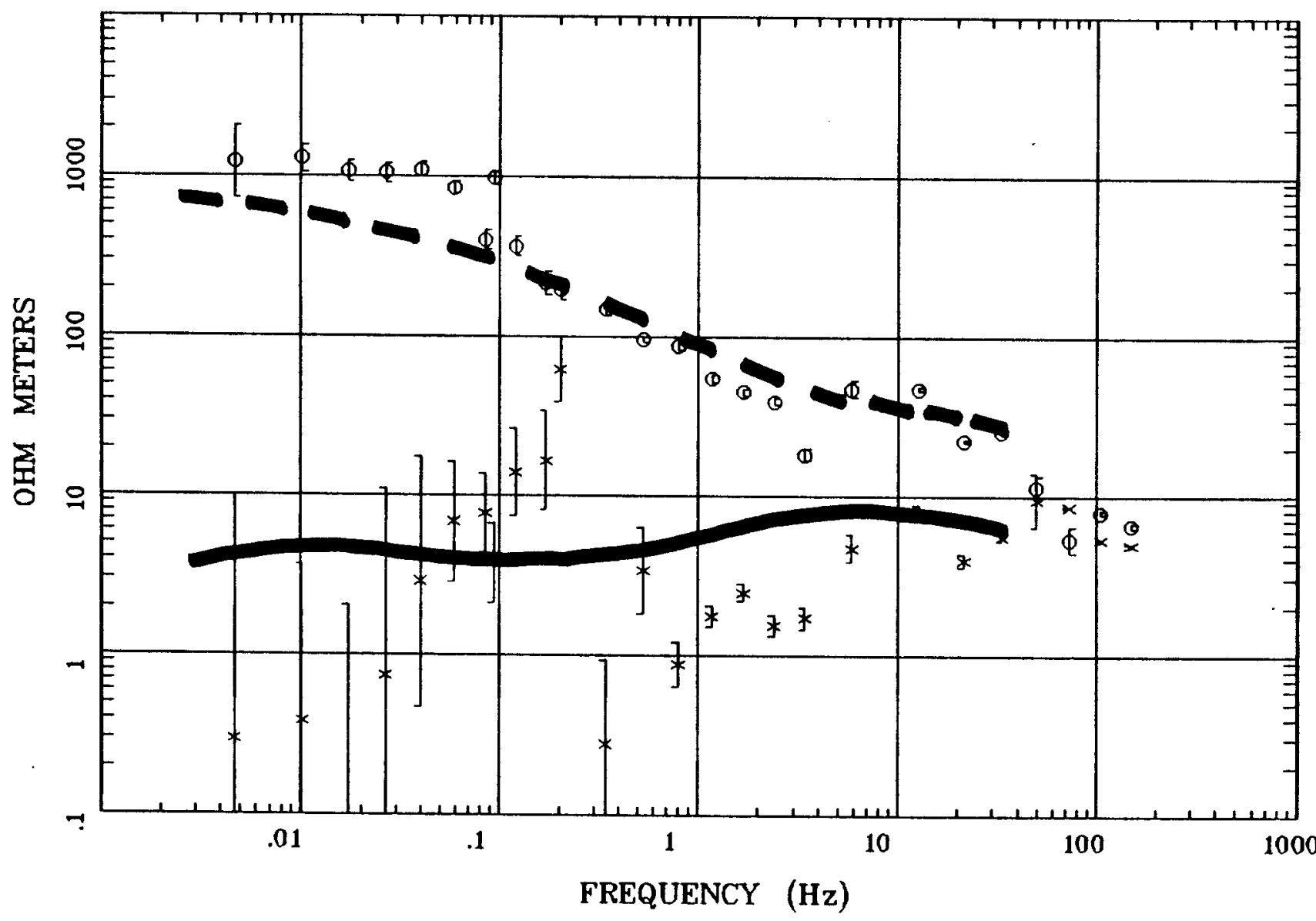

Client:

Remote:

Acquired:

Survey Co:
Rotation:

Filename: CT26C

Channels: Ch1 Ch2 Ch3 Ch4 Ch5 Ch6 Ch7

Plotted: 15:59 Dec 11, 2000

< EMI - ElectroMagnetic Instruments 


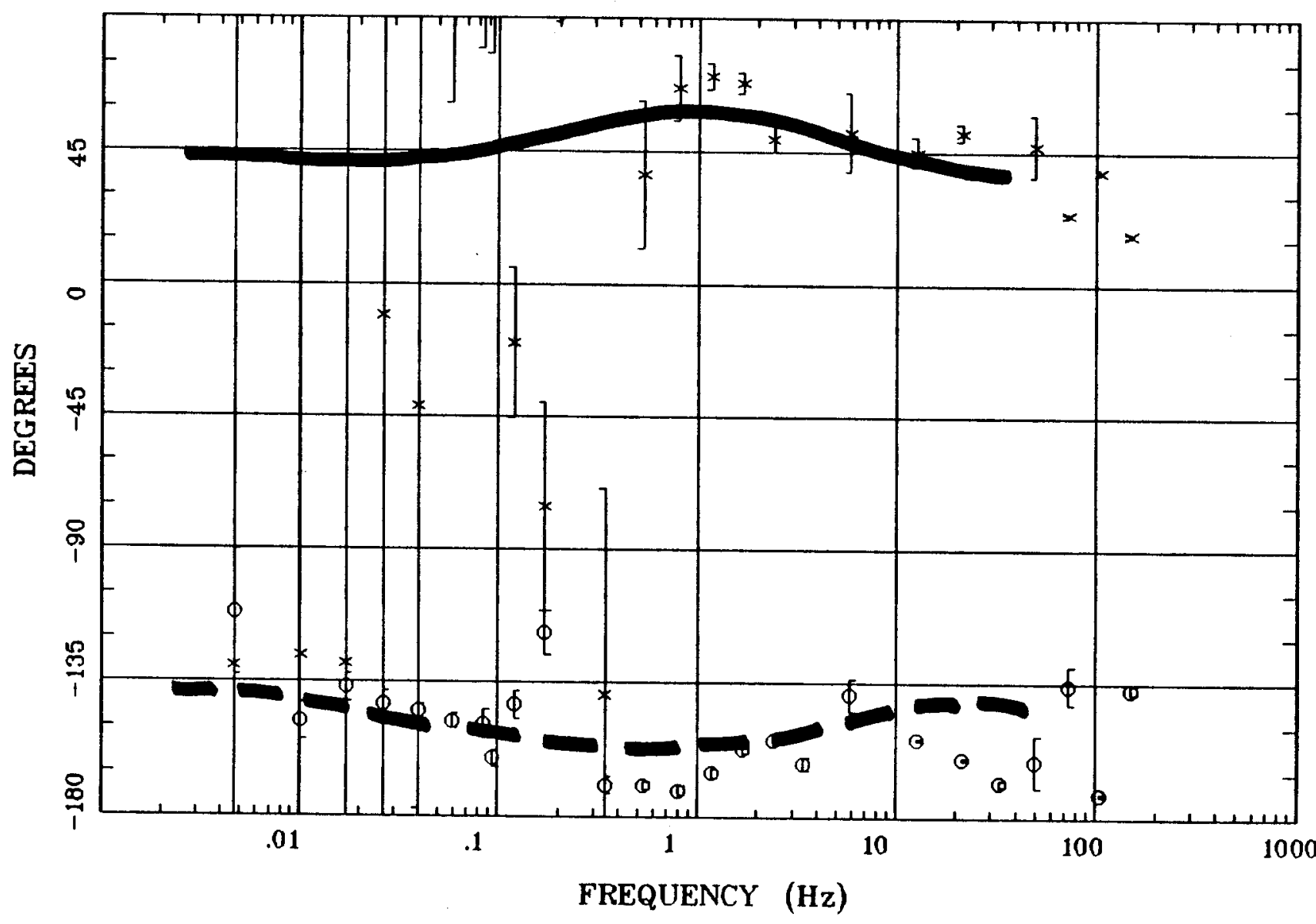

Client:

Remote: Acquired: Survey Co:
Rotation:

Filename: CT26C

Channels: Ch1 Ch2 Ch3 Ch4 Ch5 Ch6 Ch7 Plotted: 15:59 Dec 11, 2000

< EMI - ElectroMagnetic Instruments 


\section{Station 27}

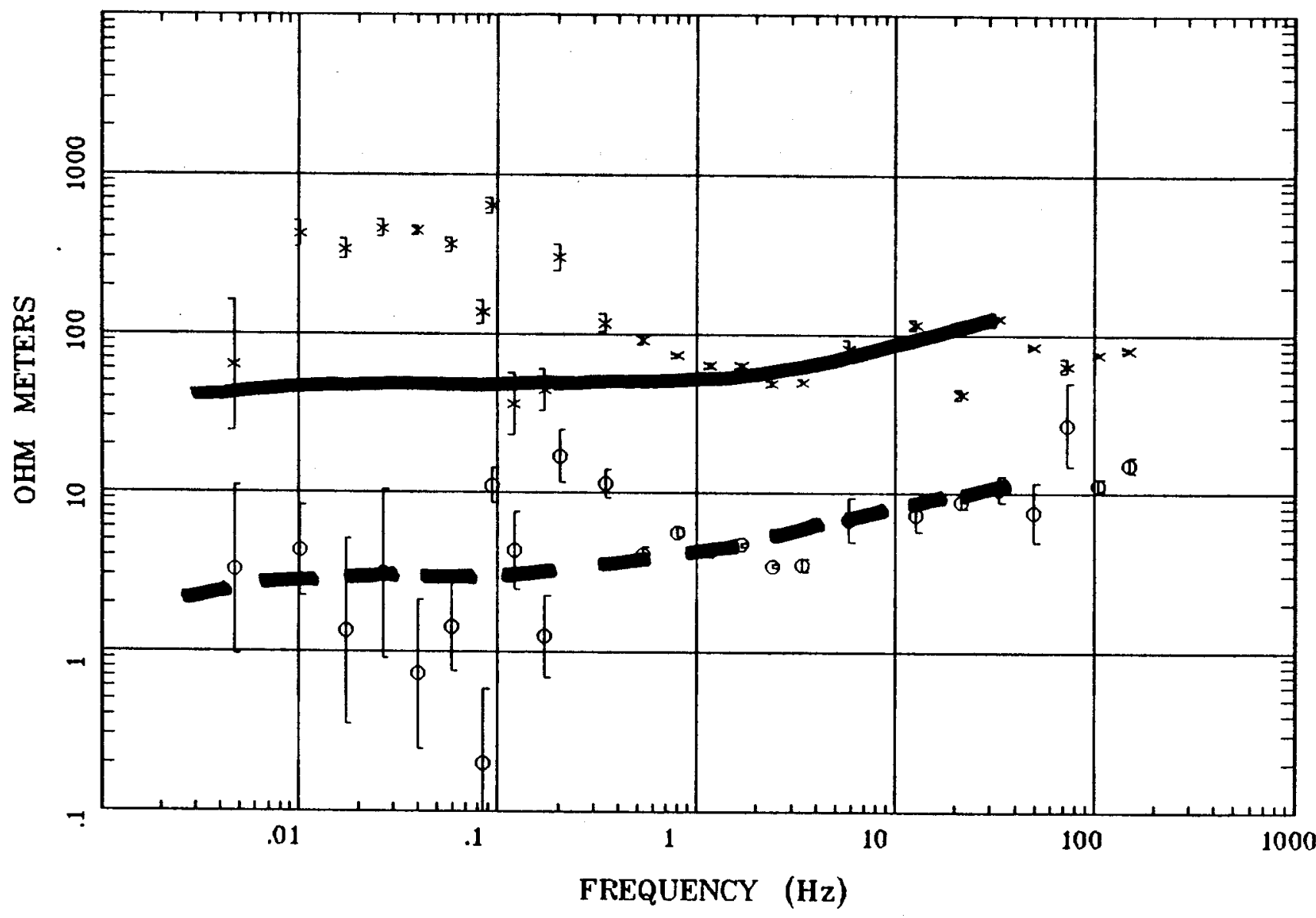

Client:

Remote:

Acquired:

Survey Co:
Rotation:

Filename: CT27A

Channels: Ch1 Ch2 Ch3 Ch4 Ch5 Ch6 Ch7

Plotted: 16:00 Dec 11, 2000

< EMI - ElectroMagnetic Instruments 


\section{IMPEDANCE PHASE}

\section{Station 27}

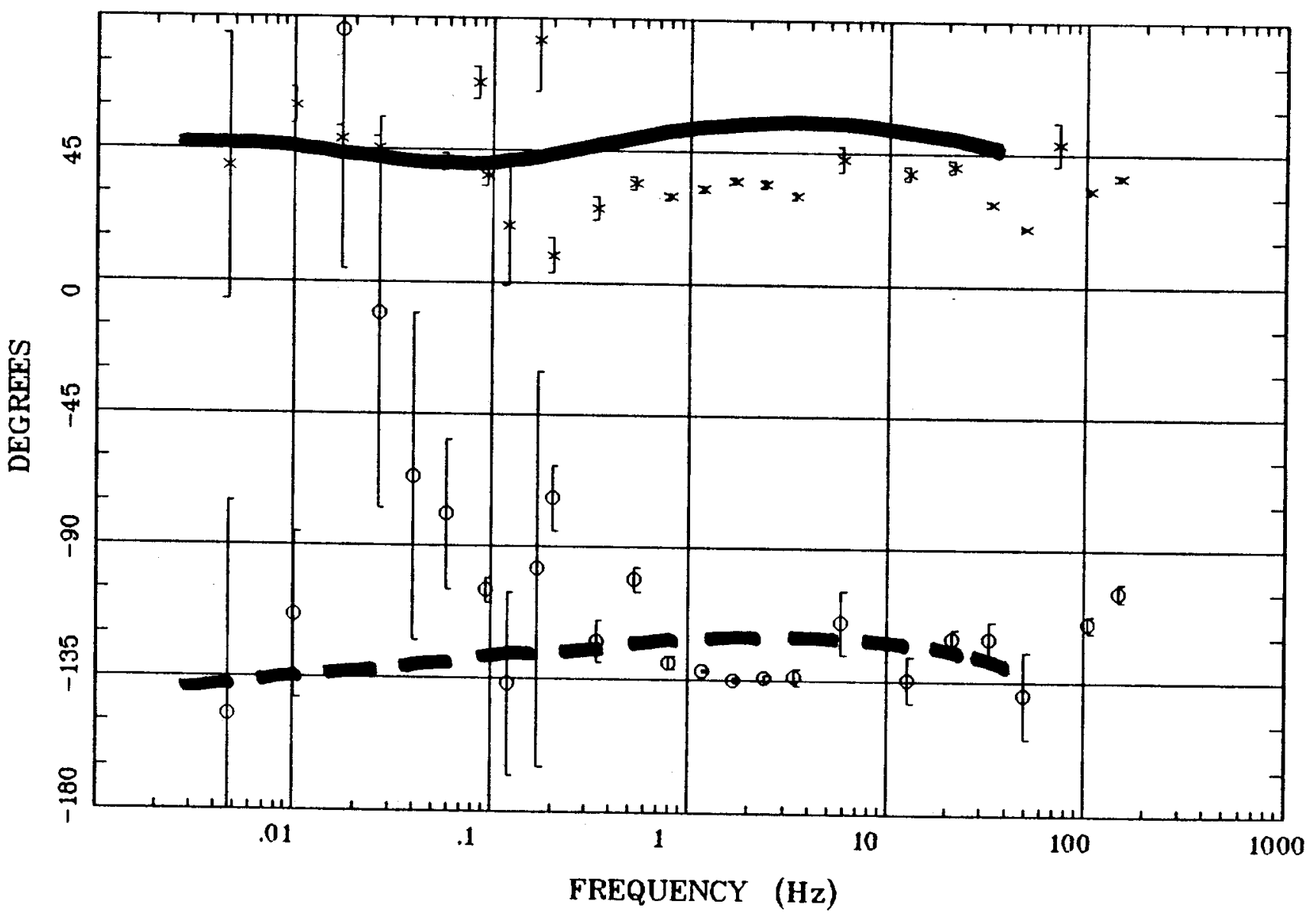

Client:

Remote:

Acquired:

Survey Co:
Rotation:

Filename: CT27A

Channels: Ch1 Ch2 Ch3 Ch4 Ch5 Ch6 Ch7

Plotted: 16:01 Dec 11, 2000

< EMI - ElectroMagnetic Instruments 
APPARENT RESISTIVITY

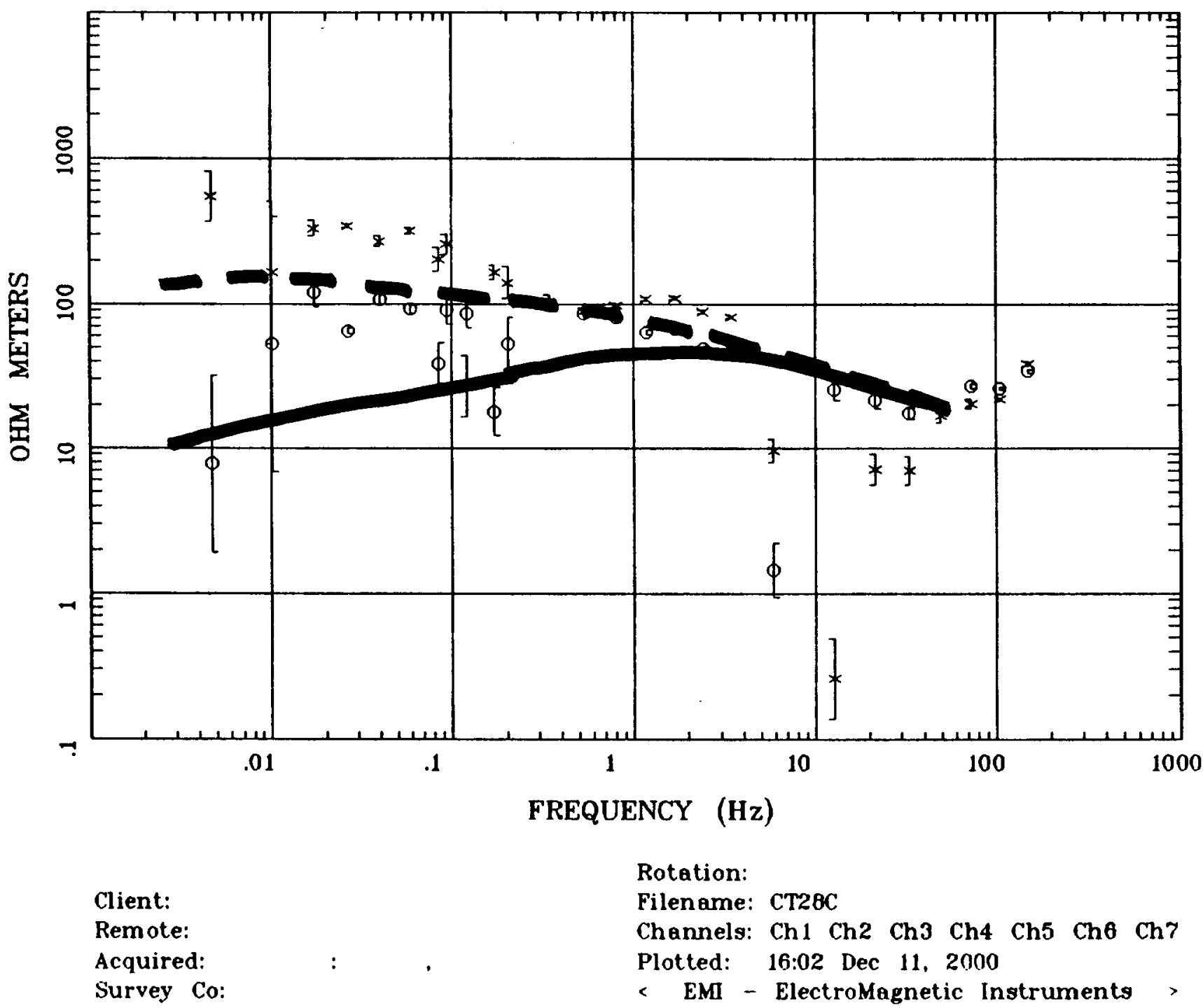


IMPEDANCE PHASE

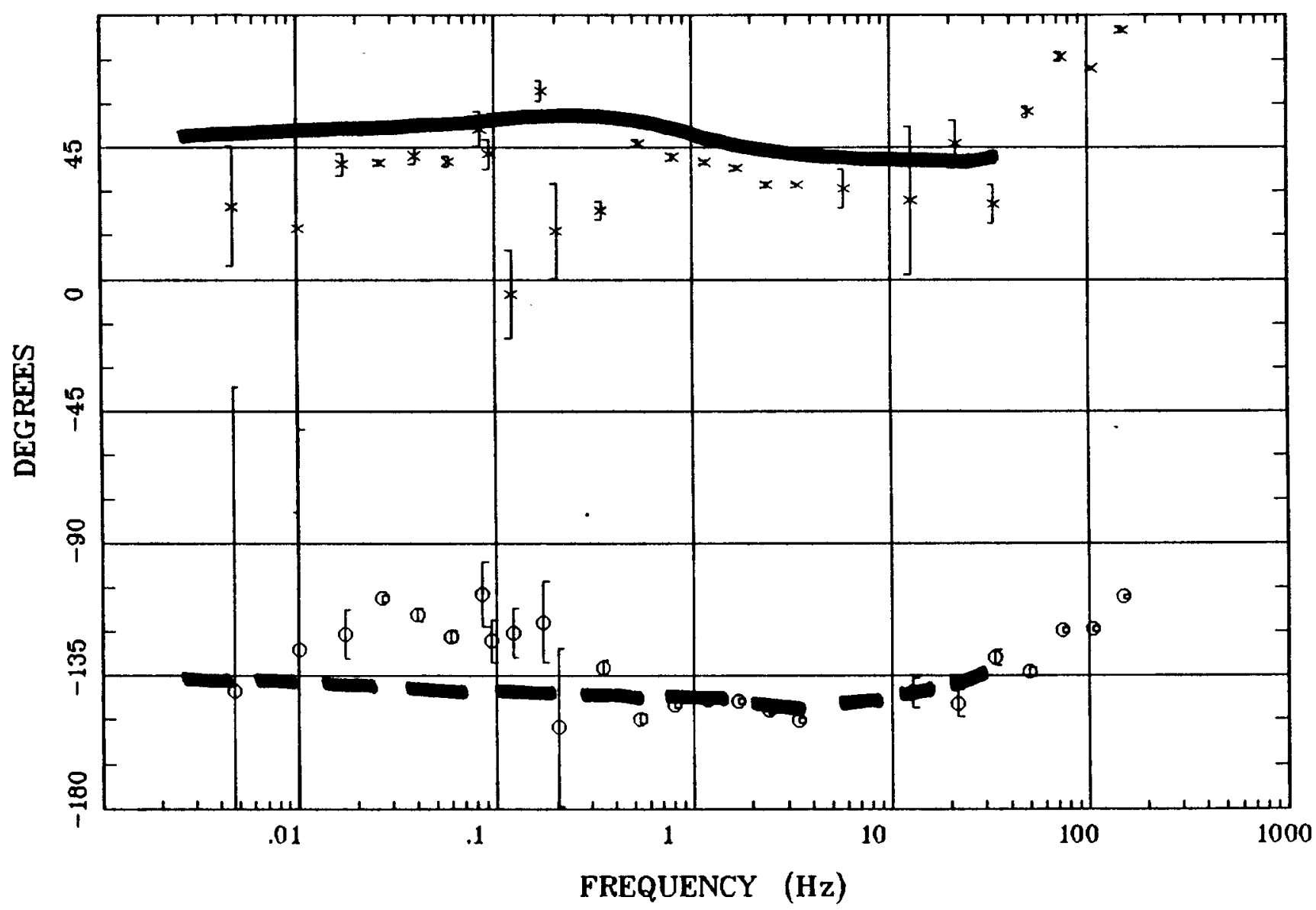

Client:

Rotation:

Remote:

Filename: CT28C

Channels: Ch1 Ch2 Ch3 Ch4 Ch5 Ch6 Ch7

Acquired:

Plotted: 16:02 Dec 11, 2000

Survey Co:

< EMI - ElectroMagnetic Instruments 


\section{OBSERVED AND CALCULATED DATA - PROFILE MT3}

Magnetotelluric (MT) observed (circle and $\mathrm{x}$ symbols) and calculated (solid and dashed lines are TE and TM modes, respectively) resistivity and phase data for profile MT3. See the "Magnetotelluric Data" section of this report for a description of the observed data and the "Resistivity Models" section for a description of the calculated data. 
Station 16

APPARENT RESISTIVITY

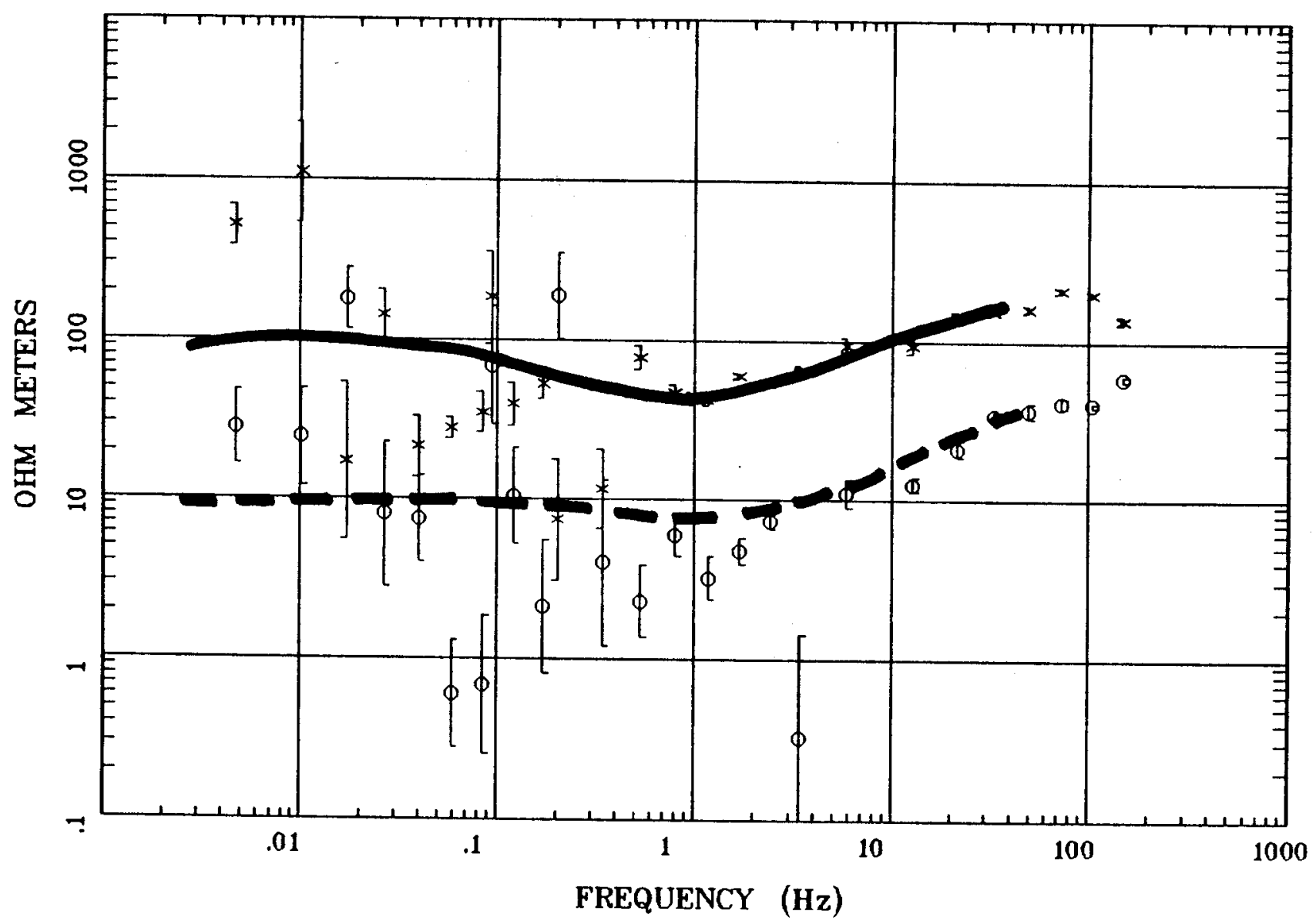

Client:

Remote:

Acquired:

Survey Co:
Rotation:

Filename: CT16C

Channels: Ch1 Ch2 Ch3 Ch4 Ch5 Ch6 Ch7

Plotted: 15:52 Dec 11, 2000

< EMI - ElectroMagnetic Instruments > 


\section{IMPEDANCE PHASE}

Station 16

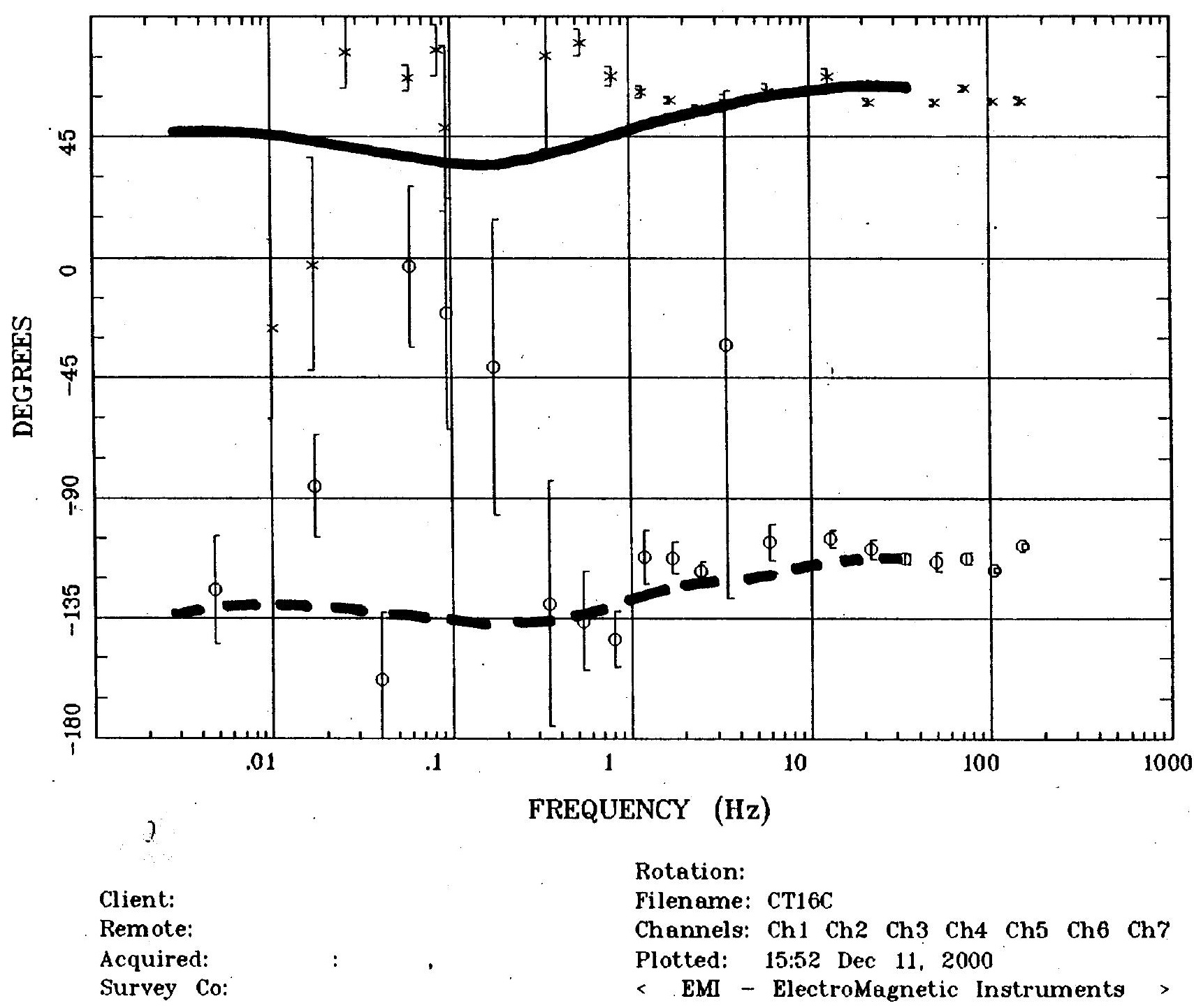


APPARENT RESISTIVITY

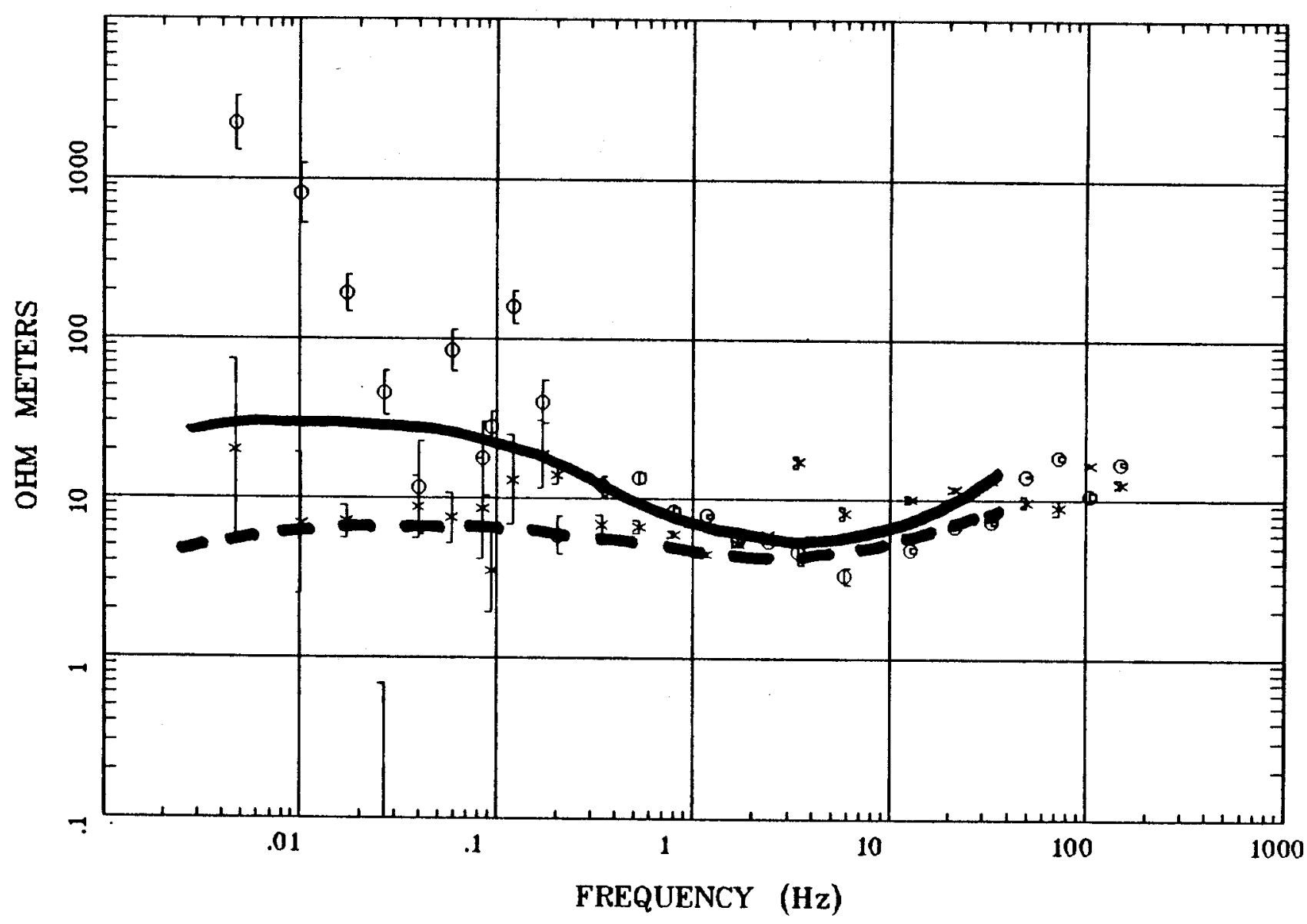

Client:

Remote:

Acquired:

Survey Co:
Rotation:

Filename: CT15F

Channels: Ch1 Ch2 Ch3 Ch4 Ch5 Ch6 Ch7 Plotted: 15:49 Dec 11, 2000

< EMI - ElectroMagnetic Instruments, 


\section{IMPEDANCE PHASE}

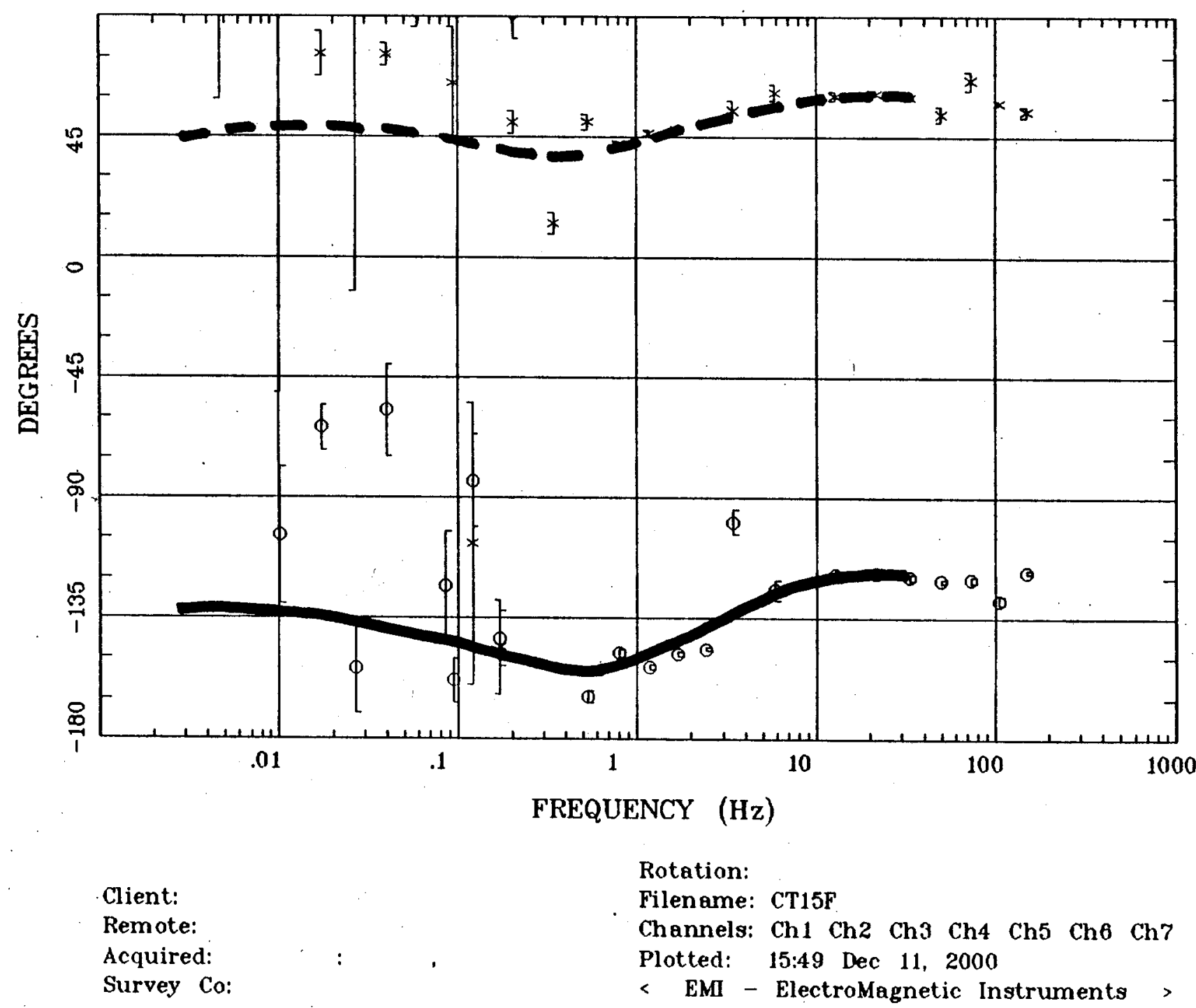


APPARENT RESISTIVITY

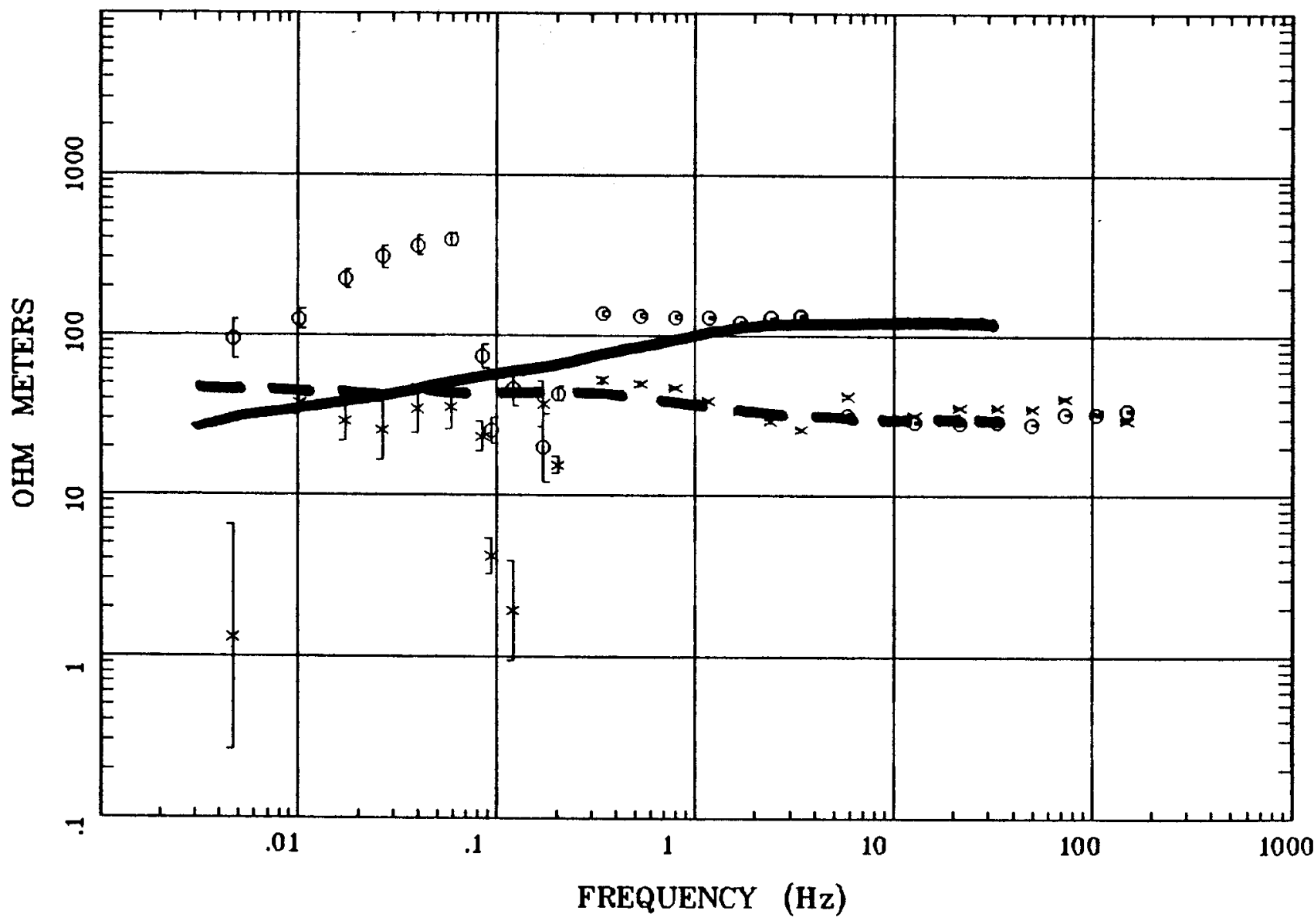

Client:

Remote:

Acquired:

Survey Co:
Rotation:

Filename: NNR01

Channels: Ch1 Ch2 Ch3 Ch4 Ch5 Ch6 Ch7

Plotted: 15:29 Dec 11, 2000

< EMI - ElectroMagnetic Instruments > 
IMPEDANCE PHASE

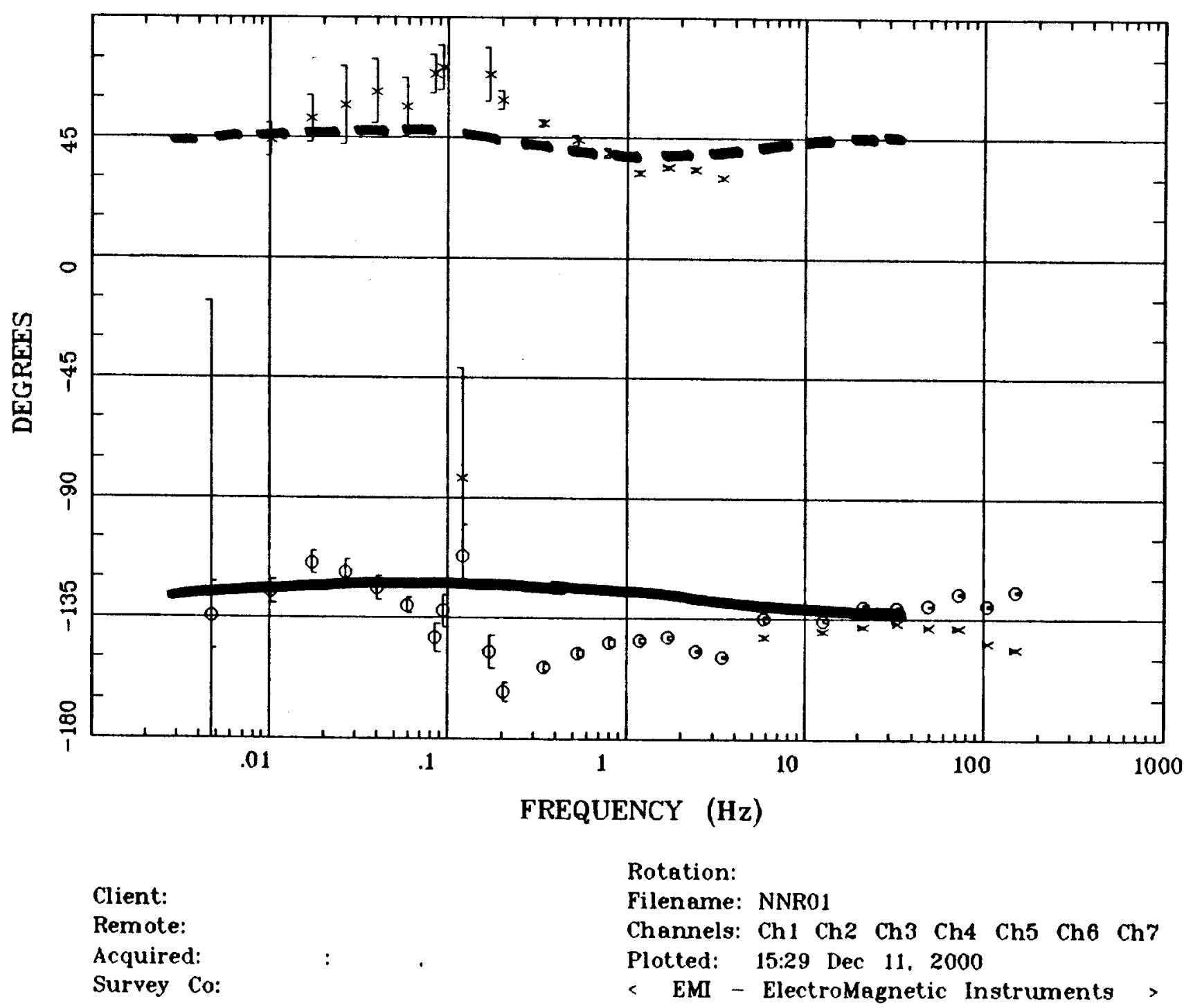


APPARENT RESISTIVITY

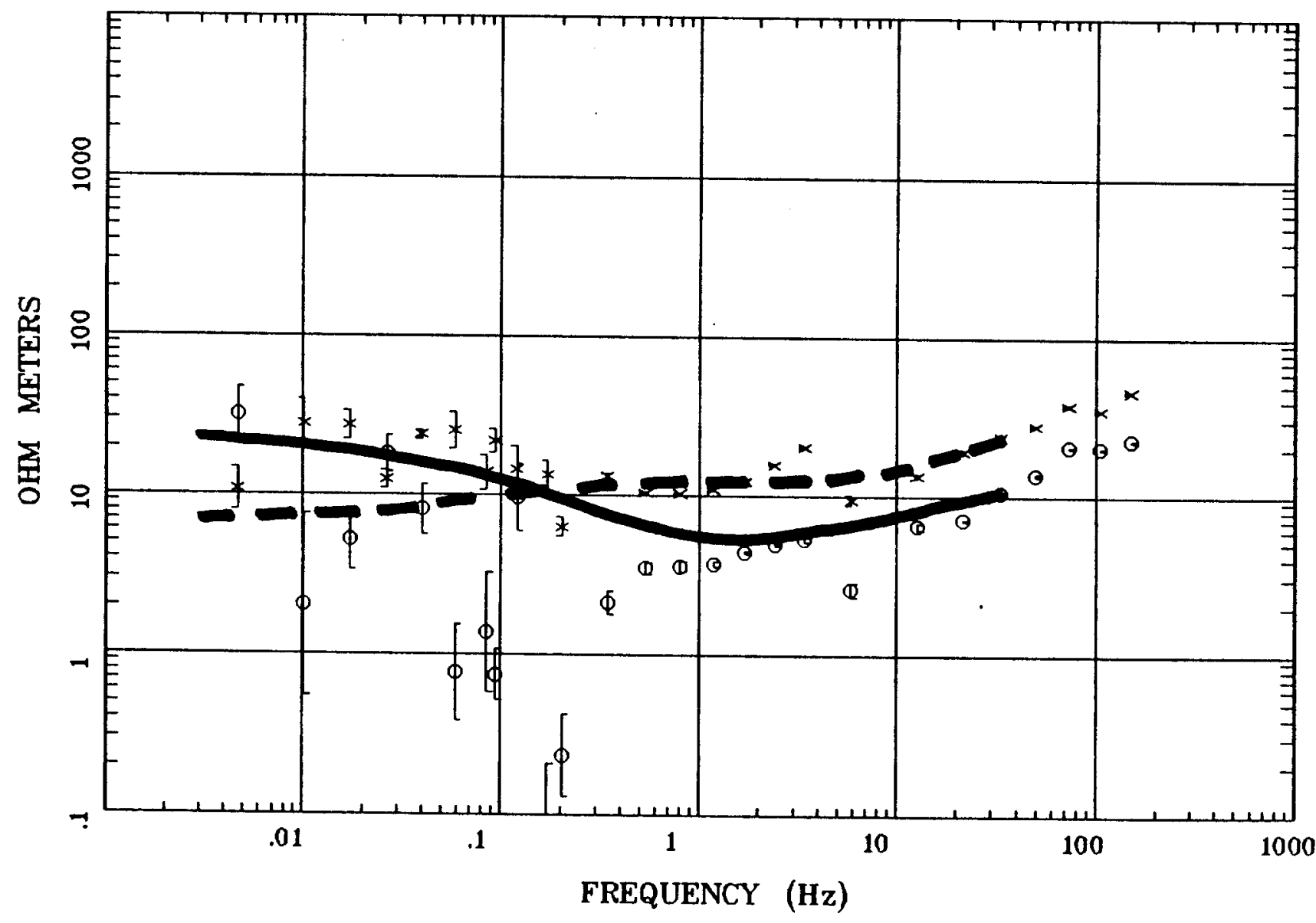

Client:

Remote:

Acquired:

Survey Co:
Rotation:

Filename: NNR02

Channels: Ch1 Ch2 Ch3 Ch4 Ch5 Che Chy

Plotted: 15:34 Dec 11, 2000

< EMI - ElectroMagnetic Instruments 


\section{IMPEDANCE PHASE}

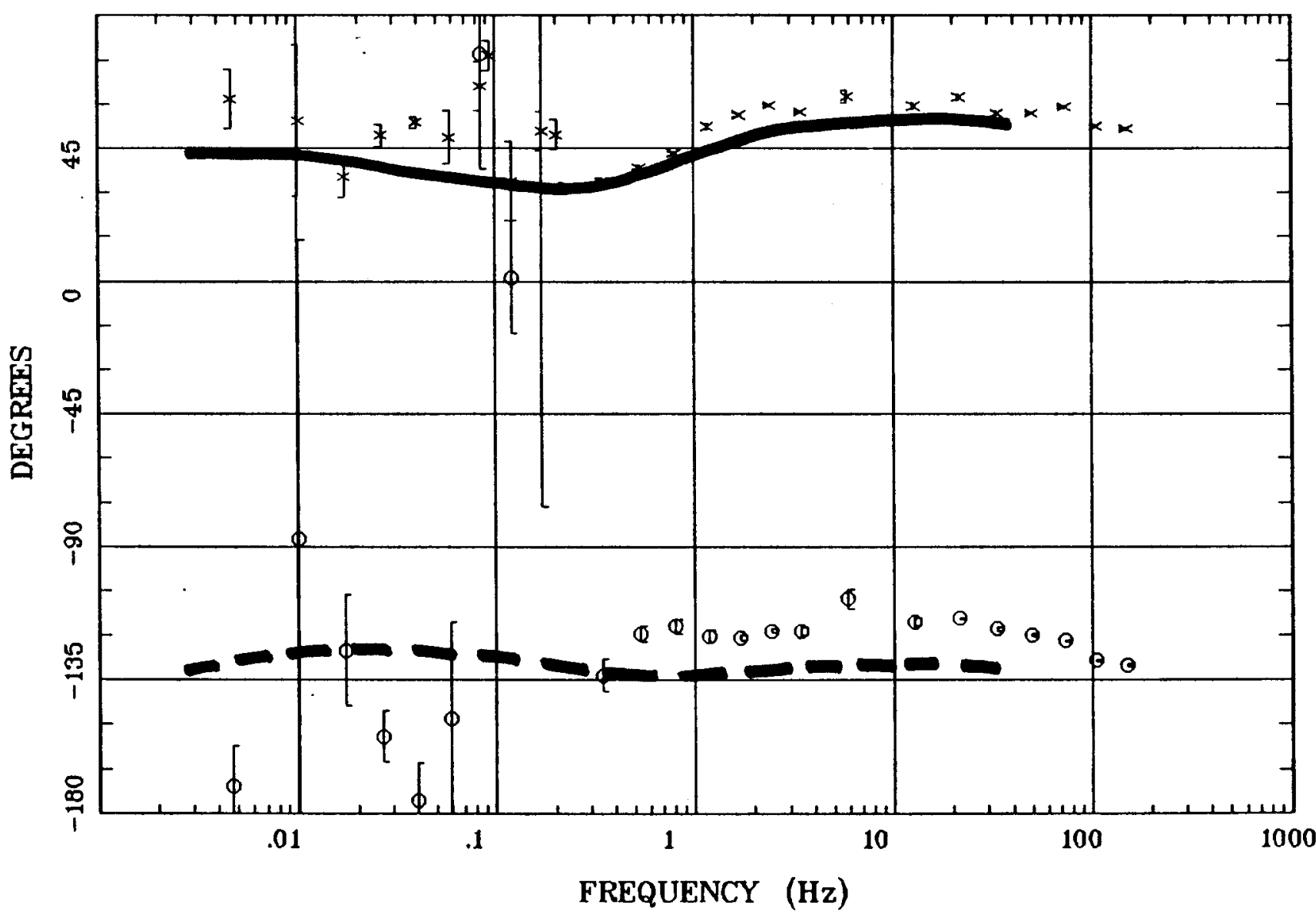

Client:

Remote:

Acquired:

Survey Co:
Rotation:

Filename: NNR02

Channels: Ch1 Ch2 Ch3 Ch4 Ch5 Ch6 Ch7

Plotted: 15:34 Dec 11, 2000

< EMI - ElectroMagnetic Instruments 
APPARENT RESISTIVITY

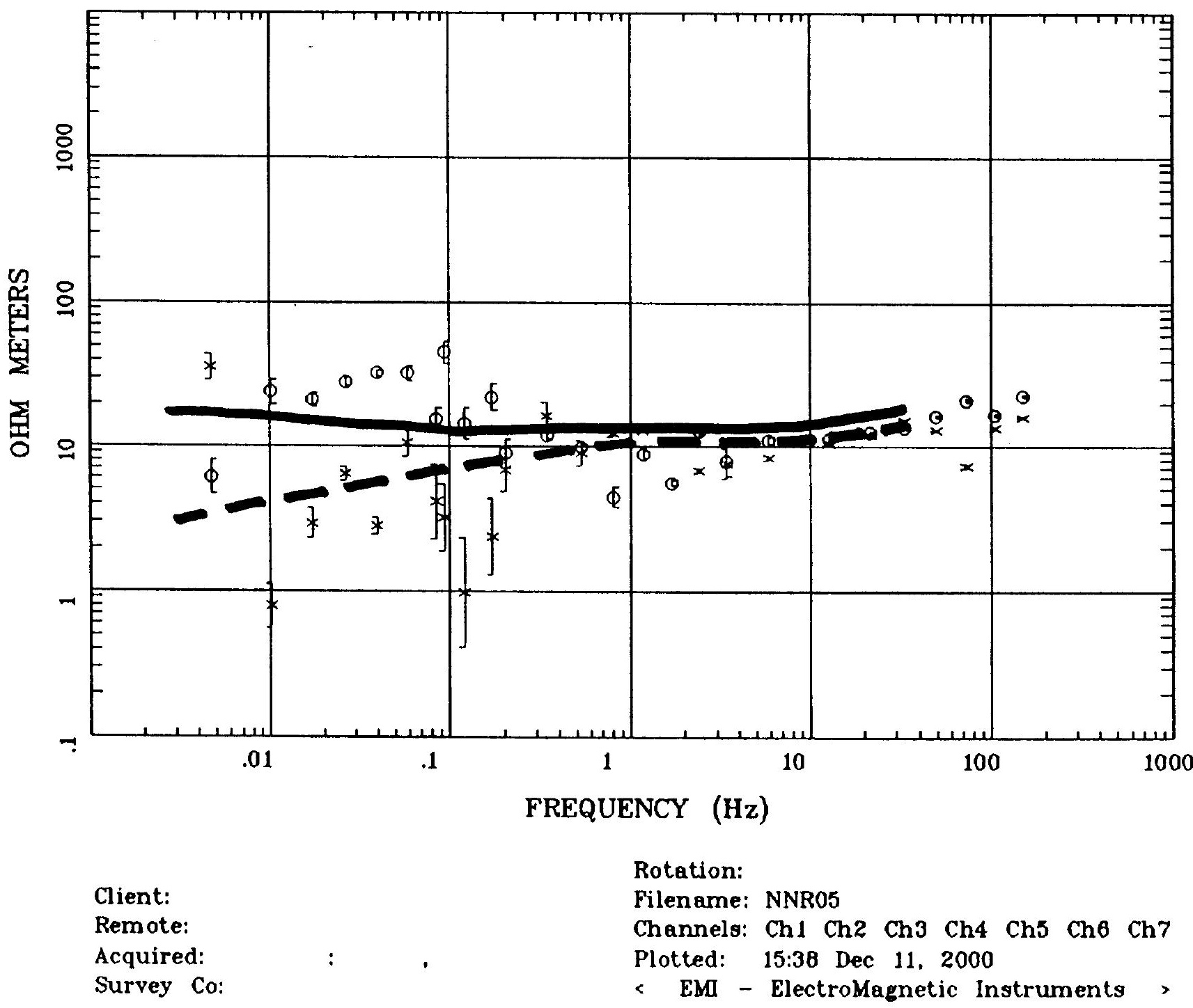




\section{Station 5A}

\section{IMPEDANCE PHASE}

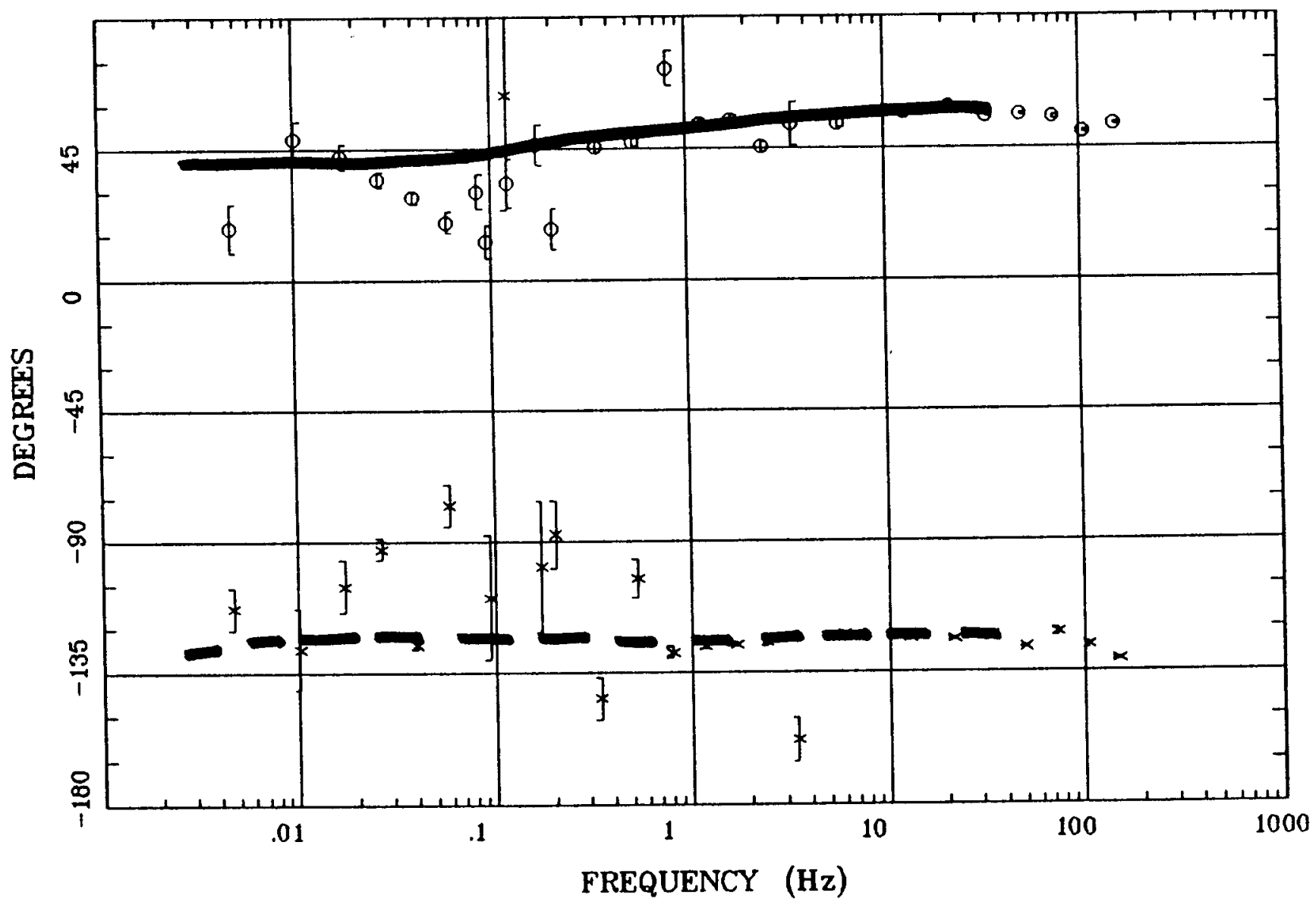

Client:

Rotation:

Remote:

Filename: NNR05

Acquired:

Channels: Ch1 Ch2 Ch3 Ch4 Ch5 Ch8 Ch7

Survey Co:

Plotted: 15:38 Dec 11, 2000

- EMI - ElectroMagnetic Instruments > 


\section{APPARENT RESISTIVITY}

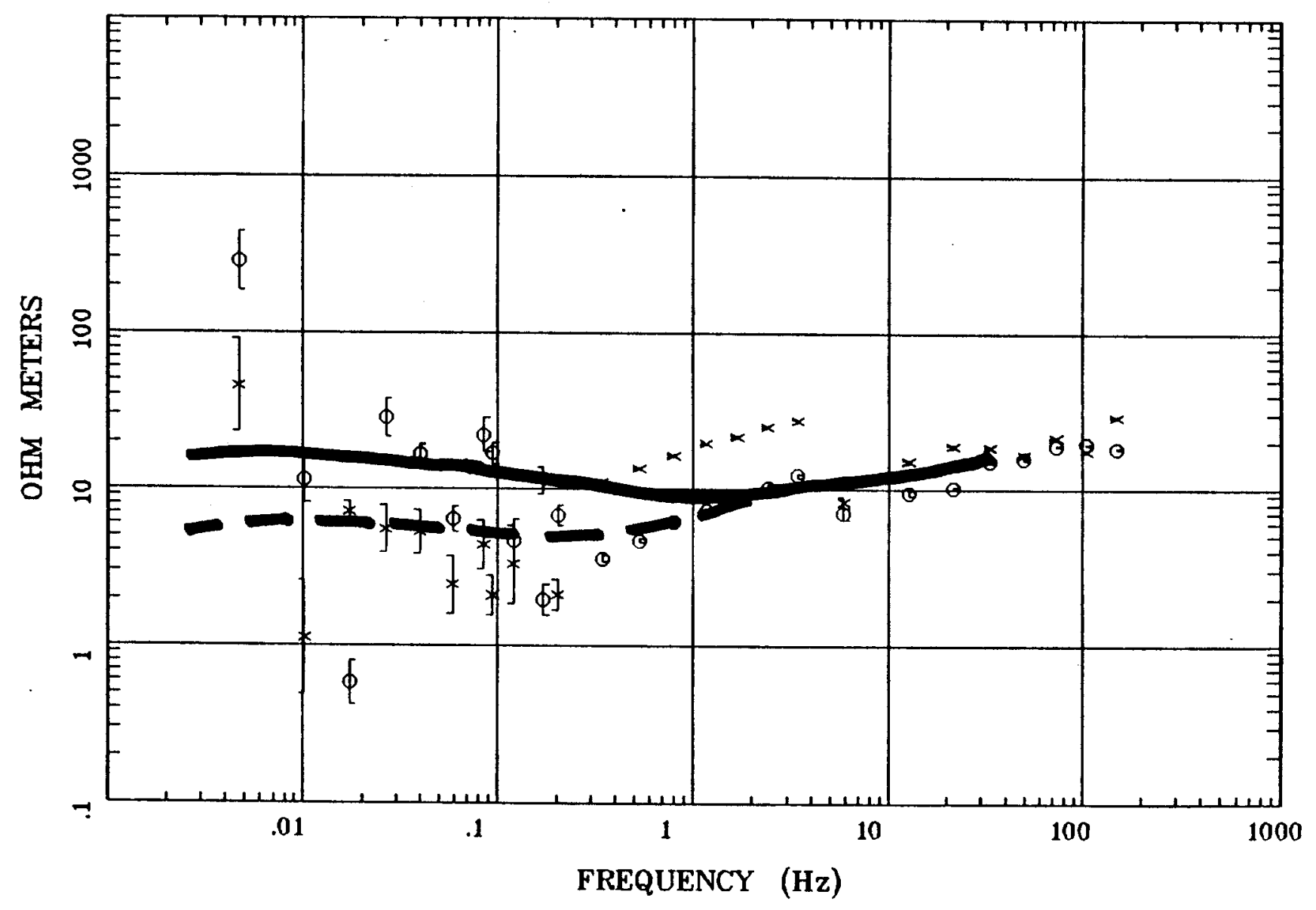

Client:

\section{Remote:}

Acquired:

Survey Co:
Rotation:

Filename: NNR03

Channels: Ch1 Ch2 Ch3 Ch4 Ch5 Ch6 Ch7

Plotted: 15:35 Dec 11, 2000

< EMI - ElectroMagnetic Instruments 


\section{Station 3A}

\section{IMPEDANCE PHASE}

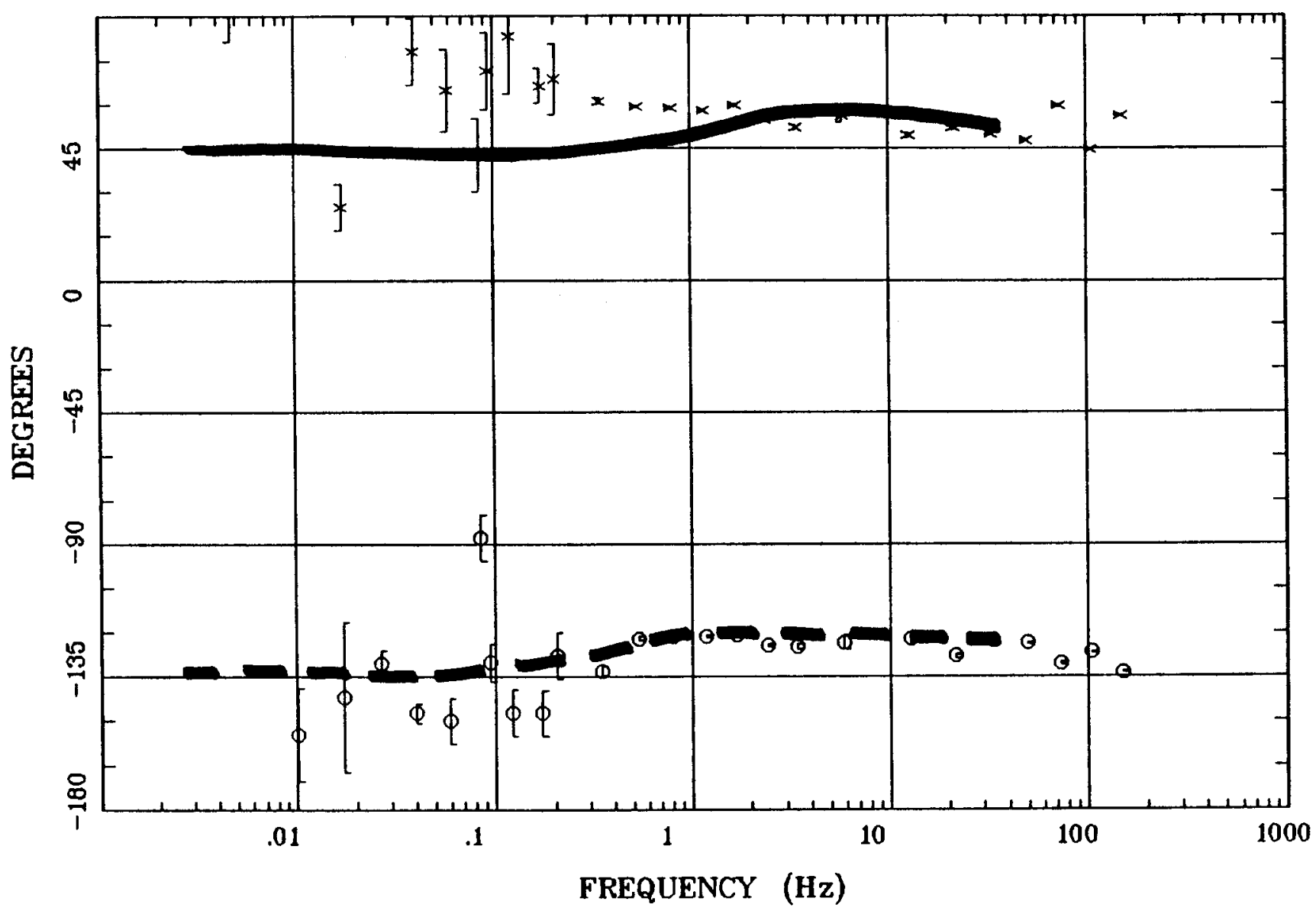

Client:

Remote:

Acquired:

Survey Co:
Rotation:

Filename: NNR03

Channels: Ch1 Ch2 Ch3 Ch4 Ch5 Ch6 Ch7 Plotted: 15:35 Dec 11, 2000

< EMI - ElectroMagnetic Instruments 


\section{APPARENT RESISTIVITY}

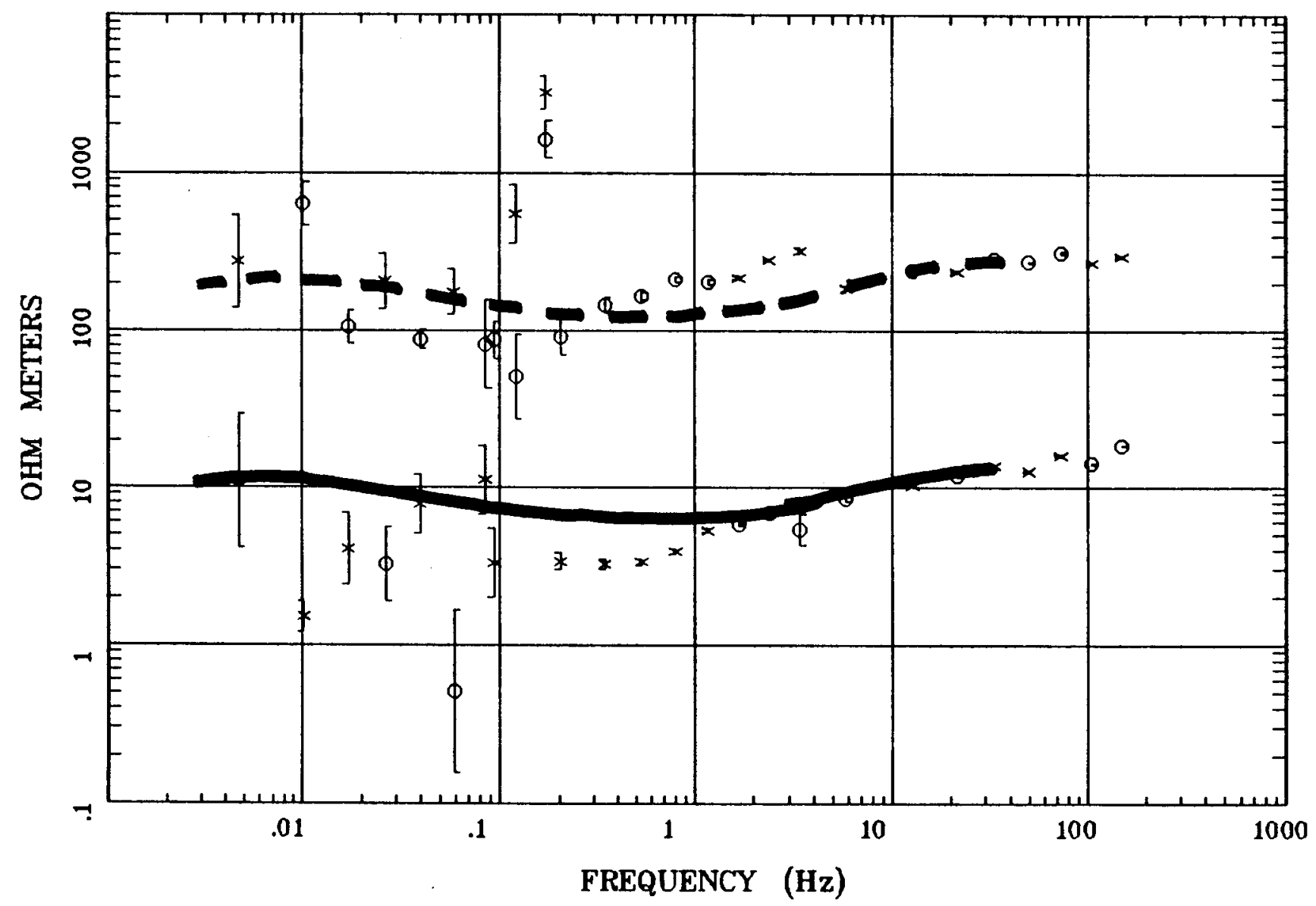

Client:

Remote:

Acquired:

Survey Co:
Rotation:

Filename: NNR04

Channels: Ch1 Ch2 Ch3 Ch4 Ch5 Ch6 Ch7

Plotted: 15:37 Dec 11, 2000

< EMI - ElectroMagnetic Instruments 
Station 4A

IMPEDANCE PHASE

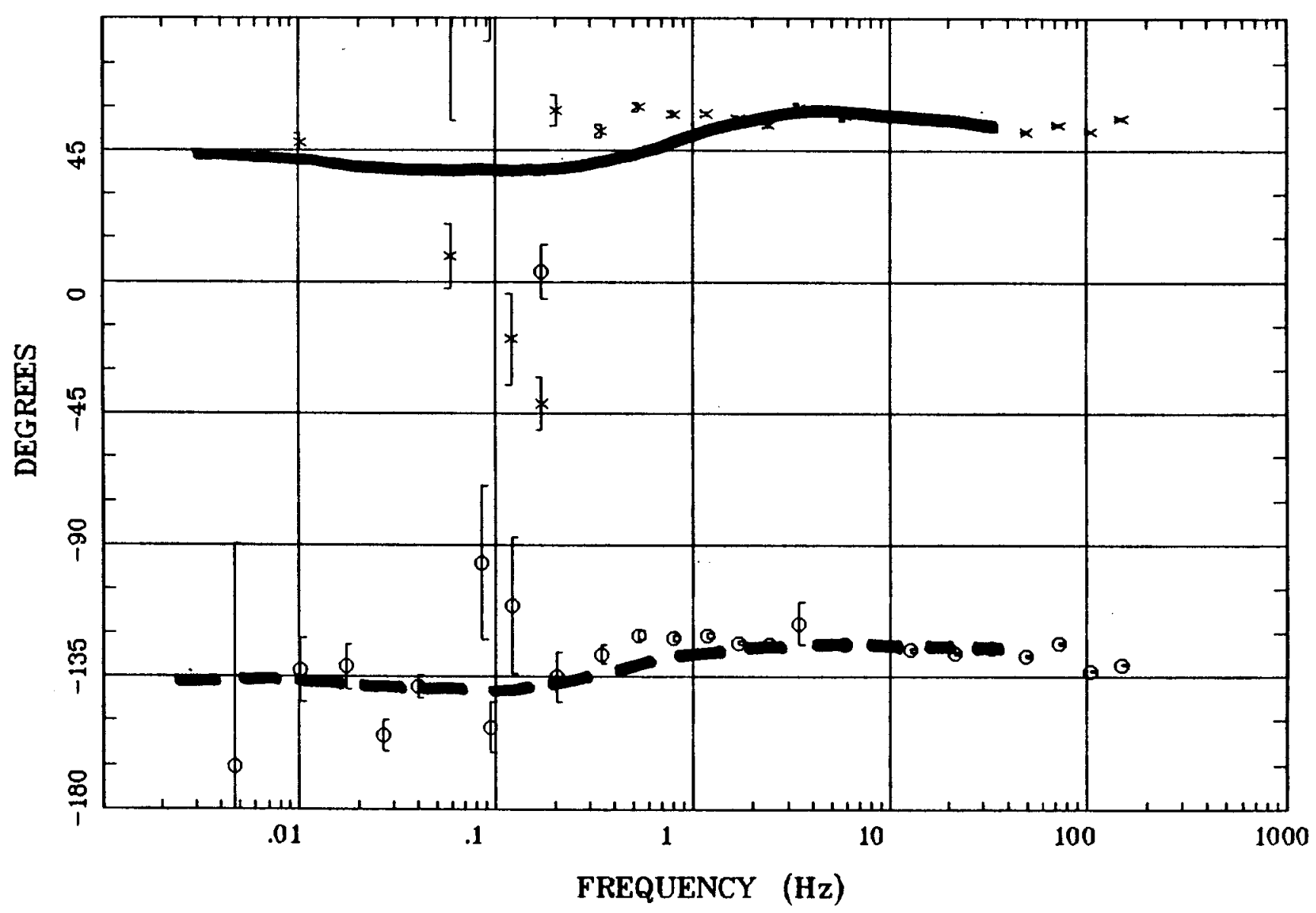

Client:

Remote:

Acquired:

Survey Co:
Rotation:

Filen ame: NNR04

Channels: Ch1 Ch2 Ch3 Ch4 Ch5 Ch6 Ch7

Plotted: 15:37 Dec 11, 2000

< EMI - ElectroMagnetic Instruments 


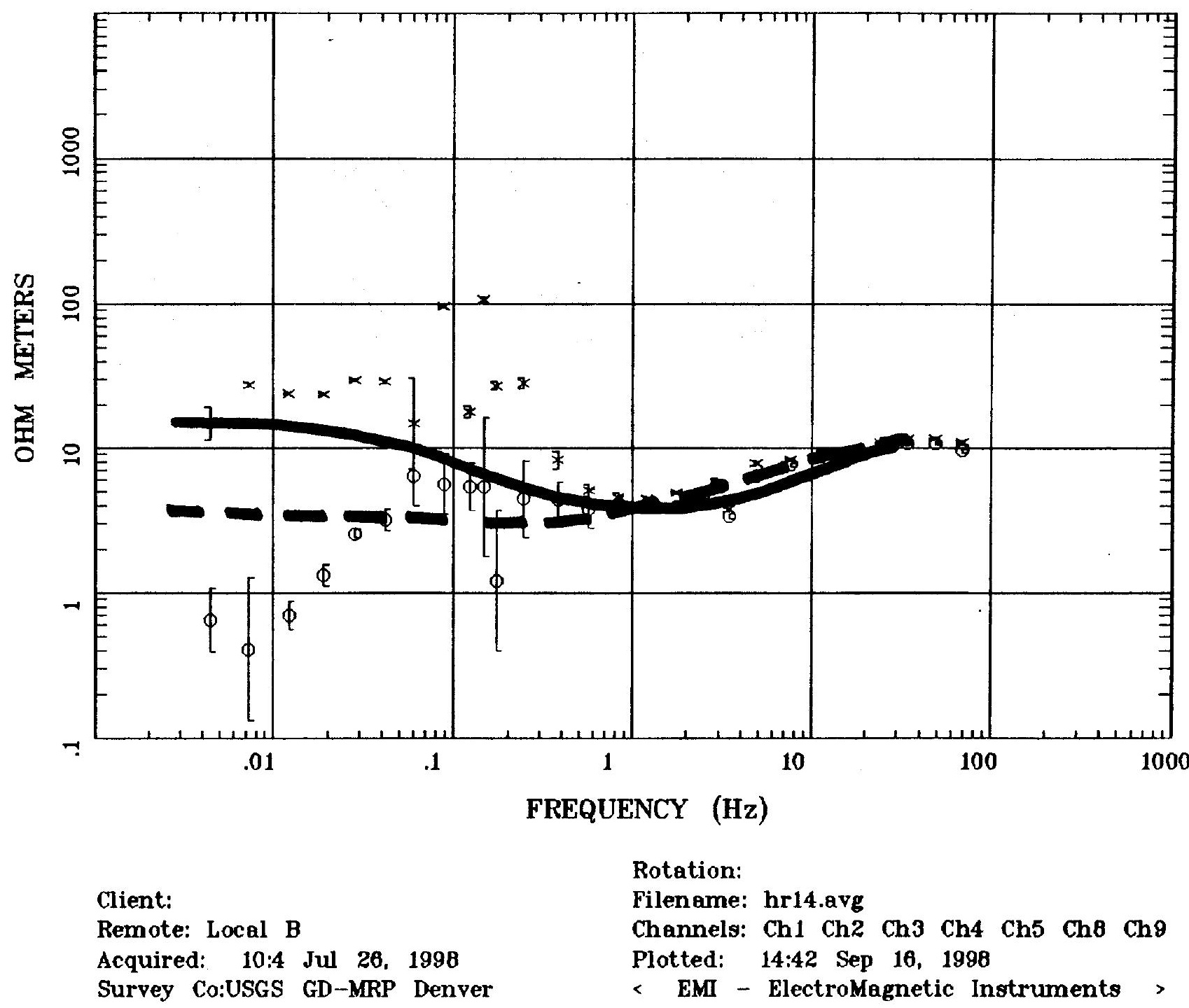




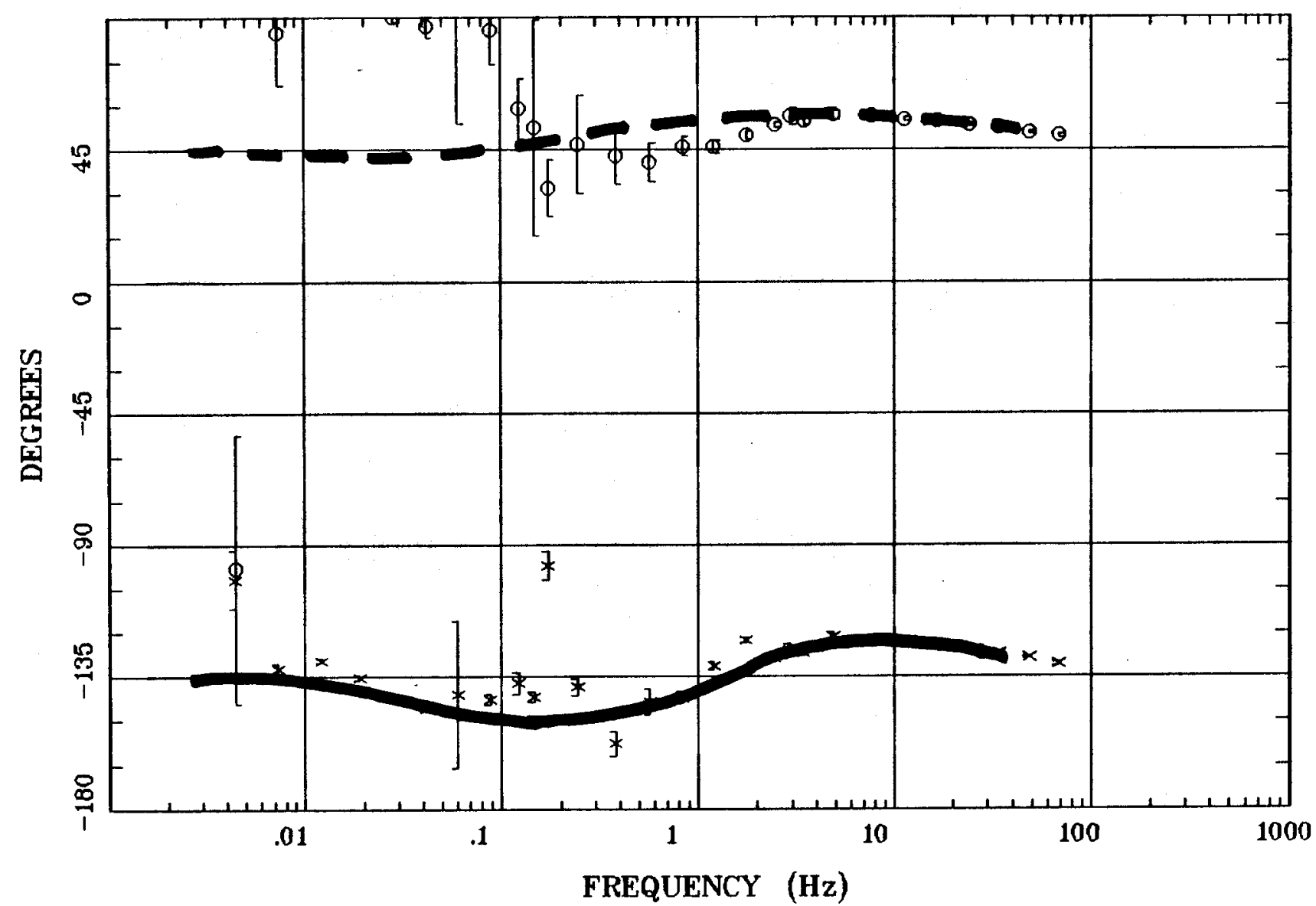

Client:

Remote: Local B

Acquired: 10:4 Jul 26, 1998

Survey Co:USGS GD-MRP Denver

\section{Rotation:}

Filename: hr14.avg

Channels: Ch1 Ch2 Ch3 Ch4 Ch5 Ch8 Ch9

Plotted: 14:42 Sep 16, 1998

< EMI - ElectroMagnetic Instruments > 


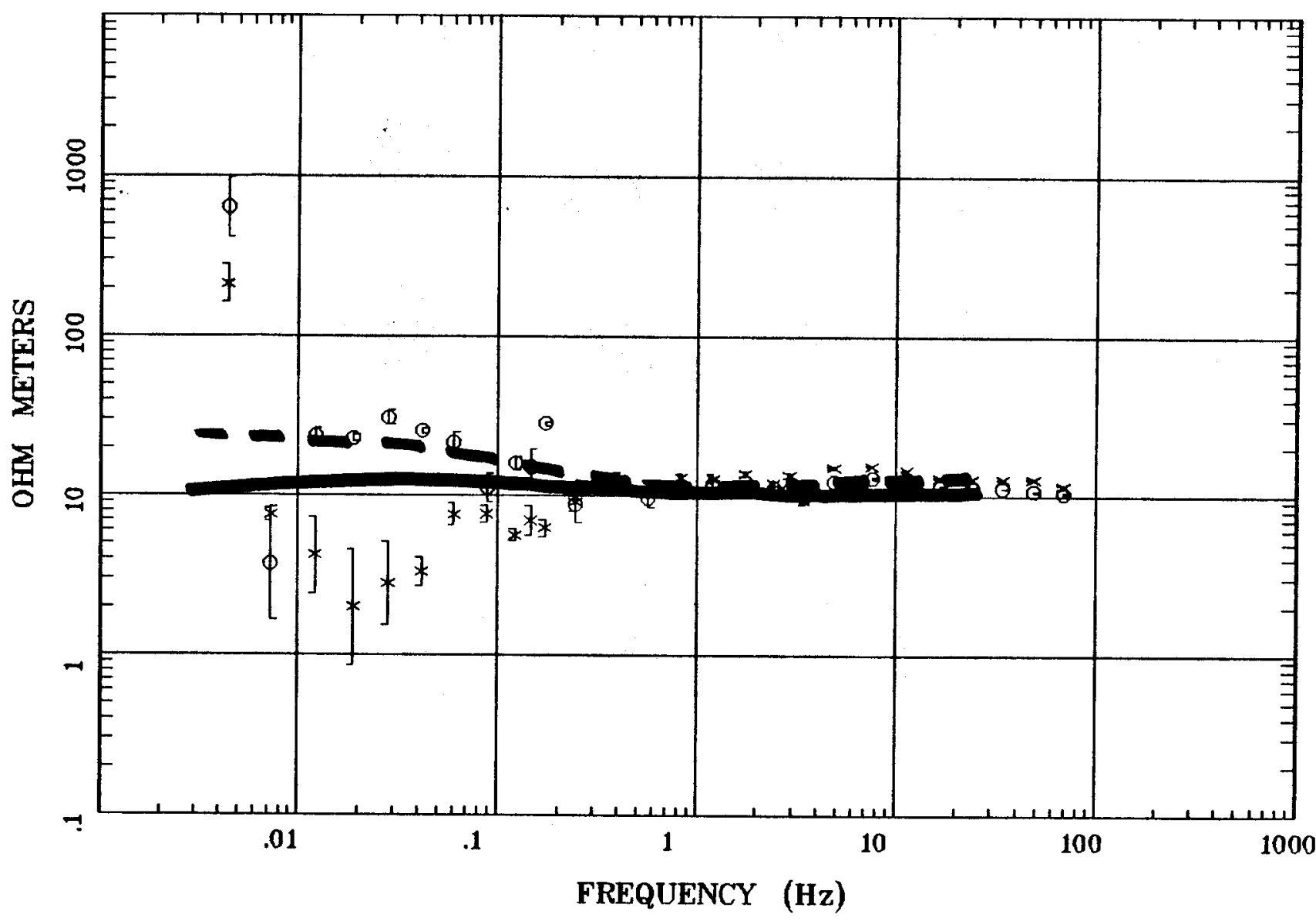

Client:

Remote: Local $B$

Acquired: 16:2 Jul 20, 1998

Survey Co:USGS GD-MRP Denver
Rotation:

Filename: hr13.avg

Channels: Ch1 Ch2 Ch3 Ch4 Ch5 Ch8 Ch9

Plotted: 14:54 Sep 16, 1998

< EMI - ElectroMagnetic Instruments > 


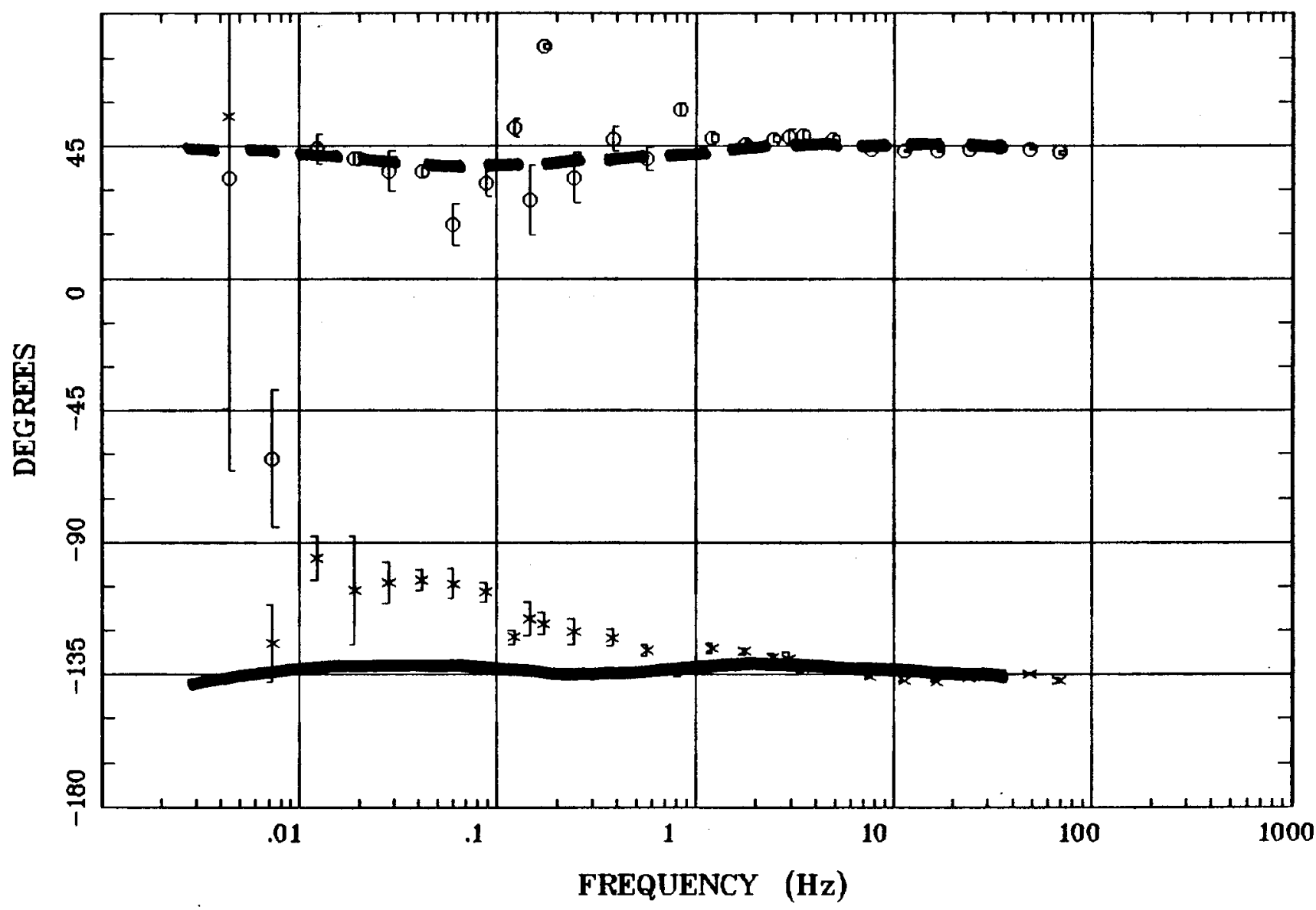

Client:

Remote: Local B

Acquired: 16:2 Jul 26, 1998

Survey Co:USGS GD-MRP Denver
Rotation:

Filename: hr13.avg

Channels: Ch1 Ch2 Ch3 Ch4 Ch5 Ch8 Ch8

Plotted: 14:54 Sep 16, 1998

< EMI - ElectroMagnetic Instruments > 


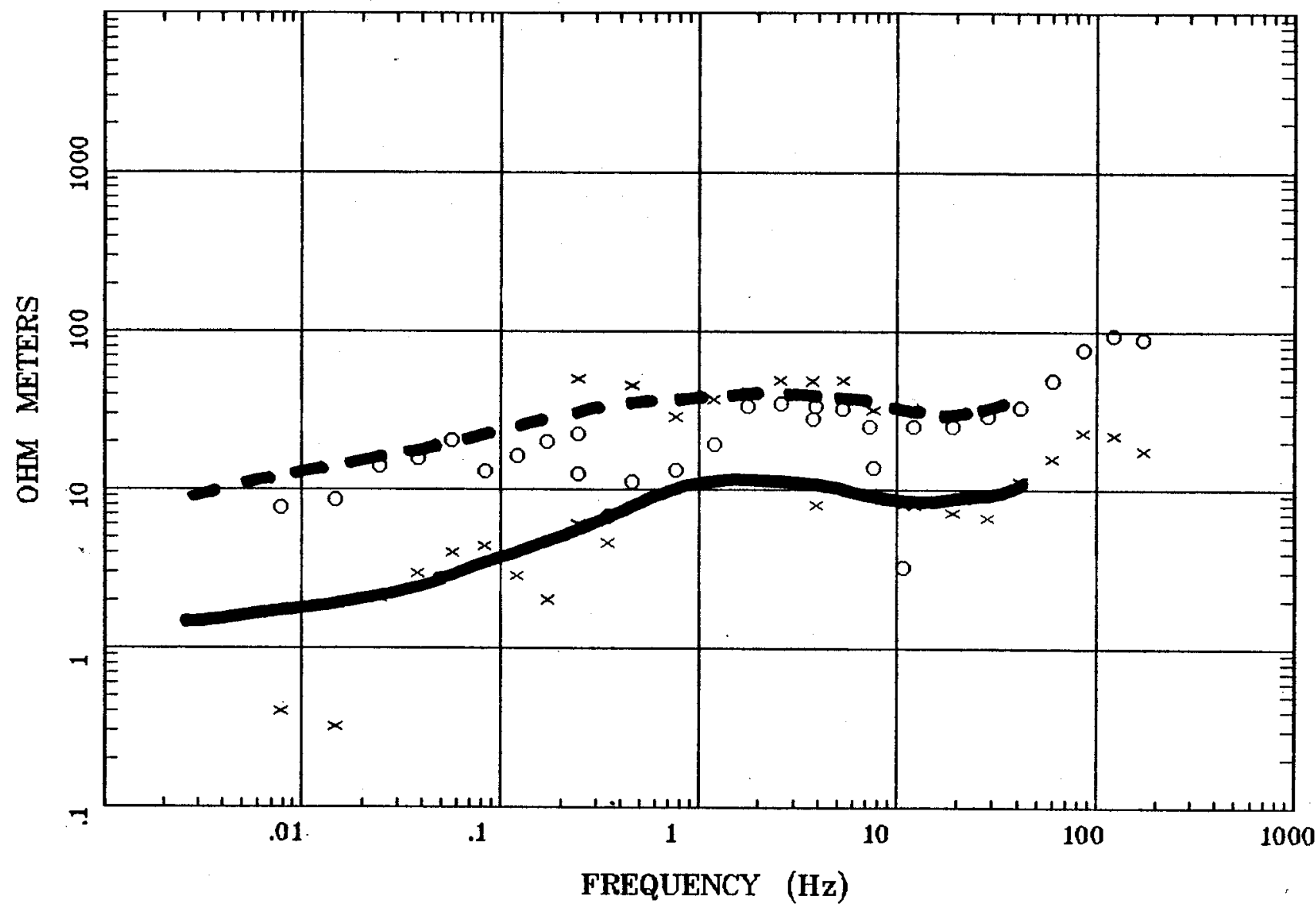

Client:

Remote:

Acquired:

Survey Co:
Rotation:

Filename: ct12a

Channels: Ch1 Ch2 Ch3 Ch4 Ch5 Ch6 Ch7

Plotted: 14:12 Sep 16, 1998

$<$ EMI - ElectroMagnetic Instruments 


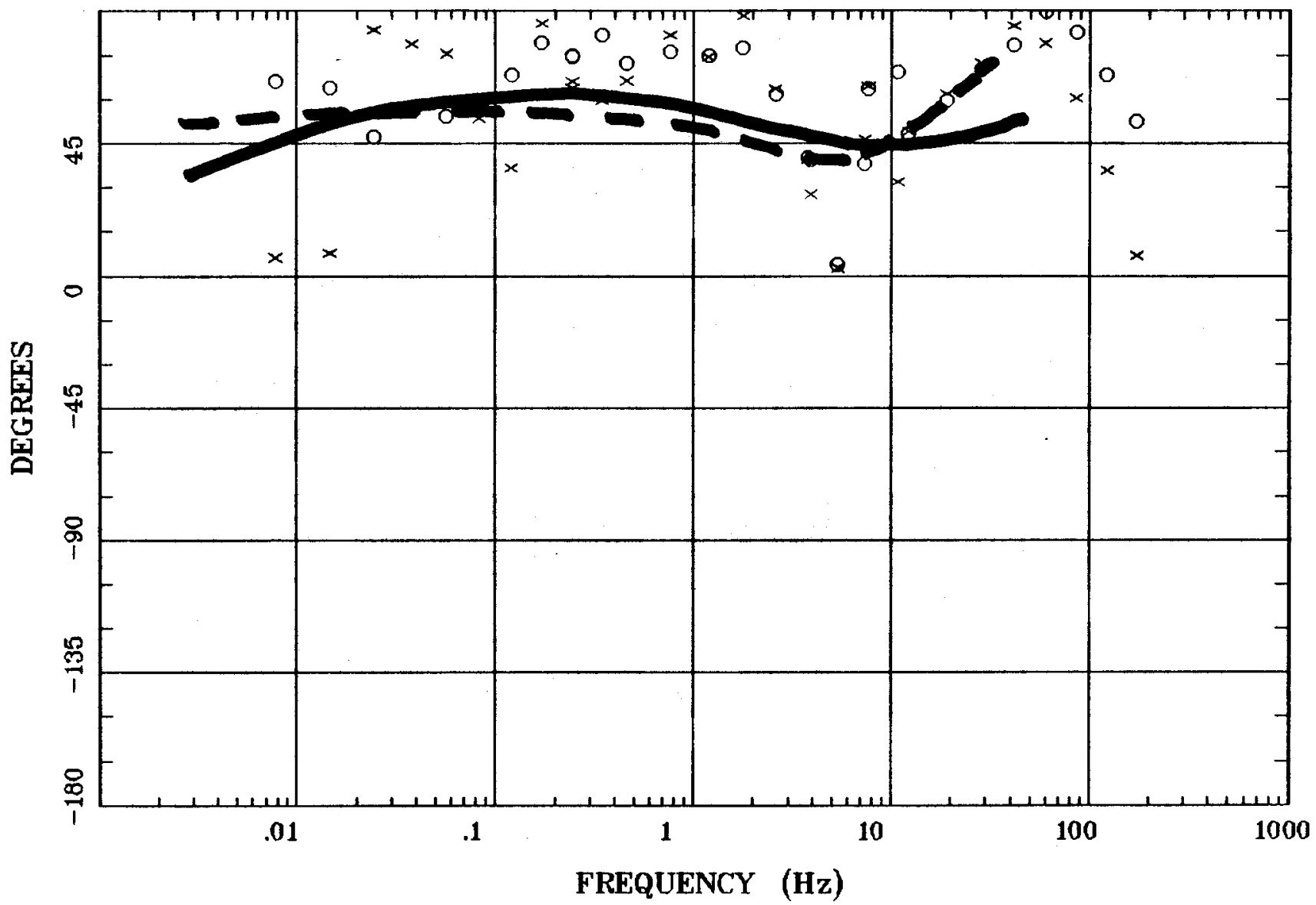

Client:

Rotation:

Client:

Filename: ct12a

Acquired:

Channels: Ch1 Ch2 Ch3 Ch4 Ch5 Che Ch7

Survey Co:

Plotted: 14:12 Sep 16, 1998

< EMI - ElectroMagnetic Instruments 


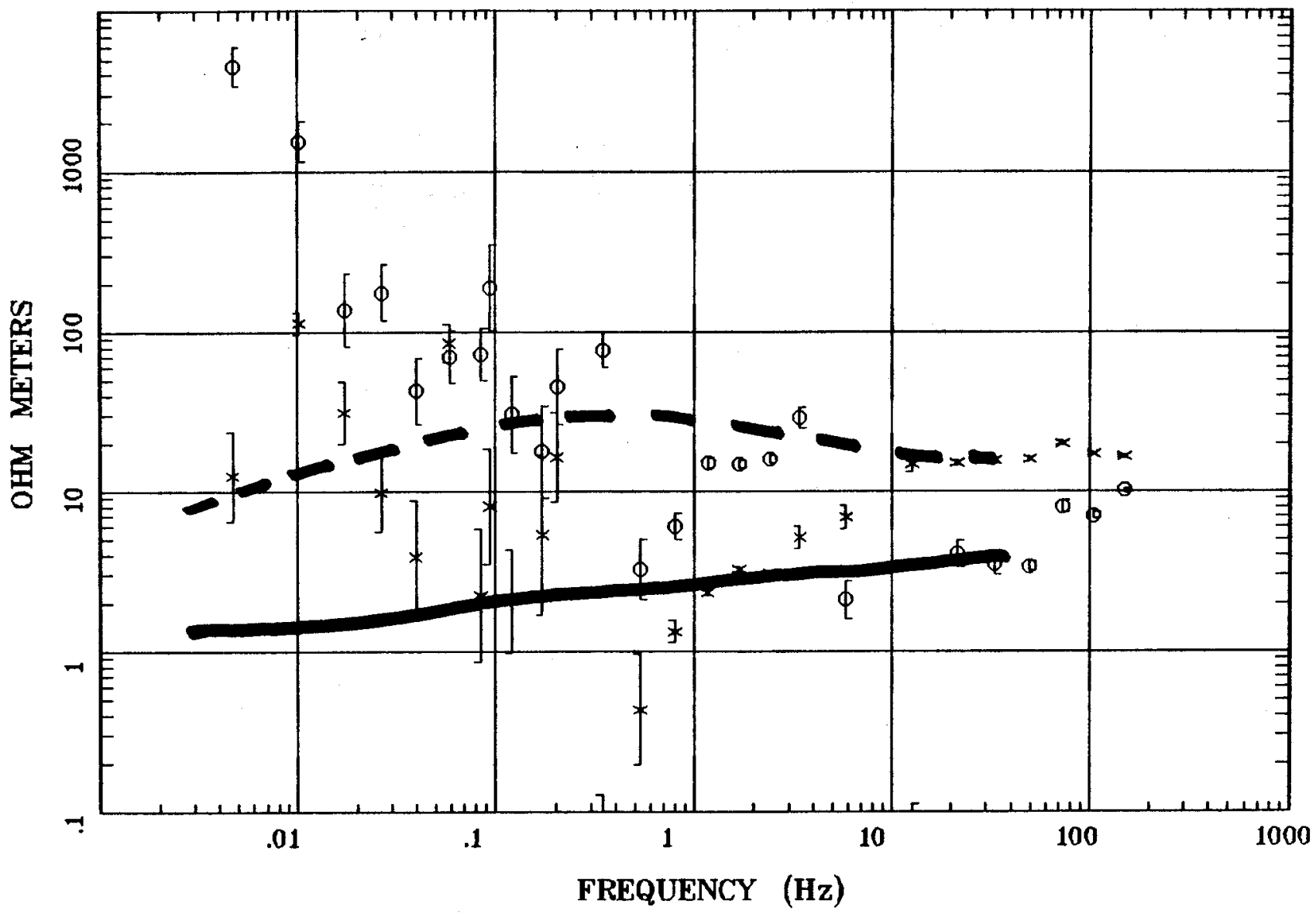

Client:

Remote:

Acquired: Survey Co:
Rotation:

Filename: CT19B

Channels: Ch1 Ch2 Ch3 Ch4 Ch5 Ch6 Ch7

Plotted: 08:10 Sep 17, 1998

< EMI - ElectroMagnetic Instruments 


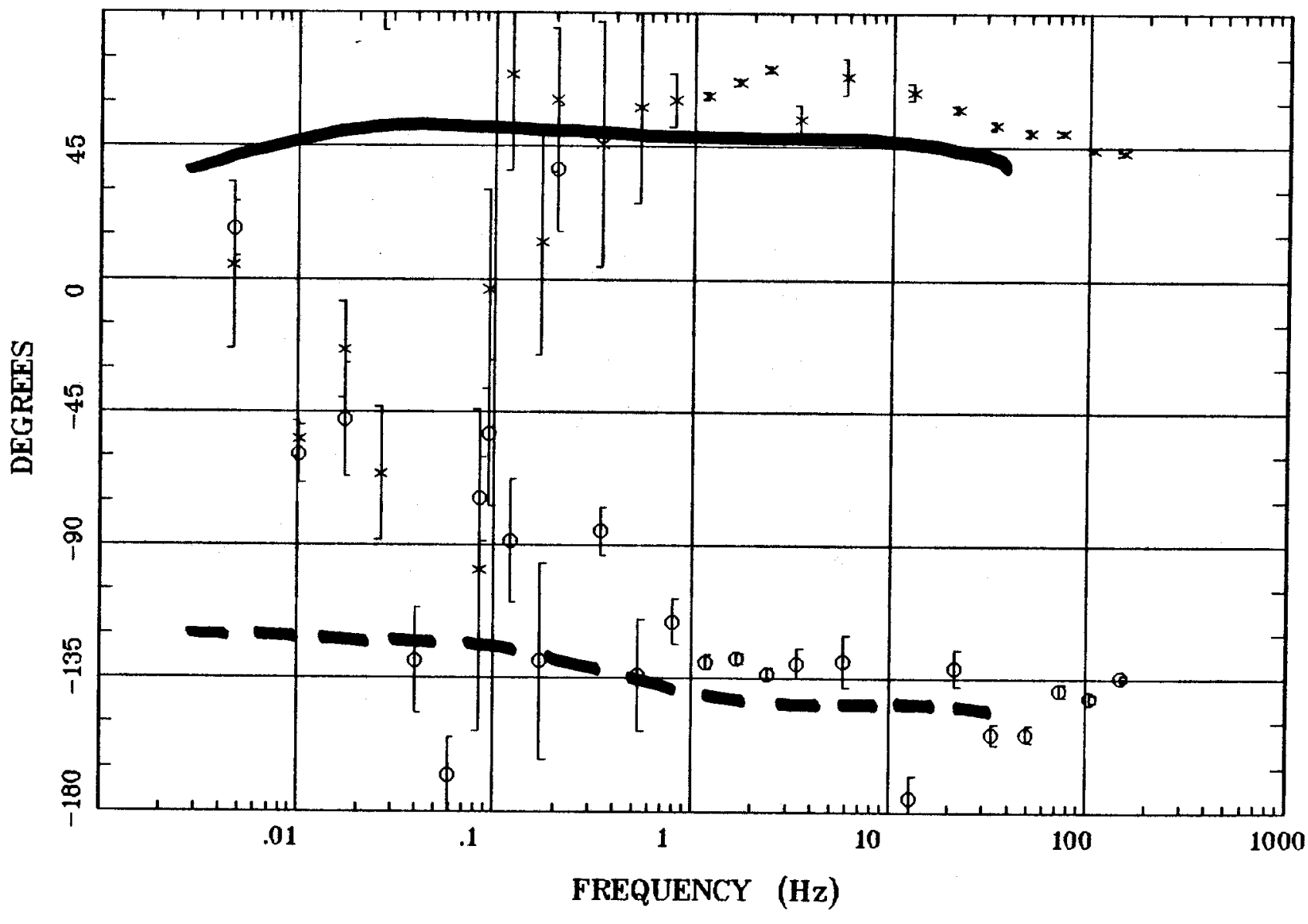

Client:

Remote:

Acquired:

Survey Co:
Rotation:

Filename: CT19B

Channels: Ch1 Ch2 Ch3 Ch4 Ch5 Ch6 Ch7

Plotted: 08:10 Sep 17, 1998

< EMI - ElectroMagnetic Instruments > 


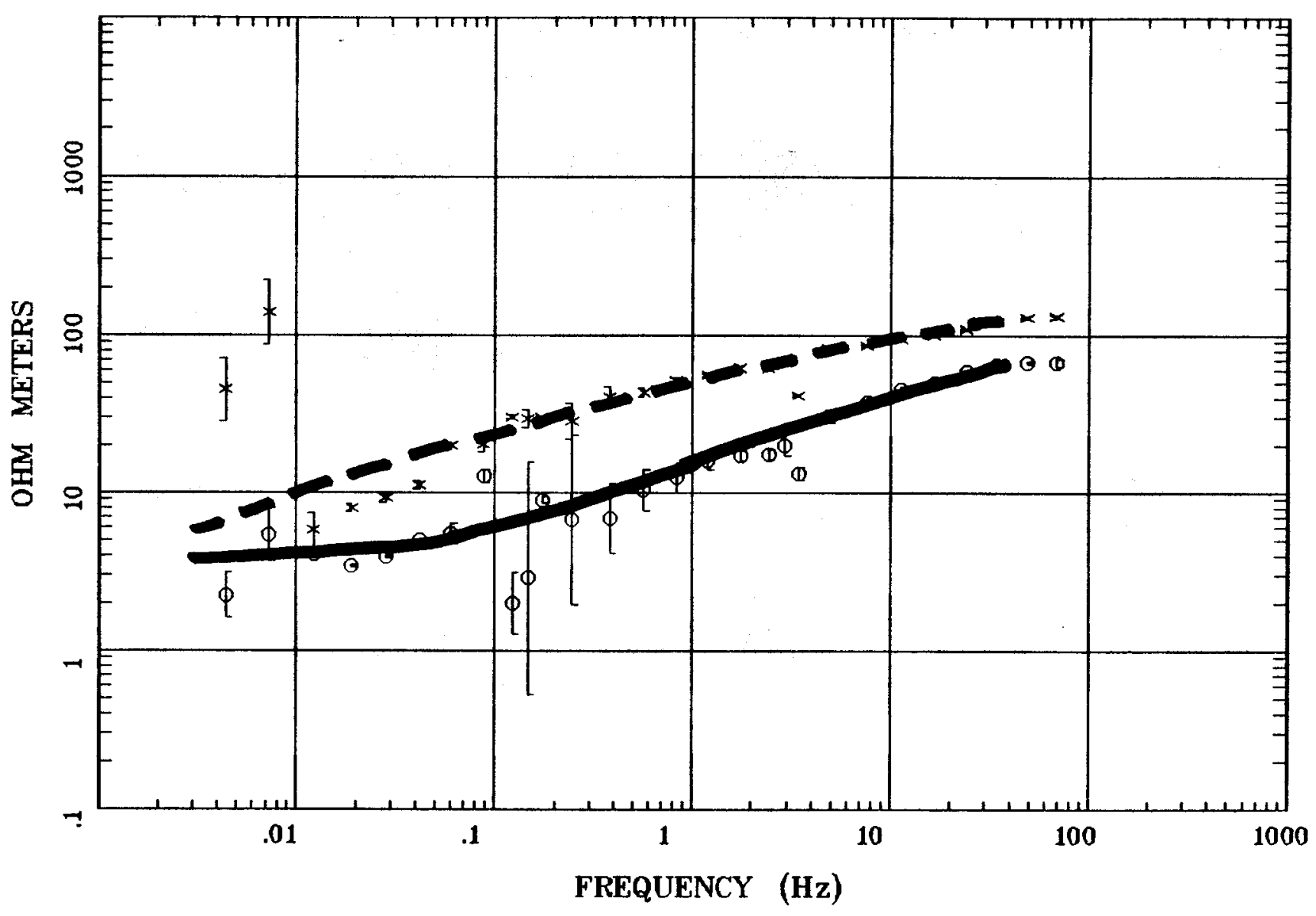

Client:

Remote: Local B

Acquired: 14:5 Jul 25, 1998 Survey Ca:USGS GD-MRP Denver

Rotation:

Filename: hr11l.avg

Channels: Ch1 Ch2 Ch3 ch4 Ch5 Ch8 Ch9 Plotted: 15:09 Sep 16, 1998

< EMI - ElectroMagnetic Instruments > 
IMPEDANCE PHASE

Carlin Trend

Station 11

$\infty$

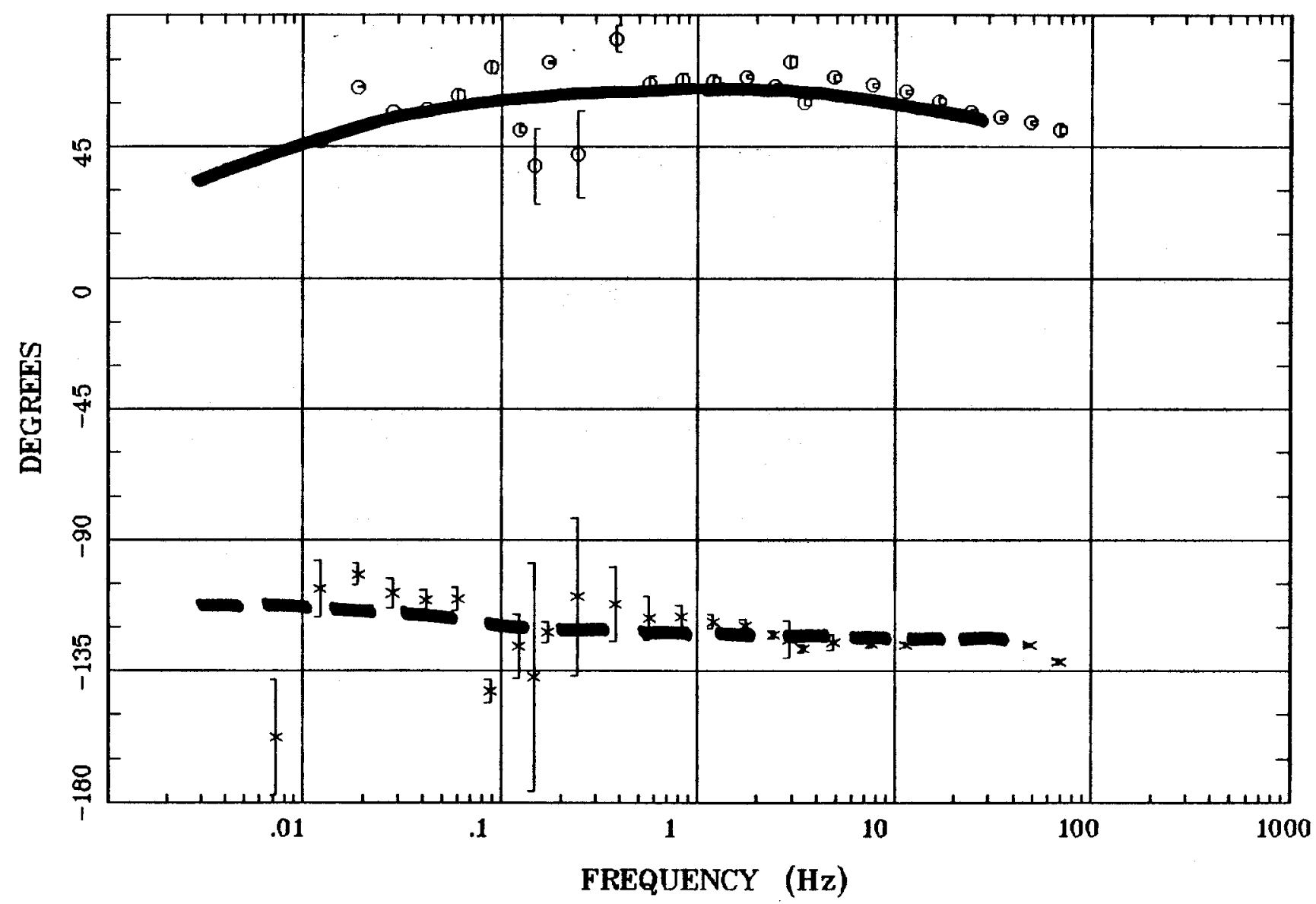

Client:

Remote: Local B

Acquired: 14:5 Jul 25, 1998

Survey Co:USGS GD-MRP Denver
Rotation:

Filename: hr11l.avg

Channels: Ch Chr Ch Ch4 Ch5 Chr Chg

Plotted: 15:09 Sep 16, 1998

< EMI - ElectroMagnetic Instruments > 


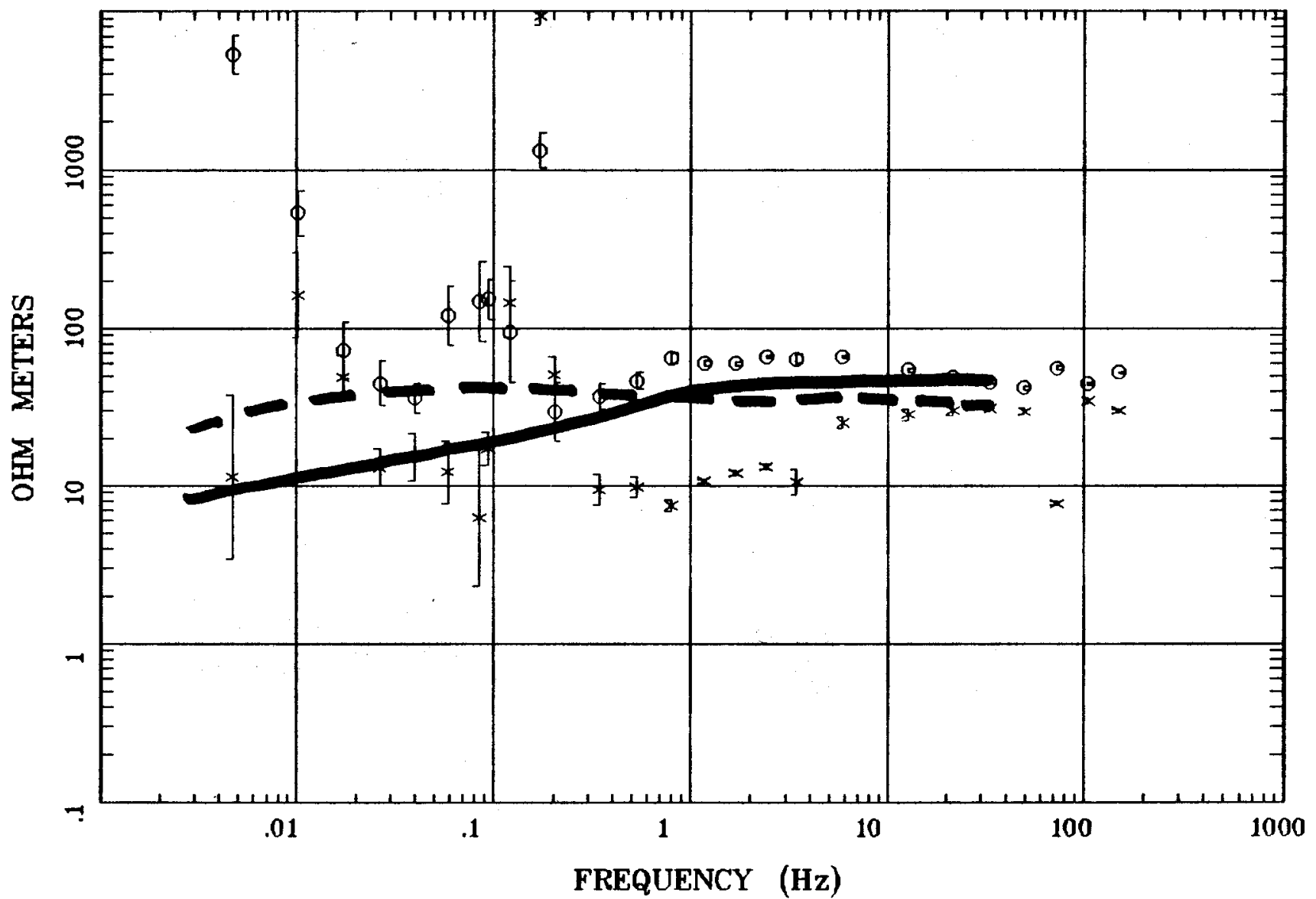

Client:

\section{Remote:}

Acquired:

Survey Co:
Ratation:

Filename: CT10

Channels: Ch1 Ch2 Ch3 Ch4 Ch5 Ch6 Ch7

Plotted: 08:12 Sep 17, 1998

< EMI - ElectroMagnetic Instruments > 


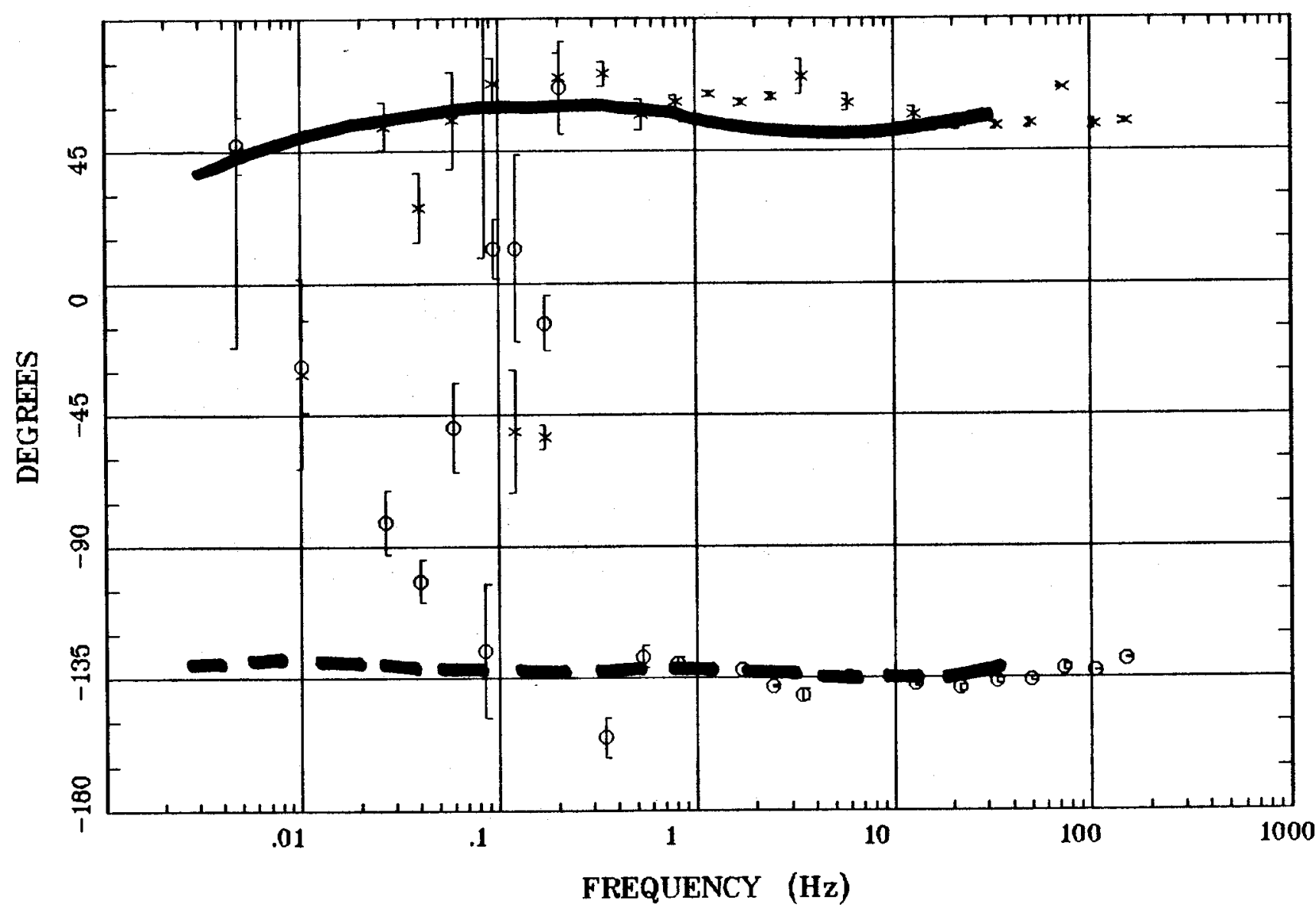

Client:

Remote:

Acquired:

Survey Co:
Rotation:

Filename: CT10

Channels: Ch1 Ch2 Ch3 Ch4 Ch5 Ch6 Ch7

Plotted: 08:12 Sep 17, 1998

< EMI - ElectroMagnetic Instruments > 


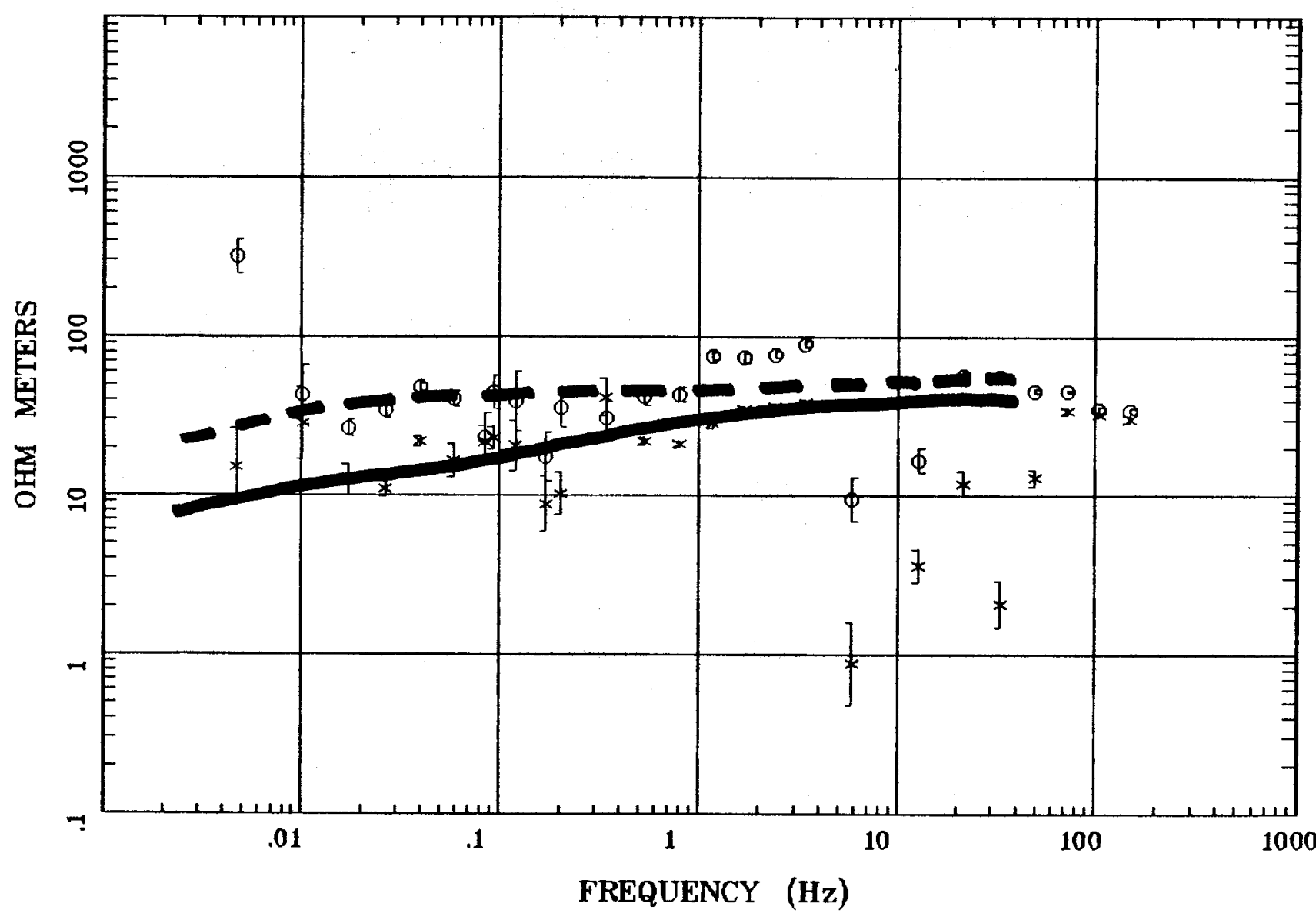

Client:

Remote:

Acquired:

Survey Co:
Rotation:

Filename: CTO9A

Channels: Ch1 Ch2 Ch3 Ch4 Ch5 Ch6 Ch7

Plotted: 08:25 Sep 17, 1998

< EMI - ElectroMagnetic Instruments 


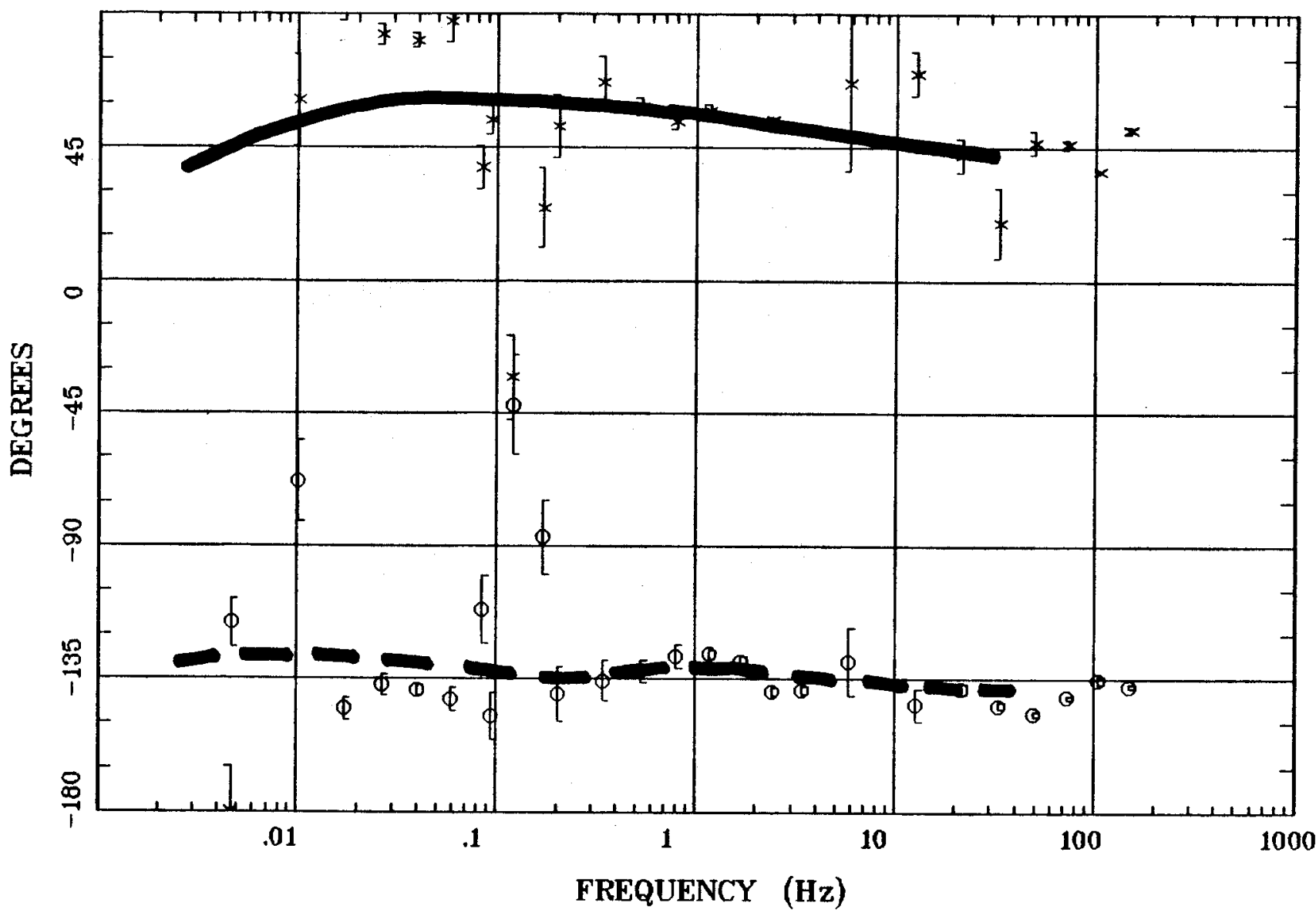

Client:

Remote:

Acquired:

Survey Co:

\section{Rotation:}

Filename: CTO9A

Channels: Ch1 Ch2 Ch3 Ch4 Ch5 Ch6 Ch7

Plotted: 08:25 Sep 17, 1998

< EMI - ElectroMagnetic Instruments 
APPARENT RESISTIVITY

Carlin, Nevada

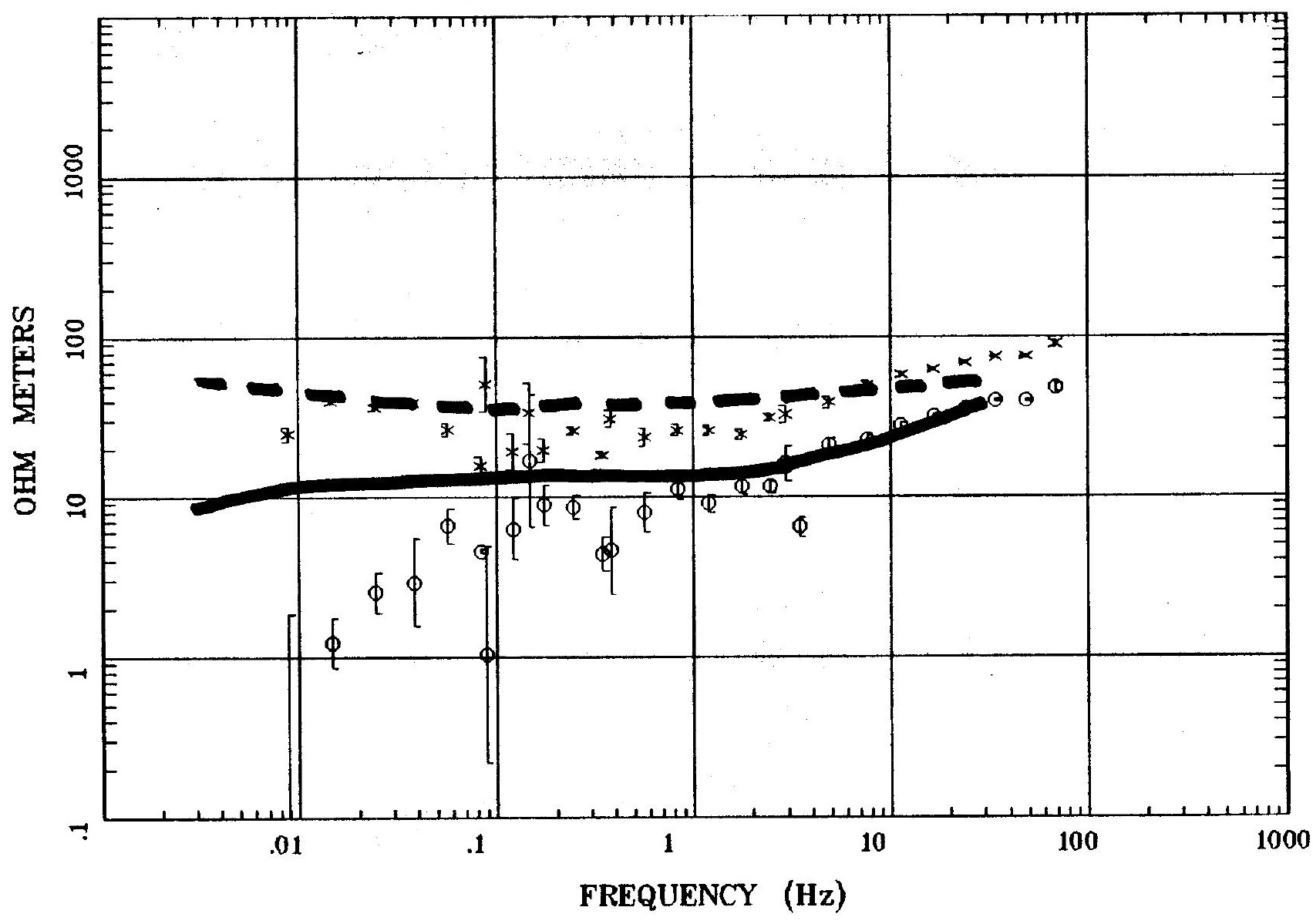

Client:

Remate: local

Acquired: 13:4 Jul 26. 1999 Survey Co:USGS
Rotation:

Filename: ct01.avg

Channels: Ch1 Ch2 Ch3 Ch4 Ch5 Ch8 Ch9

Plotted: 15:42 Jan 24, 2001

< EMI - ElectroMagnetic Instruments > 


\section{IMPEDANCE PHLASE}

Carlin, Nevada

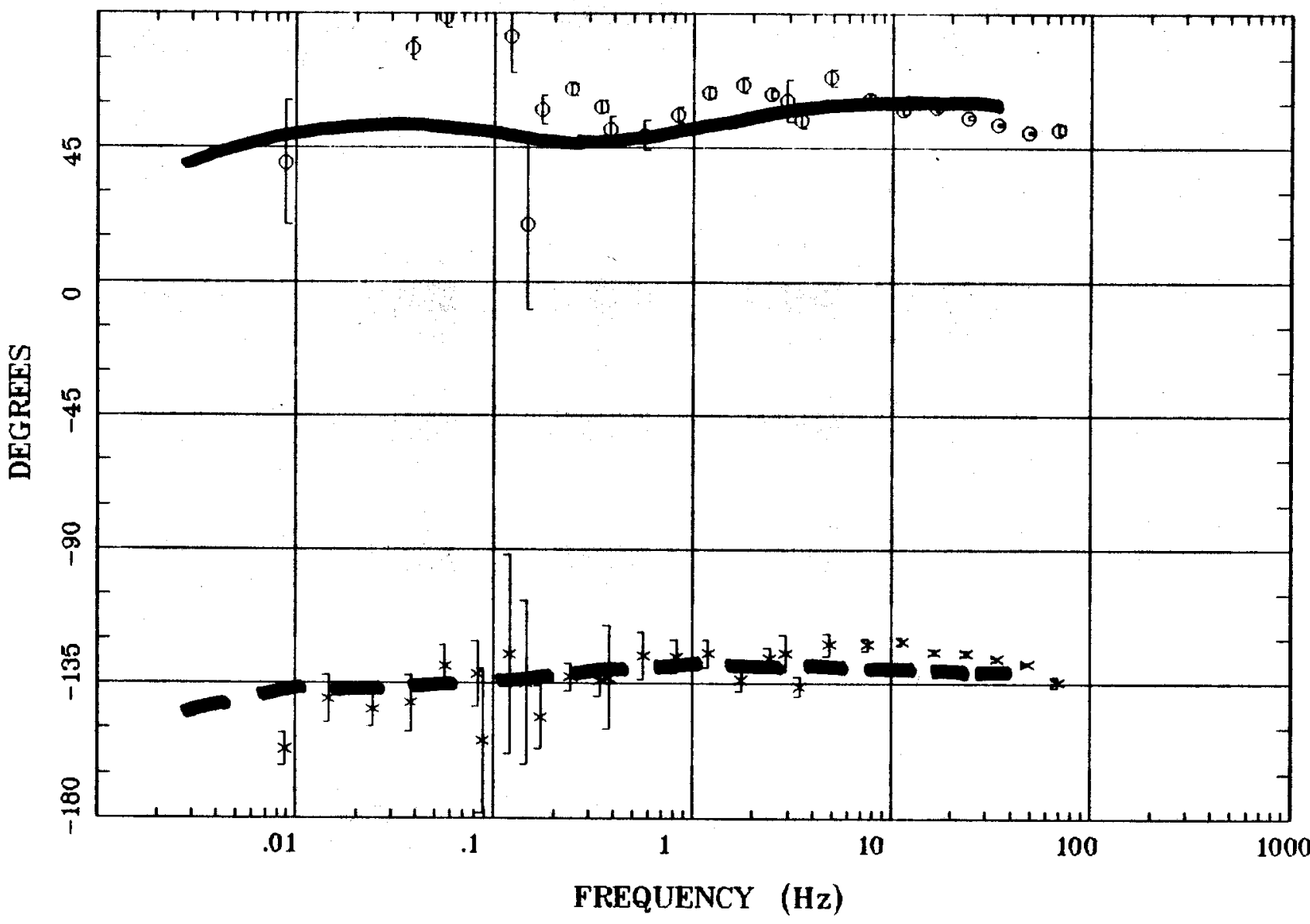

Client:

Remote: local

Acquired: 13:4 Jul 26, 1999

Survey co:USGS
Rotation:

Filename: ct01.avg

Channels: Ch1 Ch2 Ch3 Ch4 Ch5 Ch8 Ch9

Plotted: 15:42 Jan 24, 2001

< EMI - ElectroMagnetic Instruments > 


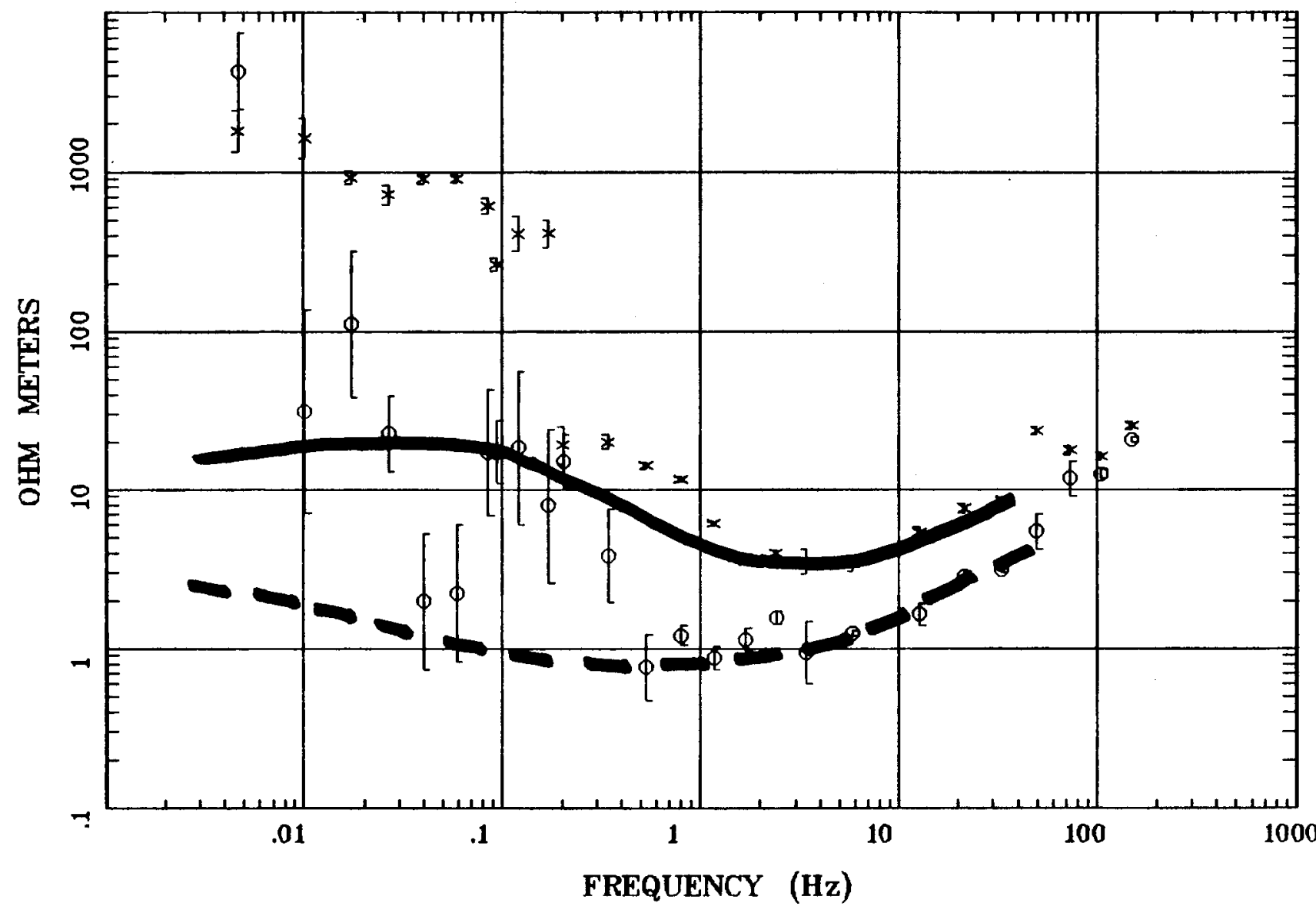

Client:

Remote: Acquired: Survey Co:
Rotation:

Filename: CT02A

Channels: Ch1 Ch2 Ch3 Ch4 Ch5 Ch6 Ch7 Plotted: 08:43 Sep 17, 1998

< EMI - ElectroMagnetic Instruments > 


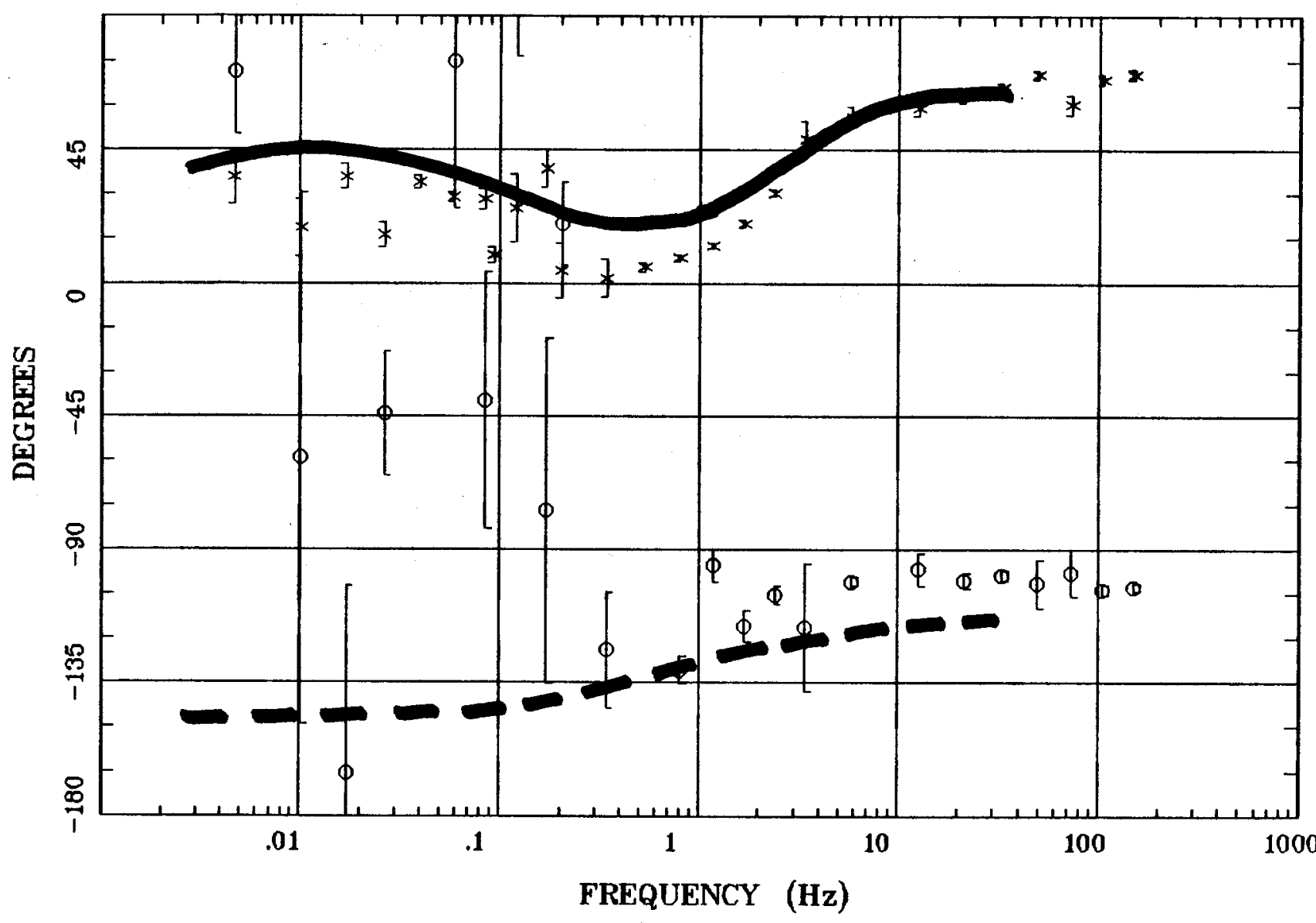

Client:

Remote:

Acquired:

Survey Co:
Rotation:

Filename: CT02A

Channels: Ch1 Ch2 Ch3 Ch4 Ch5 Ch6 Ch7

Plotted: 08:43 Sep 17, 1998

< EMI - ElectroMagnetic Instruments > 


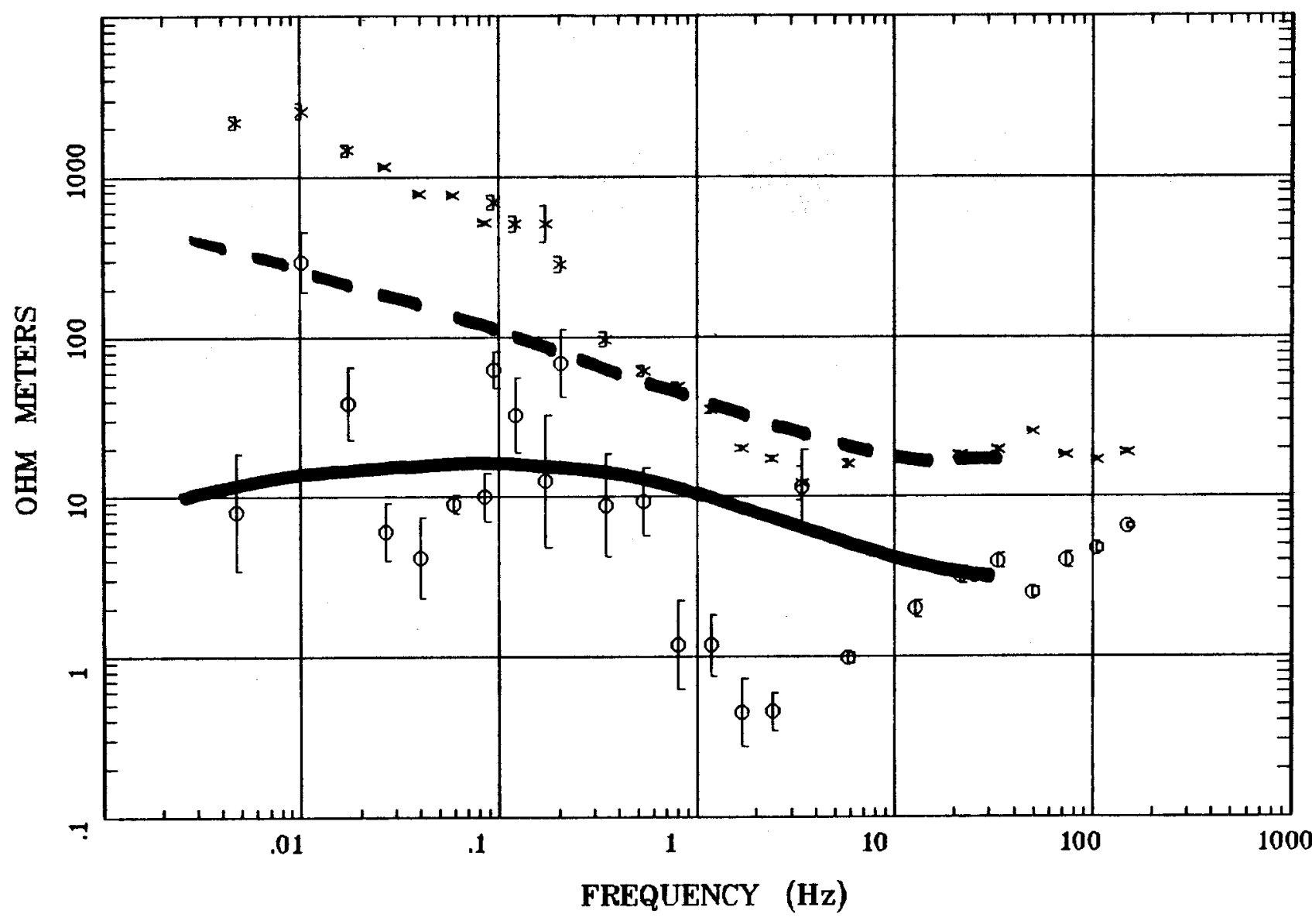

Client:

Remote:

Acquired:

Survey Co:
Rotation:

Filename: CTO3C

Channels: Ch1 Ch2 Ch3 Ch4 Ch5 Ch6 Ch7

Plotted: 08:45 Sep 17, 1998

< EMI - ElectroMagnetic Instruments > 


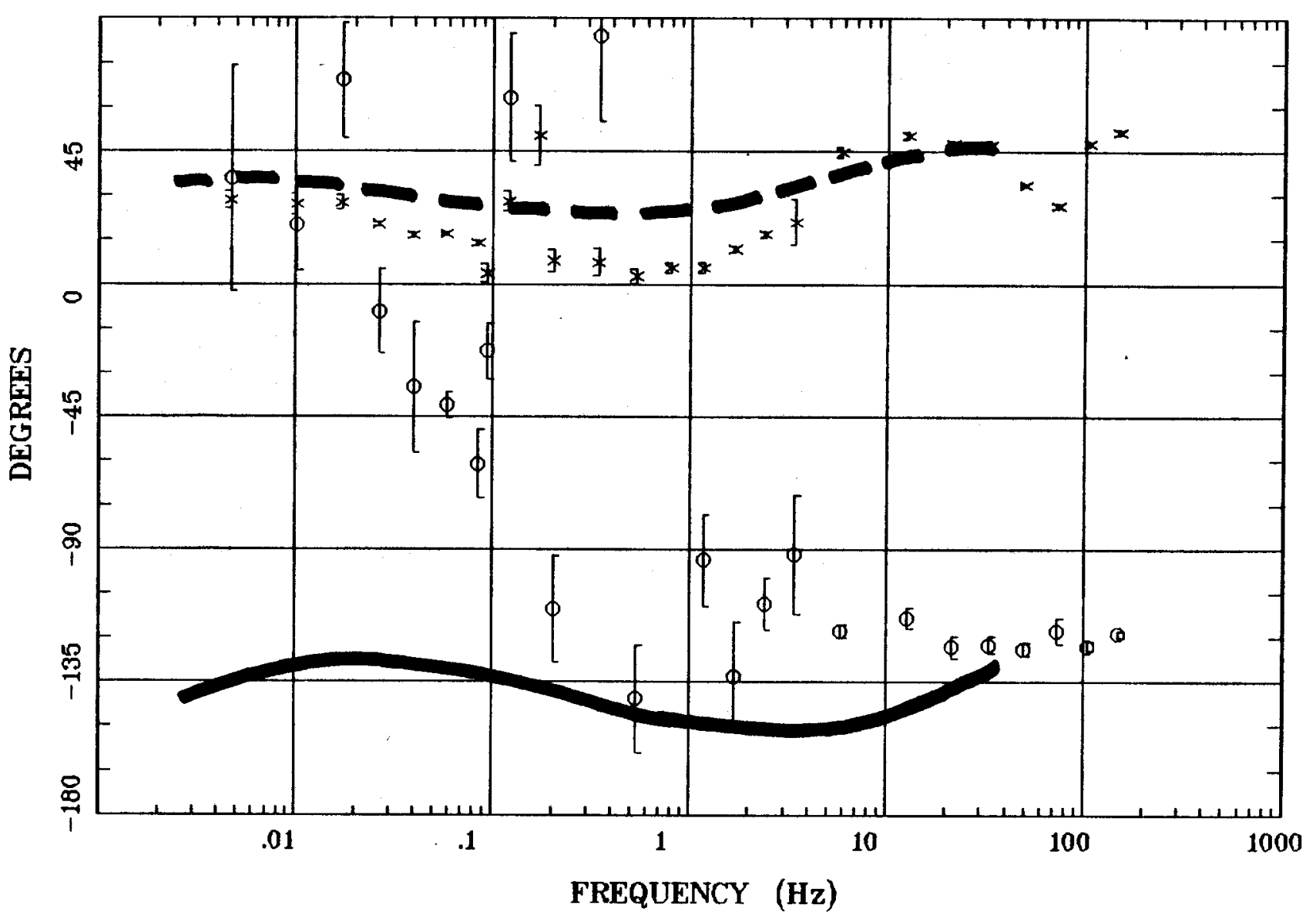

Client:

Remote:

Acquired:

Survey Co:
Rotation:

Filename: CT03C

Channels: Ch1 Ch2 Ch3 Ch4 Ch5 Che Ch7

Plotted: 08:45 Sep 17, 1998

< EMI - ElectroMagnetic Instruments 


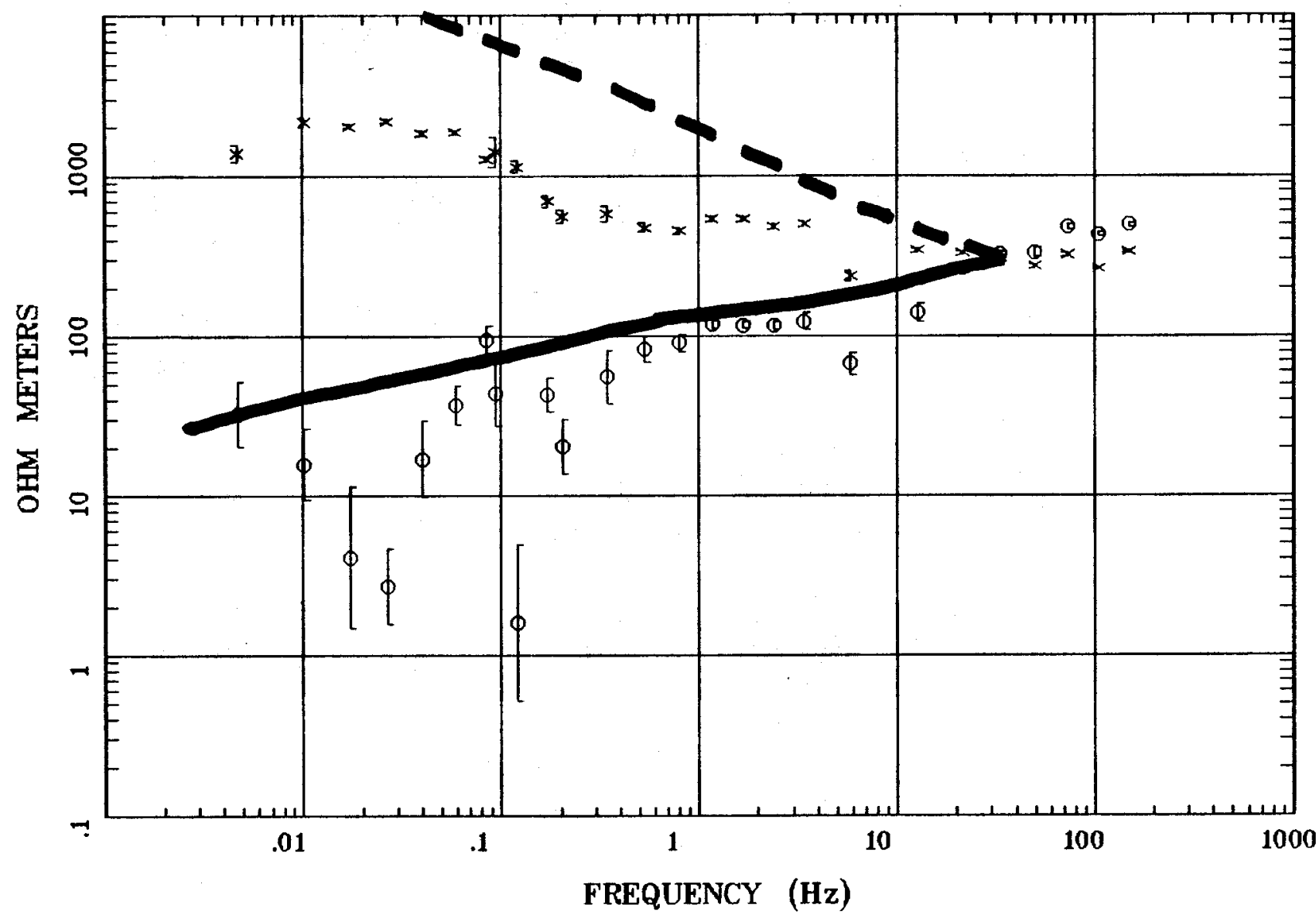

Client:

Remote:

Acquired:

Survey Co:
Rotation:

Filename: CT04A

Channels: Ch1 Ch2 Ch3 Ch4 Ch5 Ch6 Ch7

Plotted: 08:46 Sep 17, 1998

< EMI - ElectroMagnetic Instruments 


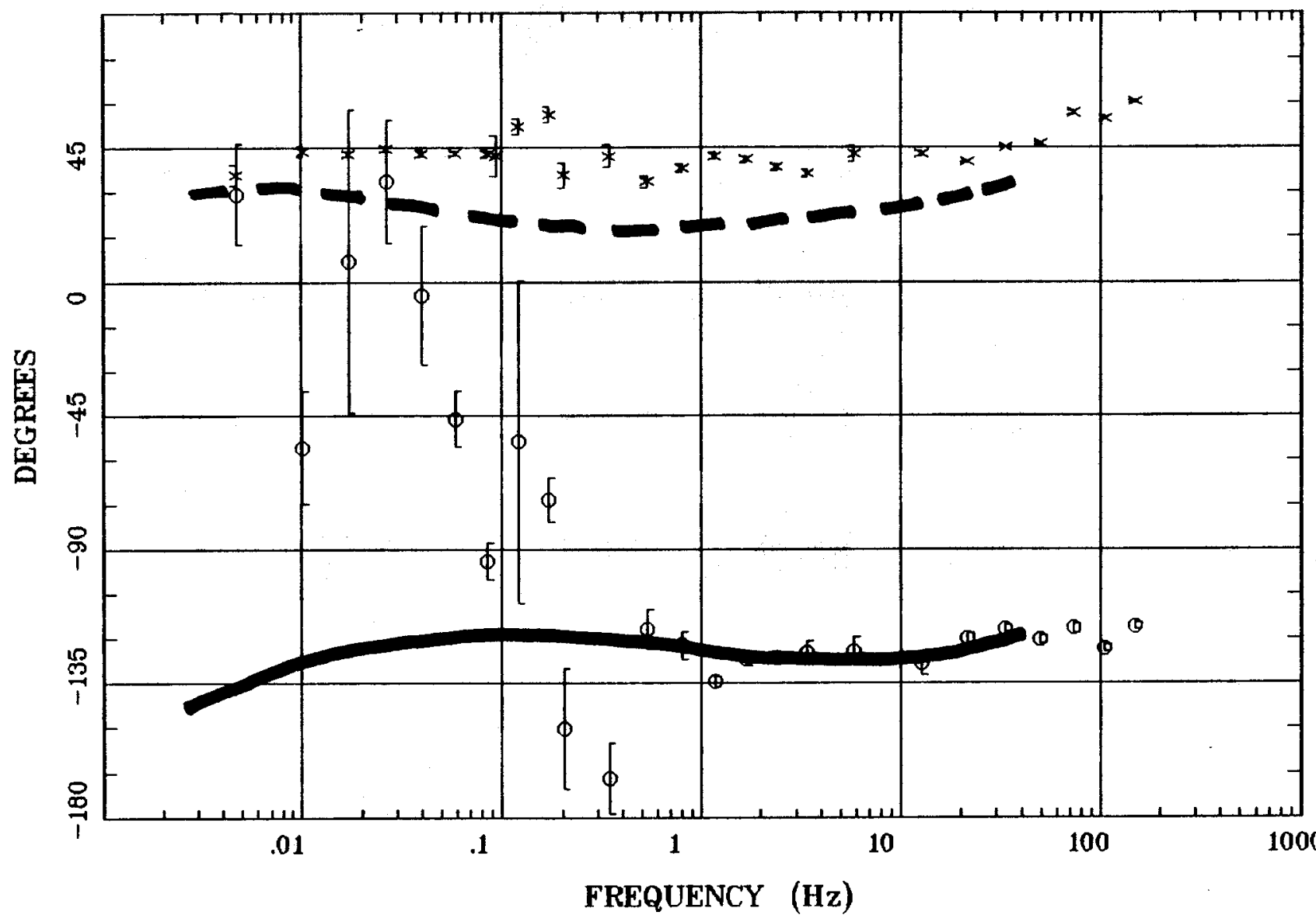

Client:

Remote:

Acquired:

Survey Co:
Rotation:

Filename: CT04A

Channels: Ch1 Ch2 Ch3 Ch4 Ch5 Ch6 Ch7

Plotted: 08:46 Sep 17, 1998

$<$ EMI - ElectroMagnetic Instruments 


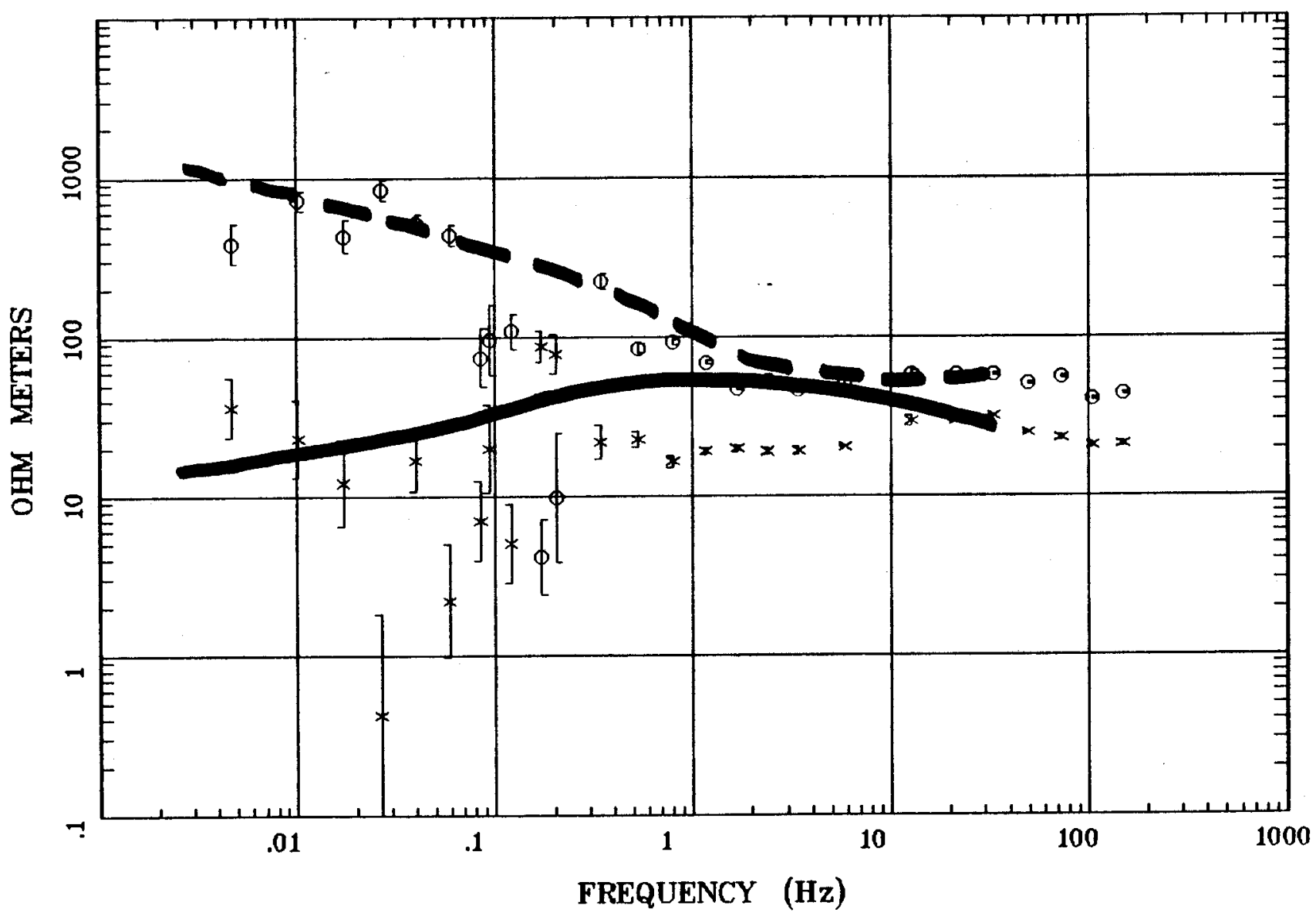

Client:

Remote:

Acquired:

Filename: CT05

Channels: Ch1 Ch2 Ch3 Ch4 Ch5 Ch6 Chy

Plotted: 08:48 Sep 17, 1998

Survey Co:

< EMI - ElectroMagnetic Instruments > 


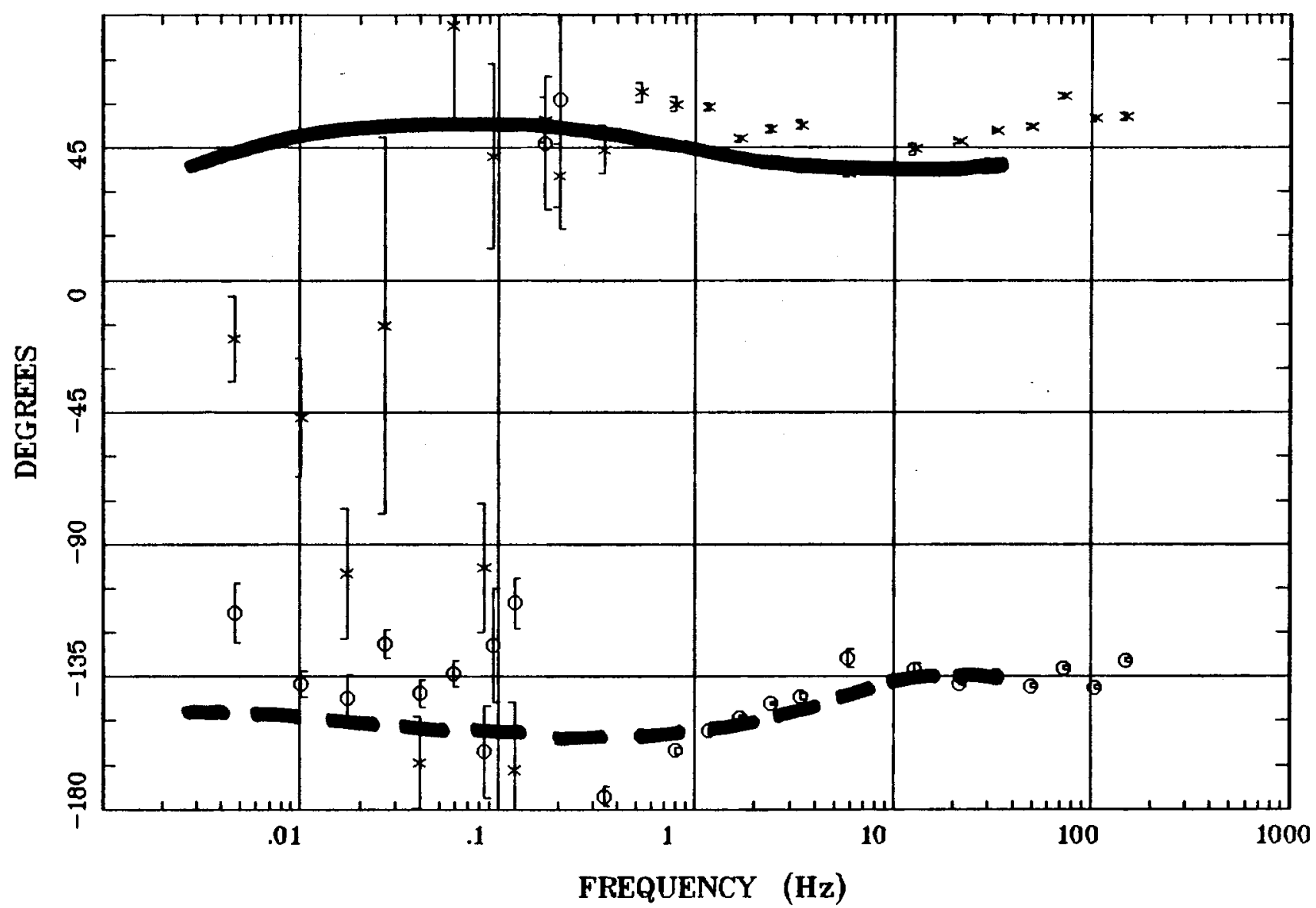

Client:

Rotation:

Filename: CT05

Remote:

Acquired:

Survey Co:
Channels: Ch1 Ch2 Ch3 Ch4 Ch5 Ch8 Ch7

Plotted: 08:48 Sep 17, 1998

< EMI - ElectroMagnetic Instruments > 


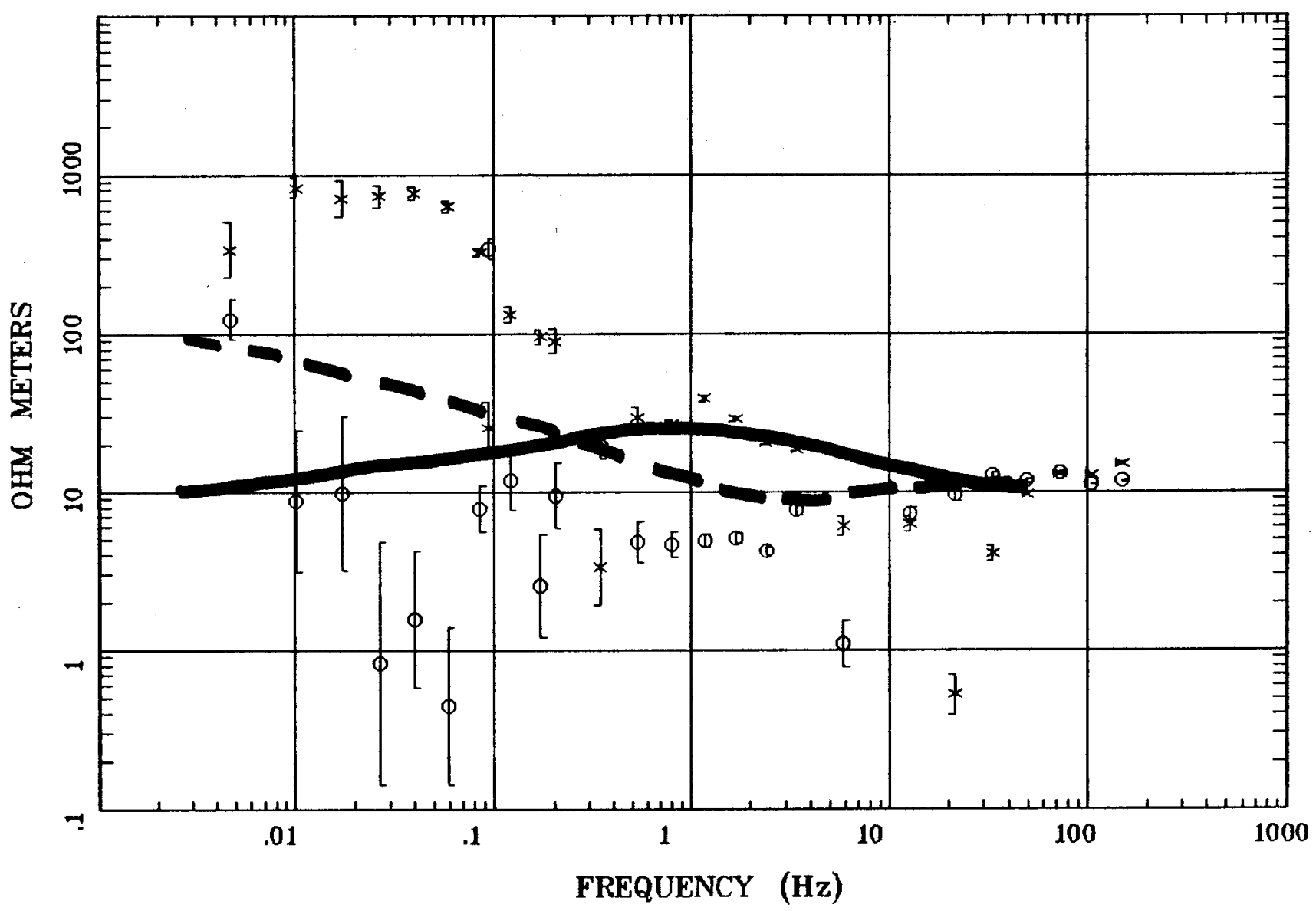

Client:

Remote:

Acquired:

Survey Co:

Ratation:

Filename: CT06B

Channels: Ch1 Ch2 Ch3 Ch4 Ch5 Ch6 Ch7

Plotted: 08:49 Sep 17, 1998

< EMI - ElectroMagnetic Instruments > 


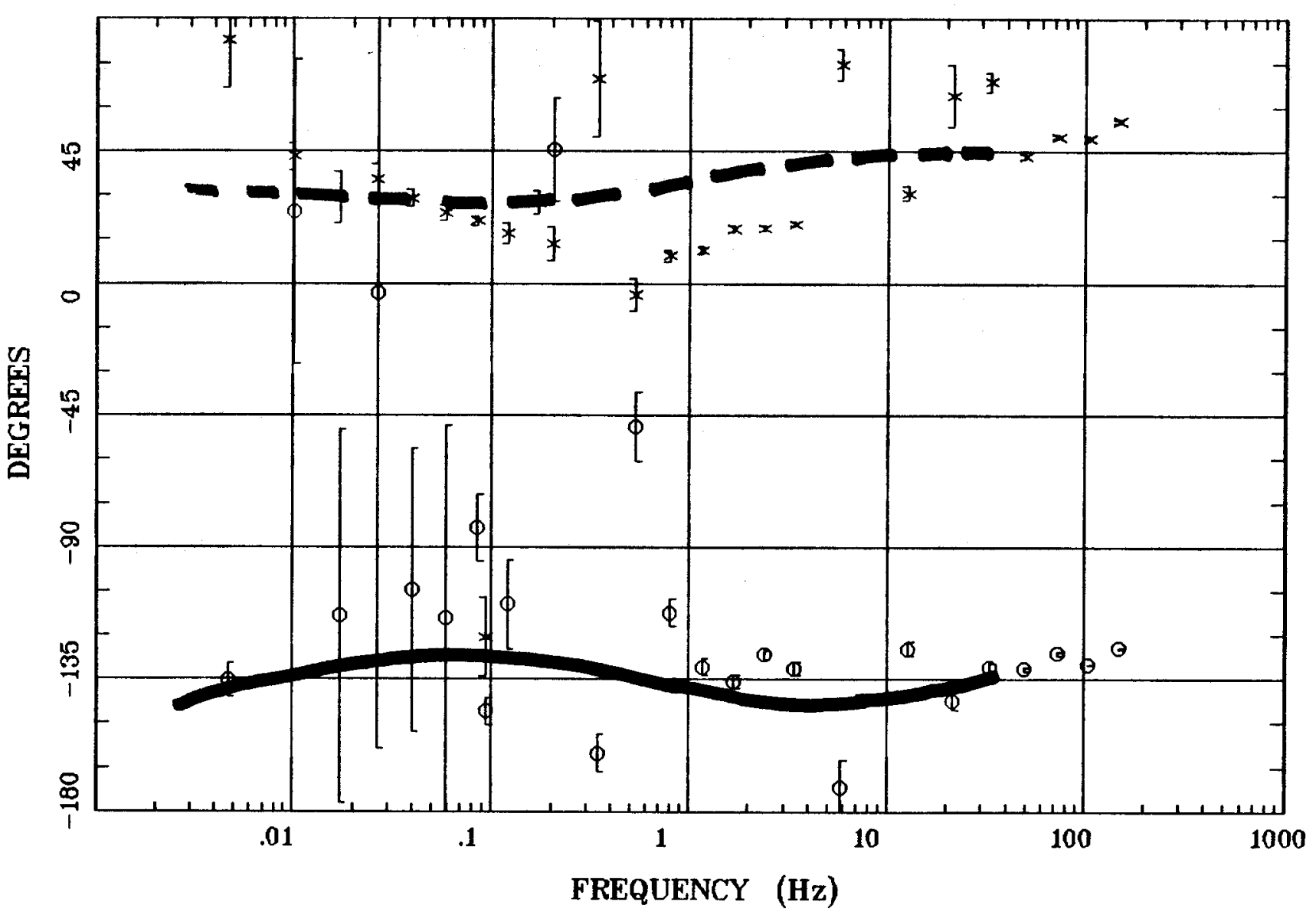

Client:

Remote:

Acquired:

Survey Co:
Rotation:

Filename: CT06B

Channels: Ch1 Ch2 Ch3 Ch4 Ch5 Chr Chy

Plotted: 08:49 Sep 17, 1988

< EMI - ElectroMagnetic Instruments 


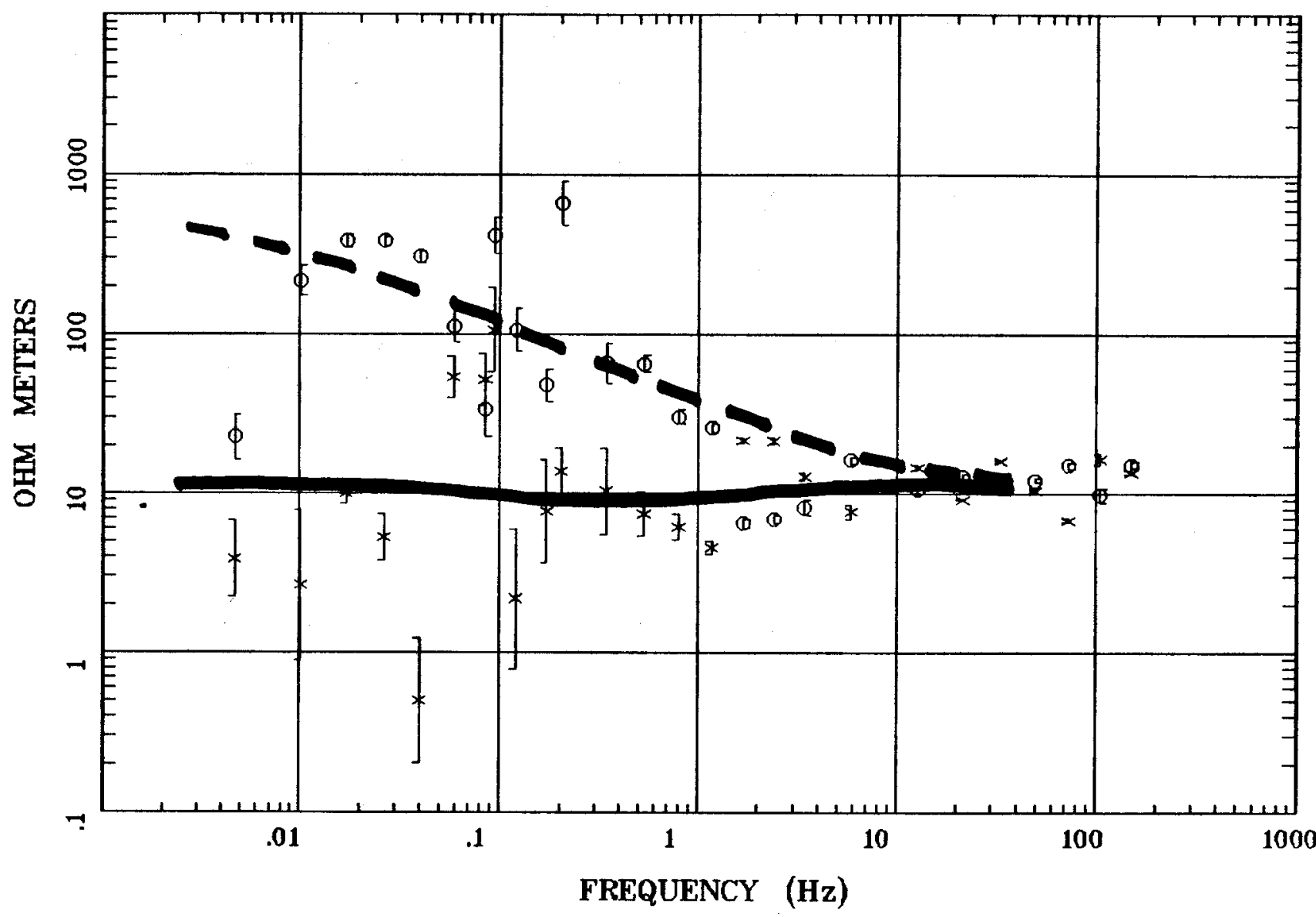

Client:

Remote:

Acquired:

Survey Co:
Rotation:

Filename: CTO7C

Channels: Ch1 Ch2 Ch3 Ch4 Ch5 Chr Ch7 Plotted: 08:50 Sep 17, 1998

< EMI - ElectroMagnetic Instruments > 


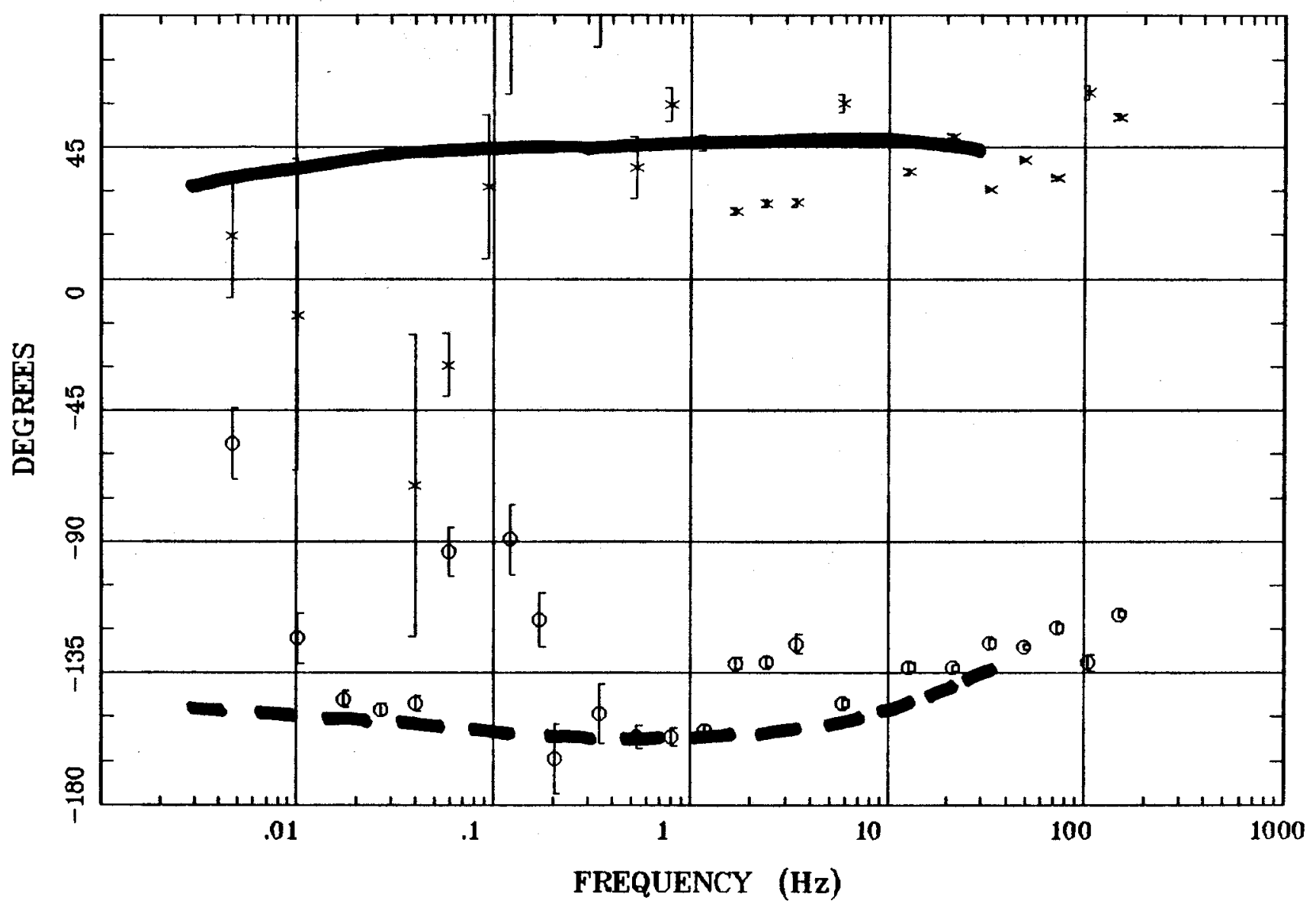

Client:

Remote:

Acquired:

Survey Co:
Rotation:

Filename: CT07C

Channels: Ch1 Ch2 Ch3 Ch4 Ch5 Chr Ch7 Plotted: 08:50 Sep 17, 1998

< EMI - ElectroMagnetic Instruments 


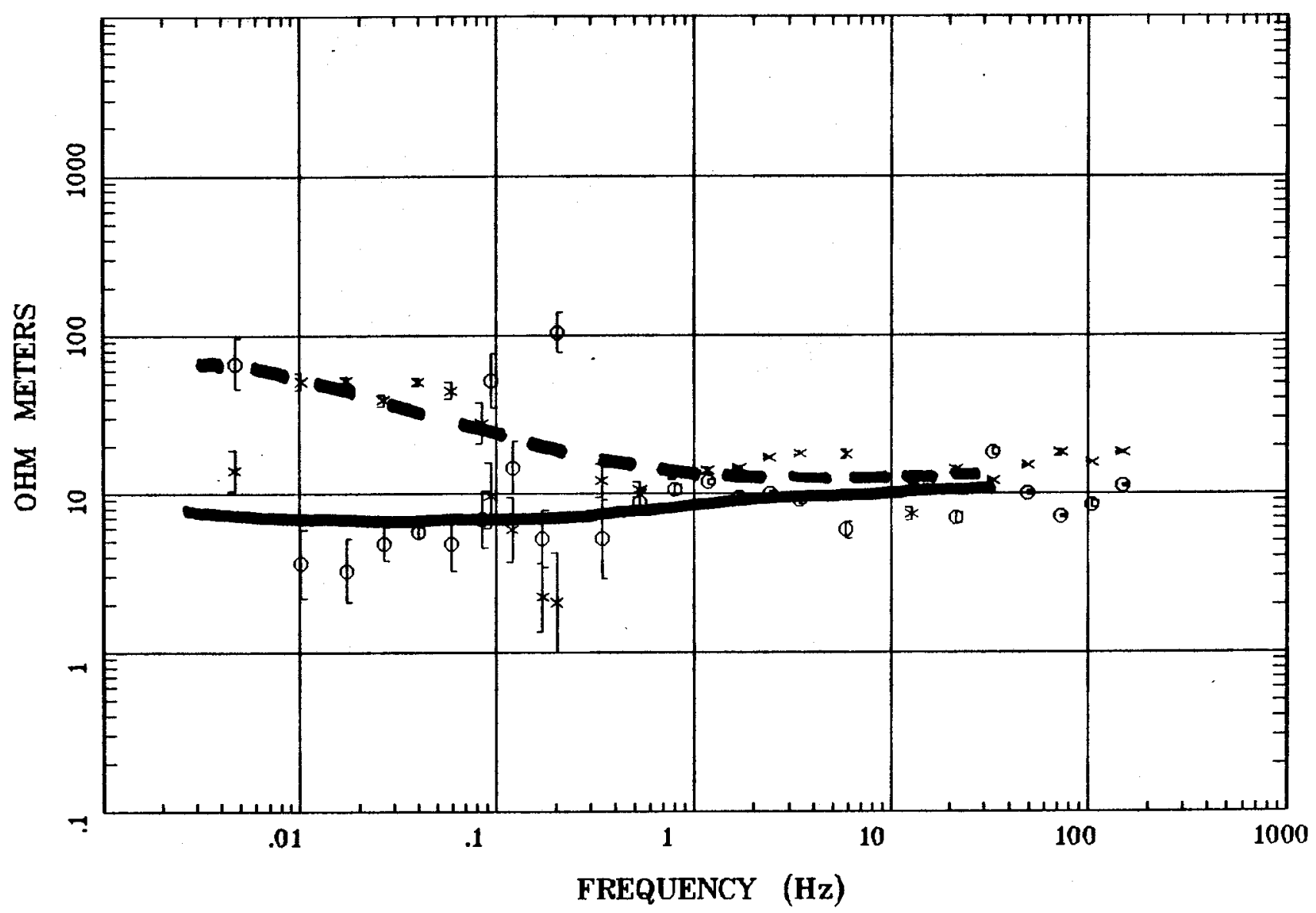

\section{Client:}

\section{Remote:}

Acquired:

Survey Co:
Rotation:

Filename: CT08D

Channels: Ch1 Ch2 Ch3 Ch4 Ch5 Ch6 Ch7 Plotted: 08:52 Sep 17, 1998

< EMI - ElectroMagnetic Instruments > 


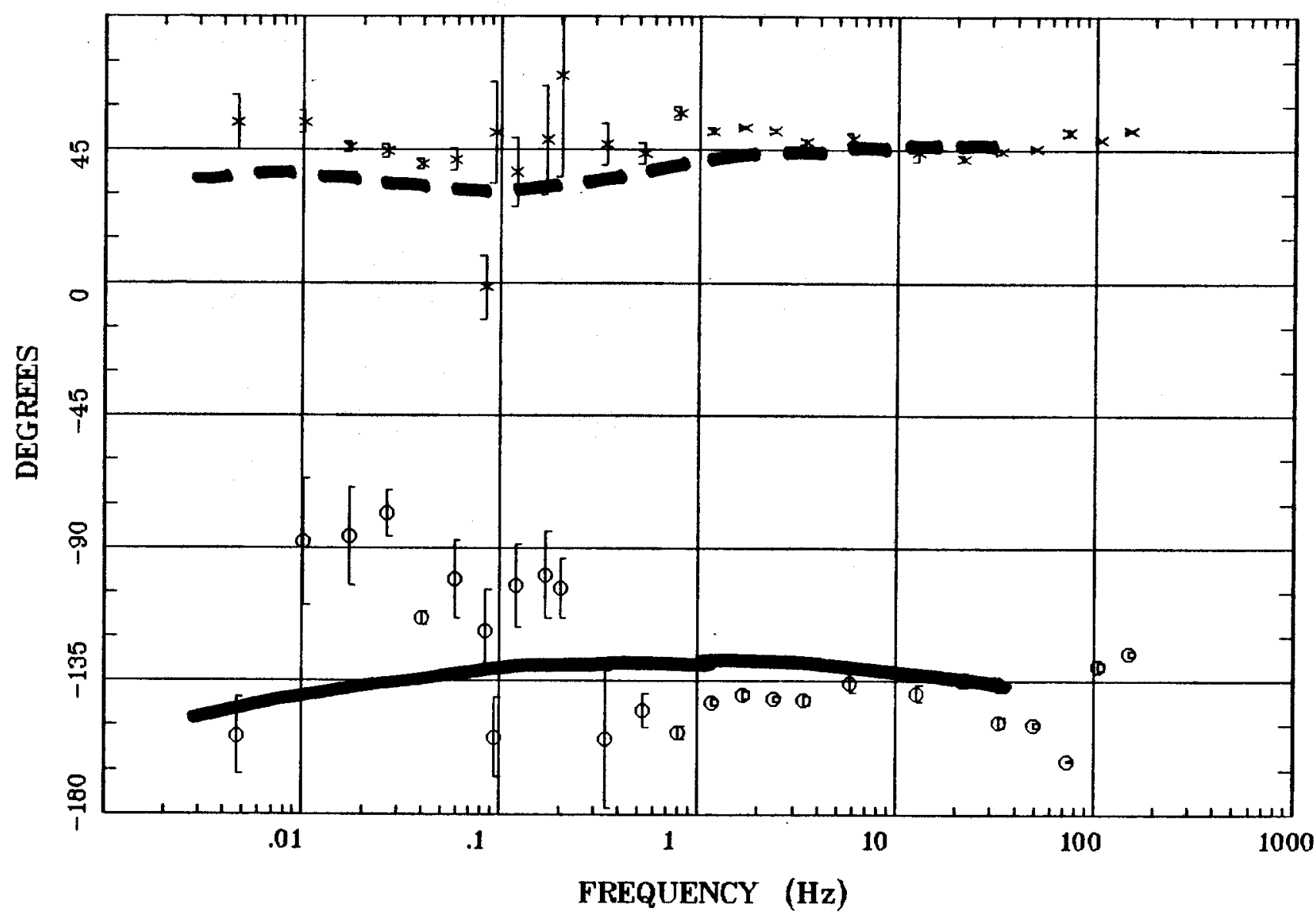

Client:

Remote:

Acquired:

Survey Co:
Rotation:

Filename: CT08D

Channels: Ch1 Ch2 Ch3 Ch4 Ch5 Ch6 Ch7

Plotted: 08:52 Sep 17, 1998

$\langle$ EMI - ElectroMagnetic Instruments > 


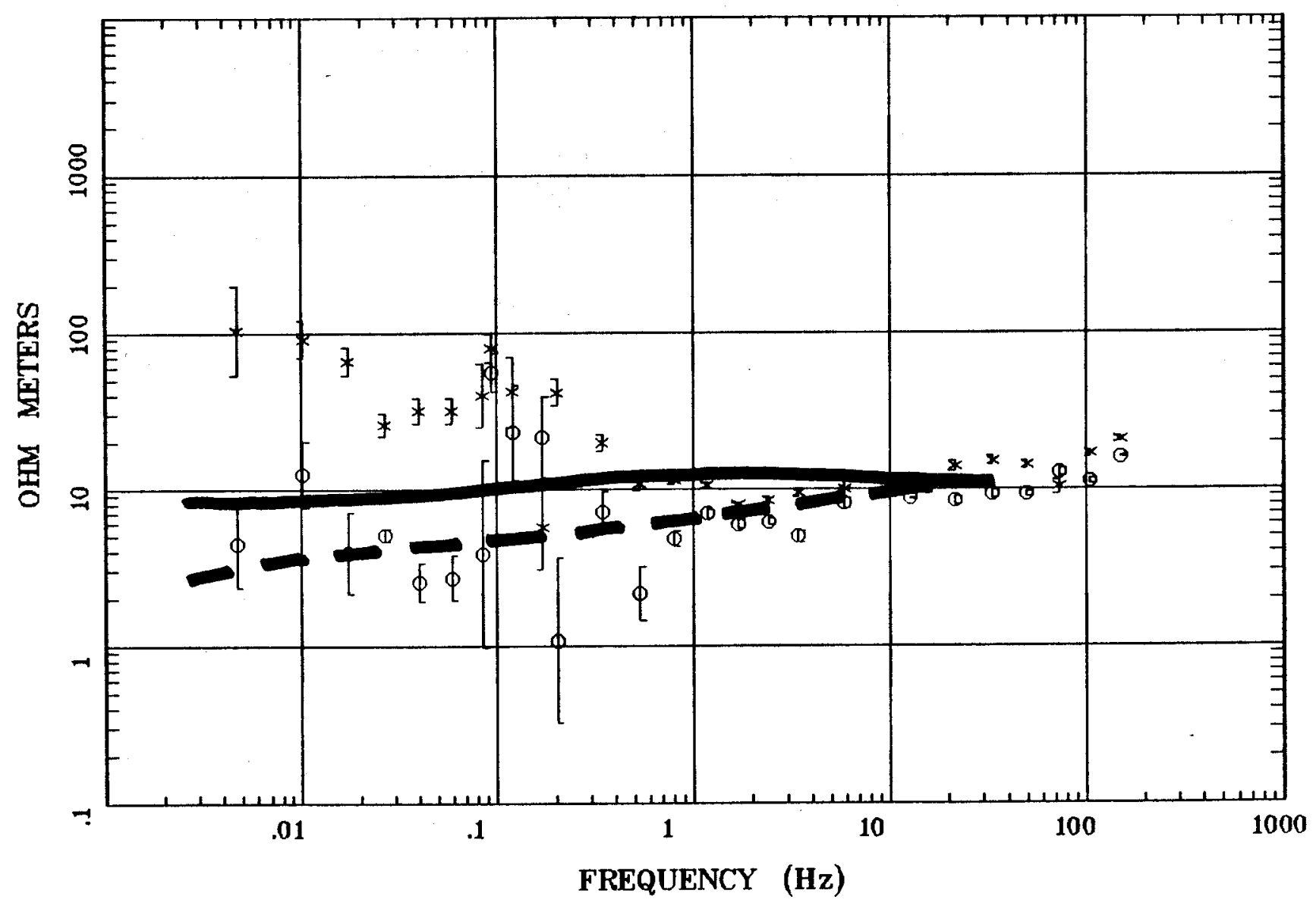

Client:

Remote:

Acquired:

Survey Co:

Rotation:

Filename: CT20C

Channels: Ch1 Ch2 Ch3. Ch4 Ch5 Ch6 Ch7

Plotted: 08:53 Sep 17, 1998

< EMI - ElectroMagnetic Instruments 


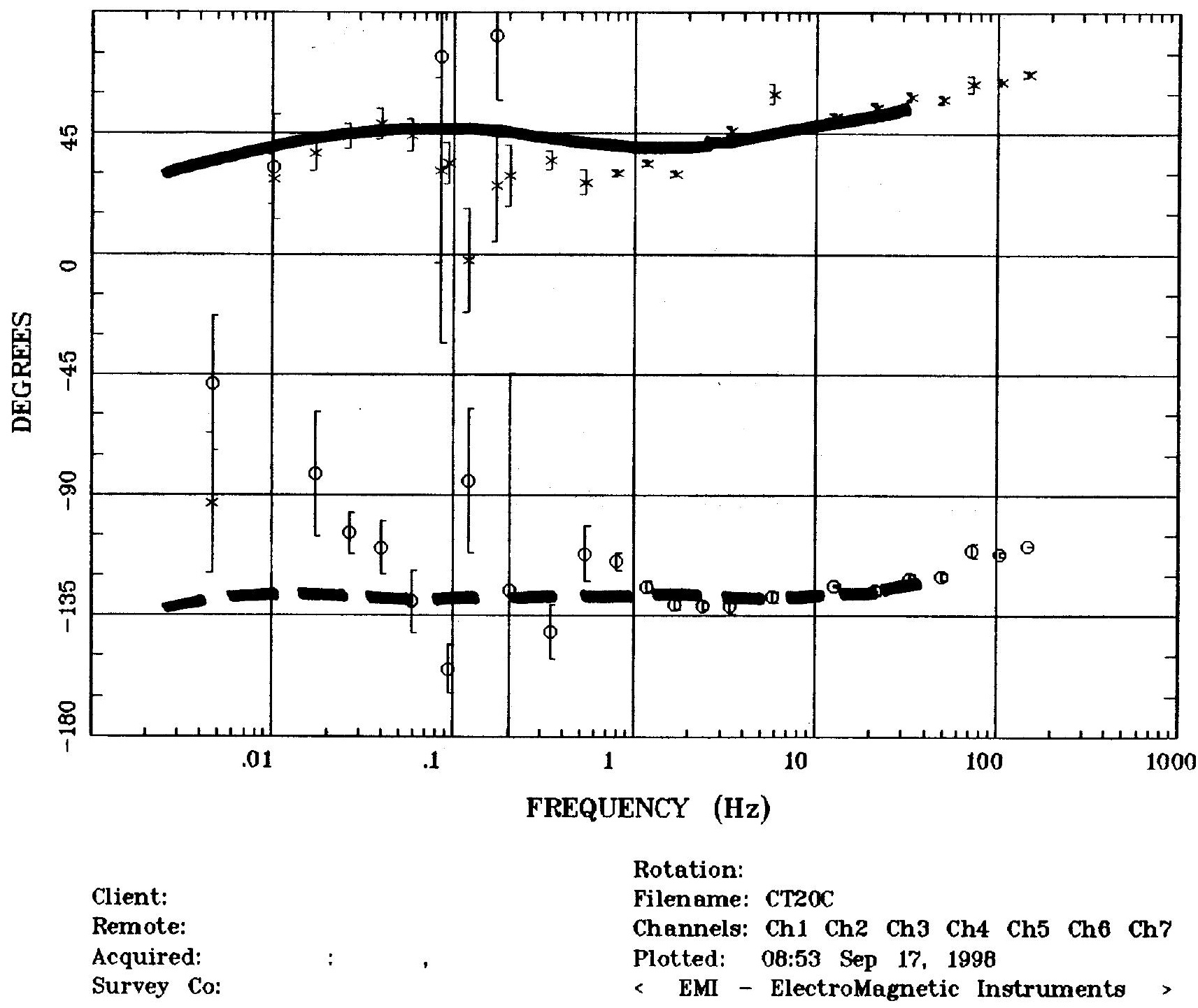




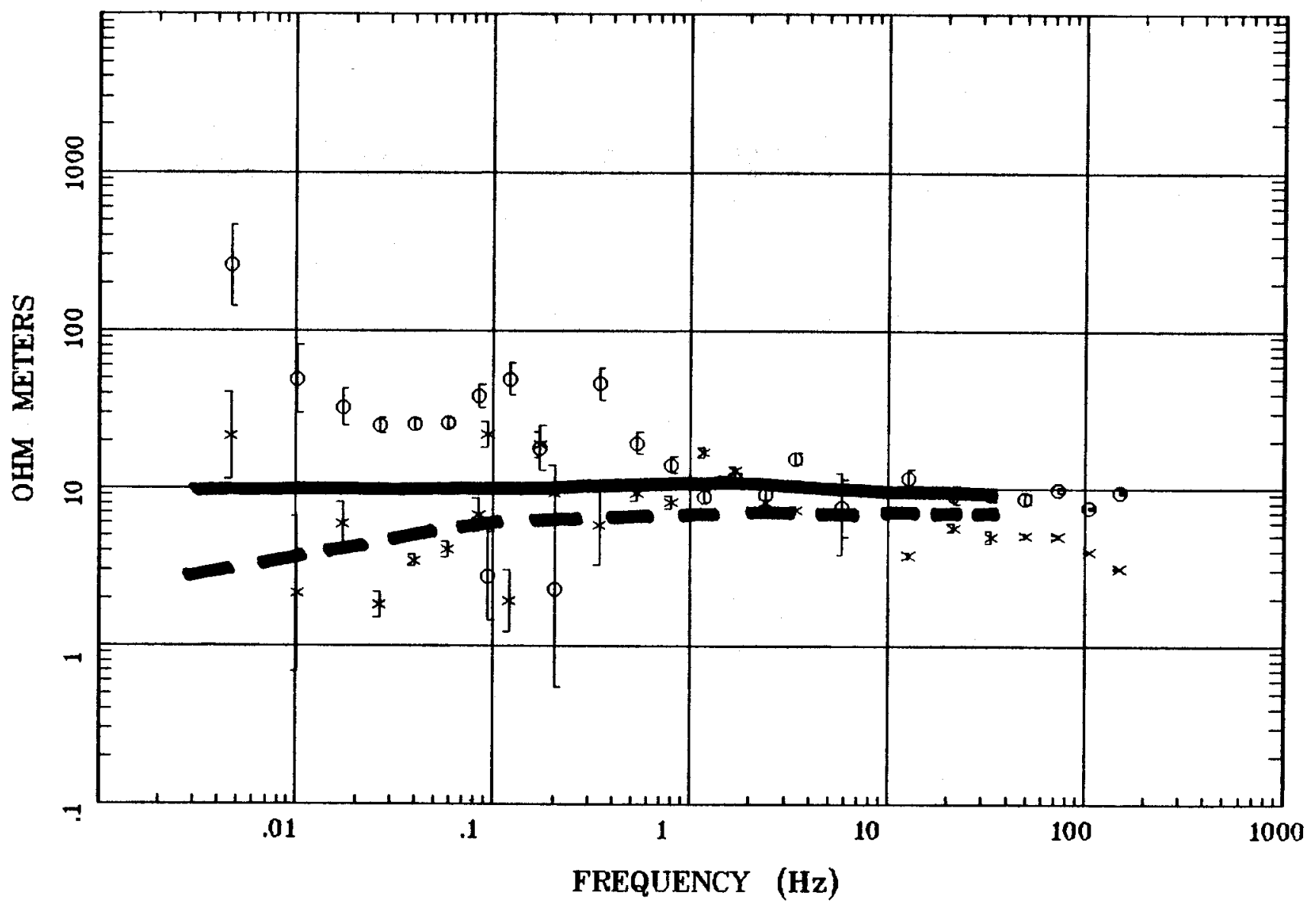

Client:

Remote:

Acquired:

Survey Ca:
Rotation:

Filename: CT21

Channels: Ch1 Ch2 Ch3 Ch4 Ch5 Ch6 Ch7 Plotted: 08:54 Sep 17, 1998

< EMI - ElectroMagnetic Instruments > 


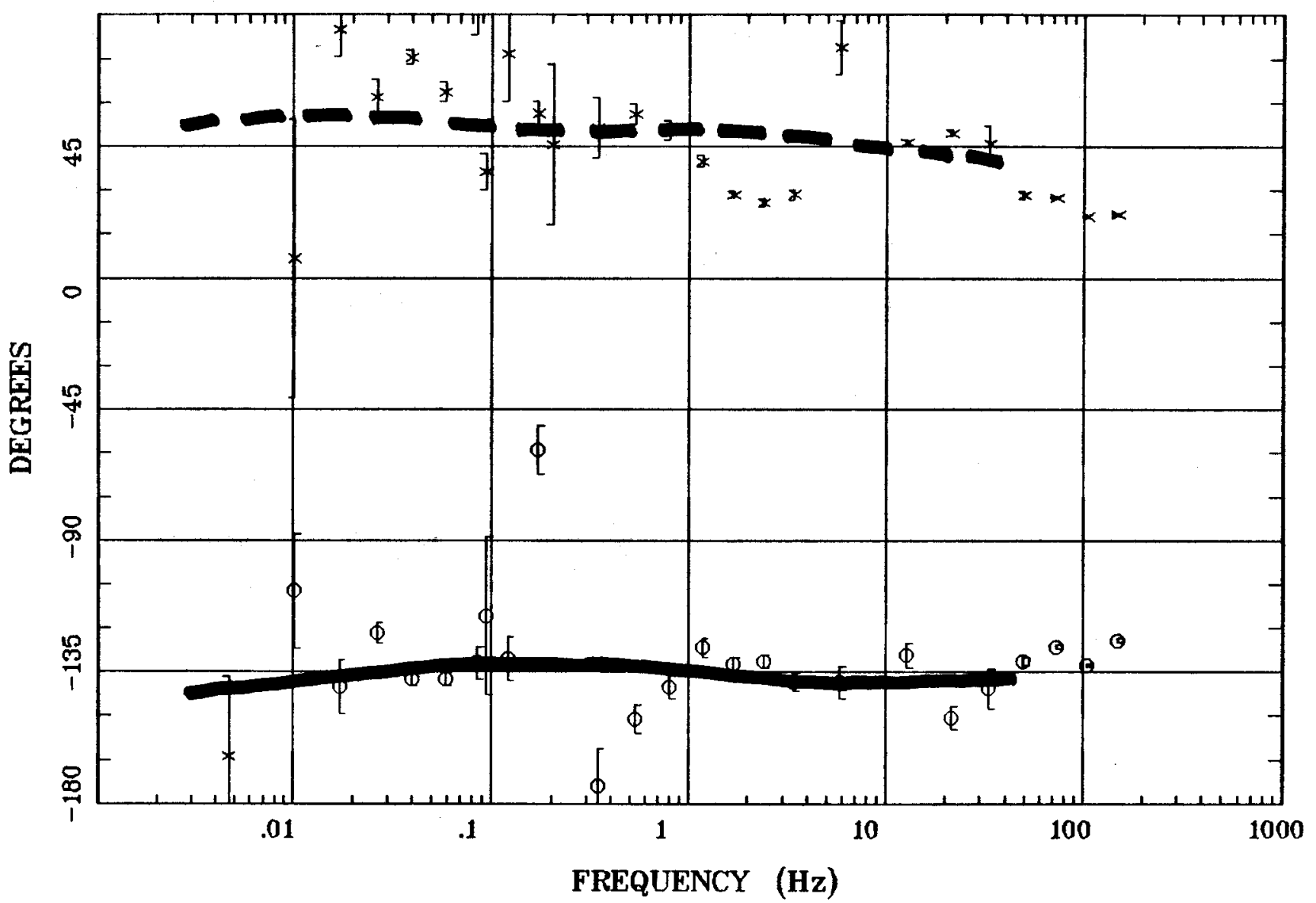

Client:

Remote:

Acquired:

Survey Co:
Rotation:

Filename: CT21

Channels: Ch1 Ch2 Ch3 Ch4 Ch5 Ch6 Ch7

Plotted: 08:54 Sep 17, 1998

< EMI - ElectroMagnetic Instruments 


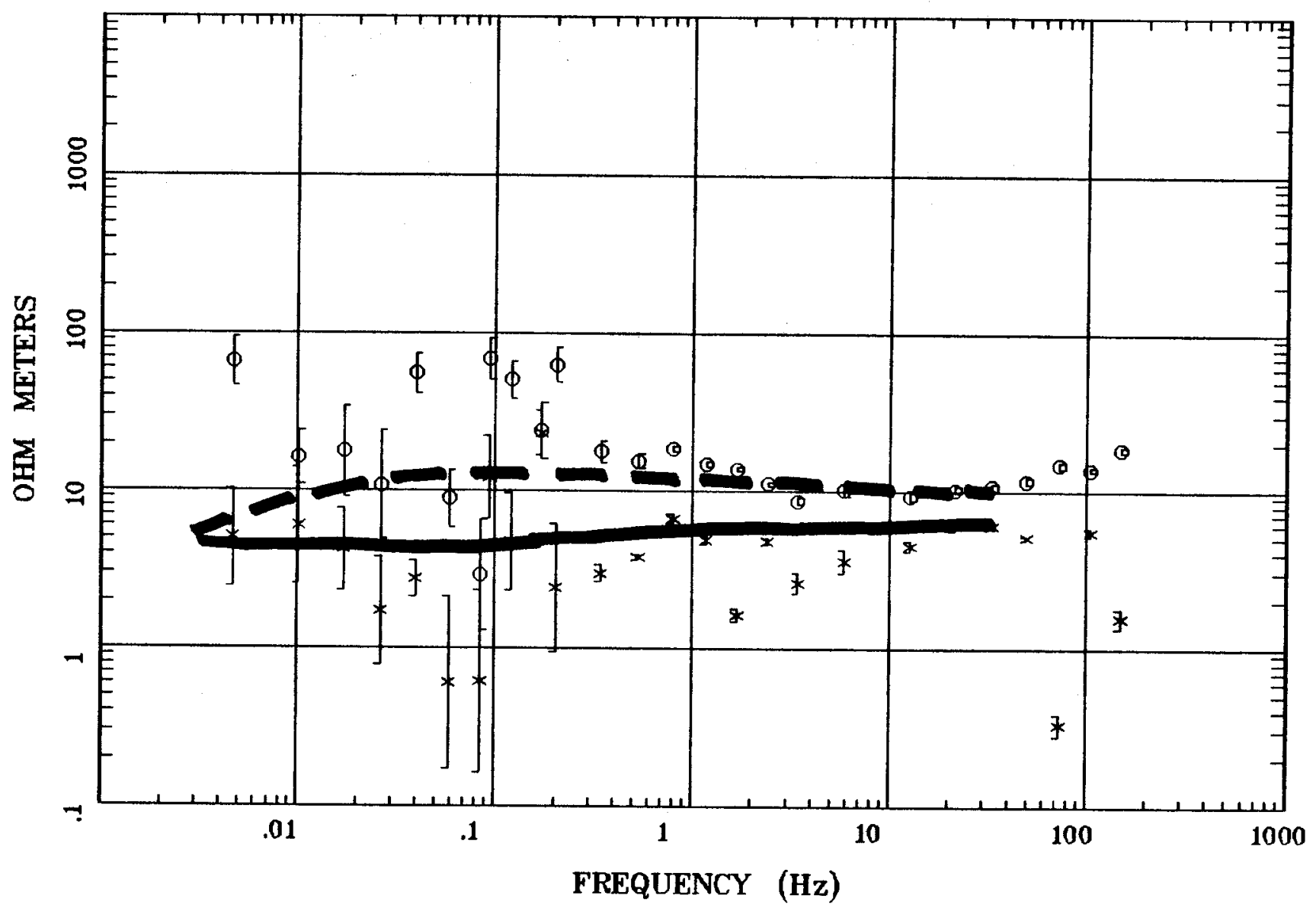

Client:

Remote:

Acquired:

Survey Co:
Rotation:

Filename: CT22A

Channels: Ch1 Ch2 Ch3 Ch4 Ch5 Ch6 Ch7

Plotted: 08:55 Sep 17, 1998

< EMI - ElectroMagnetic Instruments > 
Station 22

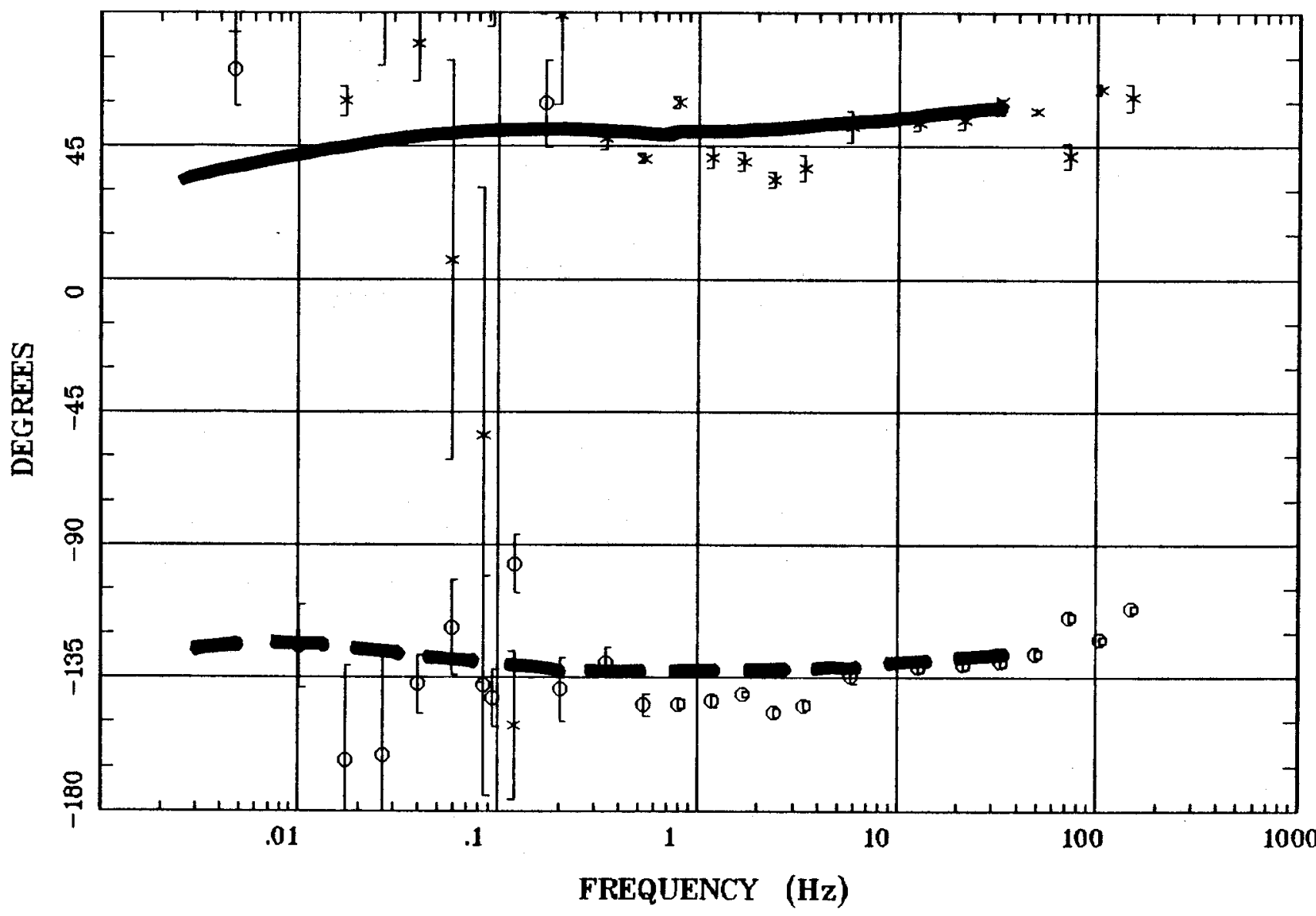

Client:

Remote:

Acquired:

Survey Ca:
Rotation:

Filename: CT22A

Channels: Ch1 Ch2 Ch3 Ch4 Ch5 Ch6 Ch7

Plotted: 08:55 Sep 17, 1998

<EMI - ElectroMagnetic Instruments > 


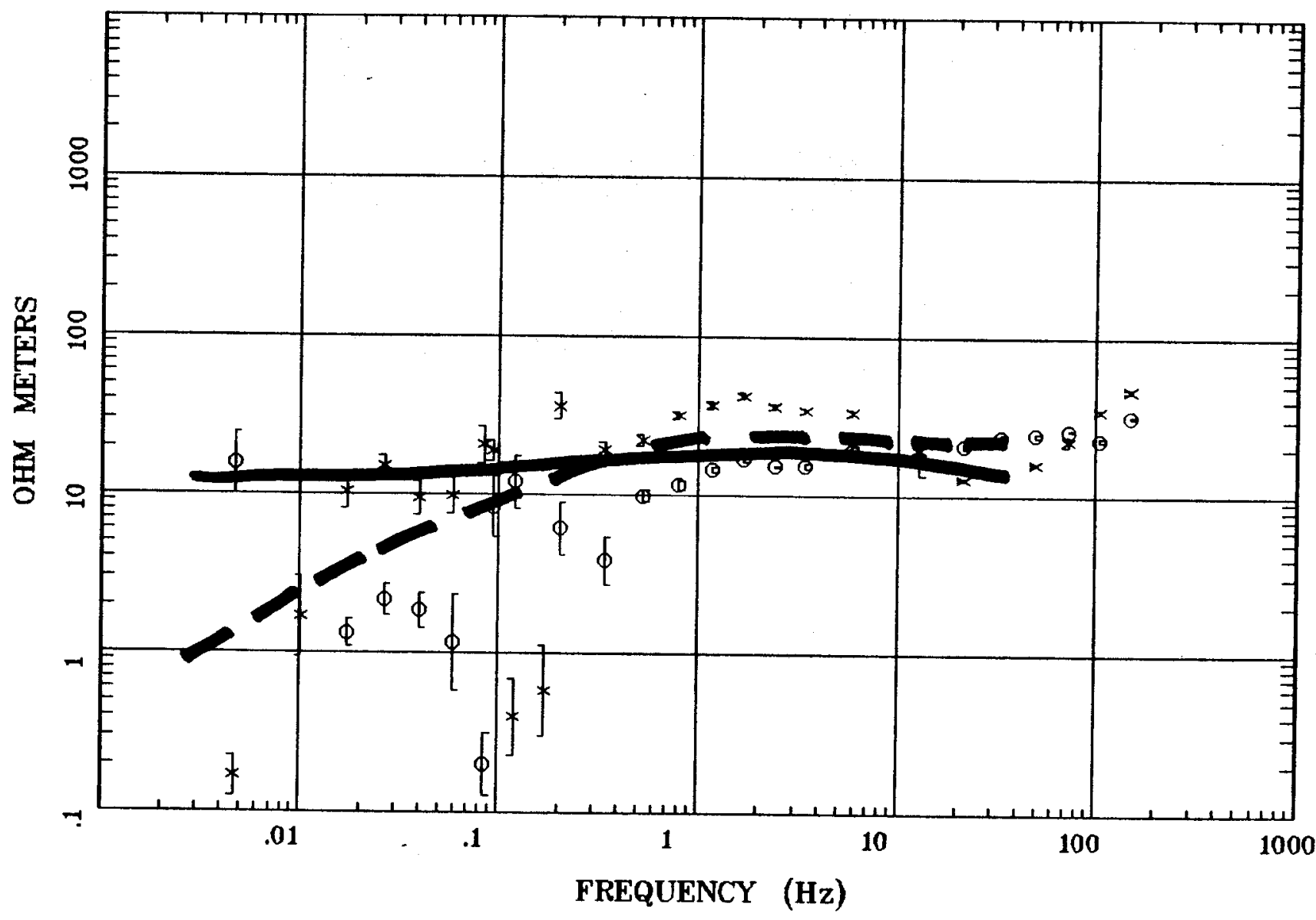

Client:

Remote: Acquired: Survey Ca:
Rotation:

Filename: CT29A

Channels: Ch1 Ch2 Ch3 Ch4 Ch5 Ch6 Ch7 Plotted: 08:57 Sep 17. 1998

< EMI - ElectroMagnetic Instruments > 


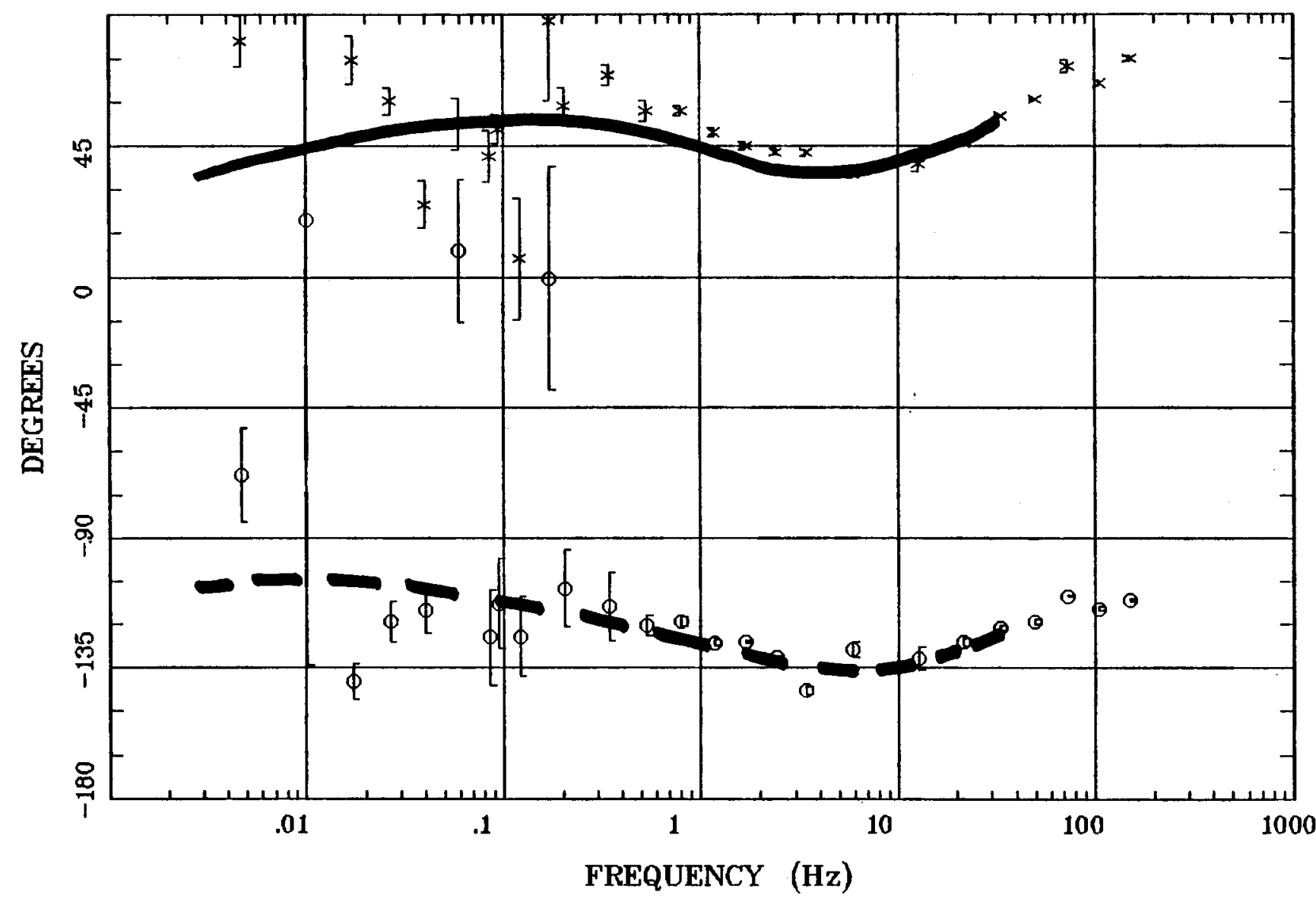

Client:

Remote: Acquired: Survey Co:
Rotation:

Filename: CT29A

Channels: Ch1 Ch2 Ch3 Ch4 Ch5 Ch6 Ch7 Plotted: 06:57 Sep 17, 1998

$<$ EMI - ElectroMagnetic Instruments 


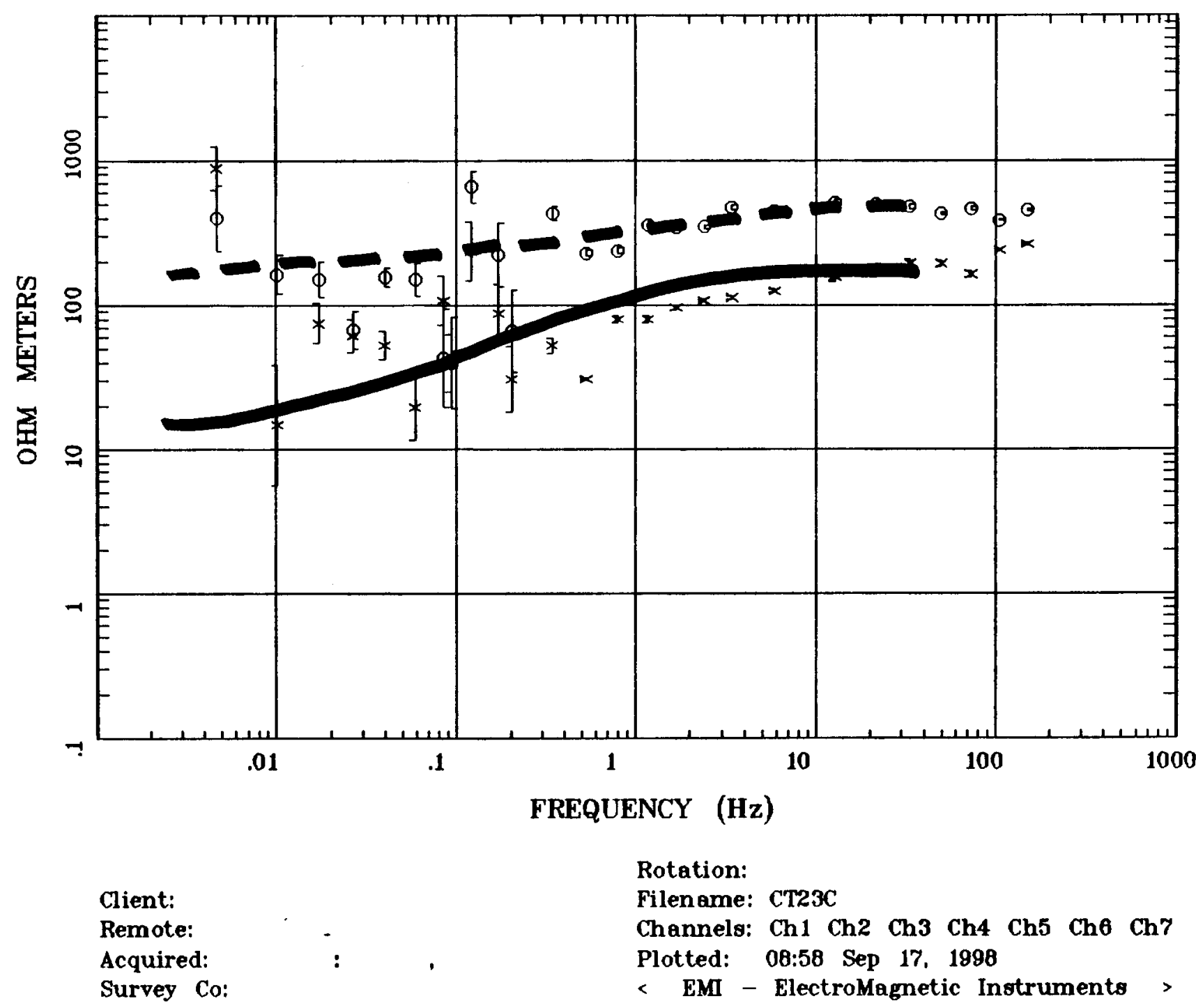




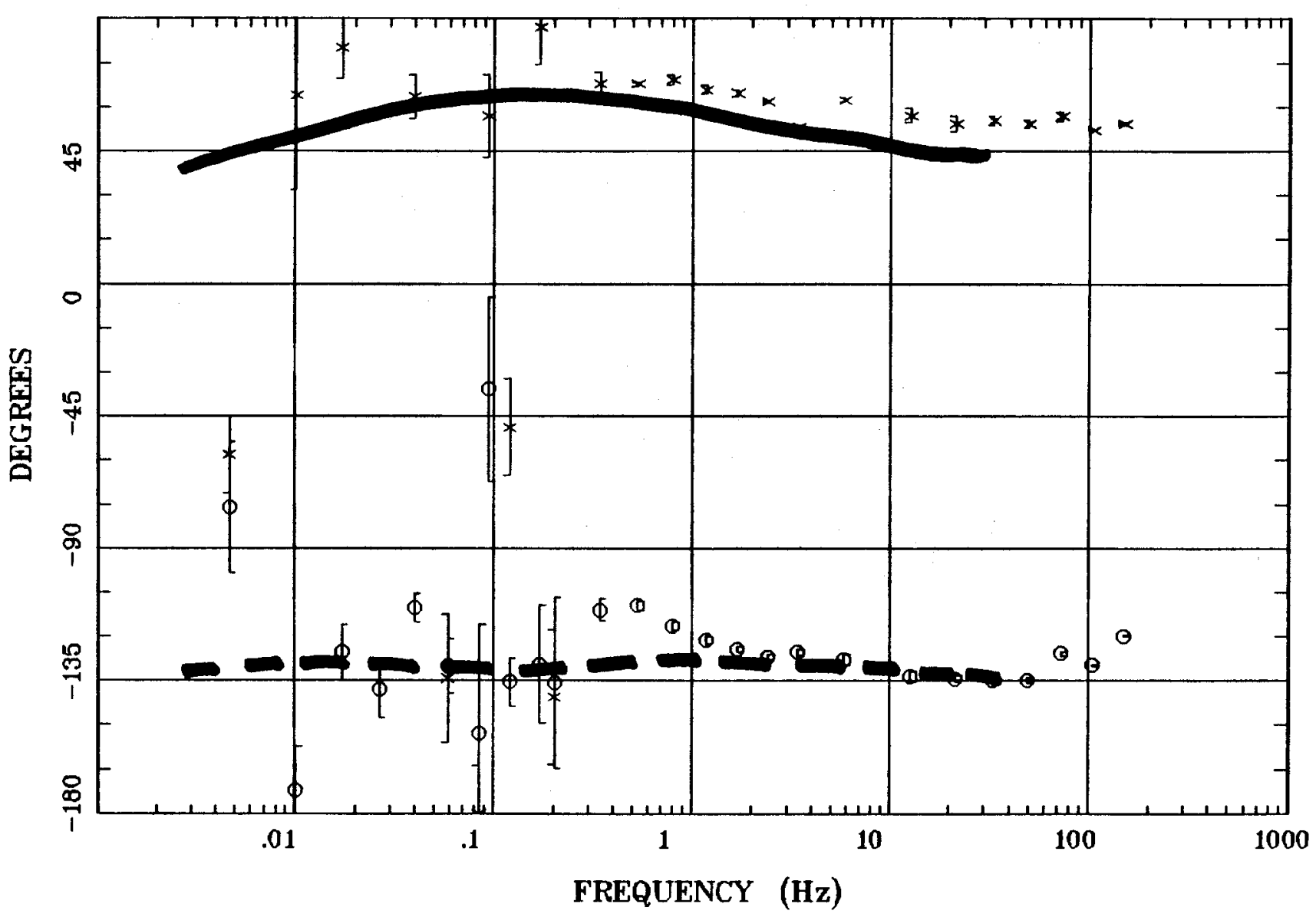

Client:

Remote:

Acquired:

Survey Co:
Rotation:

Filename: CT23C

Channels: Ch1 Ch2 Ch3 Ch4 Ch5 Che Ch7

Plotted: 08:58 Sep 17, 1998

< EMI - ElectroMagnetic Instruments 


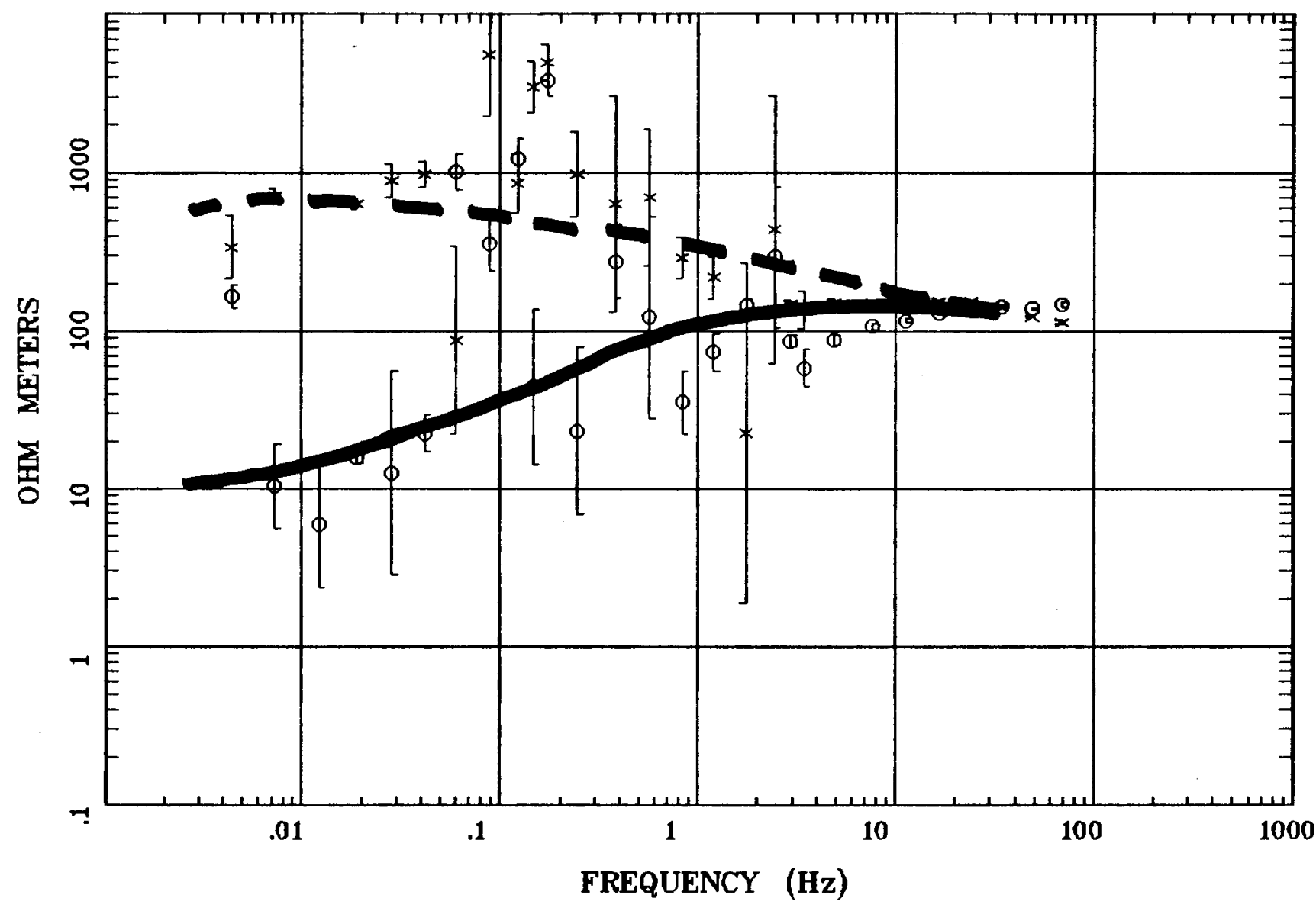

Client:

Remote: Local $\mathbf{E}$

Acquired: 16:0 Jul 27, 1998

Survey Co:USGS GD-MRP Denver
Rotation:

Filename: hr54.avg

Channels: Ch1 Ch2 Ch3 Ch4 Ch5 Ch6 Ch7

Plotted: 15:13 Sep 16, 1998

< EMI - ElectroMagnetic Instruments > 


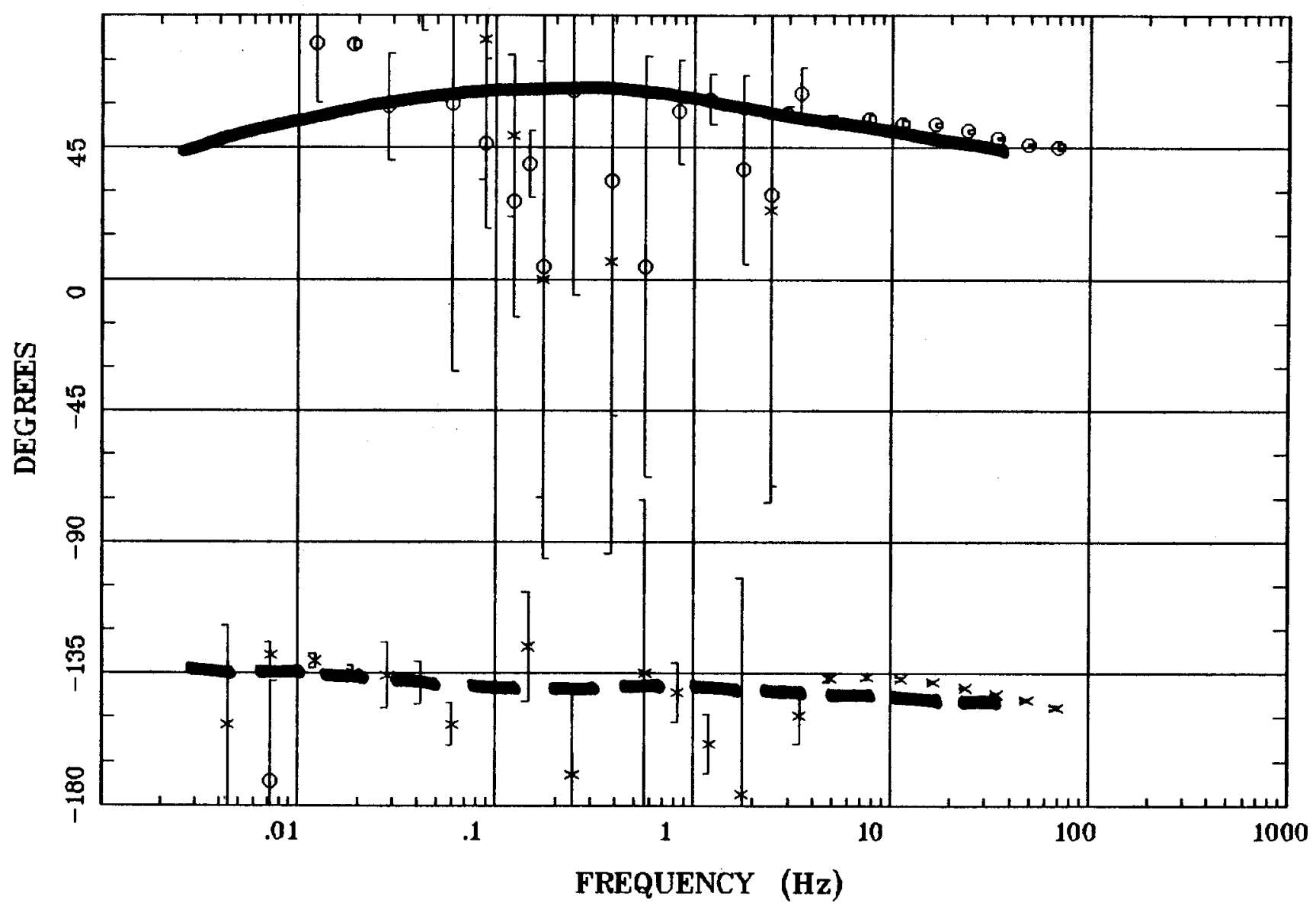

Client:

Remote: Locel E

Acquired: 16:0 Jul 27, 1998

Survey Co:USGS GD-MRP Denver
Rotation:

Filename: hr54.avg

Channels: Ch1 Ch2 Ch3 Ch4 Ch5 Chr Ch7

Plotted: 15:13 Sep 16, 1998

$<$ EMI - ElectroMagnetic Instruments > 


\section{APPENDIX C}

\section{OBSERVED AND CALCULATED DATA - PROFILE MT2}

Magnetotelluric (MT) observed (circle and $\mathrm{x}$ symbols) and calculated (solid and dashed lines are TE and TM modes, respectively) resistivity and phase data for profile MT2. See the "Magnetotelluric Data" section of this report for a description of the observed data and the "Resistivity Models" section for a description of the calculated data. 
APPARENT RESISTIVITY

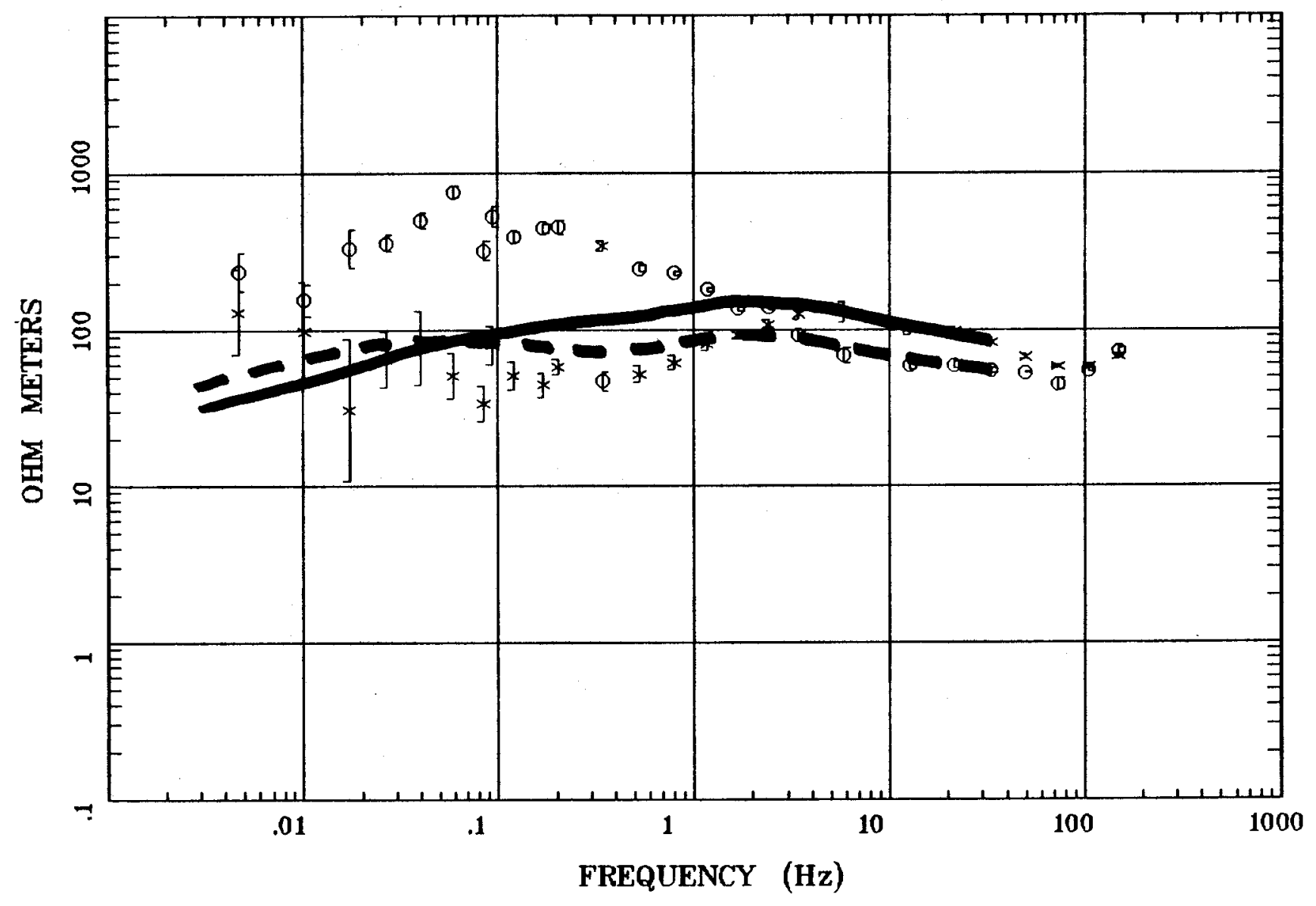

Client:

Rotation:

Remote:

Filename: CT17

Acquired:

Channels: Ch1 Ch2 Ch3 Ch4 Ch5 Che Ch7

Survey Co:

Plotted: 10:15 Jun 25, 1999

< EMI - ElectroMagnetic Instruments > 


\section{IMPEDANCE PHASE}

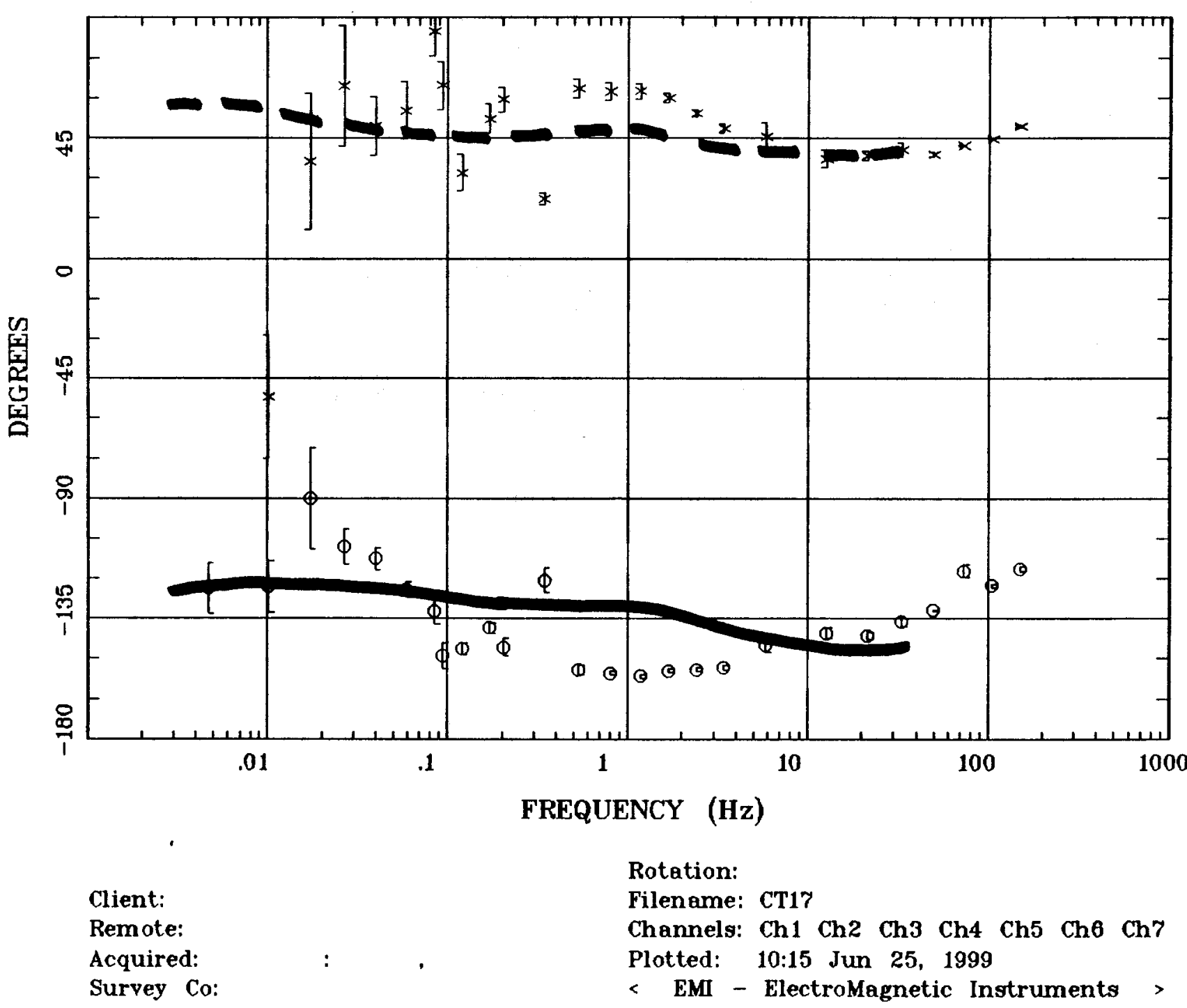




\section{Station 11A}

\section{APPARENT RESISTIVITY}

Simpson park Mts,NV 100k

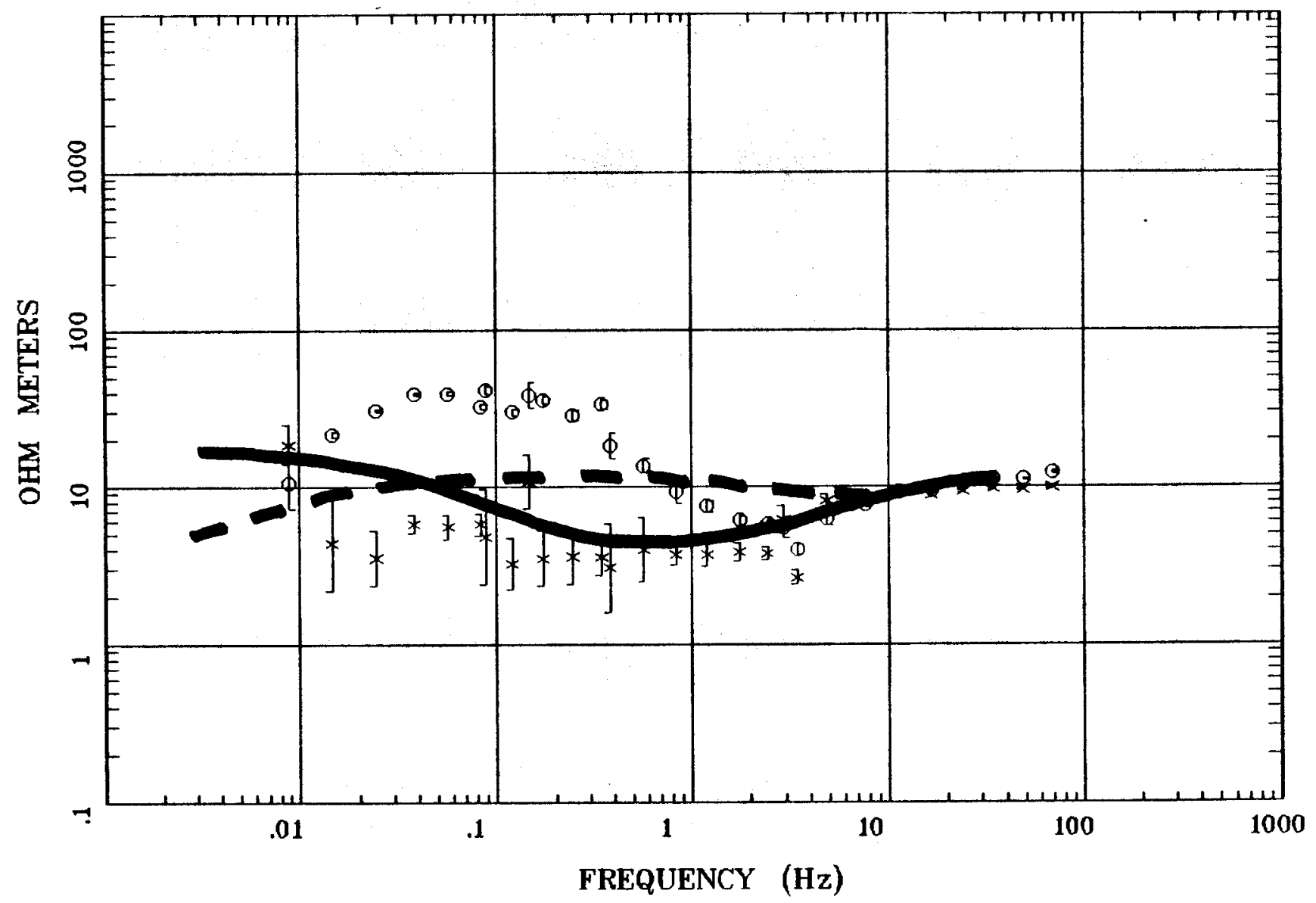

Client:

Remote: none

Acquired: 10:3 Aug 05, 2000

Survey Co:USGS
Rotation:

Filename: nnrl1b.avg

Channels: Ch1 Ch2 Ch3 Ch4 Ch5 Ch3 Ch4

Plotted: 09:41 Jan 24, 2001

\& EMI - ElectroMagnetic Instruments > 
IMPEDANCE PHASE

Simpson park Mts,NV 100k

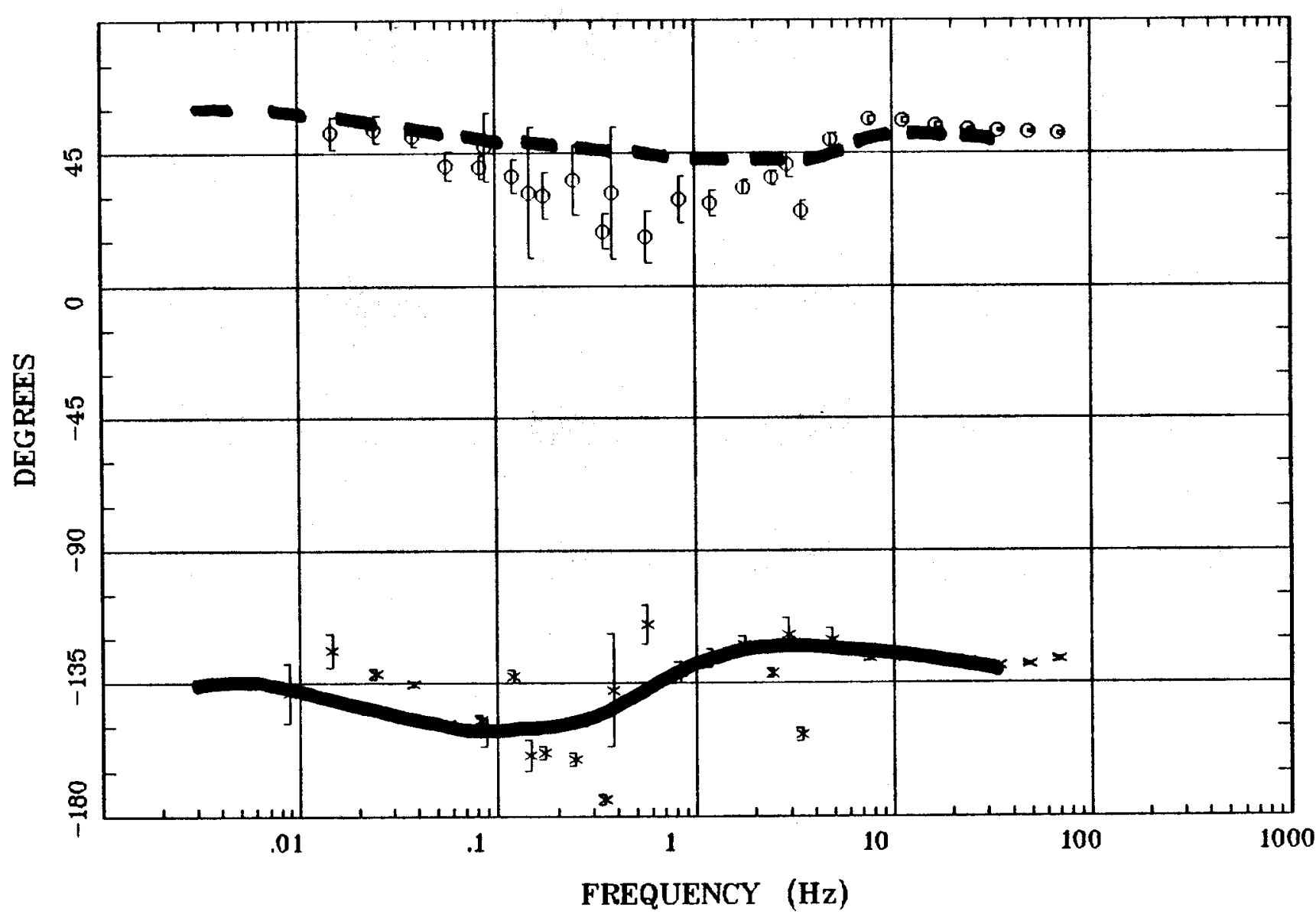

Client:

Remote: none

Acquired: 10:3 Aug 05, 2000 Survey Co:USGS
Rotation:

Filename: nnr11b.avg

Channels: Ch1 Ch2 Ch3 Ch4 Ch5 Ch3 Ch4 Plotted: 09:41 Jan 24, 2001

< EMI - ElectroMagnetic Instruments 
Station 10A

APPARENT RESISTIVITY

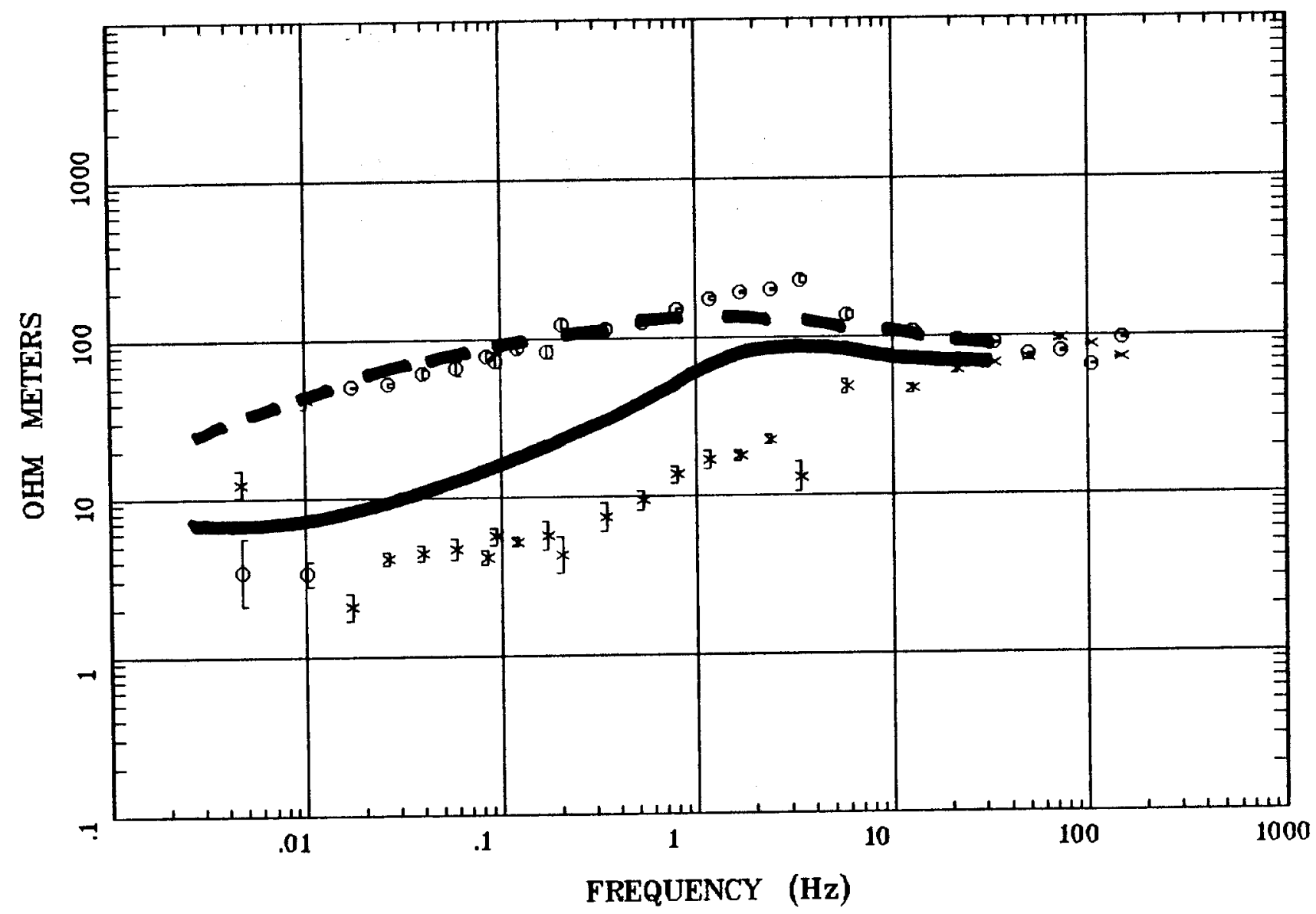

Client:

Remote:

Acquired:

Survey Co:

Rotation:

Filename: NNR10A

Channels: Ch1 Ch2 Ch3 Ch4 Ch5 Ch6 Ch7 Plotted: 17:49 Jun 24, 1999

< EMI - ElectroMagnetic Instruments > 


\section{IMPEDANCE PHASE}

Station 10A

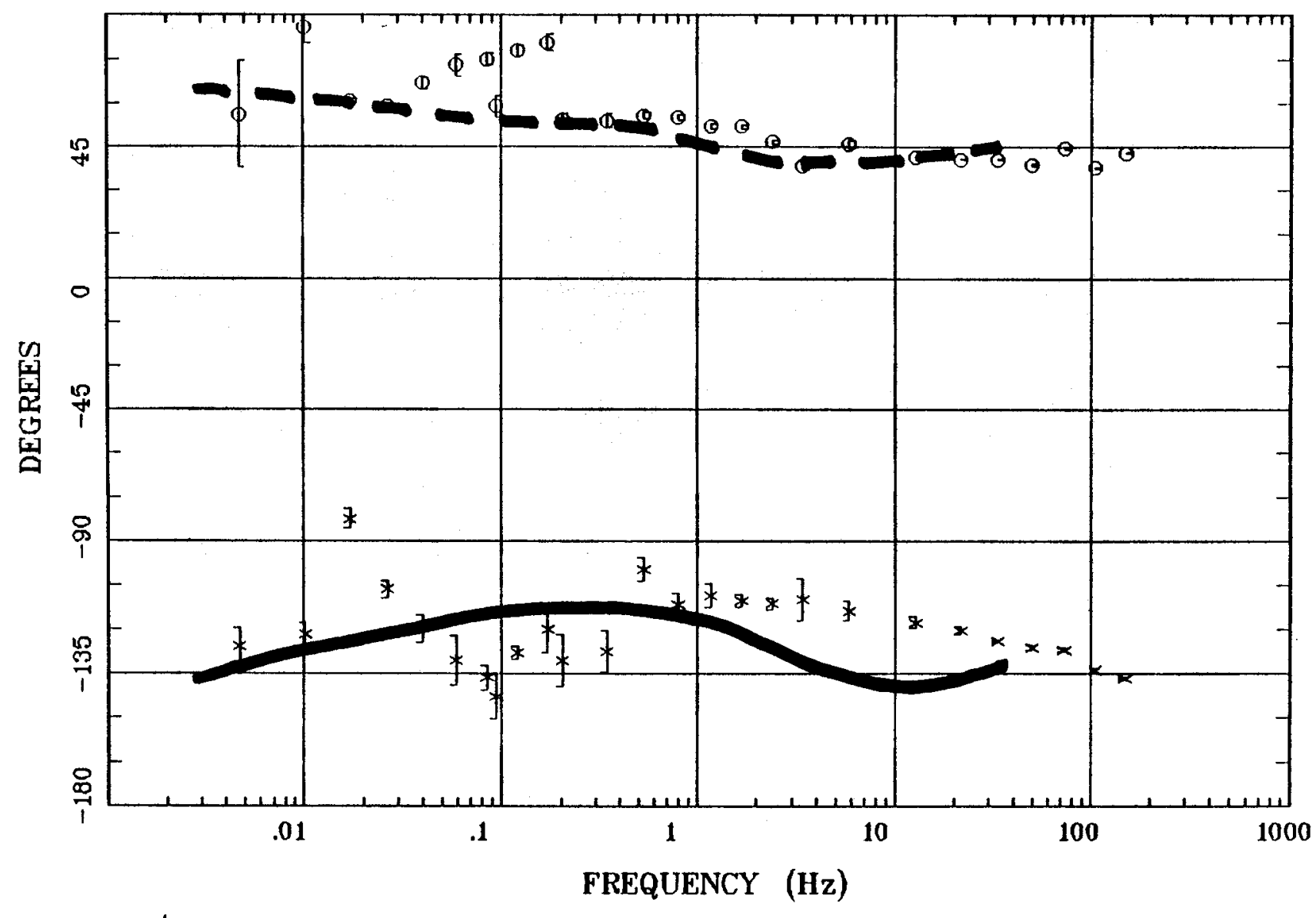

Client:

Rotation:

Filename: NNR10A

Remote:

Channels: Ch1 Ch2 Ch3 Ch4 Ch5 Ch6 Ch7

Acquired:

Plotted: 17:49 Jun 24, 1999

Survey Co:

$<$ EMI - ElectroMagnetic Instruments 


\section{APPARENT RESISTIVITY}

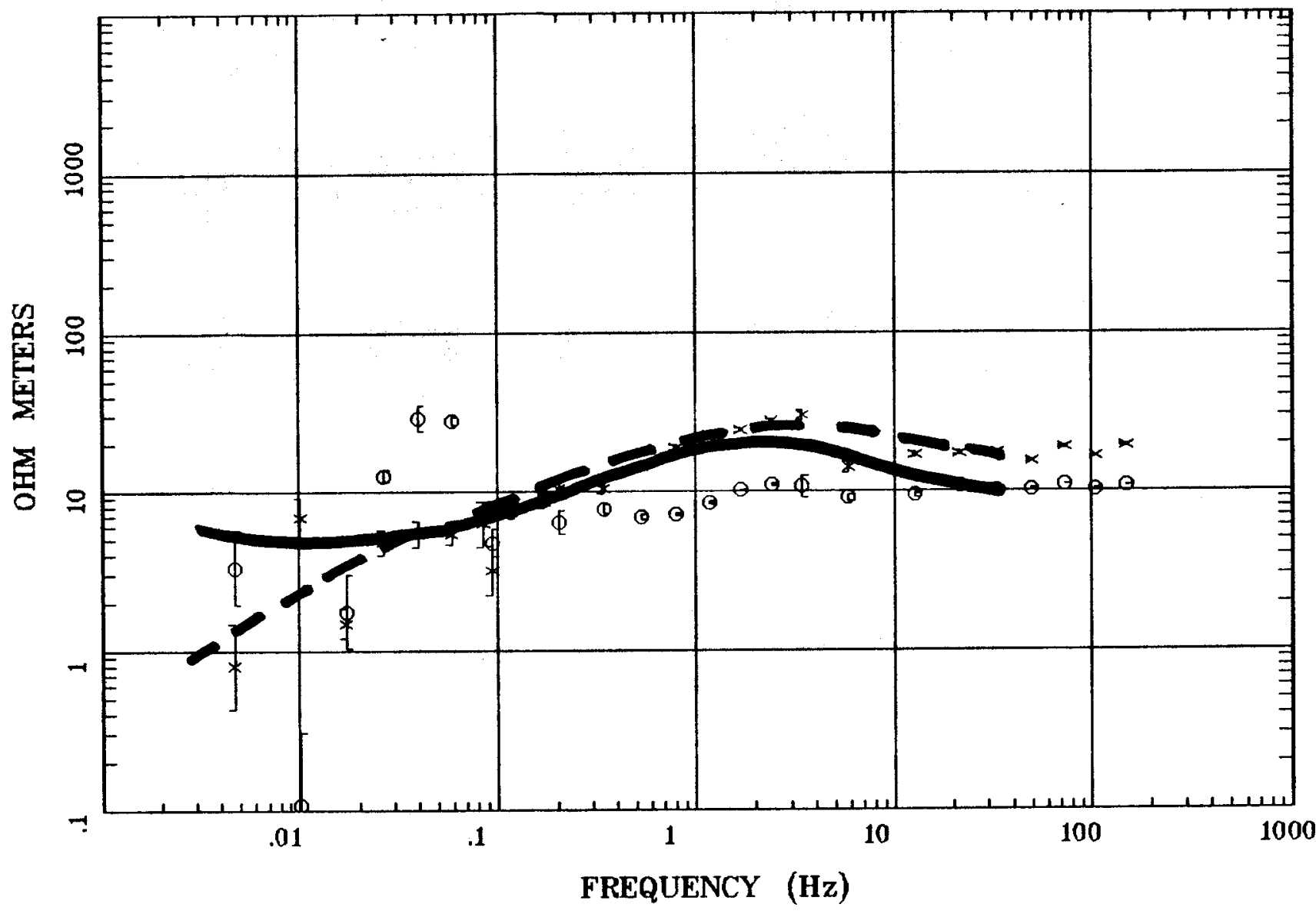

Client:

Remote:

Acquired:

Survey Ca:

Rotation:

Filename: NNR06

Channels: Ch1 Ch2 Ch3 Ch4 Ch5 Ch6 Ch7

Plotted: 18:15 Jun 24, 1999

< EMI - ElectroMagnetic Instruments 
IMPEDANCE PHASE

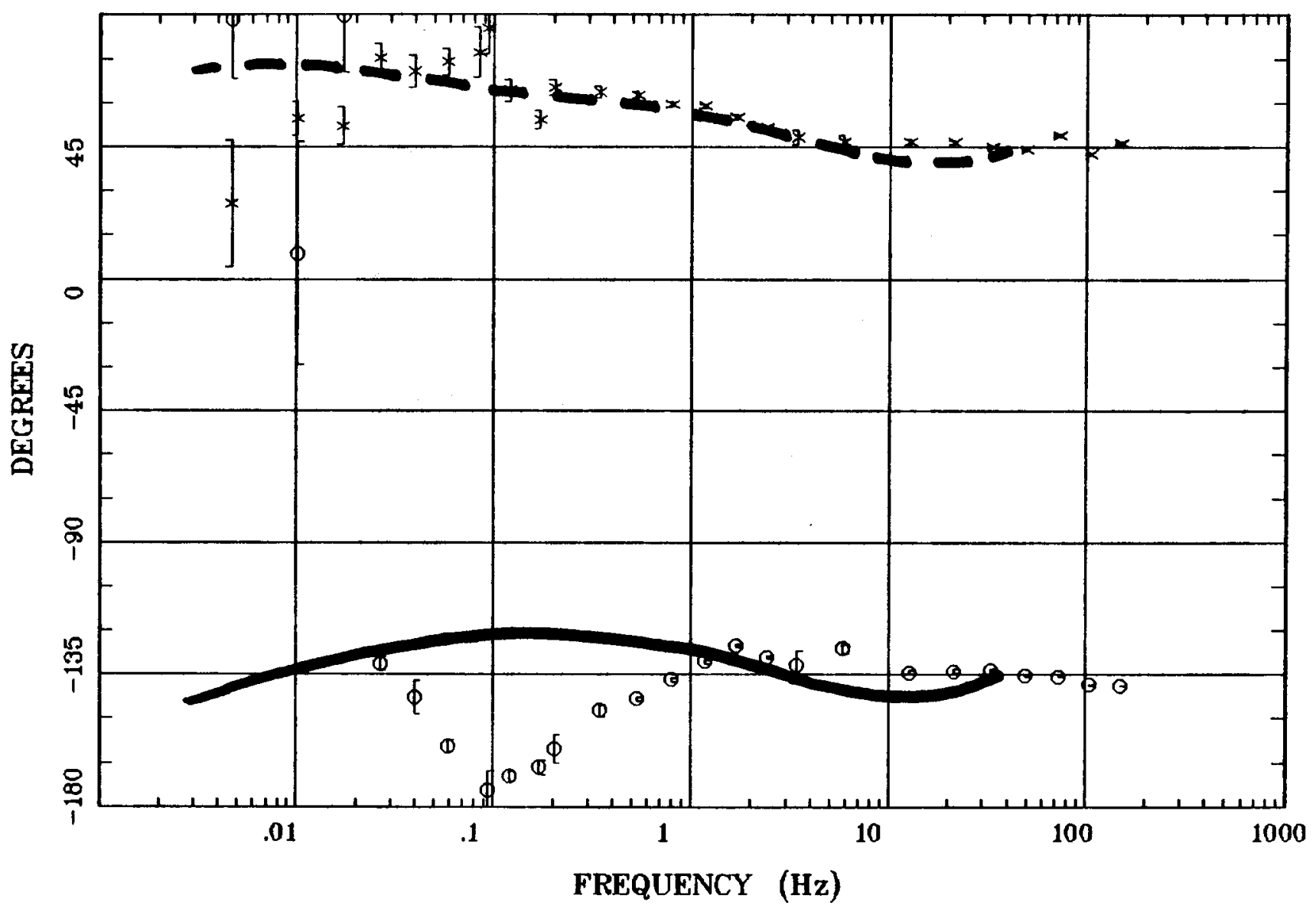

Client:

Remote:

Acquired:

Survey Co:
Rotation:

Filename: NNR06

Channels: Ch1 Ch2 Ch3 Ch4 Ch5 Ch6 Ch7

Plotted: 18:15 Jun 24, 1999

c EMI - ElectroMagnetic Instruments > 


\section{Station 9A}

\section{APPARENT RESISTIVITY}

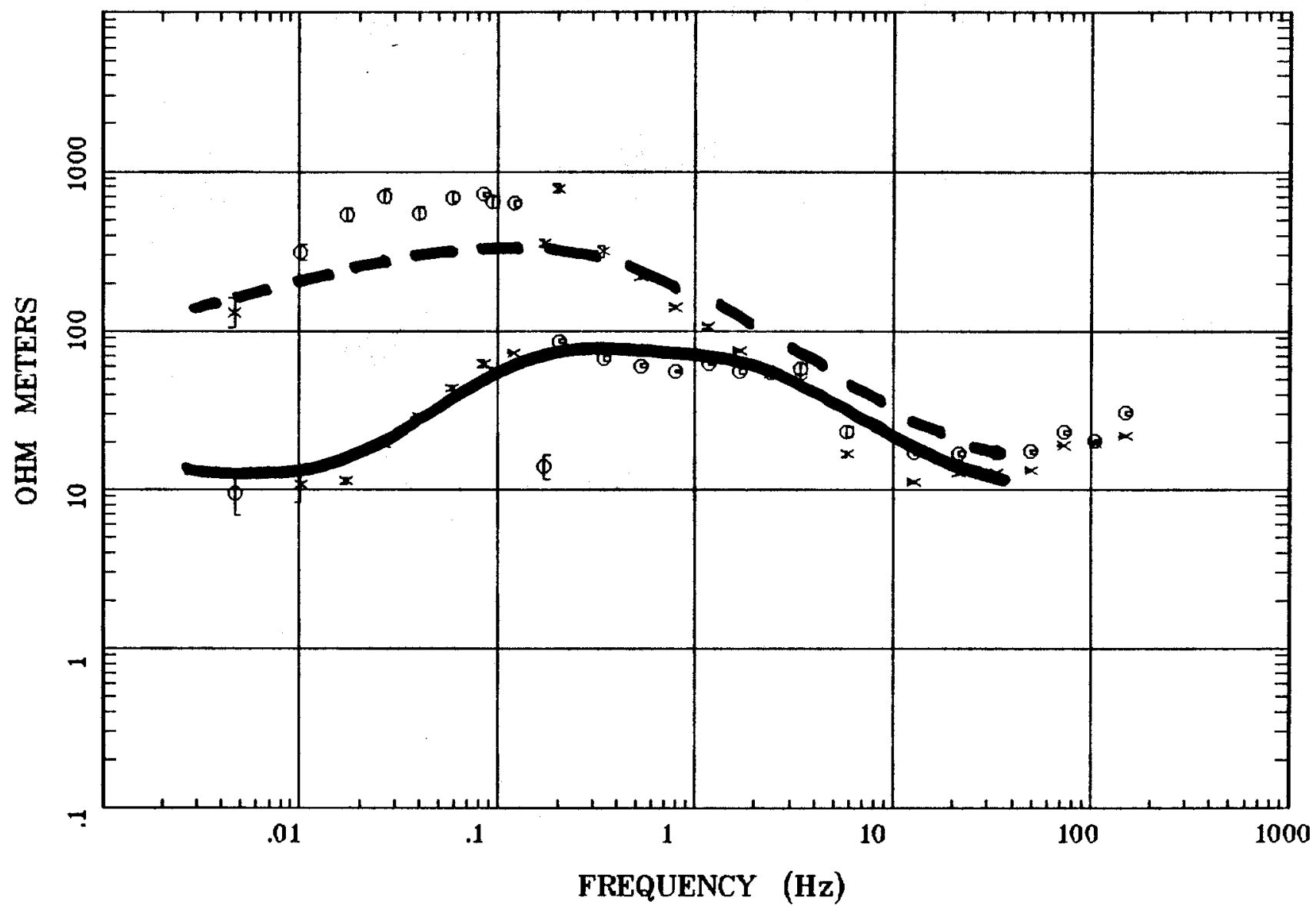

Client:

Rotation:

Remote:

Filename: NNR09

Acquired:

Channels: Ch1 Ch2 Ch3 Ch4 Ch5 Ch6 Ch7

Survey Co:

Plotted: 17:59 Jun 24, 1999

< EMI - ElectroMagnetic Instruments 


\section{Station 9A}

\section{IMPEDANCE PHASE}

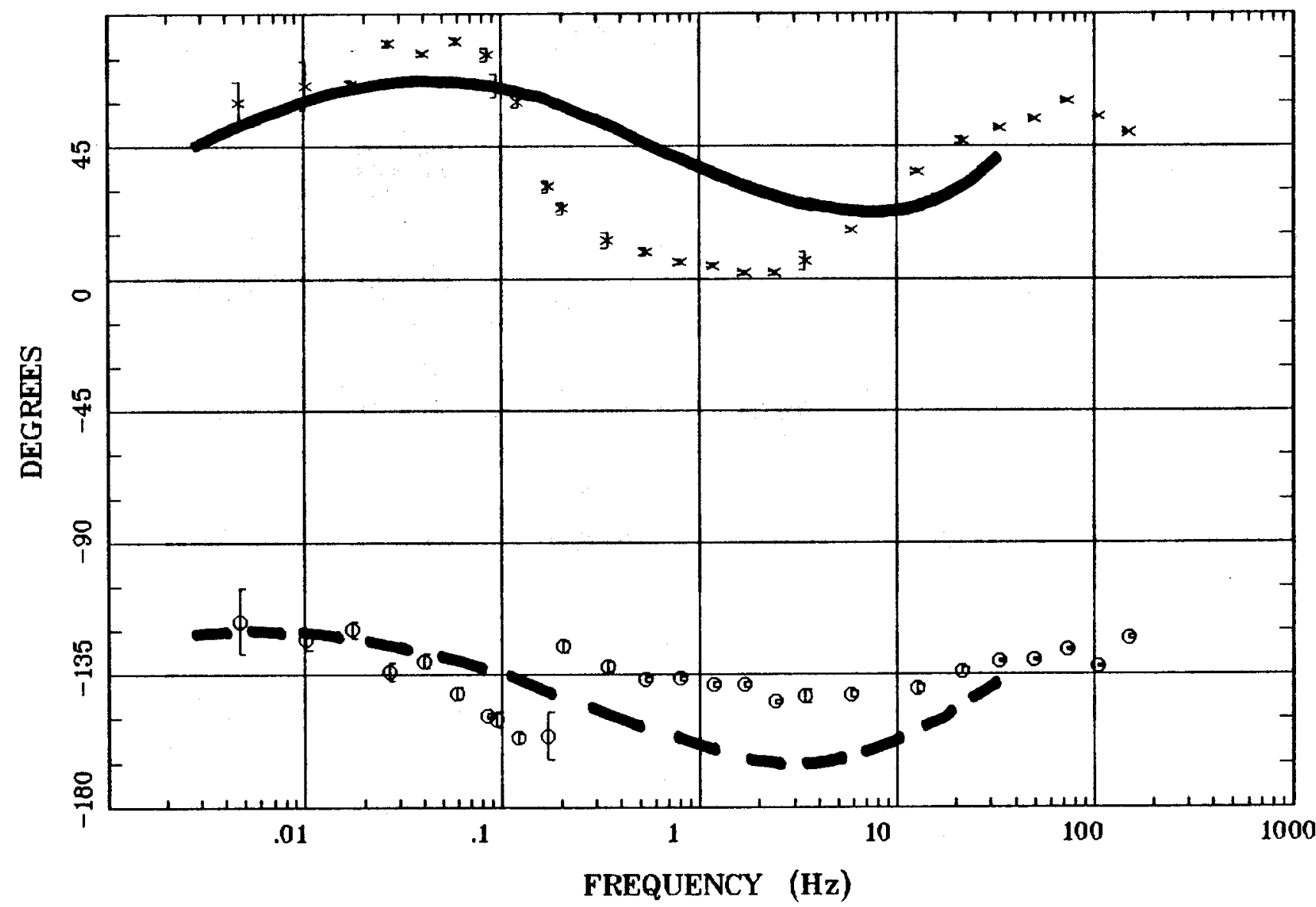

Client:

Remote:

Acquired: Survey Co:
Rotation:

Filename: NNROg

Channels: Ch1 Ch2 Ch3 Ch4 Ch5 Cho Ch7

Plotted: 17:59 Jun 24, 1999

$<$ EMI - ElectroMagnetic Instruments 


\section{APPARENT RESISTIVITY}

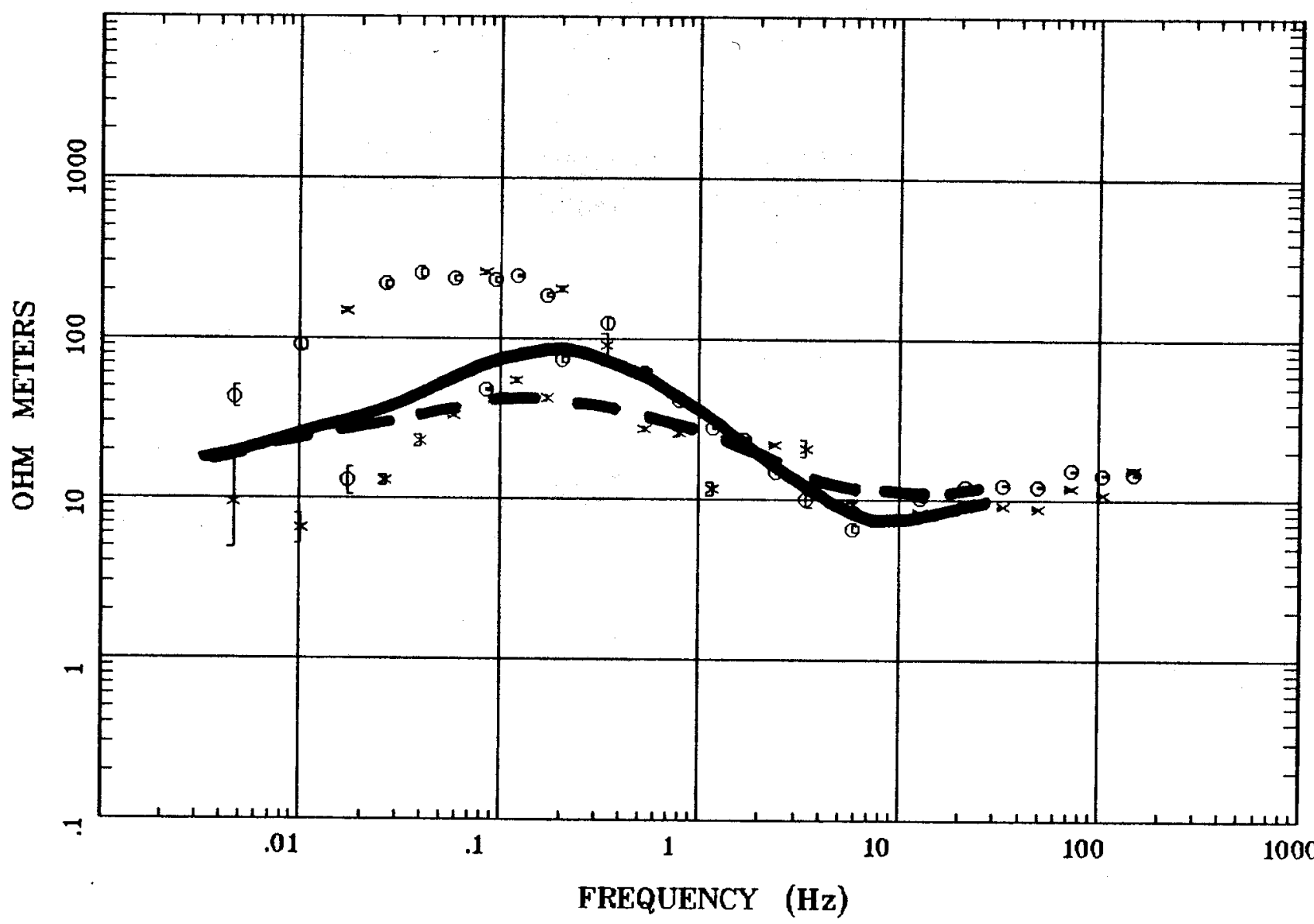

Client:

Remote:

Acquired:

Survey Co:
Rotation:

Filename: NNR08

Channels: Ch1 Ch2 Ch3 Ch4 Ch5 Ch8 Ch7

Plotted: 18:07 Jun 24, 1999

< EMI - ElectroMagnetic Instruments 
IMPEDANCE PHASE

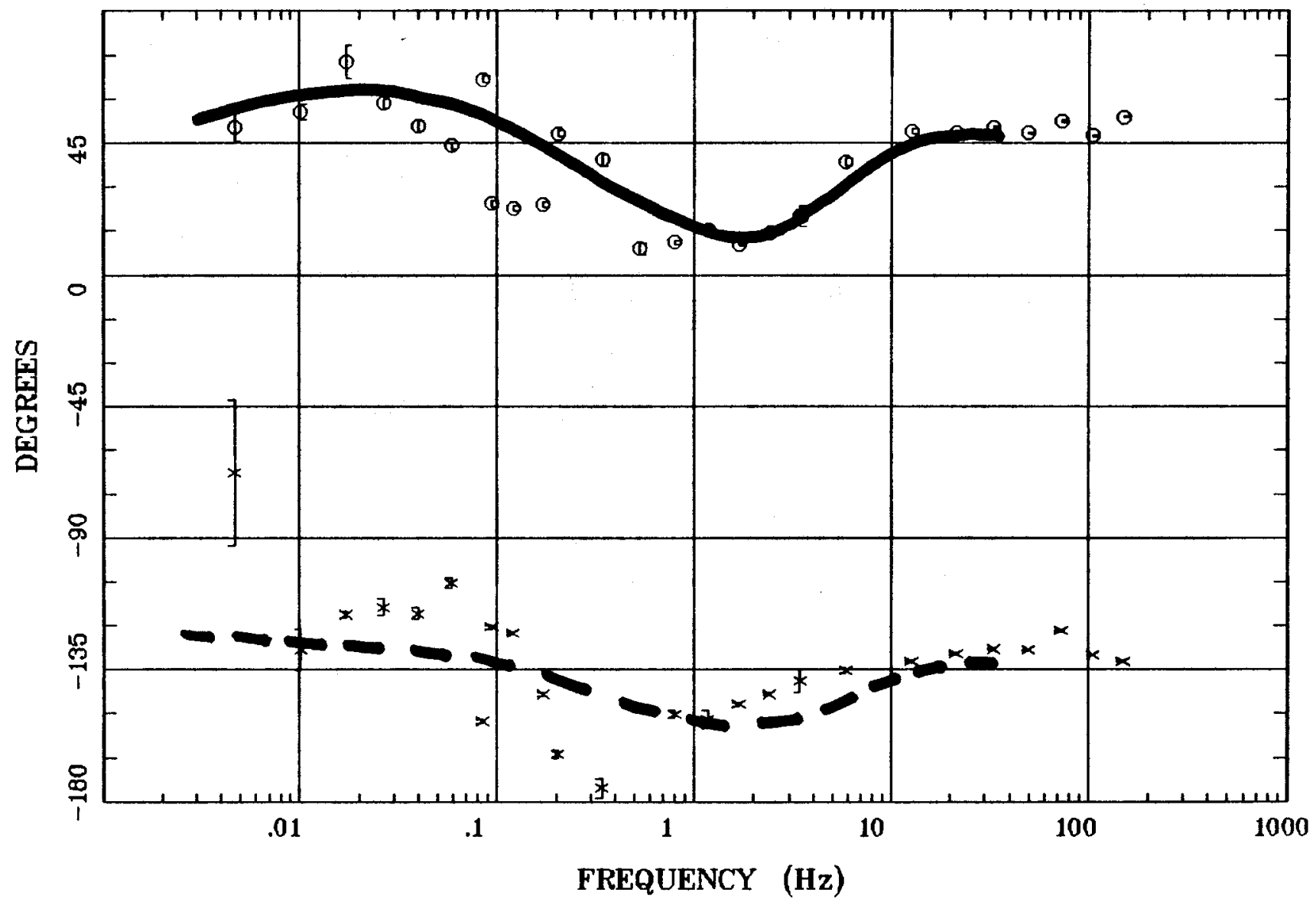

Client:

Rotation:

Remote:

Filename: NNR0B

Acquired:

Channels: Ch1 Ch2 Ch3 Ch4 Ch5 Ch6 Ch7

Plotted: 18:07 Jun 24, 1999

Survey Co:

- EMI - ElectroMagnetic Instruments 


\section{APPARENT RESISTIVITY}

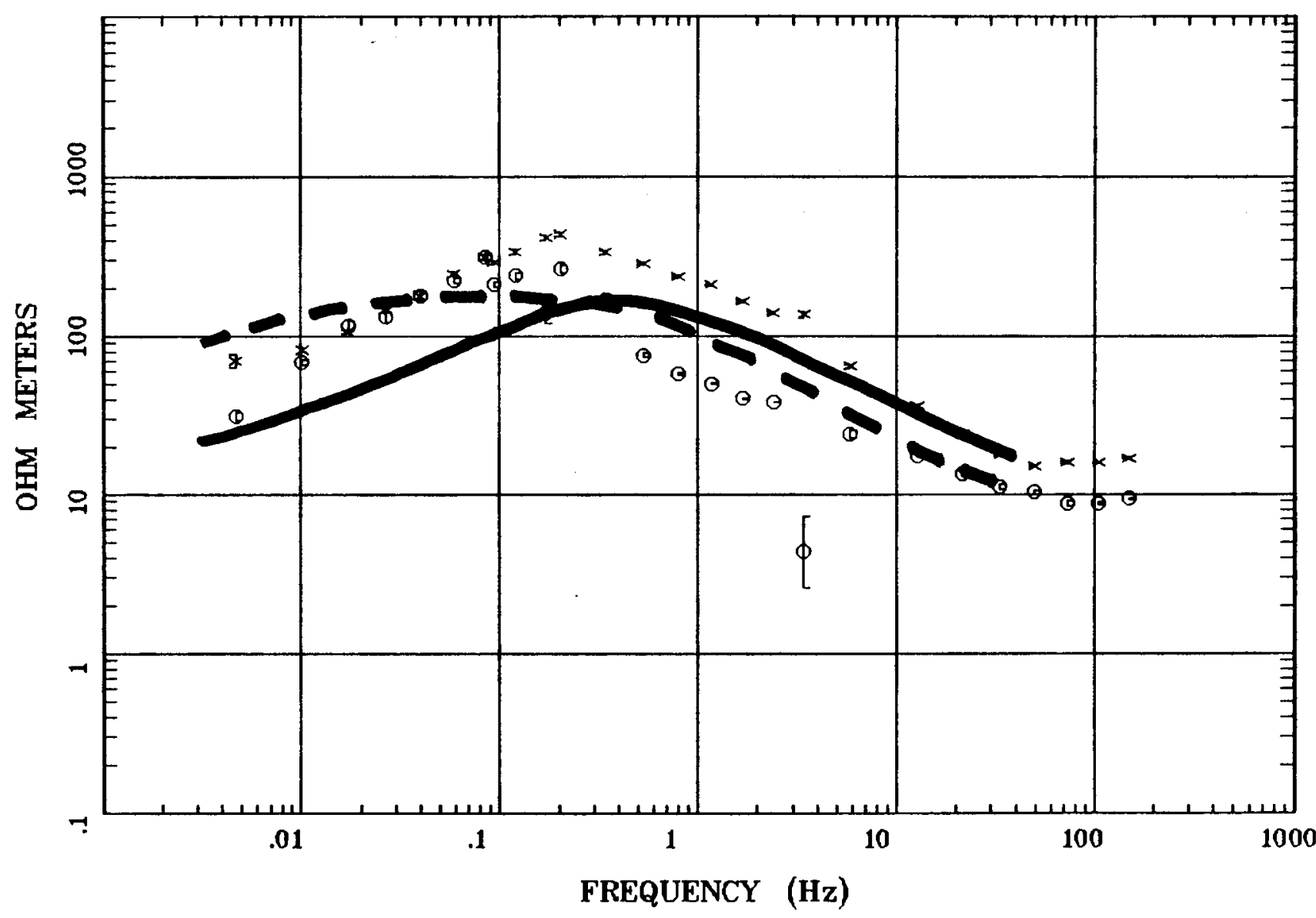

Client:

Remote:

Acquired:

Survey Co:
Rotation:

Filename: NNR07

Channels: Ch1 Ch2 Ch3 Ch4 Ch5 Chr Ch7

Plotted: 18:13 Jun 24, 1998

< EMI - ElectroMagnetic Instruments > 


\section{Station 7A}

\section{IMPEDANCE PHASE}

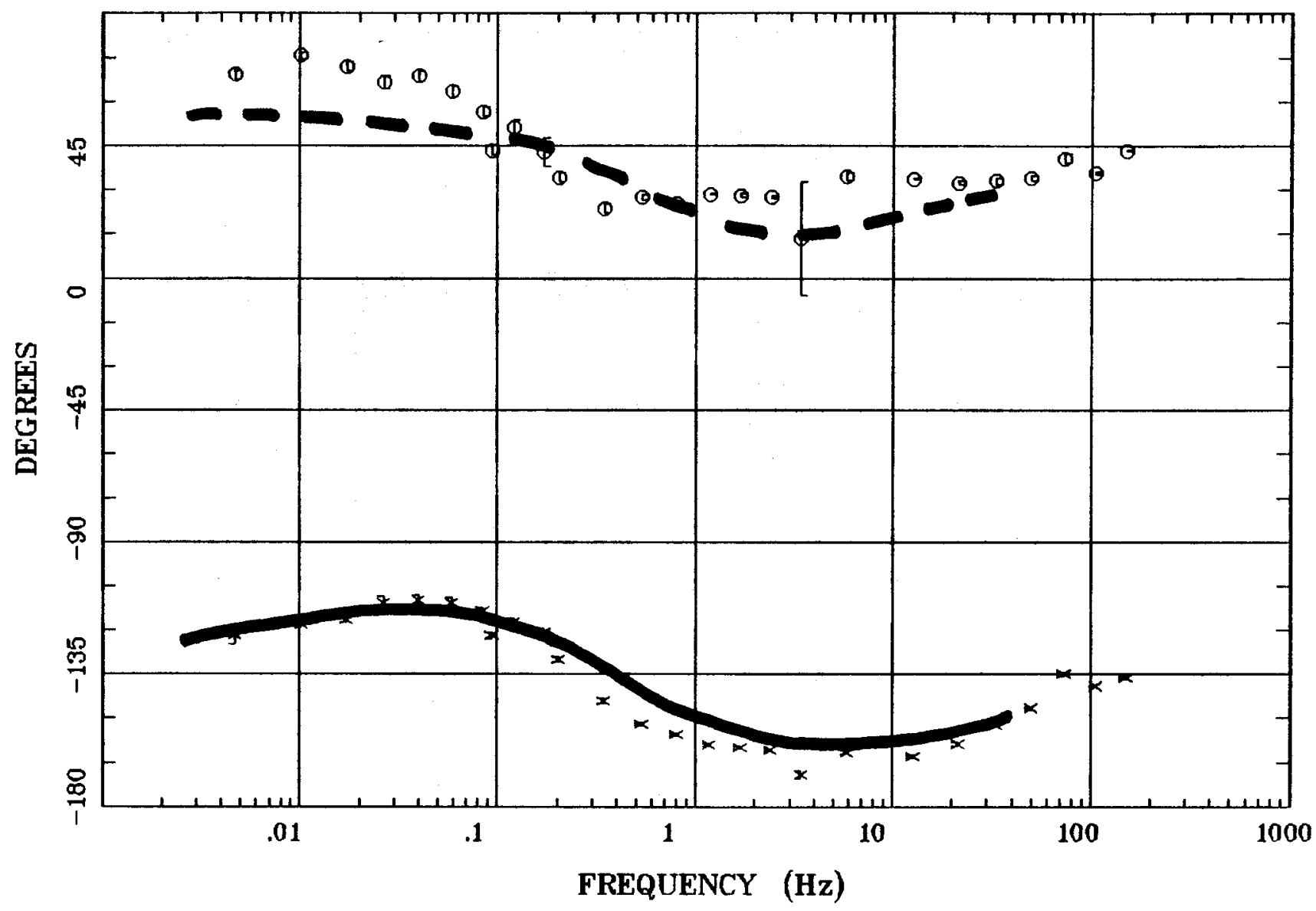

Client:

\section{Remote:}

Acquired:

Survey Co:
Rotation:

Filename: NNROT

Channels: Ch1 Ch2 Ch3 Ch4 Ch5 Ch6 Ch7

Plotted: 18:13 Jun 24, 1999

< EMI - ElectroMagnetic Instruments 


\section{Station 18}

\section{APPARENT RESISTIVITY}

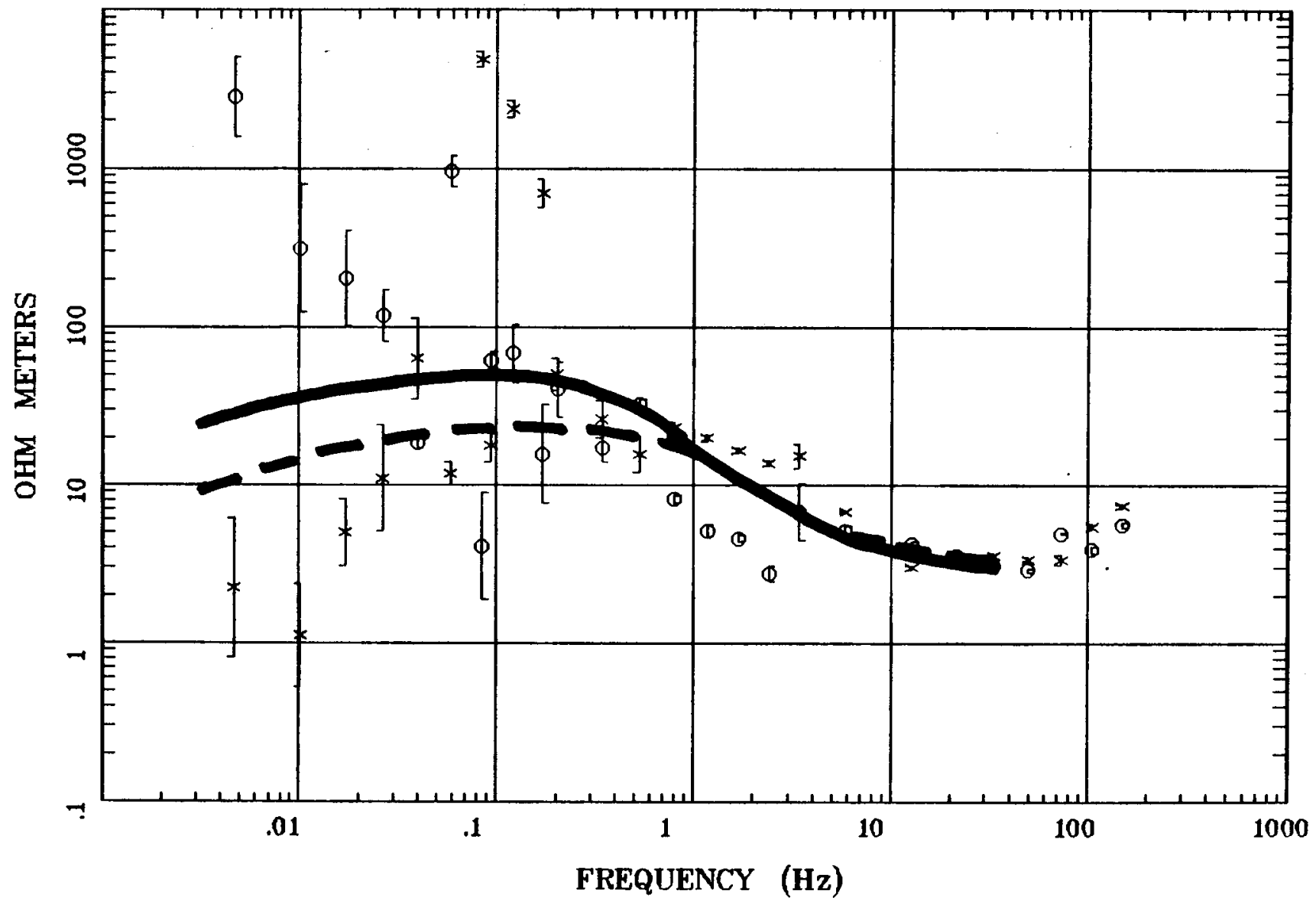

Client:

Remote:

Acquired:

Survey Co:
Rotation:

Filename: CT18

Channels: Ch1 Ch2 Ch3 Ch4 Ch5 Che Chr

Plotted: 10:14 Jun 25, 1999

< EMI - ElectroMagnetic Instruments 


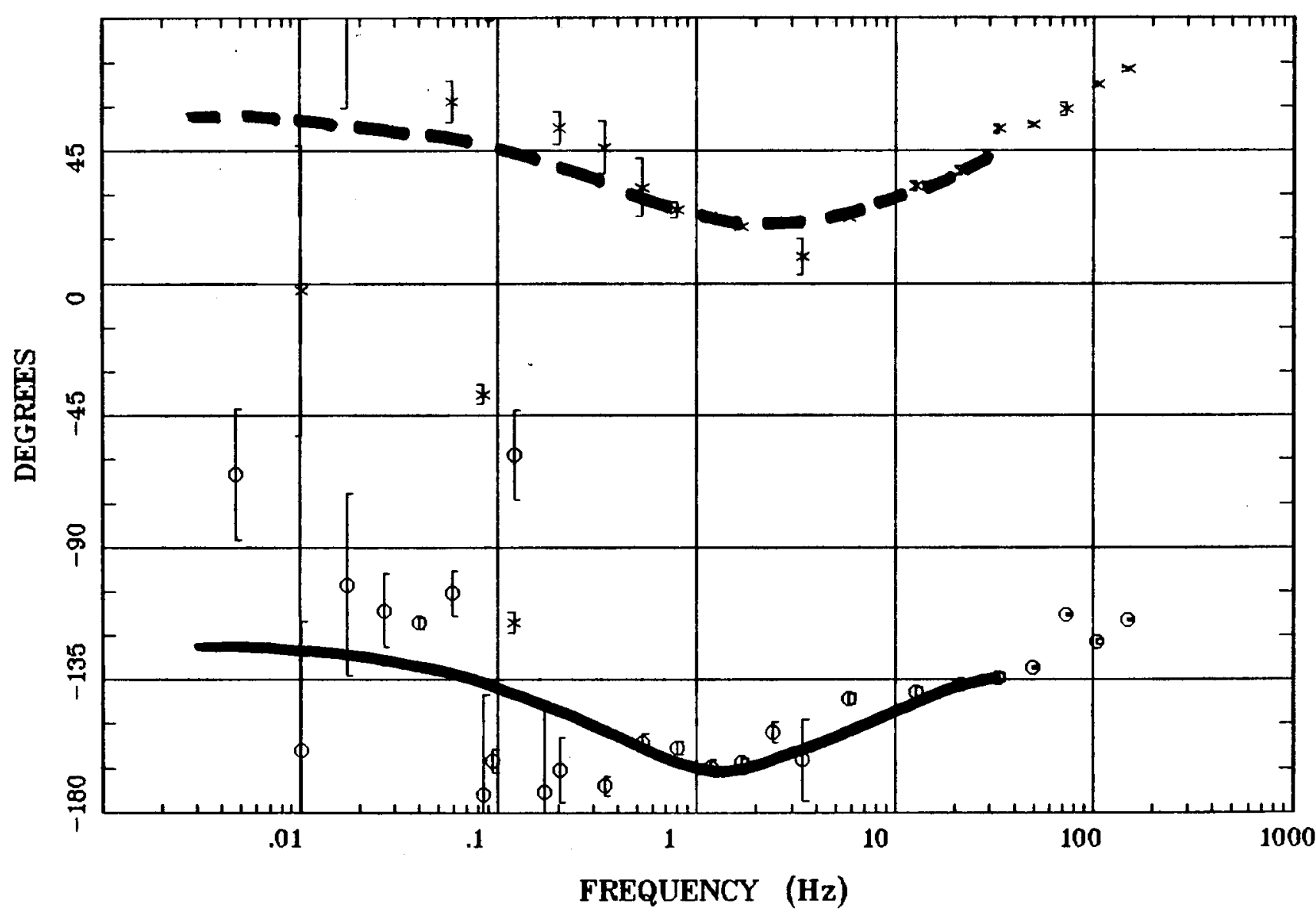

Client:

Remote:

Acquired:

Survey Co:
Rotation:

Filename: CT18

Channels: Ch1 Ch2 Ch3 Ch4 Ch5 Che Ch7 Plotted: 10:14 Jun 25, 1999

< EMI - ElectroMagnetic Instruments > 


\section{OBSERVED AND CALCULATED DATA - PROFILE MT1}

Magnetotelluric (MT) observed (circle and $\mathrm{x}$ symbols) and calculated (solid and dashed lines are TE and TM modes, respectively) resistivity and phase data for profile MT1. See the "Magnetotelluric Data" section of this report for a description of the observed data and the "Resistivity Models" section for a description of the calculated data. 


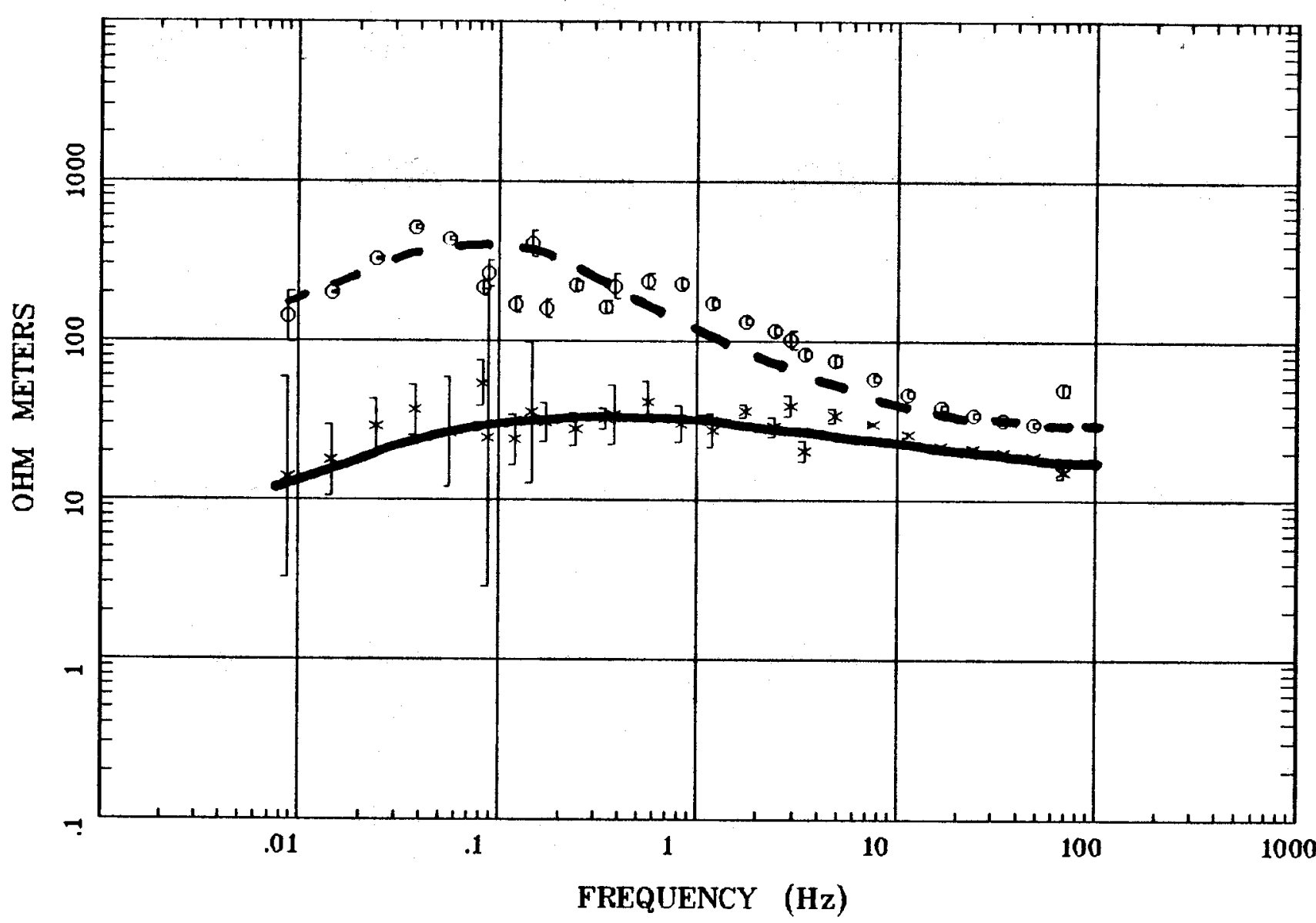

Client:

Remote: none

Acquired: 12:4 Aug 09, 1999 Survey Co:USGS
Rotation:

Filename: ar8Bb.avg

Channels: Ch1 Ch2 Ch3 Ch4 Ch5 Ch3 Ch4 Plotted: 11:07 Dec 08, 2000.

< EMI - ElectroMagnetic Instruments 
Kobeh Valley, NV

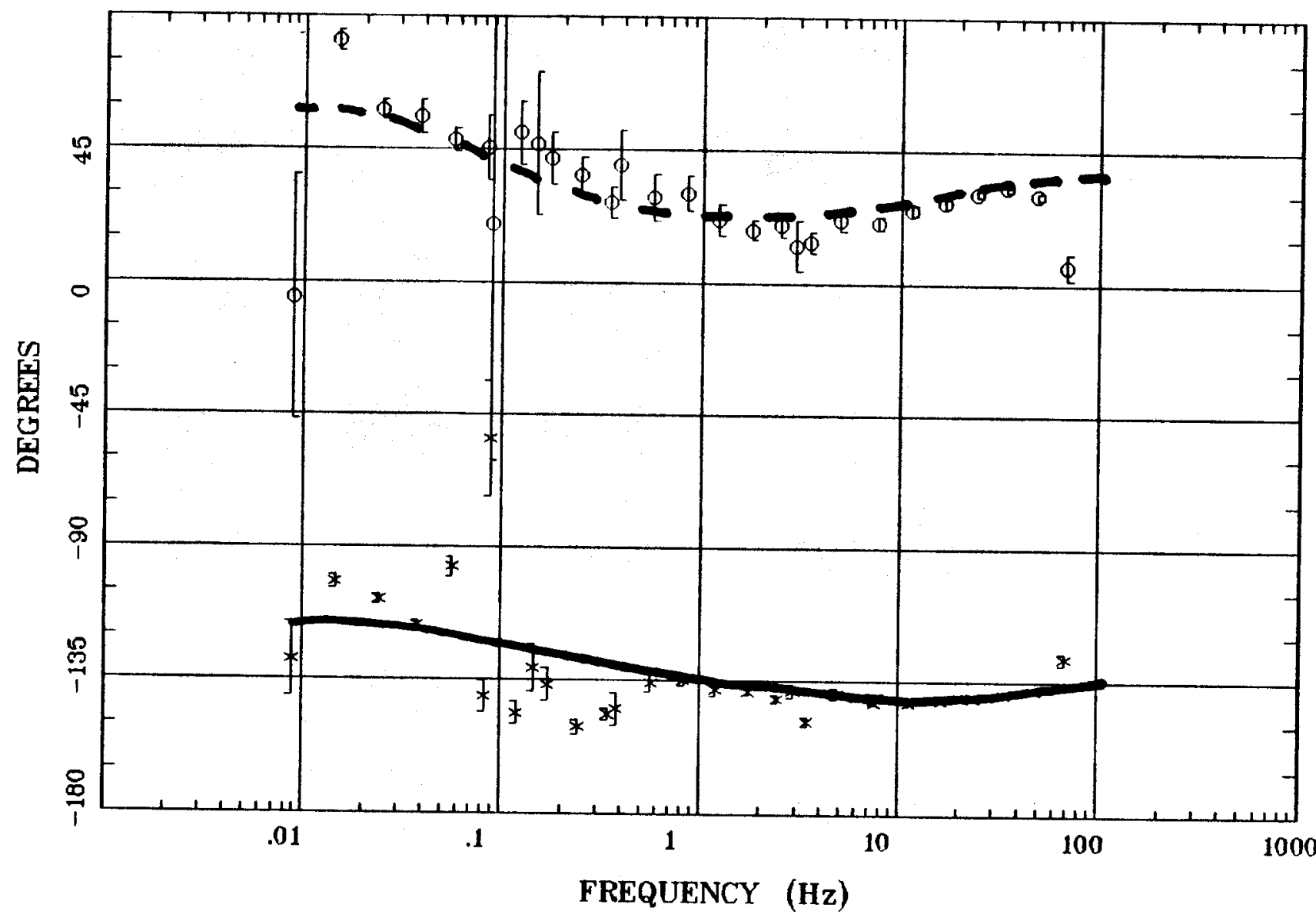

Client:

Remote: none

Acquired: 12:4 Aug 09, 1999

Survey Co:USGS
Rotation:

Filename: ar88b.avg

Channels: Ch1 Ch2 Ch3 Ch4 Ch5 Ch3 Ch4 Plotted: 11:07 Dec 08, 2000

< EMI - ElectroMagnetic Instruments 


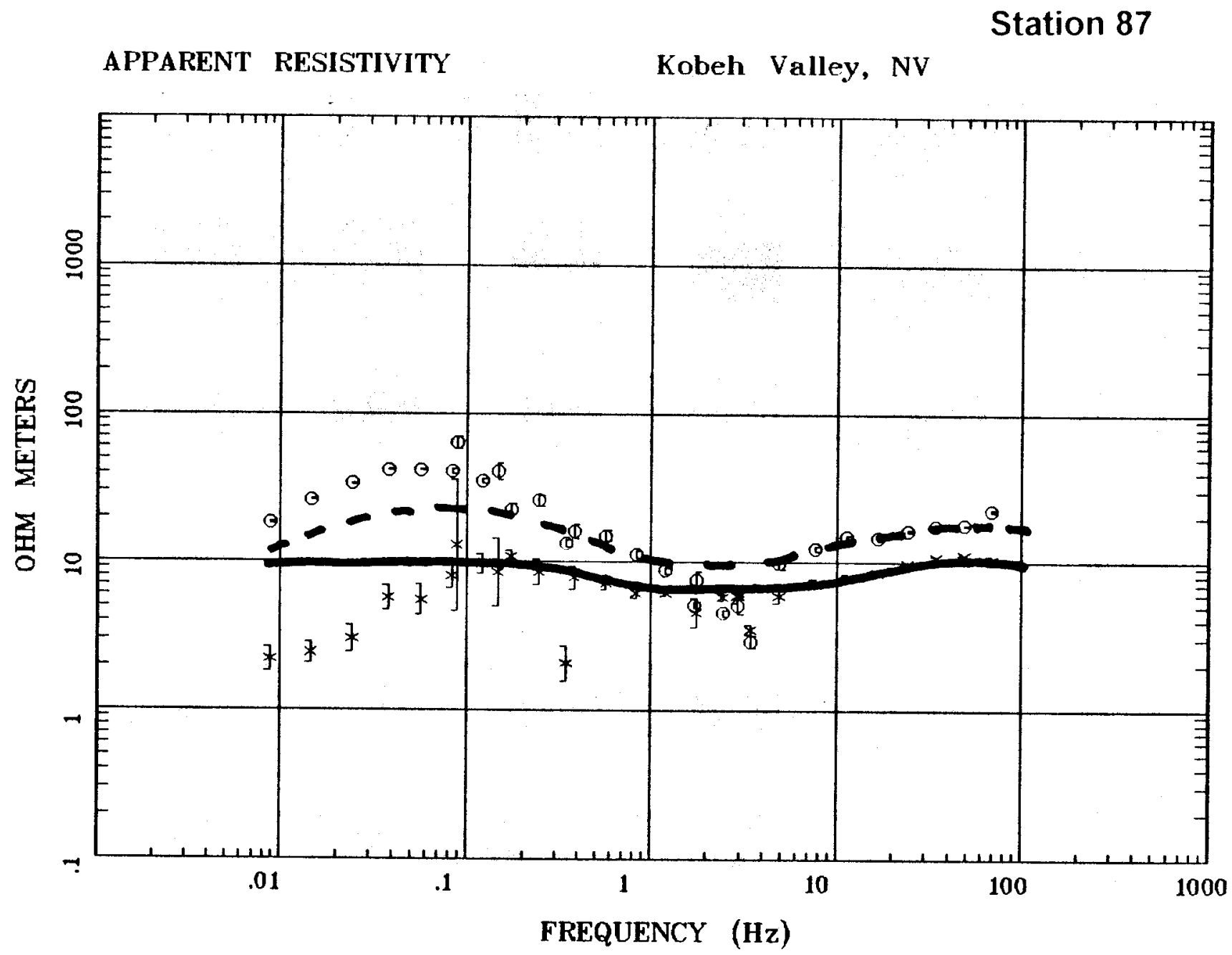

\section{Client:}

Remote: none

Acquired: 09:1 Aug 09, 1999

Survey Co:USGS
Rotation:

Filename: ar87all.avg

Channels: Ch1 Ch2 Ch3 Ch4 Ch5 Ch3 Ch4

Plotted: 11:05 Dec 08, 2000

< EMI - ElectroMagnetic Instruments 
Station 87

IMPEDANCE PHASE

Kobeh Valley, NV

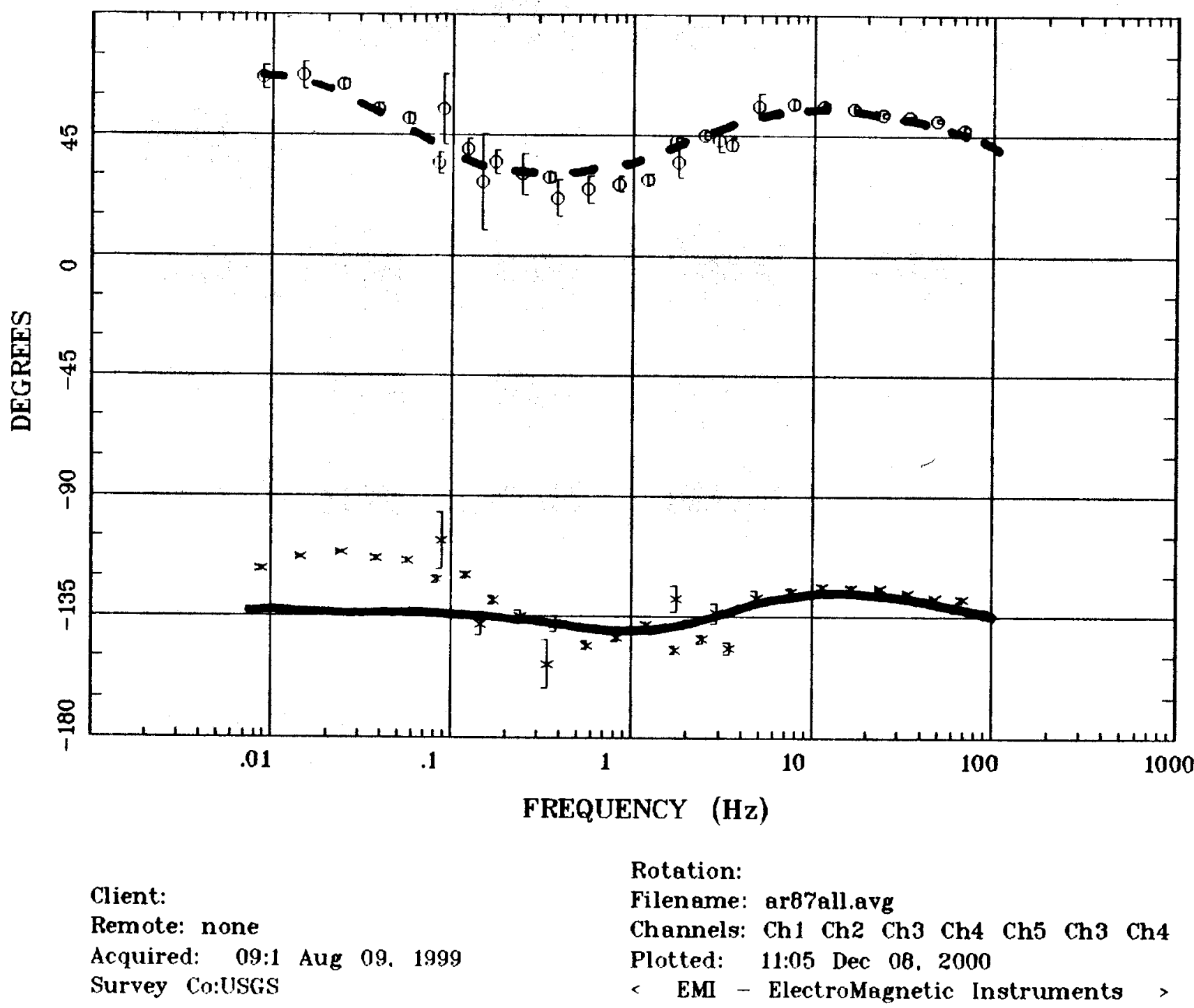


Station 86

APPARENT RESISTIVITY

Kobeh Valley, NV

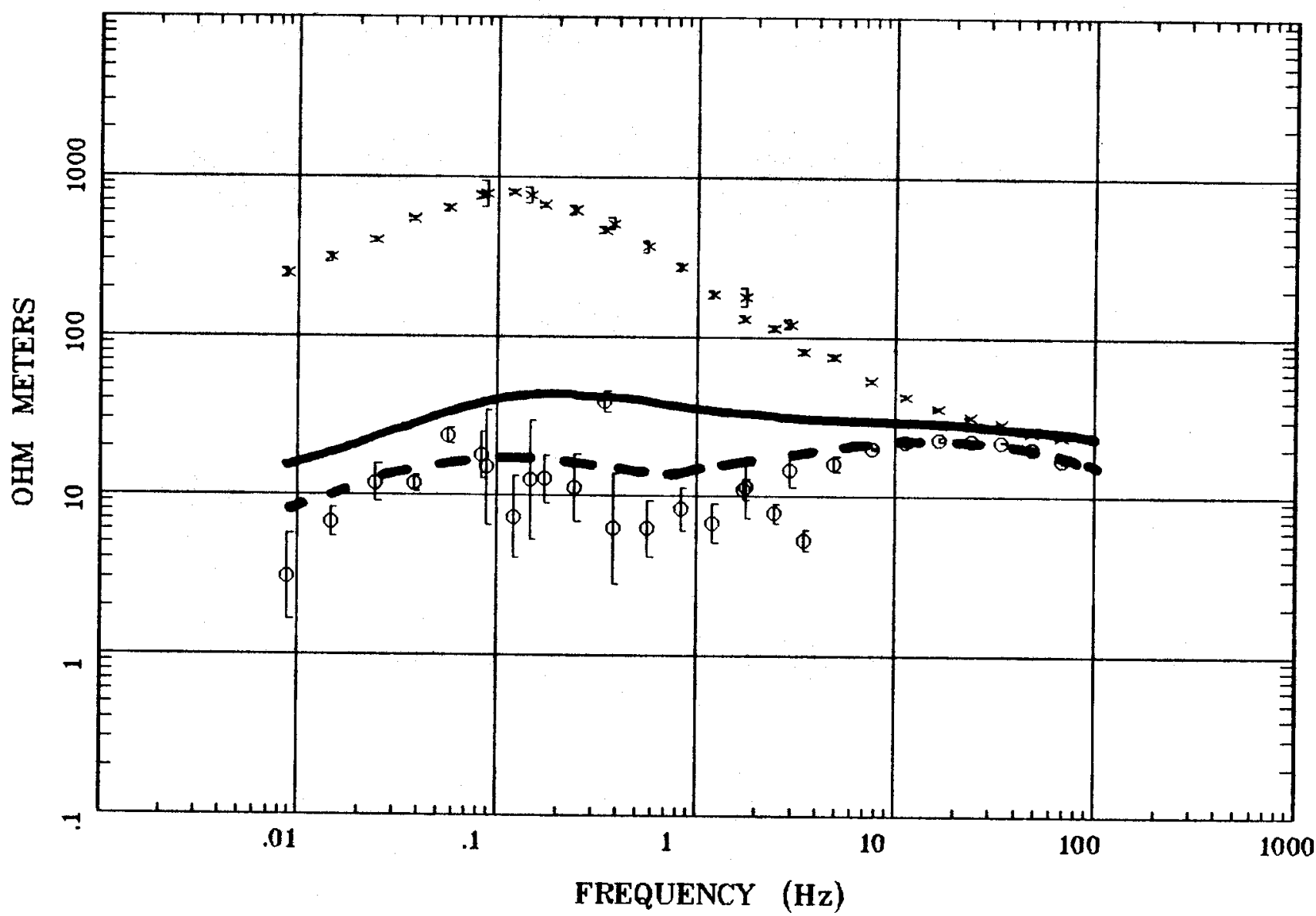

Client:

Remote: none

Acquired: 12:5 Aug 08, 1999

Survey Co:USGS
Rotation:

Filename: ar86all.avg

Channels: Ch1 Ch2 Ch3 Ch4 Ch5 Ch3 Ch4

Plotted: 11:04 Dec 08. 2000

< EMI - ElectroMagnetic Instruments 


\section{Station 86}

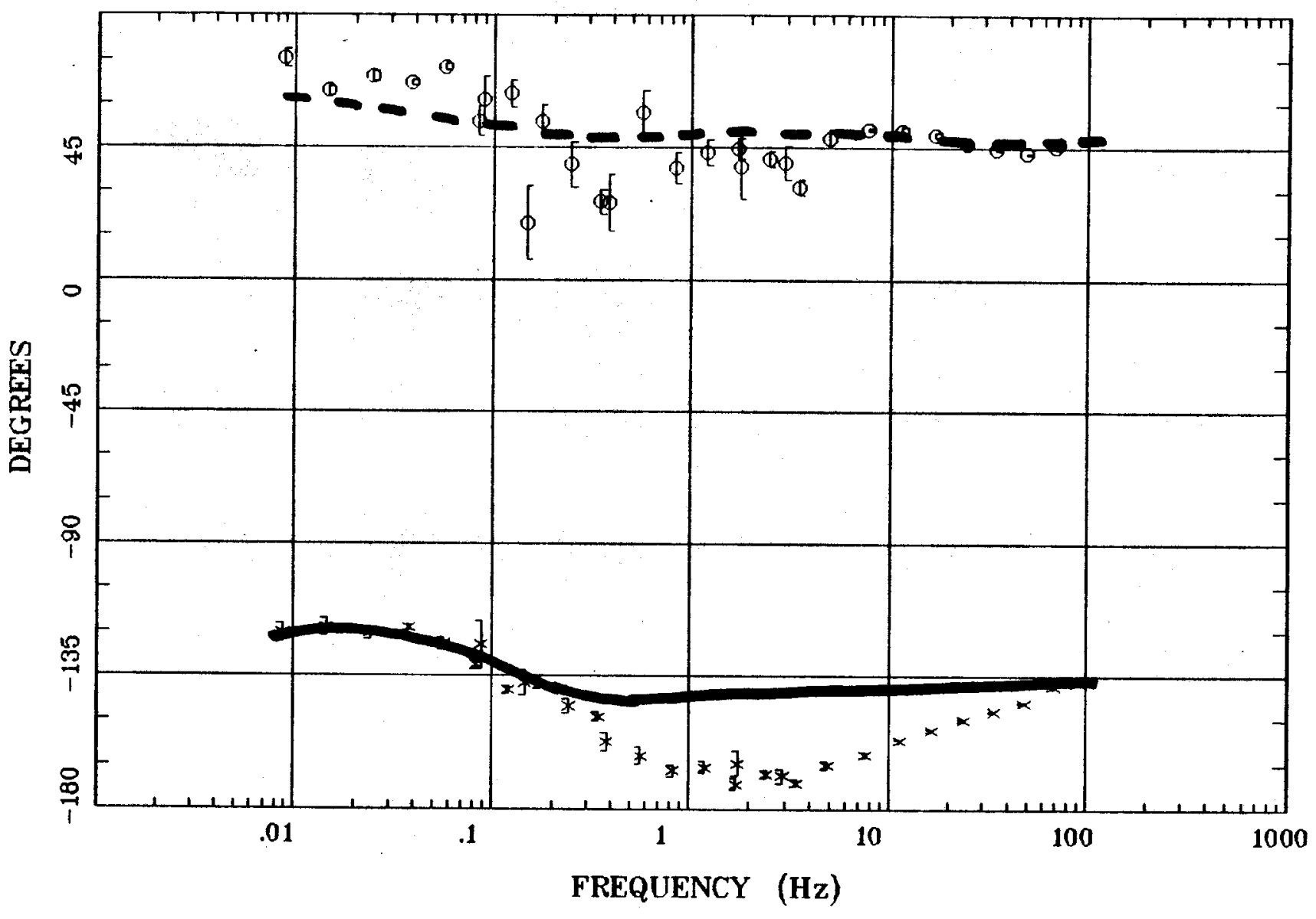

Client:

Remote: none

Acquired: 12:5 Aug 08. 1999

Survey Co:USGS
Rotation:

Filename: ar86all.avg

Channels: Ch1 Ch2 Ch3 Ch4 Ch5 Ch3 Ch4

Plotted: 11:04 Dec 08, 2000

< EMI - ElectroMagnetic Instruments 
whistler mtn.,nv

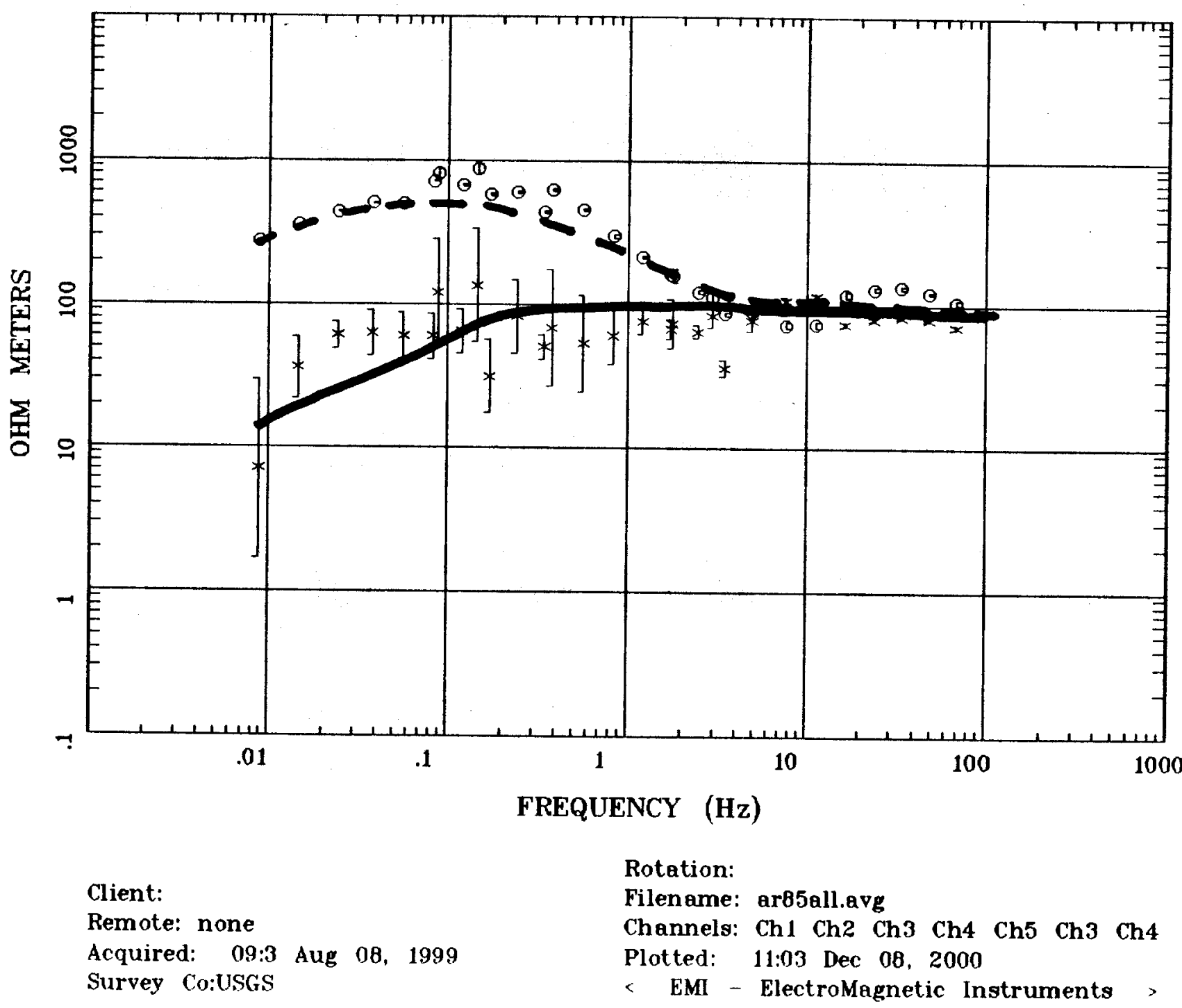


whistler mtn.,nv

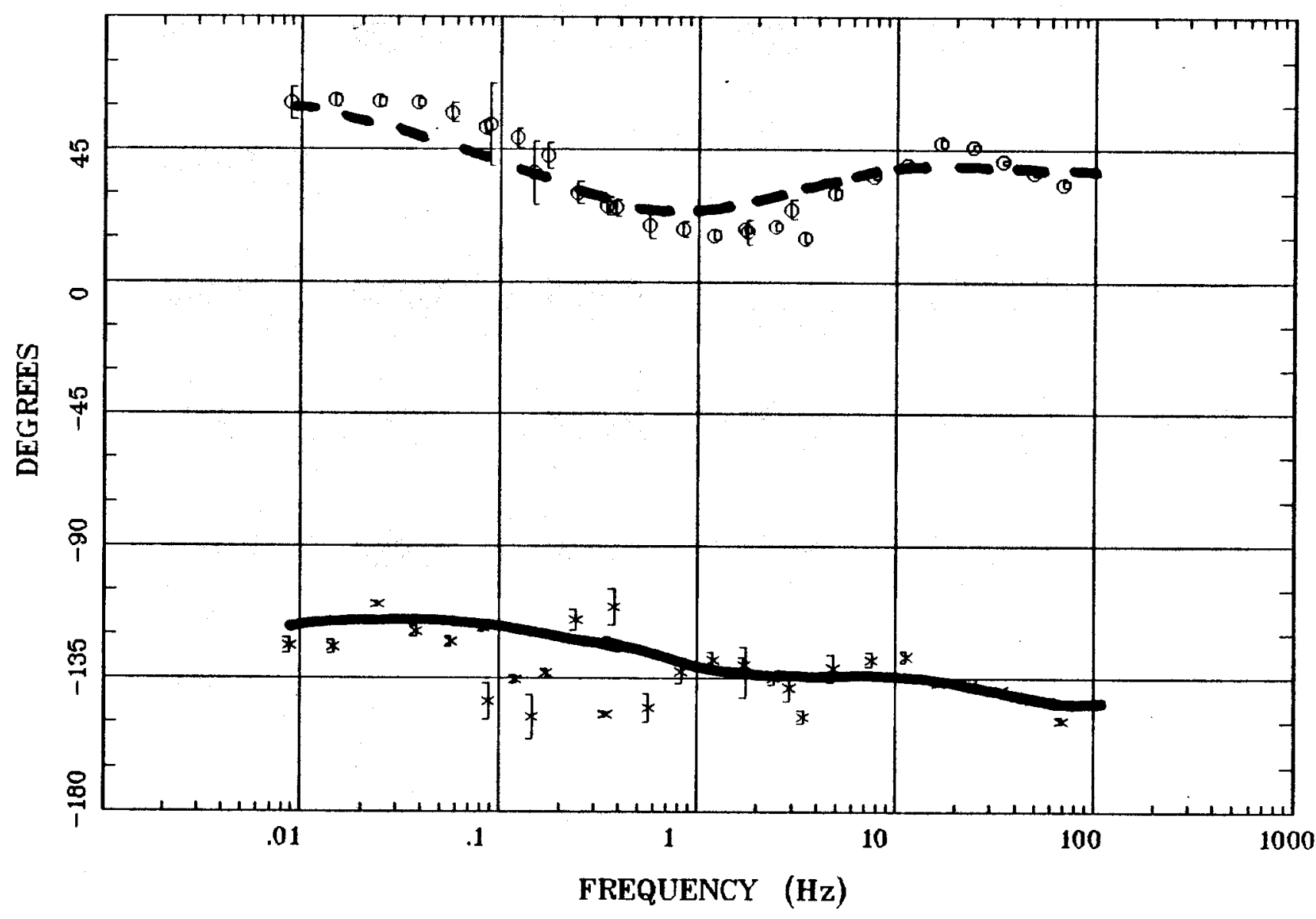

Client:

Remote: none

Acquired: 09:3 Aug 08. 1999

Survey Co:USGS
Rotation:

Filename: ar85all.avg

Channels: Ch1 Ch2 Ch3 Ch4 Ch5 Ch3 Ch4

Plotted: 11:03 Dec 08, 2000

$<$ EMI - ElectroMagnetic Instruments 


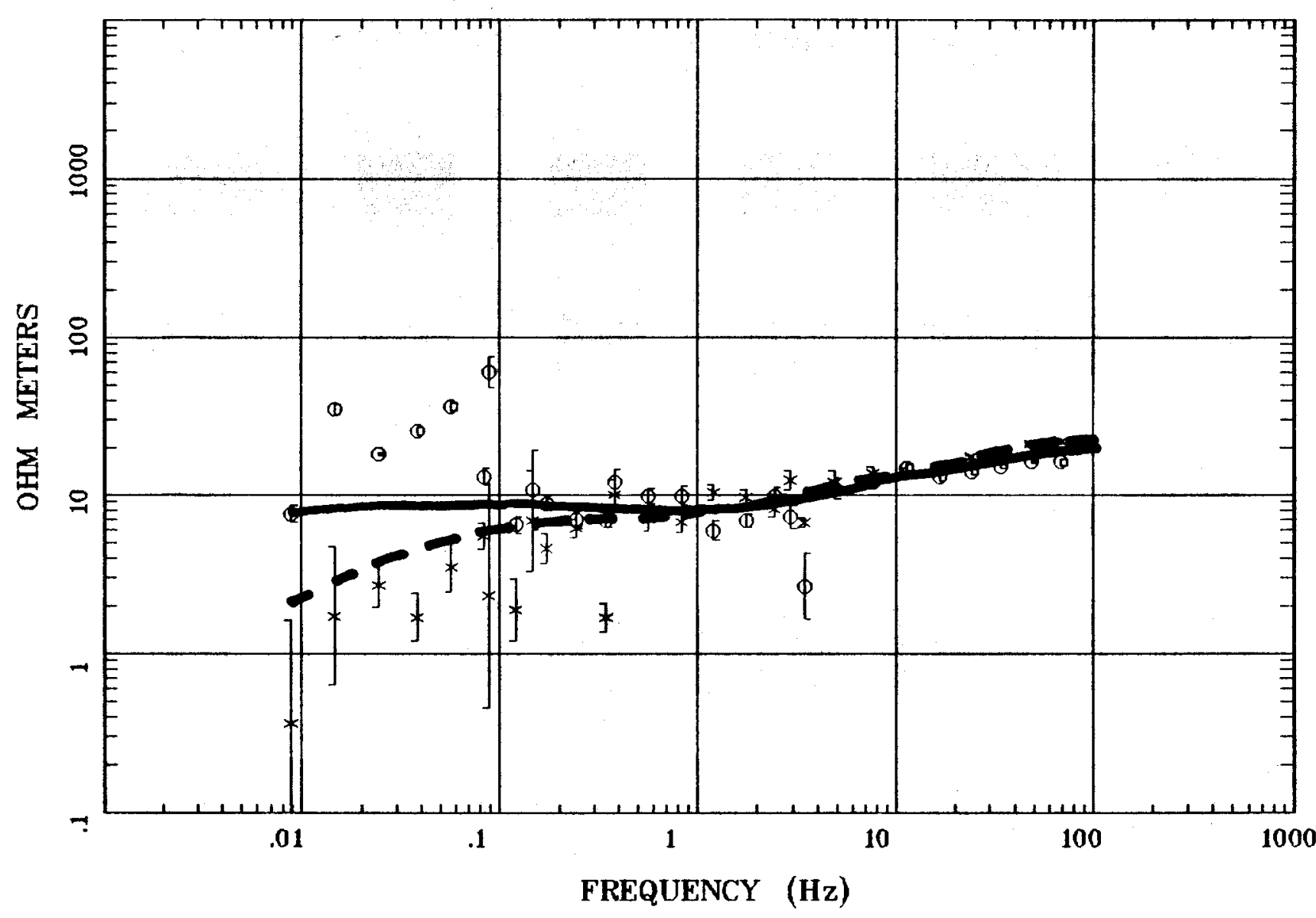

Client:

Remote: none Acquired: 11:5 Aug 10, 1999 Survey Co:USGS
Rotation:

Filename: ar89.avg

Channels: Ch1 Ch2 Ch3 Ch4 Ch5 Ch3 Ch4

Plotted: 11:08 Dec 08, 2000

$<$ EMI - ElectroMagnetic Instruments > 
IMPEDANCE PHASE

Diamond Valley, NV

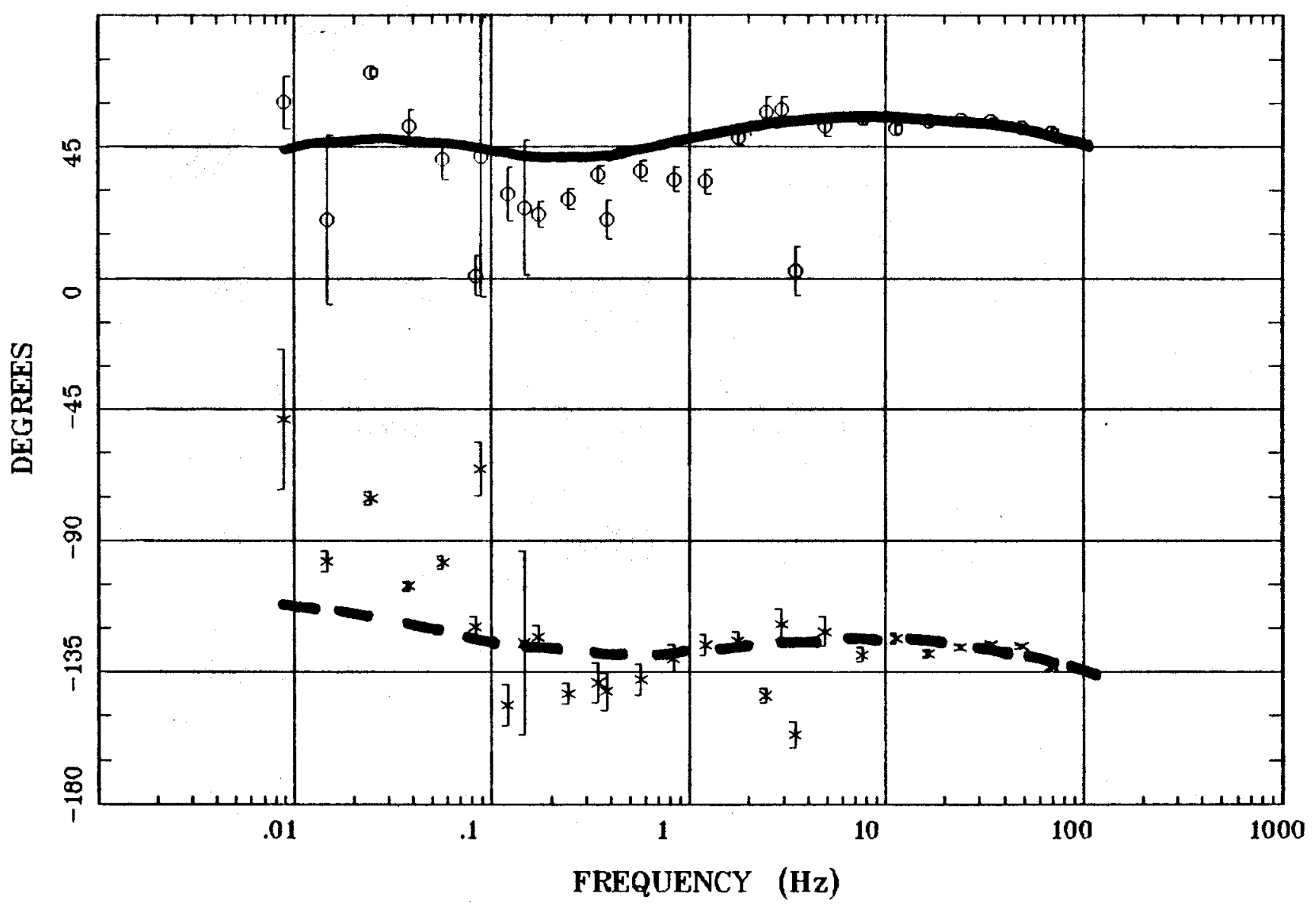

Client:

Remote: none

Rotation

Acquired: 11:5 Aug 10, 1999

Filename: ar89.avg

Channels: Ch1 Ch2 Ch3 Ch4 Ch5 Ch3 Ch4 Survey Co:USGS

Plotted: 11:08 Dec 08, 2000

< EMI - ElectroMagnetic Instruments 


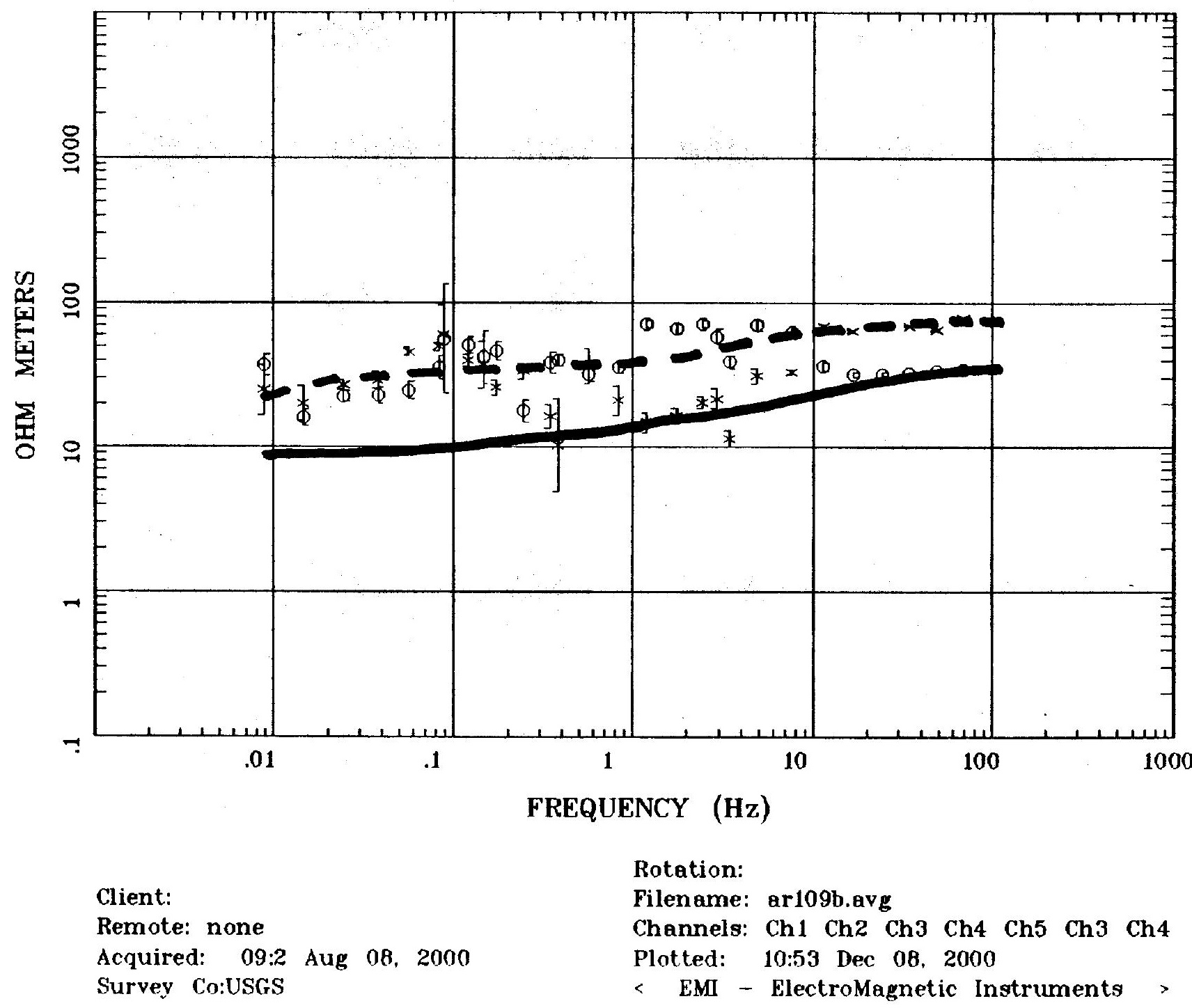




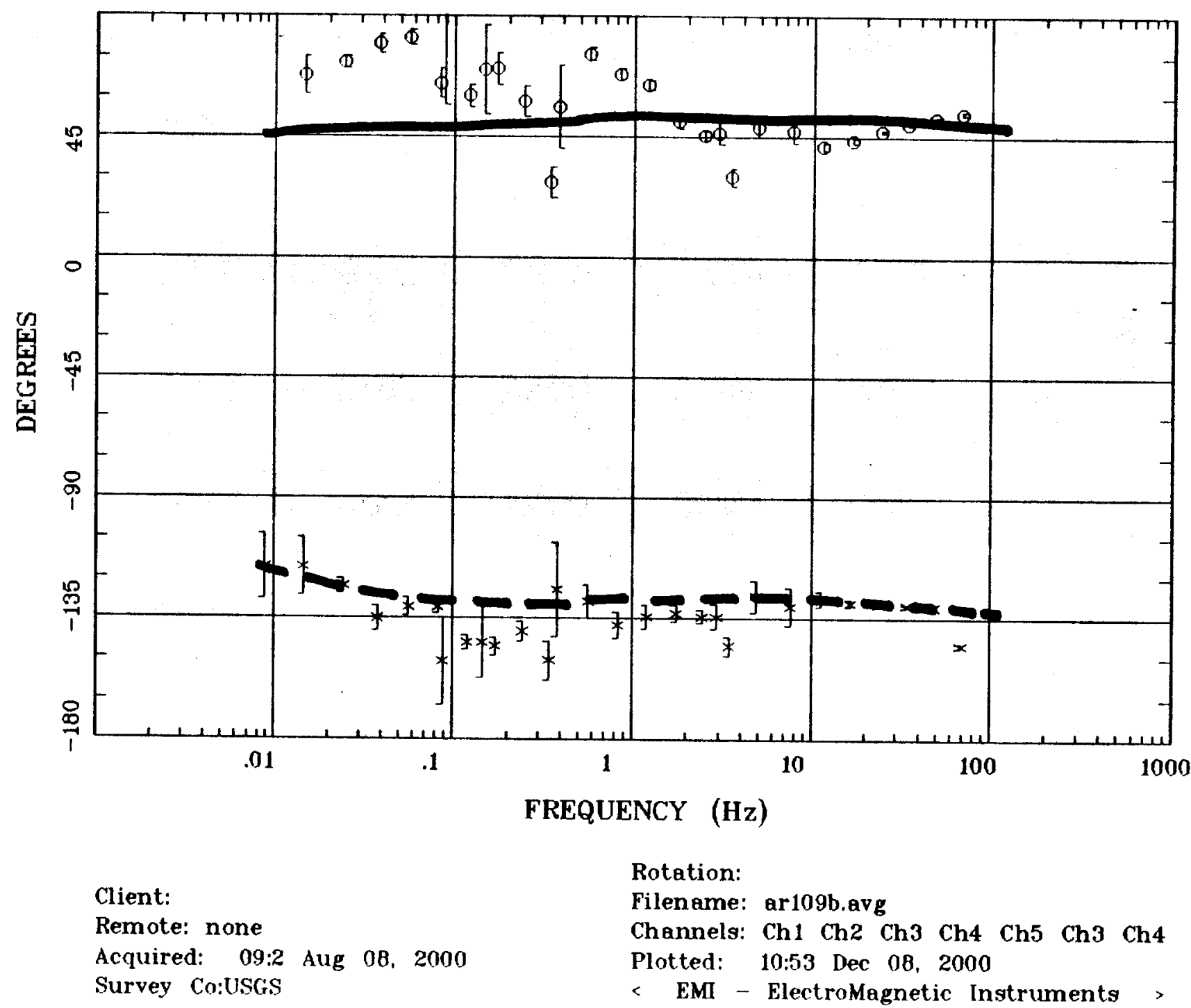


Diamond Mtns., NV

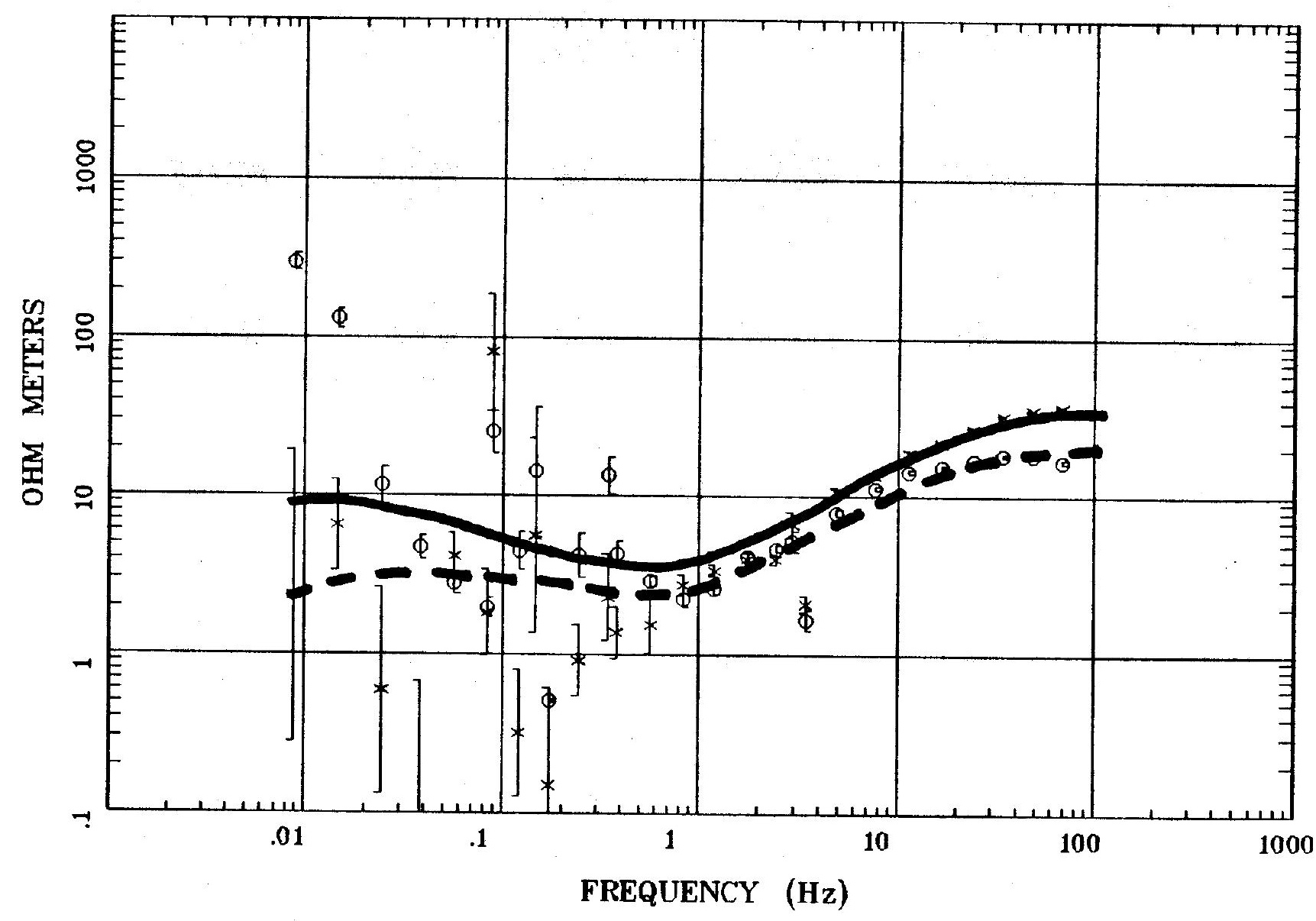

Client:

Remote: none

Acquired: 09:4 Aug 07, 1999

Survey Co:USGS
Rotation:

Filename: ar83b.avg

Channels: Ch1 Ch2 Ch3 Ch4 Ch5 Ch3 Ch4 Plotted: 11:01 Dec 08, 2000

$<$ EMI - ElectroMagnetic Instruments 
Station 83

Diamond Mtns., NV

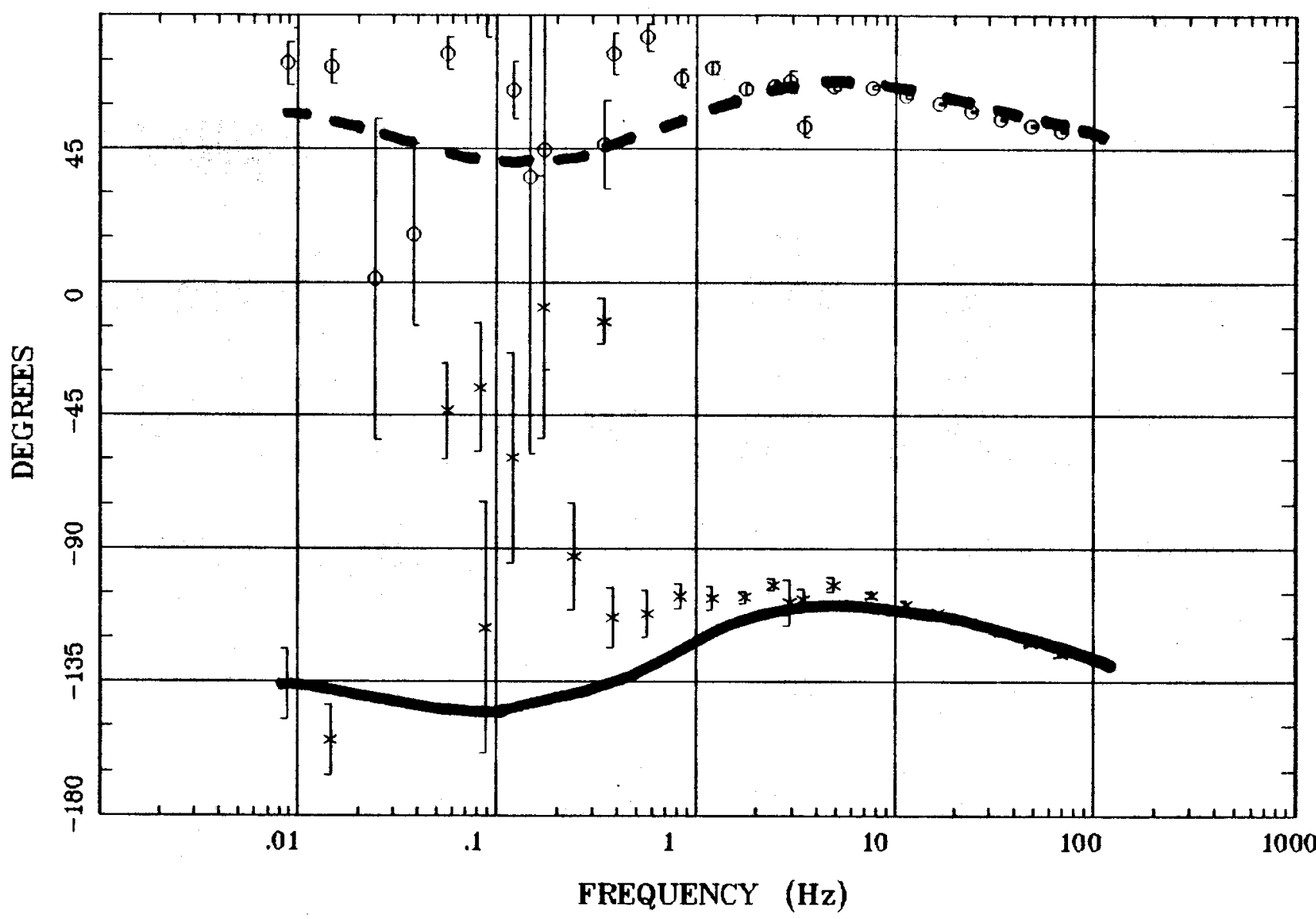

Client:

Remote: none

Acquired: 09:4 Aug 07, 1999

Survey Co:USGS
Rotation:

Filename: ar83b.avg

Channels: Ch1 Ch2 Ch3 Ch4 Ch5 Ch3 Ch4

Plotted: 11:01 Dec 08, 2000

$<$ EMI - ElectroMagnetic Instruments 


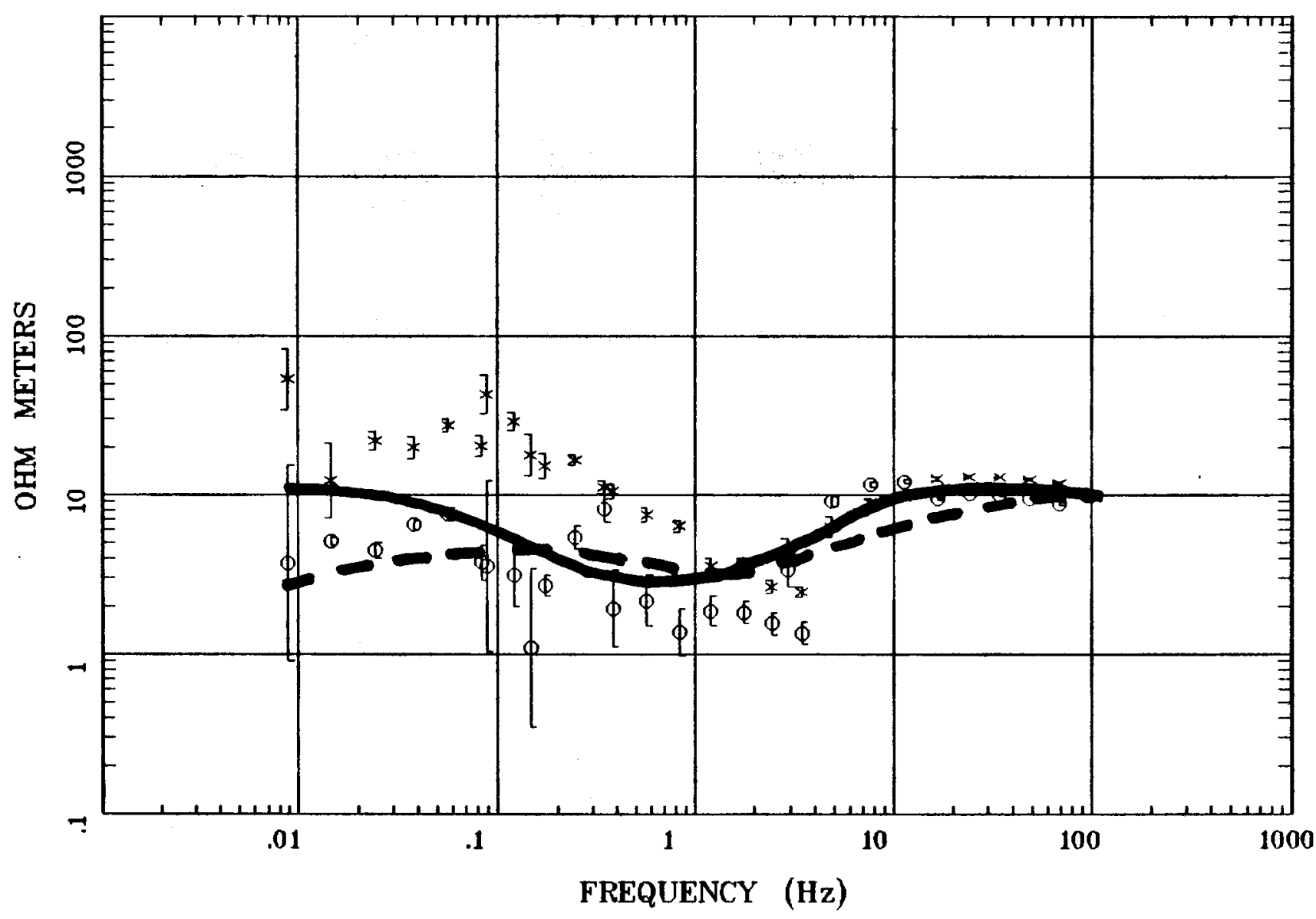

Client:

Remote: none

Acquired: 14:1 Aug 06. 1999 Survey Co:USGS
Rotation:

Filename: ar82b.avg

Channels: Ch1 Ch2 Ch3 Ch4 Ch5 Ch3 Ch4 Plotted: 11:00 Dec 08, 2000

- EMI - ElectroMagnetic Instruments 
IMPEDANCE PHASE

Newark Valley, NV

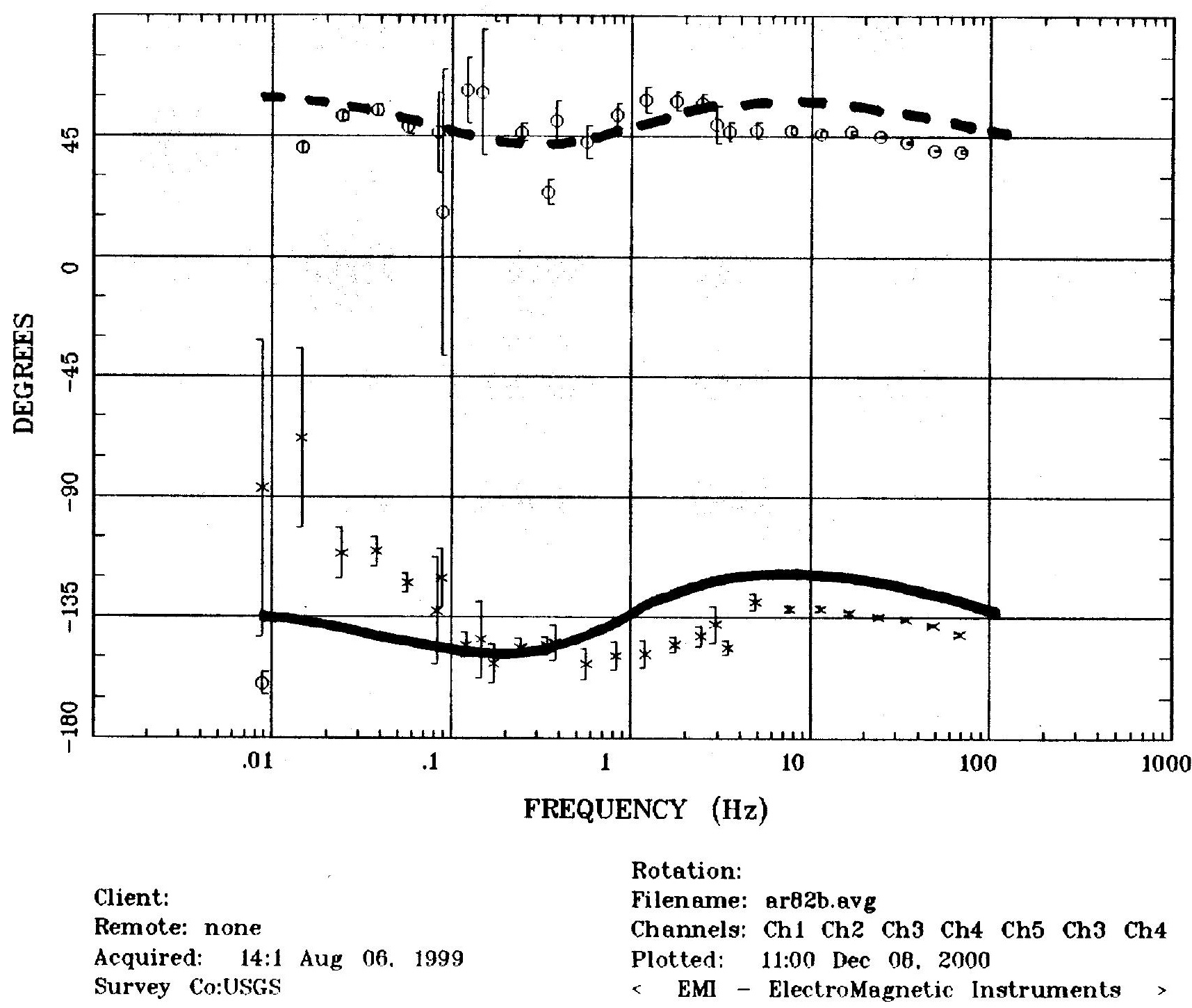




\section{Station 81}

\section{APPARENT RESISTIVITY}

newark valley,nv

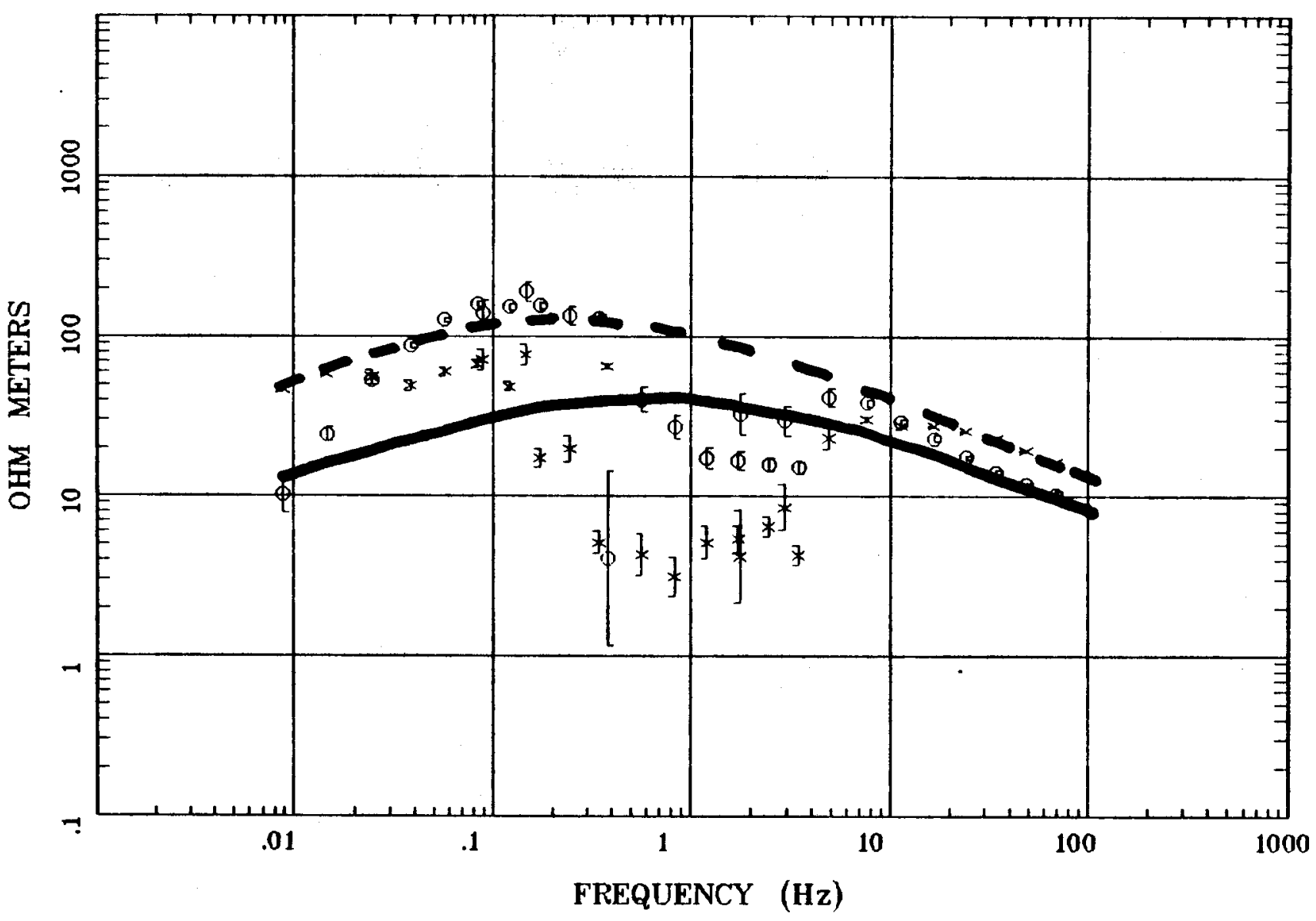

Client:

Remote: none

Acquired: 11:2 Aug 06, 1999

Survey Co:USGS
Rotation:

Filename: ar81.avg

Channels: Ch1 Ch2 Ch3 Ch4 Ch5 Ch3 Ch4

Plotted: 10:58 Dec 08, 2000

< EMI - FlectroMagnetic Instruments 


\section{IMPEDANCE PHASE}

newark valley,nv

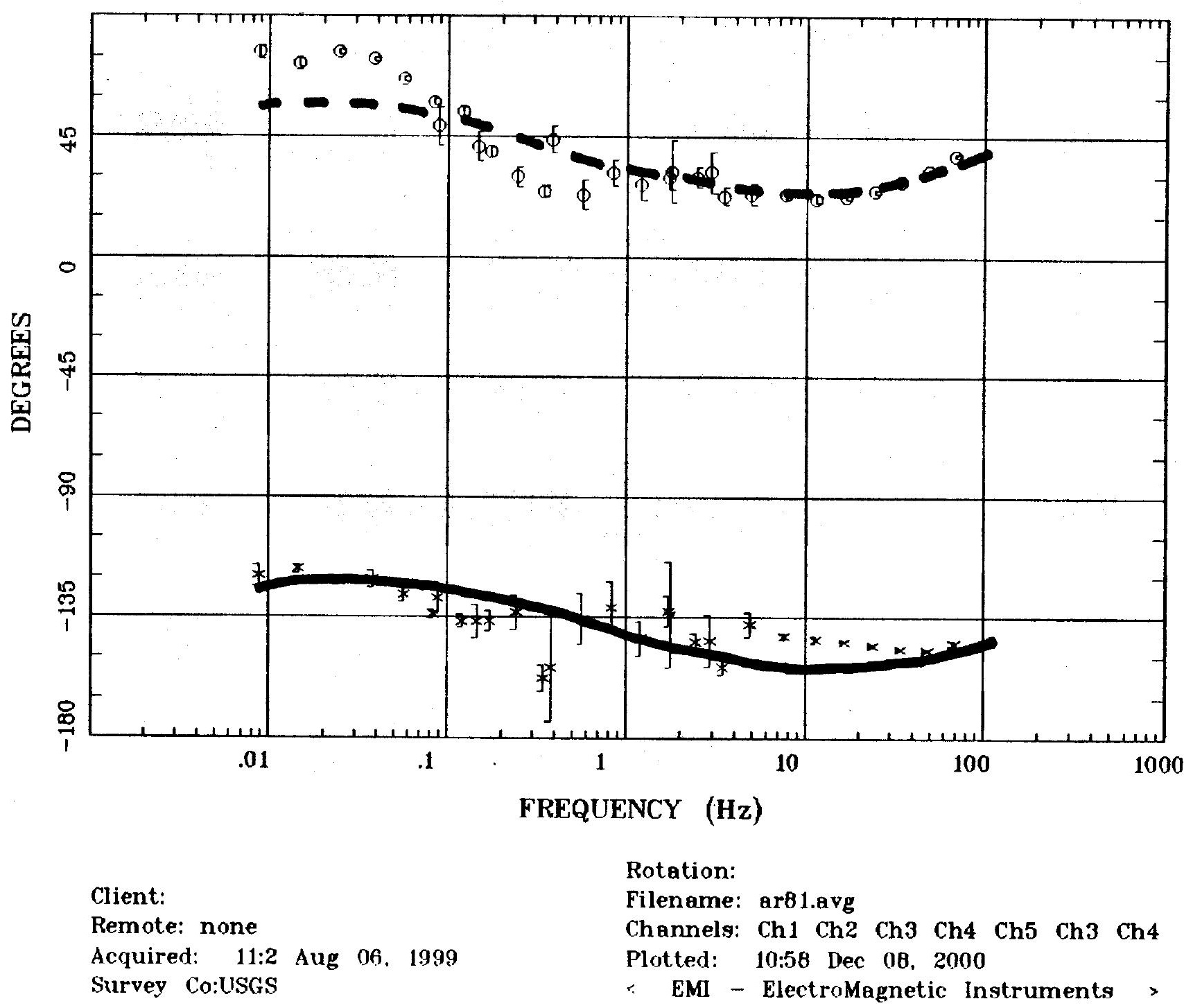




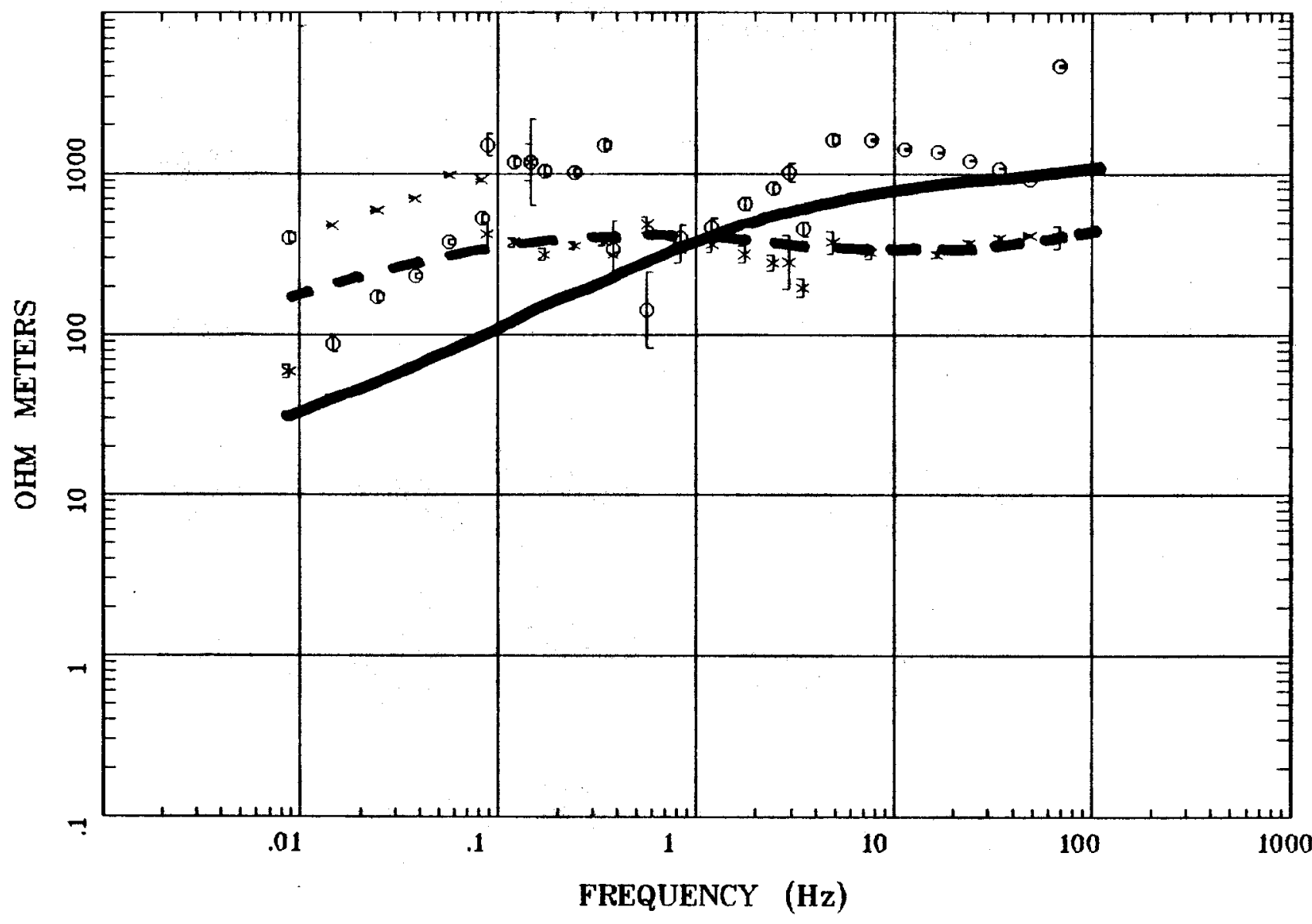

\section{Client:}

Remote: none

Acquired: 11:1 Aug 07, 2000 Survey Co:USGS
Rotation:

Filename: ar108b.avg

Channels: Ch1 Ch2 Ch3 Ch4 Ch5 Ch3 Ch4

Plotted: 10:51 Dec 08, 2000

< EMI - ElectroMagnetic Instruments 


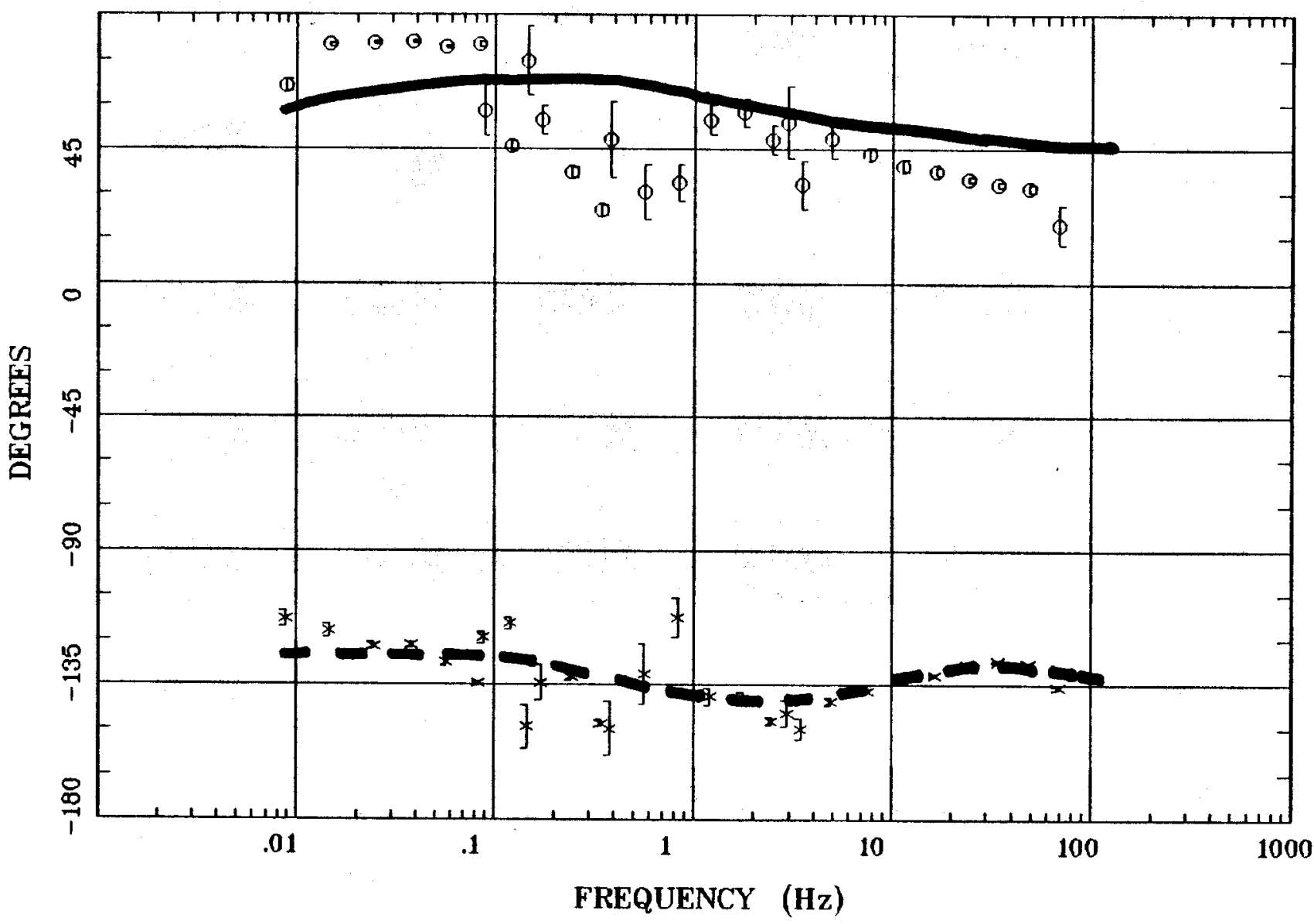

Client:

Remote: none

Acquired: 11:1 Aug 07. 2000

Survey Co:USGS
Rotation:

Filename: ar108b.avg

Channels: Ch1 Ch2 Ch3 Ch4 Ch5 Ch3 Ch4 Plotted: 10:51 Dec 08, 2000

< EMI - ElectroMagnetic Instruments 


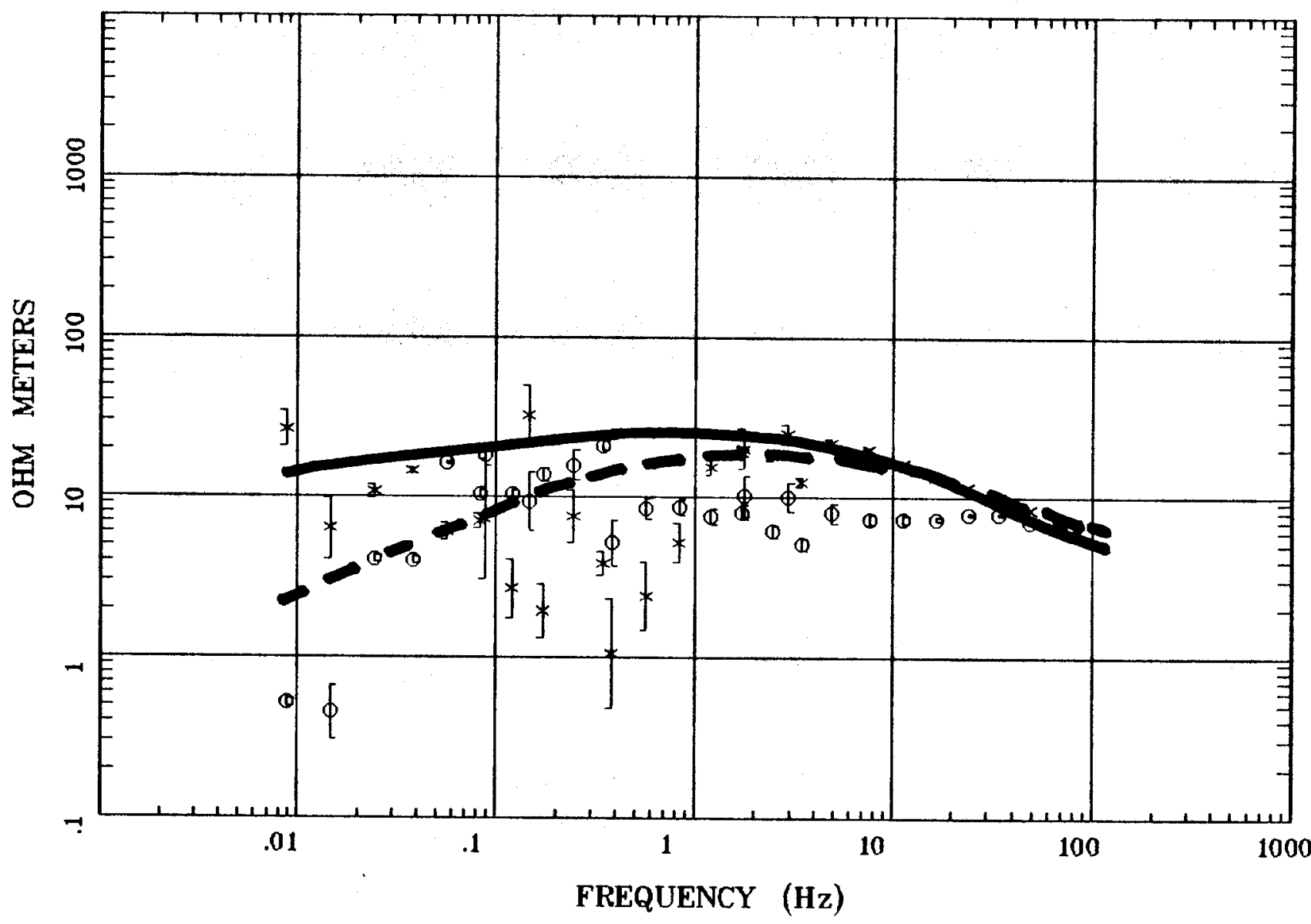

Client:

Remote: none

Acquired: 10:4 Aug 05, 1999 Survey Co:USGS
Rotation:

Filename: ar79.avg

Channels: Ch1 Ch2 Ch3 Ch4 Ch5 Ch3 Ch4

Plotted: 10:56 Dec 08, 2000

$<$ EMI - ElectroMagnetic Instruments 


\section{IMPEDANCE PHASE}

Alligator Ridge

Station 79

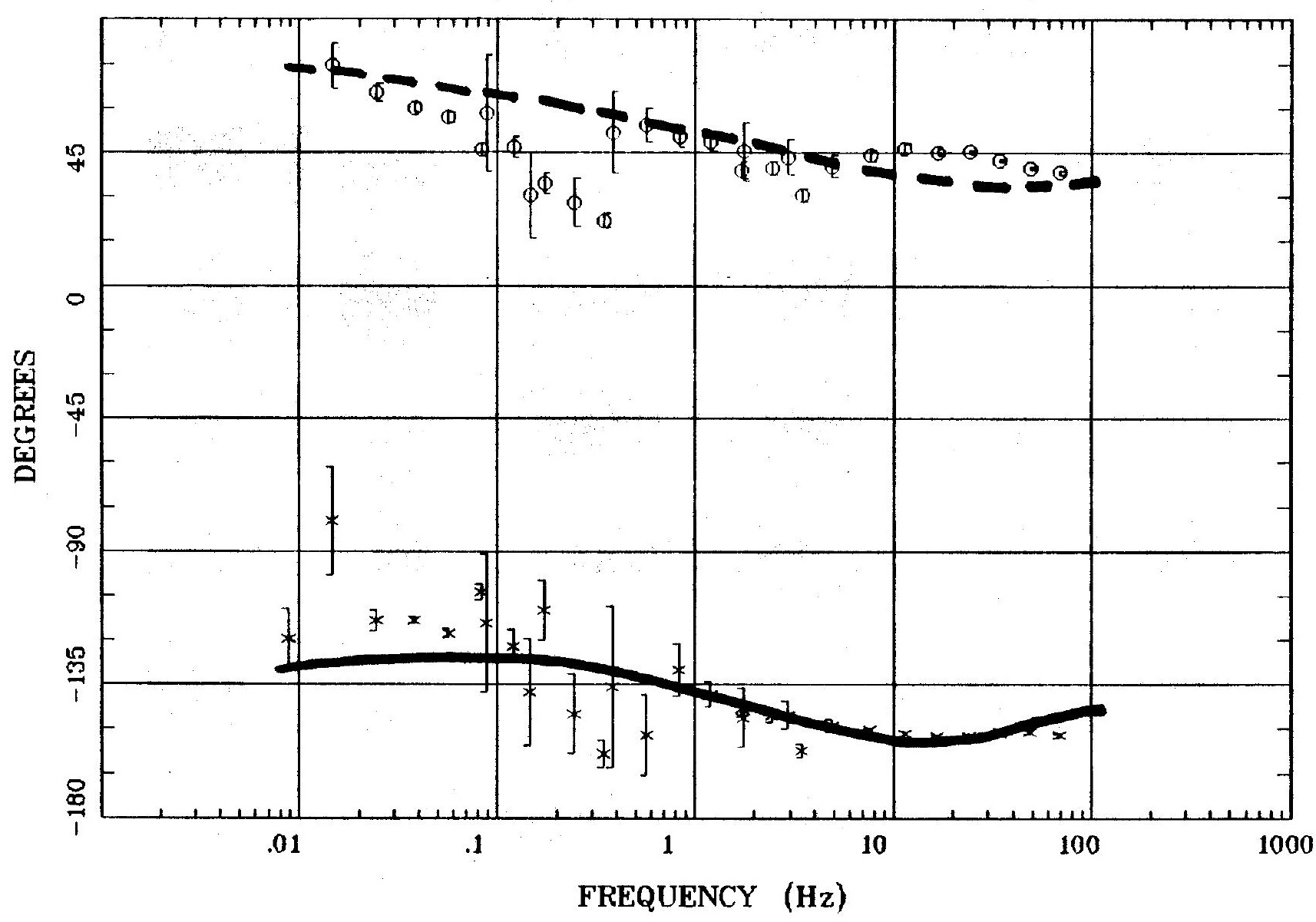

Client:

Remote: none

Acquired: 10:4 Aug 05, 1999 Survey Co:USGS
Rotation:

Filename: ar79.avg

Channels: Ch1 Ch2 Ch3 Ch4 Ch5 Ch3 Ch4

Plotted: 10:56 Dec 08, 2000

< EMI - ElectroMagnetic Instruments > 


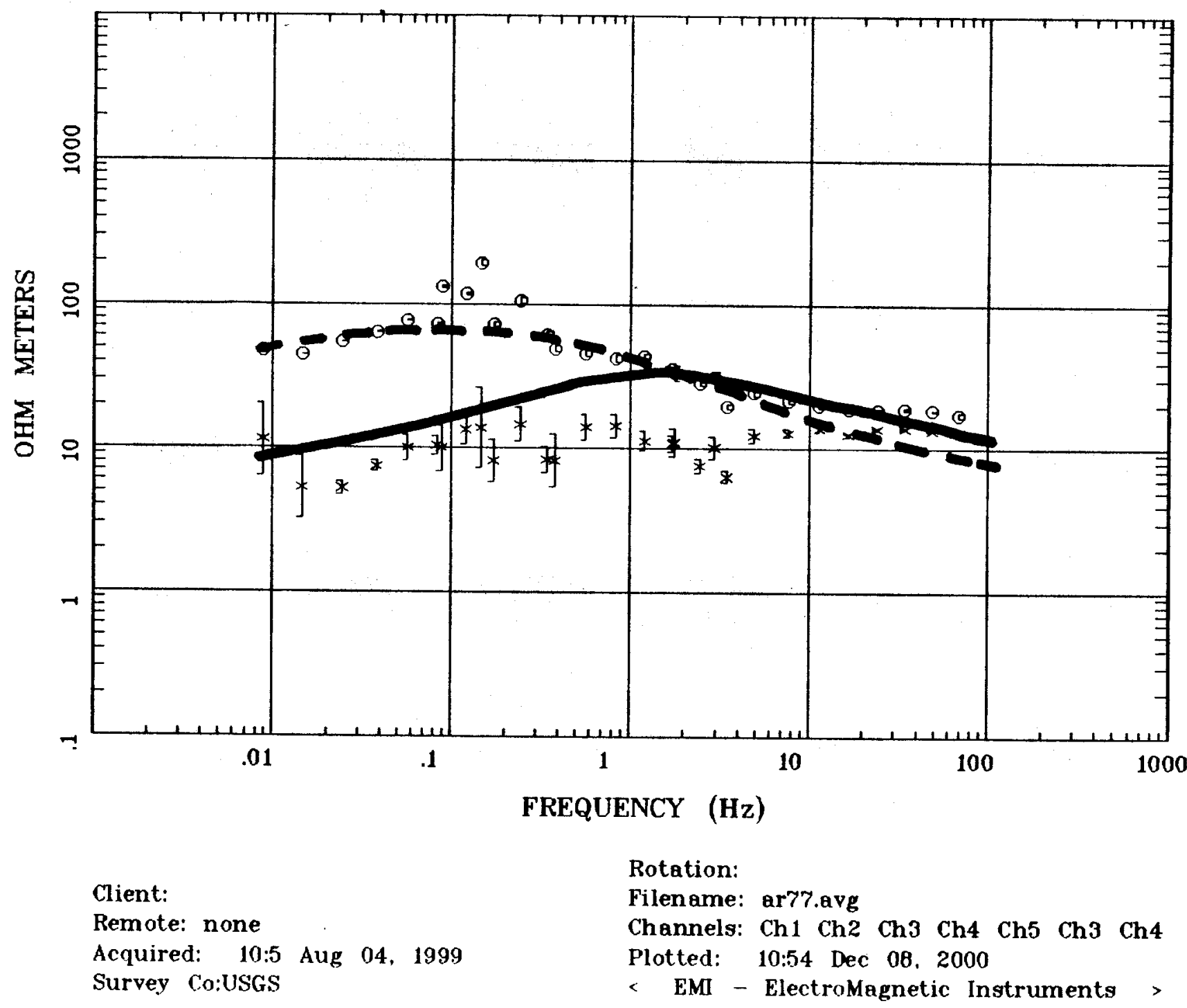




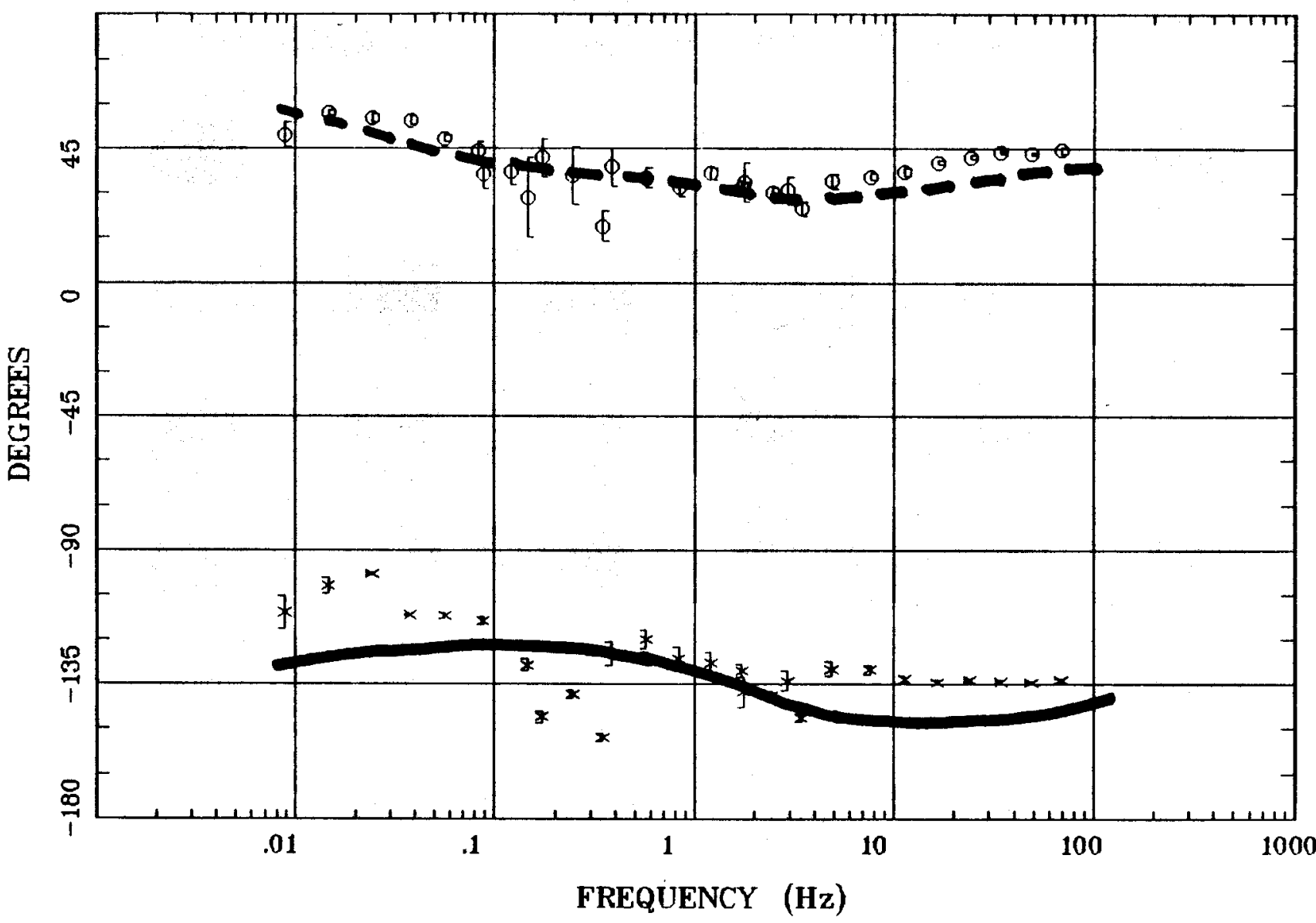

Client:

Remote: none

Acquired: 10:5 Aug 04. 1999

Survey Co:USGS
Rotation:

Filename: ar77.avg

Channels: Ch1 Ch2 Ch3 Ch4 Ch5 Ch3 Ch4

Plotted: 10:54 Dec 08, 2000

< EMI - ElectroMagnetic Instruments 


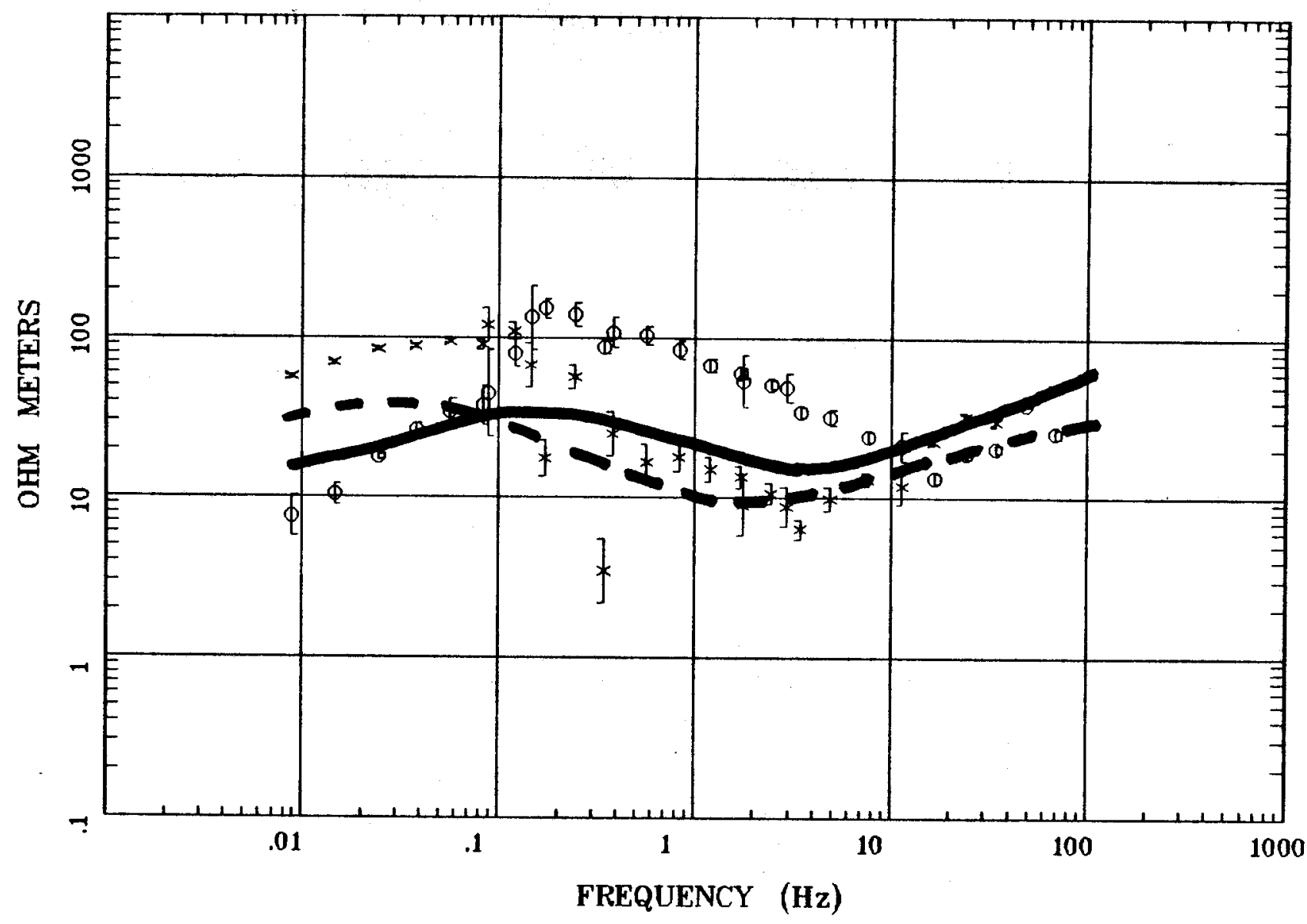

Client:

Remote: none

Acquired: 13:4 Aug 04, 1999

Survey Co:USGS
Rotation:

Filename: ar78.avg

Channels: Ch1 Ch2 Ch3 Ch4 Ch5 Ch3 Ch4

Plotted: 10:55 Dec 08, 2000

< EMI - ElectroMagnetic Instruments , 


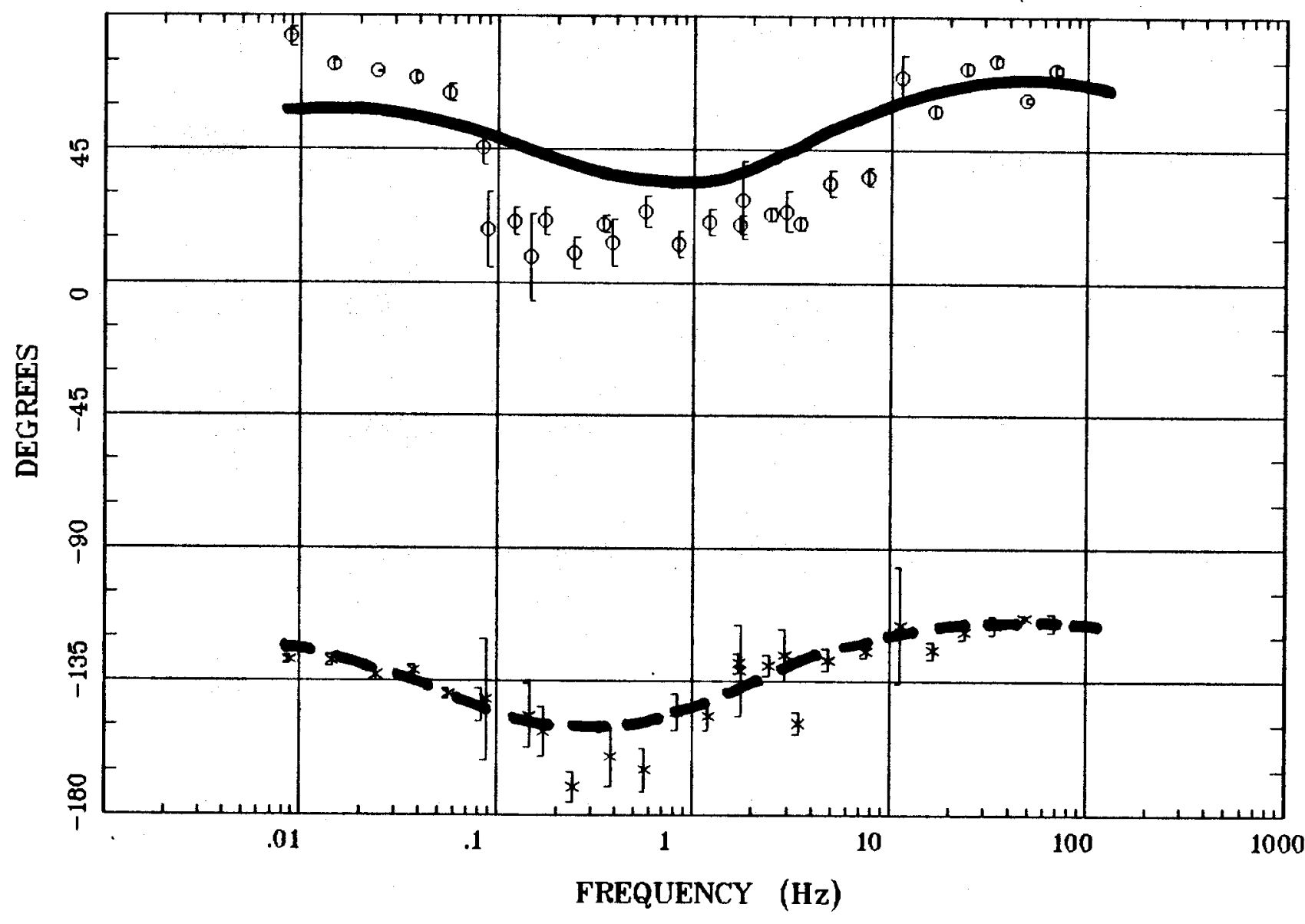

Client:

Remote: none Acquired: 13:4 Aug 04, 1999 Survey Co:USGS
Rotation:

Filename: ar78.avg

Channels: Ch1 Ch2 Ch3 Ch4 Ch5 Ch3 Ch4

Plotted: 10:55 Dec 08, 2000

< EMI - ElectroMagnetic Instruments 